\title{
Carbon Sequestration on Surface Mine Lands
}

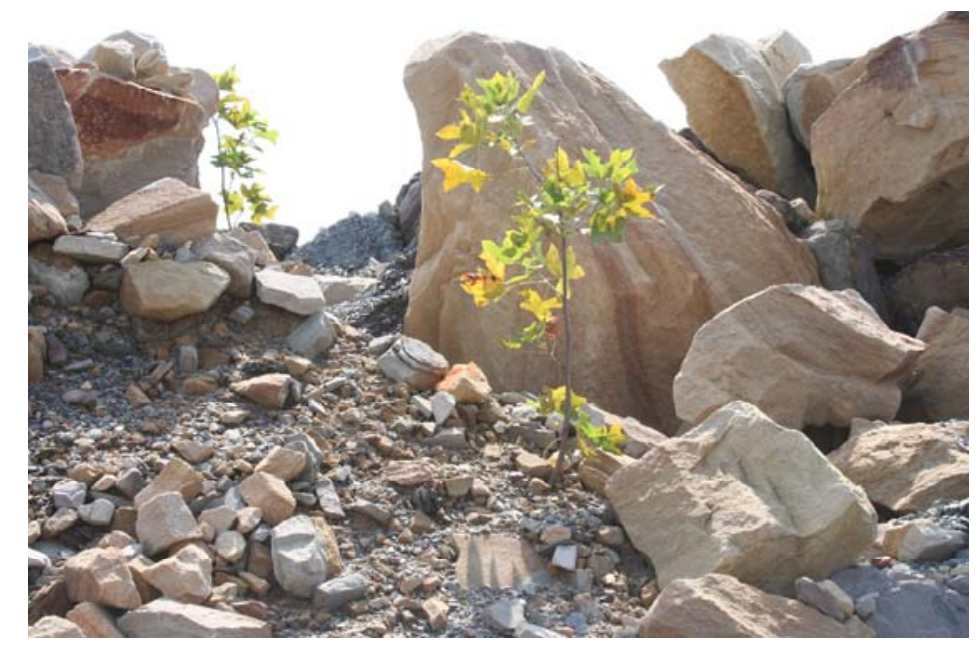

\section{Final Report \\ October 2003 - September 2006}

Principal Investigators: Donald Graves, Christopher Barton, Richard

Sweigard, Richard Warner, Carmen Agouridis

Research Assistants: Sally Maharaj, Tara Littlefield, Patrick Angle, Claudia Cotton, Bon Jun Koo, Viktor Badaker, Tim Taylor, Chris Conn, Jackie Perkins, Daphne Marshall

DOE Award Number: DE-FC26-02NT41624

University of Kentucky

Department of Forestry

Lexington, Kentucky 40546-0073

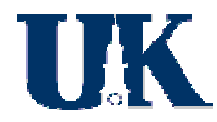




\section{DISCLAIMER}

"This report was prepared as an account of work sponsored by an agency of the United States government. Neither the United States Government nor any agency thereof, nor any of their employees, makes any warranty, express or implied, or assumes any legal liability or responsibility for the accuracy, completeness, or usefulness of any information, apparatus, product or process disclosed, or represents, that its use would not infringe on any privately owned rights. Reference herein to any specific commercial product, process, or service by trade name, trademark, or otherwise does not necessarily constitute or imply its endorsement, recommendation, or favoring by the United States Government or any agency thereof. The views and opinions of authors expressed herein do not necessarily state or reflect those of the United States Government or any agency thereof." 
TABLE OF CONTENT

I. EXECUTIVE SUMMARY

II. OVERVIEW AND OBJECTIVES 3

1. EVALUATION OF LOW SPOIL COMPACTION TECHNIQUES 5

FOR FOREST ESTABLISHMENT ON SURFACE MINED LANDS IN

KENTUCKY

1.1 INTRODUCTION 5

1.2. METHODS AND MATERIALS 7

1.2.1. General Experimental Protocol 7

1.2.2. Site Specific Protocol 13

1.2.2.1. Reforestation of Previously Reclaimed Pasture 13

1.2.2.2. Evaluating Low Compaction Reclamation Techniques on 13

Reforestation Productivity- Bent Mountain

1.2.2.3. Evaluating Spoil Amendment use on Reforestation Productivity 14

- Laurel Fork and Nelson Creek

1.2.2.4. Evaluating Geophysical and Chemical Spoil Characteristics on 16

Reforestation Productivity - Bent Mountain

1.3. RESULTS AND DISCUSSION 20

1.3.1. Reforestation of Previously Reclaimed Pasture 20

1.3.1.1. Seedling Response 20

1.3.1.1. Spoil Characteristics 26

1.3.2. Evaluating Low Compaction Reclamation Techniques on 29

Reforestation Productivity-Bent Mountain

1.3.3. Evaluating Spoil Amendment use on Reforestation Productivity - 35

Laurel Fork and Nelson Creek

1.3.4. Evaluating Geophysical and Chemical Spoil Characteristics on 39

Reforestation Productivity - Bent Mountain

1.3.5. Influence of ReclamationTechnique on Mine Land Hydrology 40

1.4. CONCLUSIONS

University of Kentucky Research Foundation iii

Final Report - 10/01/03 thru 9/30/06

DE-FC26-02NT41624 
2. DISTINGUISHING AND QUANTIFYING "NEW CARBON" FROM

“OLD CARBON" ON RECLAIMED COAL MINE SITES

2.1. INTRODUCTION

2.2. METHODS AND MATERIALS

2.2.1. Preparation of Standard Samples and Mixtures

2.2.2. Total Carbon and Nitrogen Content

2.2.3. Organic Carbon Characterization

2.2.4. Petrographic Analysis

2.2.5. Statistical Analysis

2.3. RESULTS AND DISCUSSION

2.3.1. Initial $C$ and $N$ content (total)

2.3.2. Thermogravimetric Analysis

2.3.3. Differential Scanning Calorimetry Analysis

2.3.4. Petrographic Analysis

3. EVALUATING FACTORS THAT INFLUENCE CARBON

SEQUESTRATION ON A CHRONOSEQUENCE OF REFORESTED MINE LANDS

\subsection{INTRODUCTION}

\subsection{MATERIALS AND METHODS}

3.2.1. Mine Locations and Reclamation Approach

3.2.2. Reference Study Sites

3.2.3. Biomass Harvest

3.2.4. C Accumulation Soil Sampling

3.2.5. Total Carbon and Nitrogen Content

3.2.6. Organic Carbon Characterization

3.2.7. $\mathrm{C} / \mathrm{N}$ and Isotopic Ratios 
3.2.12. Microbial Activity

3.3.3. Carbon Efflux: Soil Respiration, Microbes, and Decomposition

3.4.1. Carbon Processes

4.2.2. Reference Study Sites

4.2.3. Suitable Reference Areas

4.2.4. Reference Study Site Layout 
4.3.1. Characterization of Reference Study Sites

4.3.2. Height Development

110

4.3.3. Diameter Development

112

4.3.4. Comparing Reference to Reclamation

113

4.3.5. Mine Site Indices and Sawtimber Value

120

4.4. CONCLUSIONS

122

III. REFERENCES

123 


\section{LIST OF TABLES}

Table I.1. Location and acreage of trees planted for DOE carbon sequestration research.

Table I.2. General planting species distribution for Eastern and Western KY plots.

Table 1.1. Bulk density at 5, 15 and $30.5 \mathrm{~cm}$ depths in ripped spoil at the 17 West and the Gibraltar mines in Martin and Muhlenberg counties KY, respectively.

Table 1.2. Bulk density at 5,15 and $30.5 \mathrm{~cm}$ depths in spoils from differing reclamation practices at the Bent Mt. mine in Pike Co. KY.

Table 1.3. Mycorrhizal inoculation index of seedlings prior to planting.

Table 1.4. Bulk density at 5, 15 and $30.5 \mathrm{~cm}$ depths in spoil (control) and compost amended spoil (compost) at the Laurel Fork mine in Knott Co. KY.

Table 1.5. Bulk density at 5, 15 and $30.5 \mathrm{~cm}$ depths in spoil (control) and compost amended spoil (compost) at the Nelson Creek mine in Muhlenberg Co. KY.

Table 1.6. Seedling height and growth for 3-yr loblolly pine and northern red oak growing under differing spoil amendment treatments at the Laurel Fork and Nelson Creek mines in Knott and Muhlenberg Counties, KY, respectively.

Table 1.7. Herbaceous biomass and seedling survival for 3-yr loblolly pine and northern red oak on plots with differing spoil amendment treatments at the Laurel Fork and Nelson Creek mines in Knott and Muhlenberg Counties, KY, respectively.

Table 1.8. Bulk density at 5, 15 and $30.5 \mathrm{~cm}$ depths in brown sandstone, gray sandstone, and mixed sandstones and shale at the Bent Mountain mine in Pike Co. KY.

Table 1.9. Second year (2006) percent survival by plot at the Bent Mountain Geohydrology site in Pike Co., KY.

Table 1.10. Second year (2006) averages for tree height in centimeters by plot at the Bent Mountain Geohydrology site in Pike Co., KY.

Table 1.11. Second year (2006) averages for tree diameter at ground level in 
Table 1.12. Representative Hydrological Monitoring Results.

Table 2.1: Total C and N content from LECO analysis for standard and

reference samples.

Table 2.2: TG/DTG pyrolysis data for standards. $n=5$

Table 2.3: TG/DTG pyrolysis data for mixtures of litter, coal, and limestone.

Table 3.1. $\mathrm{C} / \mathrm{N}$ and $\mathrm{C}$ isotope values for standard samples. All samples were treated with sulfurous acid to remove carbonates before analysis.

Table 3.2. $\mathrm{C} / \mathrm{N}$ and $\mathrm{C}$ and $\mathrm{N}$ isotopes values for field samples. All samples were treated with sulfurous acid to remove carbonates before analysis.

Table 4.1. Age class determination for even-aged cuts.

Table 4.2. Mean heights and standard deviations per age class for white oak stands in the eastern Kentucky coal fields.

Table 4.3. Mean diameters and standard deviations per age class for white oak stands in the eastern Kentucky coal fields.

Table 4.4. White oak percent survival for Starfire Mine reforestation cells, 1997-2004.

Table 4.5. Summary of linear regressions ( $p$-values) comparing mean reference tree height $(\mathrm{cm})$ to mean mine tree height for white oak (reference $\mathrm{n}=240$ ) for all surface and subsurface treatments.

Table 4.6. Summary of linear regressions ( $p$-values) comparing mean reference tree $\mathrm{dbh}(\mathrm{m})$ to mean mine tree $\mathrm{dbh}$ for white oak (reference $\mathrm{n}=240$ ) for all surface and subsurface treatments.

Table 4.7. Site index and stumpage value as a function of stand height for white oak on mulched mine land and regenerating forests in eastern Kentucky.

Table 4.8. Site index and stumpage value as a function of stand dbh for white oak on mulched mine land and regenerating forests in eastern Kentucky. 


\section{LIST OF FIGURES}

Figure I.1. Locator map for sites containing carbon sequestration plots. 2

Figure 1.1. Example of a site prior to planting that exhibited a traditional 10 grading practice (control).

Figure 1.2. Example of a site prior to planting that exhibited the loose-dumped grading practice.

Figure 1.3. Example of a site prior to planting that has been ripped.

Figure 1.4. Example of a ripper attached to a D11 dozer.

Figure 1.5. Example of a site that was reclaimed as pasture and is being ripped to alleviate the level of compaction in preparation for tree planting.

Figure 1.6. Compost amended site, Knott Co. KY.

Figure 1.7. Aerial view of geohydrology plots at Bent Mountain, Spring 2005.

Figure 1.8. Conceptual view of the research area.

Figure 1.9. Lysimeter and drain tile position under loose spoil material.

Figure 1.10. Monitoring station for water quality/hydrology measurements.

Figure 1.11. Average survival of planted seedlings at the 17 West mine in Martin Co. KY.

Figure 1.12. Average seedling height at the 17 West mine in Martin Co. KY.

Figure 1.13. Average leaf area of dominant species at the 17 West mine in Martin Co. KY.

Figure 1.14. Average seedling survival at the Gibraltar mine in Muhlenberg Co. KY.

Figure 1.15. Average seedling height at the Gibraltar mine in Muhlenberg Co. KY.

Figure 1.16. Average seedling height at the Gibraltar mine in Muhlenberg Co.

KY.

Figure 1.17. Soil carbon and nitrogen change at 0-5 cm depth for a three year period on the 17 West mine in Martin Co., KY. 
Figure 1.18. Soil carbon and nitrogen change at $0-5 \mathrm{~cm}$ depth for a three year period on the Gibraltar mine in Muhlenberg Co. KY.

Figure 1.19. Mean cumulative height $(\mathrm{cm})$ and survival rate for white oak for the four low compaction and control (traditional) treatments. Means with the same letter are not significantly different at the $p=0.05$ confidence level. Capital letters refer to statistical relationships for survival, while lower case letters refer to height.

Figure 1.20. Mean cumulative height $(\mathrm{cm})$ and survival rate for northern red oak for the four low compaction and control (traditional) treatments. Means with the same letter are not significantly different at the $p=0.05$ confidence level. Capital letters refer to statistical relationships for survival, while lower case letters refer to height.

Figure 1.21. Mean cumulative height $(\mathrm{cm})$ and survival rate for yellow poplar for the four low compaction and control (traditional) treatments. Means with the same letter are not significantly different at the $\mathrm{p}=0.05$ confidence level. Capital letters refer to statistical relationships for survival, while lower case letters refer to height.

Figure 1.22. Mean cumulative height $(\mathrm{cm})$ and survival rate for black locust for the four low compaction and control (traditional) treatments. Means with the same letter are not significantly different at the $p=0.05$ confidence level. Capital letters refer to statistical relationships for survival, while lower case letters refer to height.

Figure 1.23. Mean cumulative height $(\mathrm{cm})$ and survival rate for white ash for the four low compaction and control (traditional) treatments. Means with the same letter are not significantly different at the $\mathrm{p}=0.05$ confidence level. Capital letters refer to statistical relationships for survival, while lower case letters refer to height.

Figure 1.24. One-year old N. Red Oak on non- amended site, Muhlenberg Co. KY.

Figure 1.25. One-year old N. Red Oak on compost amended site, Muhlenberg Co. KY.

Figure 2.1. Representative TG (I) and DTG (II) patterns for (a) grass litter (b) coal and (c) limestone.

Figure 2.2. Representative TG (I) and DTG (II) for a laboratory mixture of grass litter, coal, and limestone. 
Figure 2.3. Representative TG (I)/DTG (II) patterns for (a) cellulose, (b) NIST apple leaves, and (c) lignin.

Figure 2.4. Expected C (\%) versus TG (\%) for (a) grass litter, (b) coal, (c) limestone fractions from mixtures, $n=10$. Figures (a), (b), and (c) also show relationship between actual recoveries and a theoretical perfect linear regression line (1:1).

Figure 2.5. Representative DSC patterns for (a) grass litter, (b) cellulose, (c) lignin, and (d) coal.

Figure 2.6. Representative photomicrographs of (a) grass litter, (b) sycamore leaves, (c) limestone, and (d) coal. All photomicrographs were taken under oil immersion, $\mathrm{a}, \mathrm{b}$, and $\mathrm{c}$ using blue-light and $\mathrm{d}$ using reflected white-light illumination.

Figure 3.1. Locations of reclaimed coal mines and reference sites in KY used in this study.

Figure 3.2. Experimental design of sites and plots.

Figure 3.3. Two (a), three (b), and seven-year-old (c) Sycamore were manually and randomly harvested by using a chain saw and shovels.

Figure 3.4. Carbon sequestered by four tree species, representing 3 age classes (2, 3 , and 7 years) on a loose dump mined site in the Southern Appalachian Coalfield region.

Figure 3.5. Soil carbon sequestered on mined study sites. Rhizosphere soils were presented for 3 and 7 years old trees.

Figure 3.6. Cumulative carbon sequestered by tree and soil on study mined sites.

Figure 3.7. Average $\mathrm{C}$ efflux from soil for the year 2005 in $\mathrm{kg} \mathrm{C} / \mathrm{ha} / \mathrm{yr}$. $\mathrm{F}$ indicates forests regenerating after logging and $\mathrm{M}$ indicates forests regenerating after mining. The numbers following $\mathrm{F}$ and $\mathrm{M}$ indicate the age of the stand. Error bars indicate standard error.

Figure 3.8. Dehydrogenase Activity in top $10 \mathrm{~cm}$ of soil collected in fall 2005. Results are reported in ug TPF/g soil. F indicates forests regenerating after logging and $\mathrm{M}$ indicates forests regenerating after mining. The numbers following $\mathrm{F}$ and $\mathrm{M}$ indicate the age of the stand. $\mathrm{M} 2 \mathrm{G}$ and $\mathrm{M} 8 \mathrm{G}$ are reclaimed grassland mine sites and $\mathrm{F} 80-\mathrm{X}$ and $\mathrm{F} 80-\mathrm{M}$ are 80 year old forests that are either xeric (SW facing) or mesic (NE facing). Error bars indicate standard error. 
Figure 3.9. Microbial Biomass $\mathrm{C}$ and $\mathrm{N}$ data from the top $10 \mathrm{~cm}$ of soils collected in the fall 2005. Results reported in ppm. F indicates forests regenerating after logging and $\mathrm{M}$ indicates forests regenerating after mining. The numbers following $F$ and $M$ indicate the age of the stand. M2G and M8G are reclaimed grassland mine sites and F80-X and F80-M are 80 year old forests that are either xeric (SW facing) or mesic (NE facing). Error bars indicate standard error.

Figure 3.10. Soil Respiration and Soil Temperature taken every 3 weeks over the course of 2005/2006. Soil Respiration results are reported in umole $/ \mathrm{m} 2 / \mathrm{s}$ and soil $\mathrm{T}$ is reported in ${ }^{0} \mathrm{C}$. $\mathrm{F}$ indicates forests regenerating after logging and $\mathrm{M}$ indicates forests regenerating after mining. The numbers following $\mathrm{F}$ and $\mathrm{M}$ indicate the age of the stand.

Figure 3.11. Decomposition rates for mixed oak-maple-sycamore leaf litter in 2005. Decay constants were calculated using the equation - ( $\ln (\%$ Mass Remaining)/(100))/(t) in years). Error bars indicate standard error.

Figure 3.12. Decomposition rates for mixed oak-maple-sycamore leaf litter for summer 2005. Decay constants were calculated using the equation - (ln (\%Mass Remaining)/ (100))/ (t) in years). Error bars indicate standard error.

Figure 3.13. Percent nitrogen of decomposing litter over 2005. F indicates forests regenerating after logging and $\mathrm{M}$ indicates forests regenerating after mining. The numbers following $\mathrm{F}$ and $\mathrm{M}$ indicate the age of the stand.

Figure 3.14. $\mathrm{C} / \mathrm{N}$ ratio of decomposing litter over 2005. F indicates forests regenerating after logging and $\mathrm{M}$ indicates forests regenerating after mining. The numbers following $\mathrm{F}$ and $\mathrm{M}$ indicate the age of the stand.

Figure 3.15. Variation of $\delta^{13} \mathrm{C}$ with age of reclaimed coal mine sites.

Figure 3.16. Variation of $\mathrm{Ca}, \mathrm{Mg}$, and $\mathrm{Mn}$ concentrations over time for samples from reclaimed coal mine sites, Bent Mountain (0 and 2-year) and Starfire Mine (3 and 8-year). 80-year Robinson Forest is the reference site.

Figure 3.17. Variation of $\delta^{13} \mathrm{C}$ with $\mathrm{C} / \mathrm{N}$ ratios over time for (a) Bent Mountain Site (0 and 2-year); (b) Starfire Mine Site (3 and 8-year); (c) 80-year forested reference site; and (d) grass litter.

Figure 3.18. Representative TG/DTG patterns for Bent Mountain- (a) 0-year and (b) 2-year. 
Figure 3.19. Representative TG (I)/DTG (II) patterns for Starfire Mine- (a) 3year and (b) 8-year.

Figure 3.20. Representative TG (I)/DTG (II) pattern for Robinson Forest reference site- 80-year.

Figure 3.21. Variations in "old" and "new" soil in relation to biomass changes over forest stand development.

Figure 4.1. The Wetlands Research Program's reforestation assessment showing growth trajectories or performance curves in relation to a reference range (Kentla et al. 1993).

Figure 4.2. Study area and the physiographic regions of Kentucky.

Figure 4.3. White oak study sites grouped according to age class.

Figure 4.4. Study site layout showing six replicated plots and three soil plots.

Figure 4.5. (a.) Reference height range for white oak, 0-20 years; (b.)

Reference height range for white oak, 0-80 years.

Figure 4.6. (a.) Reference diameter range for white oak, 0-20 years; (b.)

Reference diameter range for white oak, 0-80 years.

Figure 4.7. Chronosequence of height development for white oak comparing mean tree heights from reference stands to mean tree heights from reforestation plots on Starfire Mine that have and have not been amended with straw mulch, and have been reclaimed with (a.) conventional reclamation, (b.) strike off reclamation, and (c.) loose dumped reclamation.

Figure 4.8. Chronosequence of diameter development for white oak comparing mean tree diameters from reference stands to mean tree diameters from reforestation plots on Starfire Mine that have and have not been amended with straw mulch, and have been reclaimed with (a.) conventional reclamation, (b.) strike off reclamation, and (c.) loose dumped reclamation. 


\section{EXECUTIVE SUMMARY}

Since the implementation of the federal Surface Mining Control and Reclamation Act of 1977 (SMCRA) in May of 1978, many opportunities have been lost for the reforestation of surface mines in the eastern United States. Research has shown that excessive compaction of spoil material in the backfilling and grading process is the biggest impediment to the establishment of productive forests as a post-mining land use (Ashby, 1998, Burger et al., 1994, Graves et al., 2000).

Stability of mine sites was a prominent concern among regulators and mine operators in the years immediately following the implementation of SMCRA. These concerns resulted in the highly compacted, flatly graded, and consequently unproductive spoils of the early post-SMCRA era. However, there is nothing in the regulations that requires mine sites to be overly compacted as long as stability is achieved. It has been cultural barriers and not regulatory barriers that have contributed to the failure of reforestation efforts under the federal law over the past 27 years. Efforts to change the perception that the federal law and regulations impede effective reforestation techniques and interfere with bond release must be implemented. Demonstration of techniques that lead to the successful reforestation of surface mines is one such method that can be used to change perceptions and protect the forest ecosystems that were indigenous to these areas prior to mining.

The University of Kentucky initiated a large-scale reforestation effort to address regulatory and cultural impediments to forest reclamation in 2003. During the three years of this project 383,000 trees were planted on over 556 acres in different physiographic areas of Kentucky (Table 1, Figure 1). Species used for the project were similar to those that existed on the sites before mining was initiated (Table 2). A monitoring program was undertaken to evaluate growth and survival of the planted species as a function of spoil characteristics and reclamation practice. In addition, experiments were integrated within the reforestation effort to address specific questions pertaining to sequestration of carbon (C) on these sites. 
Table I.1. Location and acreage of trees planted for DOE carbon sequestration research.

\begin{tabular}{lllcc} 
Year & Site & County & Trees Planted & Acres \\
\hline 2003 & 17 West & Martin & 72,760 & 107 \\
2003 & Peabody & Muhlenberg & 38,760 & 57 \\
2004 & Peabody & Muhlenberg & 43,760 & 62 \\
2004 & Laurel Fork & Breathitt/Knott & 86,600 & 125 \\
2004 & Bent Mountain & Pike & 73,661 & 107 \\
2005 & Peabody & Henderson & 47,600 & 70 \\
2005 & Bent Mountain & Pike & 19,860 & 28 \\
& & & & \\
& & Total: & $\mathbf{3 8 3 , 0 0 1}$ & $\mathbf{5 5 6}$ \\
\hline
\end{tabular}
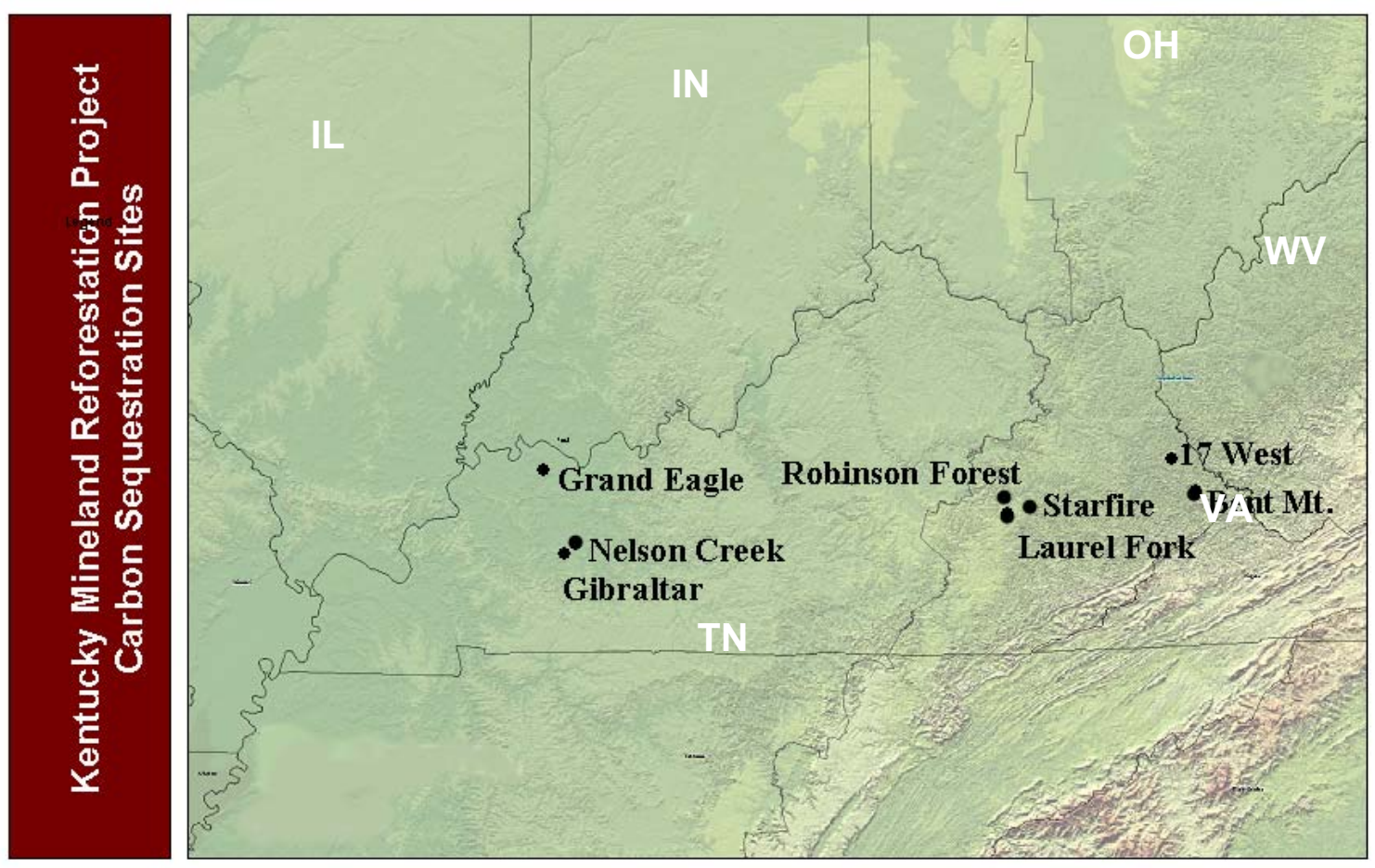

Figure I.1. Locator map for sites containing carbon sequestration plots. 
Table I.2. General planting species distribution for Eastern and Western KY plots. $+\uparrow$

\begin{tabular}{|lclc|}
\hline \multicolumn{3}{c|}{ Tree Species Planted in Eastern Kentucky and Western Kentucky } \\
Spastern Kentucky & \multicolumn{2}{c|}{ Western Kentucky } \\
Green Ash & $\%$ & Species & $\%$ \\
Sycamore & 14.9 & Green Ash & 14.7 \\
White Oak & 3.6 & N Red Oak & 13.5 \\
Chestnut Oak & 17.4 & Shumard Oak & 8.3 \\
N Red Oak & 7.2 & White Oak & 14.1 \\
Sugar Maple & 24.6 & Bur Oak & 12.8 \\
Yellow Poplar & 3.3 & Yellow Poplar & 14.1 \\
Black Locust & 9.1 & Bald Cypress & 1.9 \\
White Pine & 8.7 & Black Locust & 8.3 \\
Red Bud & 4.7 & Pitch/Lob Pine & 5.8 \\
Dogwood & 3.3 & Silky Dogwood & 3.8 \\
Total: & 3.2 & Redbud & 2.7 \\
\hline
\end{tabular}

Distribution varies between sites due to differing experimental objectives.

$\dagger$ List not inclusive of all species planted.

\section{OVERVIEW AND OBJECTIVES}

Carbon (C) sequestration is defined simply as "the process of increasing the carbon content of a carbon pool other than the atmosphere" (Intergovernmental Panel on Climate Change [IPCC], 2000). Projected climate change resulting from the increase in atmospheric carbon dioxide $\left(\mathrm{CO}_{2}\right)$ has given rise to various strategies designed to store additional $\mathrm{C}$ in terrestrial ecosystems (IPCC 1991, 2000). Efforts to remove C from the atmosphere and sequester it within terrestrial ecosystems are intended to complement reductions in net energy use accomplished by improving the efficiency of new and existing power plants and by adopting energy conservation plans (Zilberman and Sunding, 2001).

Land management options designed to increase terrestrial $\mathrm{C}$ inventories include both improving present land use practices as well as land use conversion (Lal et al. 1998). Because of the current spatial extent of forest, crop and grazing land there is potential to build terrestrial $\mathrm{C}$ stocks through improved management. Fertilization, thinning, and elongation of rotation lengths are strategies for increasing $\mathrm{C}$ storage on productive forest 
lands (Winjum and Schroeder, 1997; Nabuurs et al. 1999). On agricultural lands, improved management options include establishing highly productive deep-rooted pasture grasses (Fisher et al. 1994), adoption of conservation tillage (Kern and Johnson, 1993), and sewage sludge or animal manure amendment (Lal et al. 1998). Land conversion options considered as globally significant strategies for increasing terrestrial $\mathrm{C}$ inventories include establishing conservation reserves on agricultural lands, reforesting agricultural land, and rehabilitating degraded lands, such as contaminated industrial areas or mine lands (IPCC, 2000; Nabuurs et al. 1999).

In the Appalachian region, where the majority of the 2.4 million hectares disturbed by US coal mining resides (Zeleznik and Skousen, 1996), C sequestration complements traditional reclamation objectives, but information on the capacity of these systems to sequester $\mathrm{C}$ is limited. In addition, the ability of these sites to simply support a forest after surface mining activities have been completed is highly debated. As such, a project was undertaken to demonstrate reforestation techniques on surface mine lands that would lead to the establishment of high value (economic and ecological) forest. Demonstration areas were established in both the Eastern and Western KY coal fields using a variety of techniques to examine the effect of spoil type and reclamation practice on tree growth and survival (Figure 1). Considering that reclaimed spoils are essentially devoid of soil organic and plant associated $\mathrm{C}$ immediately after mining, the planting of forests was expected to dramatically affect $\mathrm{C}$ processes on those sites through $\mathrm{C}$ accumulation in soils and in forest biomass. Given these conditions, carbon sequestration rates and processes influencing these rates were evaluated in the reforestation demonstration areas.

For this project we hypothesized that an increase in forest productivity (both above and below ground) will result in an increase in $\mathrm{C}$ sequestration. As such, treatments were implemented to examine factors that may lead to increased productivity on surface mined lands. An evaluation of productivity based upon growth and survival parameters is possible on young stands, but evaluating $\mathrm{C}$ change in plantations between one to three years in age presents some logistical complications because growth rates during that period are slow. Moreover, the heterogeneous nature of spoils presents logistical problems for evaluating $\mathrm{C}$ accumulation because they may be enriched with $\mathrm{C}$ University of Kentucky Research Foundation 
from ancient sources (coal and carbonates). As such, the following documentation is organized in three sections to address the above concerns:

1. Evaluation of reforestation success and productivity on surface mined lands using low compaction reforestation techniques.

2. Development of a method to quantify $\mathrm{C}$ of new versus ancient origins from mine spoils.

3. Determining $\mathrm{C}$ sequestration rates in uncompacted spoils from a chronosequence of reforested minelands and regenerating forests.

\section{EVALUATION OF LOW SPOIL COMPACTION TECHNIQUES FOR FOREST ESTABLISHMENT ON SURFACE MINED LANDS IN KENTUCKY}

\subsection{INTRODUCTION}

Prior to SMCRA, reforestation was the reclamation technique of choice in the east; however, since its passage a steady decline in the amount, diversity, and productivity of forestland in all coal producing areas of the country has been observed (Burger, 1999). When attempts were made to reforest post-law sites high seedling mortality, slow growth, and poor production typically occurred due to highly compacted soils with inappropriate chemical characteristics and intense competition from ground cover. The two features of SMCRA that have had the largest effect on the reforestation of surface mined sites are: 1) returning the land to its "approximate original contour" (Torbert et al., 2000; Ashby and Kolar, 1998; Ashby, 1991) and 2) requiring the mining company to reclaim the land to a point where it may "support the uses which it was capable of supporting prior to any mining, or higher or better uses" (United States Congress, 1977).

SMCRA necessitates that mining companies be issued work permits based on several prerequisites: that the company post a performance bond to cover the cost of restoring the site, that the mined land be returned to its "approximate original contour (AOC)," and that the posted bond money be released only when the final vegetation of 
the site has been determined to be "successful" (United States Congress, 1977). The post-mining landscape on surface mined lands using mountaintop removal is essentially void of its original relief, and after the coal is removed, bull dozers repeatedly compact the residual spoil material in the process of returning the land to its AOC. As a result, the reclaimed land is so compact that it prohibits root development and tree establishment. Specifically, compacted soil increases bulk density and soil resistance to mechanical penetration, and reduces hydraulic conductivity, as well as air and nutrient flow in the soil (Barnhisel and Massey, 1969).

The second reforestation problem created by SMCRA stems from the former and future uses of land designated for mining. SMCRA requires that mined land be reclaimed to a point where it may "support the uses which it was capable of supporting prior to any mining, or higher or better uses" (United States Congress, 1977). After the passage of SMCRA, coal operators more often chose hayland or wildlife habitat (two of four post mining land uses: cropland, hayland/pastureland, wildlife habitat, or forestland) instead of the original forest for revegetation due to bond release expediency and satisfaction of regulatory requirements concerning sedimentation and erosion control. Burger (1999) reported that $95 \%$ of previously forested mined lands are reclaimed to a hayland or wildlife habitat post mining land use, and are abandoned to eventually revert to forests through natural succession (conservatively $\sim 120$ years for eastern deciduous forests). Unfortunately, an additional 50-80 years or more are needed before heavyseeded species, such as oaks and hickories, could become a dominant canopy component.

Until recently, most landowners and mining companies have seen tree planting on post-law mined lands as a waste of time because of the poor results of early trials and due to misconceptions (Ashby 1999). In contrast, research has shown that pre-law mined sites can have an equal or higher productivity than that of non-mined forests under certain conditions (Rodrigue et al. 2002; Pope 1989; Ashby 1991). The reclamation of pre-law sites typically resulted in a landscape composed of ridges and troughs, which allowed for less compaction, better rooting capacity, and improved water retention (Zeleznik and Skousen 1996). Based on observations of pre-law sites that are now developing into healthy forests, field studies have been established by researchers since the establishment 
of SMCRA to uncover the right combination of treatments that will determine the most effective way to re-establish productive forests on these degraded sites. Stone (1984) and Carmean (1975) established that tree growth was a function of soil and site quality. Forest productivity can be estimated using minesoil properties (Conrad 2002; Andrews et al. 1998; Torbert et al. 1998; Burger et al. 1994), and adequate minesoil quality can be obtained through selecting proper topsoil substitutes (Torbert et al. 1994; Burger and Torbert 1992).

Although there are formidable obstacles to reforesting reclaimed surface mined sites, promising results of post-law site research have been steadily increasing in the past 15 years in Appalachia and the Midwest (Angel et al. 2006; Burger and Zipper 2002; Conrad et al. 2002; Rodrigue 2001; Graves et al. 2000; Torbert et al. 2000; Ashby 1999; Burger and Torbert 1992). Two notable projects that have had shown positive results with high value commercial soft and hardwoods are the University of Kentucky's Starfire Mine High Value Tree Project in Perry County, KY, established in 1996 and 1997 (Angel et al. 2006; Graves et al. 2000; Thomas et al. 1999) and Virginia PolyTecnic Institute and State University's Powell River Project in Wise County, VA, established in 1980 (Burger 1999; Torbert et al 1985; Burger and Torbert 1992). The findings from these two projects have contributed to a movement back towards reforestation being a primary post mining land use in the east.

Successful reforestation techniques for surface mined lands continue to be studied, developed, and streamlined, but questions remain. Do specific surface and subsurface treatments affect growth trajectories and productivity of reforested surface mined lands? How does natural variation in the geophysical and chemical make-up of spoils affect forest productivity on mine lands? To answer these questions several experiments were established to evaluate forest productivity on mine lands as influenced by: reclamation technique, spoil type and spoil amendments.

\subsection{METHODS AND MATERIALS}

\subsubsection{General Experimental Protocol}

Experimental plots were established in three distinct mining regions in Kentucky's eastern and western coalfields regions. Specific mining sites are located in University of Kentucky Research Foundation 
southeastern Kentucky near the West Virginia border, in southeastern Kentucky near Hazard and in western Kentucky near Central City (Figure I.1).

Tree species selections were chosen that were suited for growth in a particular region and to provide a gradient of tree growth and litter quality. Tree species included white oak (Quercus alba), red oak (Quercus rubra), yellow-poplar (Liriodendron tulipifera), and green ash (Fraxinus pennsylvanica) and other available species (Tables I1 and I-2). Seedlings of each species were planted randomly in mixed species plots on compacted (control), dozer ripped and leveled loose-dumped spoil.

Sample plots were established in the mixed species planting areas at the reforestation sites. Plots were designed in a manner to both adequately sample each species planted and to account for differences with respect to site preparation activities and micro-topographic variability amongst planting units. As such, multiple 50 x 50 meter plots (8) were set within planting units that exceeded 8 hectares in area. This scenario was replicated within each reforestation site and for the differing reclamation practices employed (ripped vs. uncompacted vs. compacted). In addition, complete seedling inventories were analyzed in several smaller plots (1-2 ha.) that presented unique features in the reforestation areas. The sampling strategy provided for a minimum of 100 seedlings per species per planting unit, which allowed for statistical comparison of the differing species within the differing planting conditions and sites.

Seedling height and diameter were measured within the monitoring plots on an annual basis. Notes were taken on seedling health, vigor, growth form and level of herbivory. Leaf area measurements were performed on a subset of trees from selected plots. Once measured, individual leaves were collected, dried, weighed and analyzed for $\mathrm{C}$ and N. Clip plots $\left(1 \mathrm{~m}^{2}\right)$ were measure in selected areas to assess herbaceous production on the mine soil.

Soil samples were collected from selected plots at 0-5, 5-10, 10-20 and 20-40 cm increments for chemical and mineralogical characterization. Physical attributes of soils on the sites were determined using a recording cone penetrometer and a nuclear density guage. Both instruments provided information on the relative level of compaction or depth of resistance. 
Hydrology and water quality monitoring equipment was installed in selected reforestation sites. Flumes and stilling wells were placed adjacent to the planting areas to measure runoff from rain events. ISCO automatic water samplers were installed to evaluate export of solids and $\mathrm{C}$ from the planting areas. Solar panels and liquid level actuators were connected to the ISCO samplers to: 1) provide a constant power source and 2) to initiate sampling only when runoff was detected. Pressure transducers and minidataloggers were installed to provide continuous (10 minute interval) stage data for determination of flow rates. Water samples were collected from the ISCOs after each event that produced sample; then, transferred to the University of Kentucky in coolers at $4^{0} \mathrm{C}$ where they were analyzed for total and suspended solids, total dissolved solids, particle size analysis, and total organic carbon. A weather station consisting of a tipping bucket style rain gauge was installed to monitor rainfall events at each flume location. Data is recorded at five-minute intervals using HOBO event datalogger. Additional weather stations were installed in each of the major reforestation regions to measure precipitation volume, temperature, relative humidity, wind speed and direction and solar radiation.

Low compaction or compaction alleviation techniques were compared to sites that were reclaimed using normally accepted spoil handling techniques that resulted in a smooth graded surface (Figure 1.1). These traditionally reclaimed areas served as controls. Loose-dumped areas were constructed with fresh spoil material from the mining operation. To create this treatment, large earth moving trucks were used to end-dump the spoil material in consecutive piles four to eight feet thick that tightly abutted each other. After which, the areas received one or two passes with a bulldozer (D-8) which struckoff or leveled the tops of the consecutive spoil piles (Figure 1.2). Other areas were ripped using a plow like implement attached to a dozer to scarify the planting surface and alleviate compaction from excessive grading. The rippers varied in size and shape but generally resulted in a 1 to $1.5-\mathrm{m}$ deep furrow. 


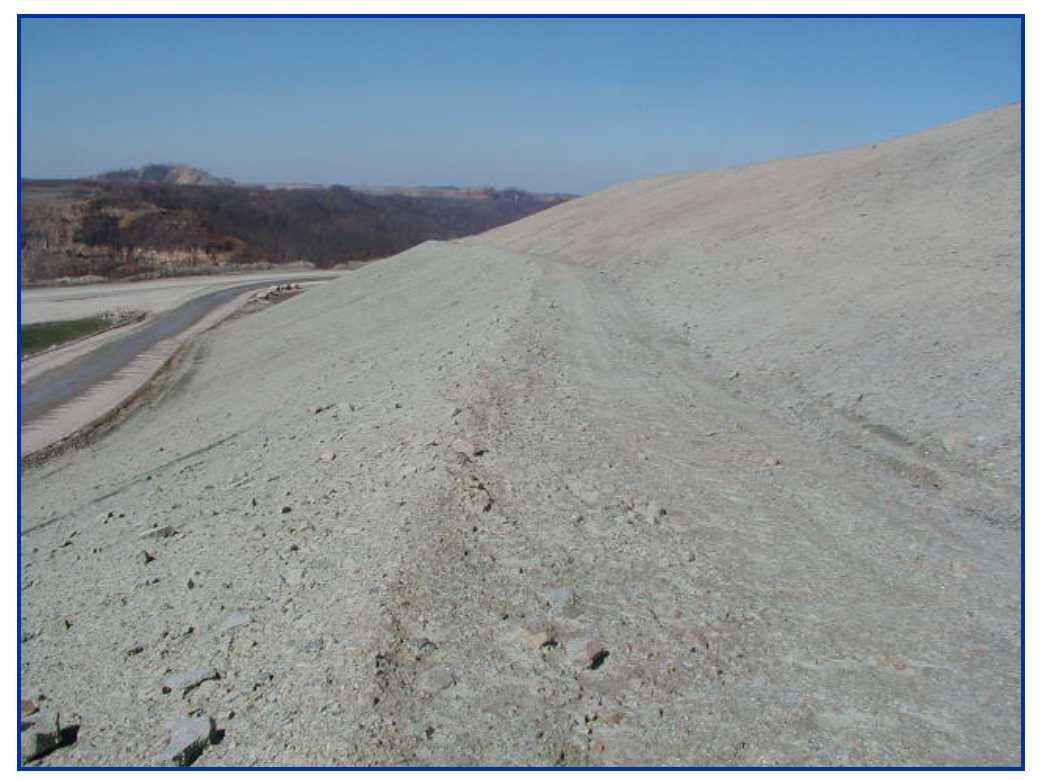

Figure 1.1. Example of a site prior to planting that exhibited a traditional grading practice (control).

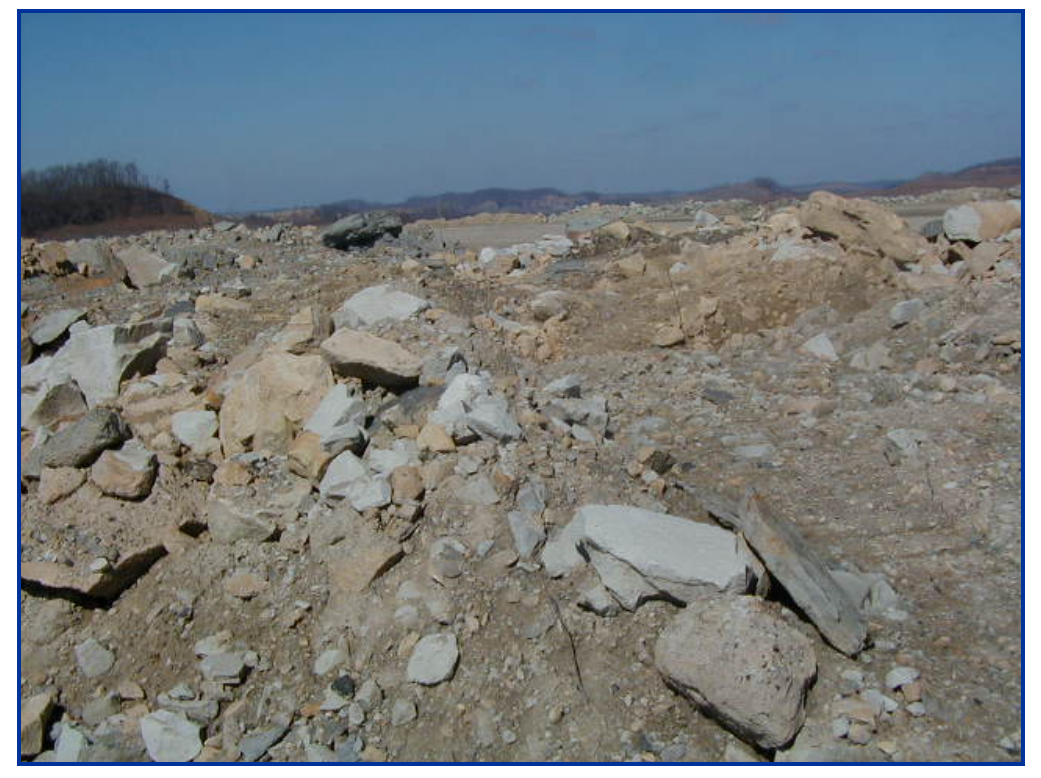

Figure 1.2. Example of a site prior to planting that exhibited the loose-dumped grading practice. 


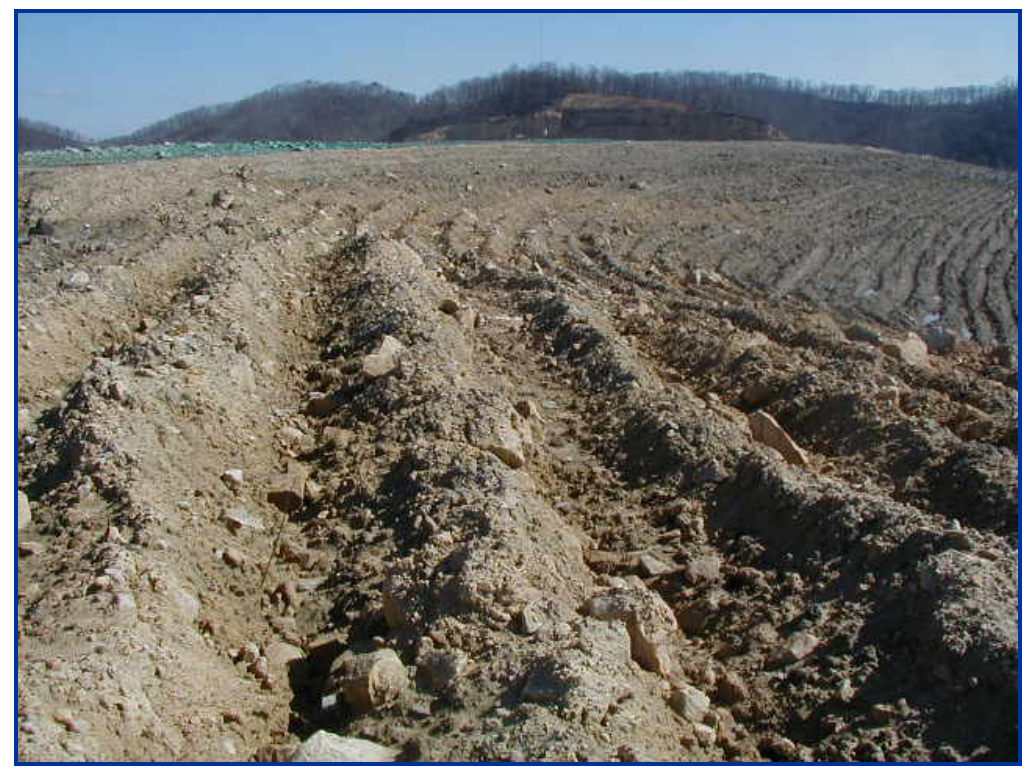

Figure 1.3. Example of a site prior to planting that has been ripped. 


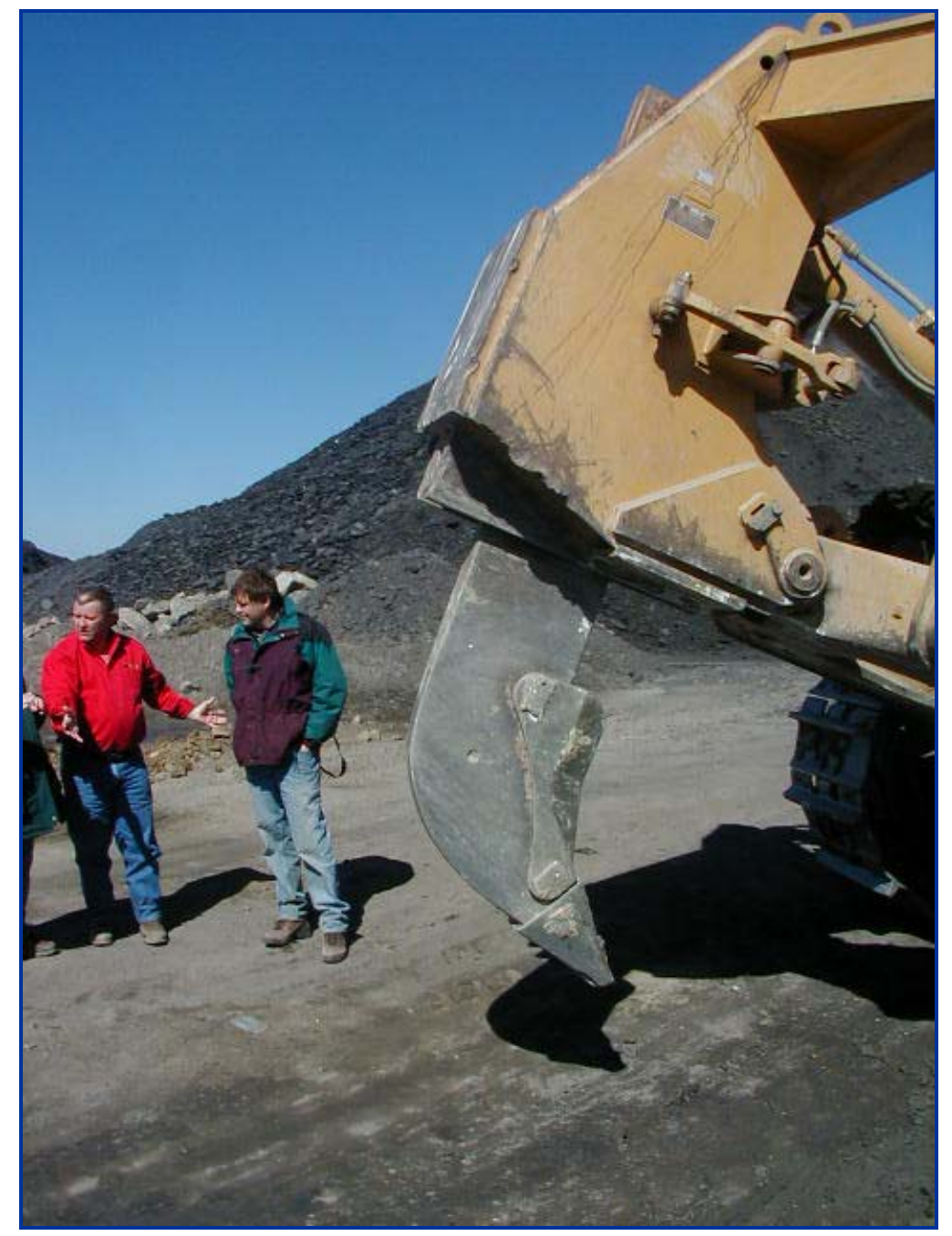

Figure 1.4. Example of a ripper attached to a D11 dozer. 


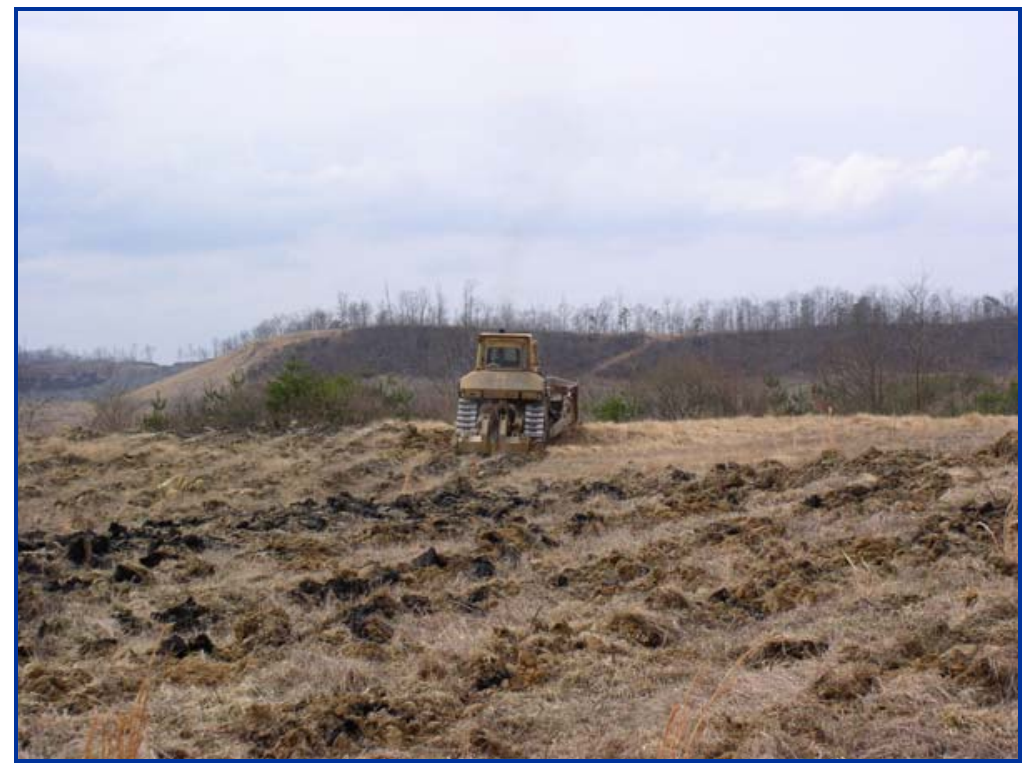

Figure 1.5. Example of a site that was reclaimed as pasture and is being ripped to alleviate the level of compaction in preparation for tree planting.

\subsubsection{Site Specific Protocol}

\subsubsection{Reforestation of Previously Reclaimed Pasture}

An evaluation of ripping as a method for alleviating compaction on mine land previously reclaimed as pasture was examined in Muhlenberg Co., KY at the Gibraltar Mine and in Martin Co., KY at the 17 West Mine. Both sites were initially ripped with a dozer and planted with mixture of species commonly found on the sites prior to mining. Sample plots were established in the mixed species planting areas at the reforestation sites in 2004 for evaluating seedling survival and productivity. Multiple 50 x 50 meter plots (8) were set within each planting unit and all trees with the plot were repeatedly measured. This scenario was replicated within each reforestation site.

\subsubsection{Evaluating Low Compaction Reclamation Techniques on Reforestation Productivity- Bent Mountain}

Four methods to reduce compaction on reclaimed surface mines were compared at the Bent Mountain research site on Brushy Fork near the community of Meta in Pike County Kentucky. The methods included: single shank ripped spoil, triple shank ripped spoil, excavated spoil, and rough graded spoil. Normally graded spoil was also examined as a control to represent a traditional reclamation practice. A single shank ripper was used in gently sloping areas to a depth of $\approx 2-\mathrm{m}$, while the triple shank ripper was used University of Kentucky Research Foundation 
primarily on level spoil to a depth of $\approx 1.5-\mathrm{m}$. Both rippers were pulled with a D-11 dozer. Excavated spoil was created by digging out compacted spoil to a depth of $\approx 1$-m and dropping it in place. The rough graded spoil was created by dumping mixed sandstones and shale spoil from a dump truck to a depth of 2 to $2.5-\mathrm{m}$ followed by minimal grading (single pass) with a D-9 dozer to strike-off the piles. All sites were planted with native hardwood species in 2004.

Three $50 \times 50-\mathrm{m}$ plots were established on the five different spoil treatments for a total of 15 plots. During the spring of 2004, all of the trees in the 15 research plots were tagged and measured. Tree number, species and height to the nearest centimeter were recorded. Also recorded was vigor class and distinguishing features that may influence productivity. Measurements were repeated on an annual basis. Bulk density was measured annually on each treatment using a nuclear density probe.

\subsubsection{Evaluating Spoil Amendment use on Reforestation Productivity - Laurel Fork and Nelson Creek}

Detailed studies to address specific questions pertaining to forest productivity were initiated with the development of manipulative plots to examine the influence of mycorrhizae, spoil chemical and mineralogical properties, and use of amendments on forest establishment and carbon sequestration. Based upon earlier studies by UK and the USDA Forest Service, mycorrhizal fungi have been shown to play a major role in the survival, nutrient uptake and biomass development (above and below ground) of seedlings planted on mined sites and abandoned industrial areas. Given that the current Reforestation study intends to examine the potential for enhanced carbon sequestration on mined sites via $\mathrm{C}$ accumulation in soil and forest biomass, then efforts to maximize seedling survival and growth are being further examined. As such, a factorial experiment using inoculated vs. non-inoculated species in non-fertilized, fertilized only, amended (organic mulch) only, and fertilized + amended plots was established in 2004.

Seedlings used for this study were grown at the Kentucky Division of Forestry Nursery, Morgan County nursery. The mycorrhizal trees were initially inoculated with Pisolithus tinctorius (Pt) and Scleroderma cepa $(\mathrm{Sc})$ in the beds. The mycorrhizal plots received additional spore application in the field after they were transplanted University of Kentucky Research Foundation 
(MycorTree ${ }^{\circledR}$ ecotomycorrhizal spores, per the manufacturers' instructions, approx. $10 \mathrm{~g}$ spores per $5 \mathrm{~L}$ of water and each plant received approx. $100 \mathrm{~mL}$ of solution). The application was performed to potentially enhance the inoculation index of the planted seedlings. The non-mycorrihizal plots received an application of fungicide (Bayleton; 1 $\mathrm{kg}$ per plot)) to suppress natural inoculation. Fertilizer plots received 150 pounds of 20 20-20 fertilizer per acre on an annual basis. The research plots were established on mined sites in Knott and Muhlenberg Counties, KY (Figures I.1 and 1.6). Fifty-four 15 x 15 meter plots were delineated on each site. Prior to planting, each site was ripped to a depth of approximately 2-meters using a dozer. Half of the area received an application of 40 tonnes per acre of a wood chip/manure compost mixture. The composted areas were subsequently ripped again to incorporate the material into the spoil. Two tree species; Pinus taeda (Loblolly Pine) and Quercus rubra (Northern Red Oak), were planted in the plots. Each plot received 100 seedlings spaced at 1.5 meter centers. Each treatment was examined in triplicate for each species. At 100 trees per plot $\mathrm{x} 3$ plots per treatment $\mathrm{x} 8$ treatments $\times 2$ species, 4,800 seedlings were planted per site. Half of the seedlings from each plot were tagged and repeatedly measured for growth and survival statistics. Whole tree harvesting and tissue samples were collected from the remaining seedlings.

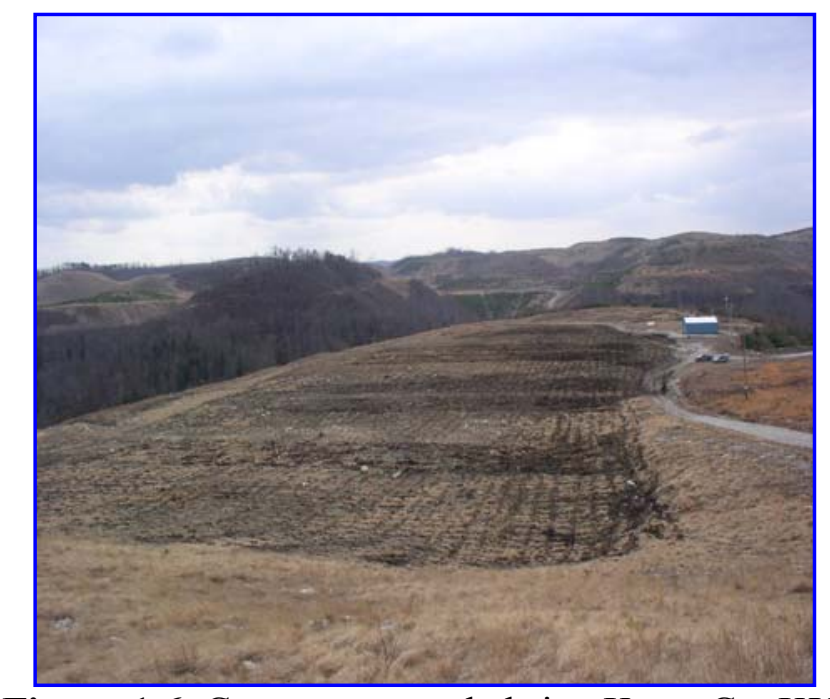

Figure 1.6. Compost amended site, Knott Co. KY. 


\subsubsection{Evaluating Geophysical and Chemical Spoil Characteristics on Reforestation Productivity - Bent Mountain}

Research plots were established in March 2005 on an active mountaintop removal operation for the purpose of evaluating tree performance, conducting water characterization studies and determining the mineralogical, chemical and physical characteristics of three different types of loose-graded spoils (Figure 1.7).

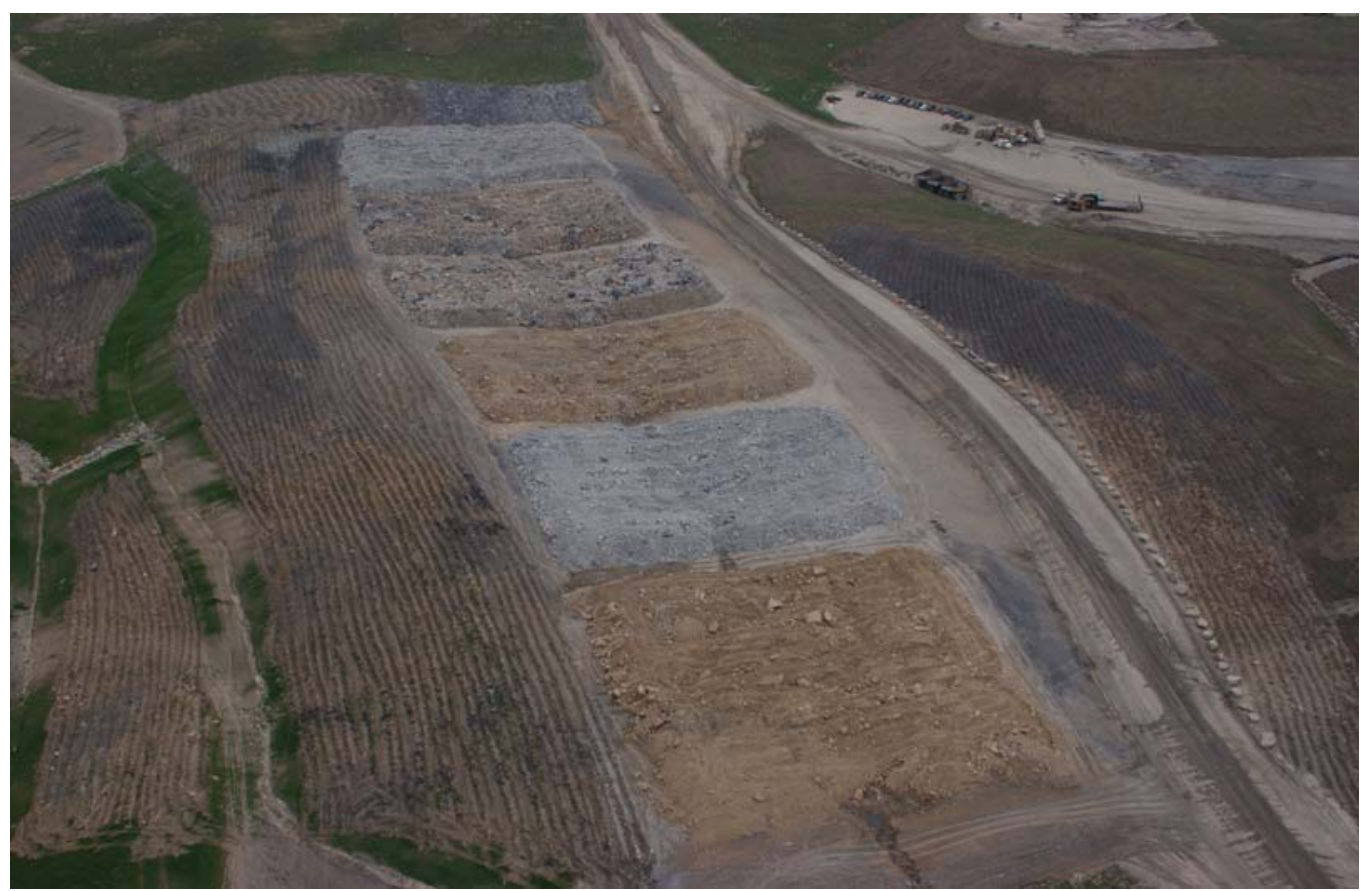

Figure 1.7. Aerial view of geohydrology plots at Bent Mountain, Spring 2005.

The mine site is located on Bent Mountain near the community of Meta in Pike County Kentucky (latitude N $37^{\circ} 35^{\prime} 50^{\prime \prime}$, longitude W 82 $23^{\prime} 38^{\prime \prime}$ ). Three spoil types are involved: (1) predominately brown weathered sandstone; (2) predominately gray unweathered sandstone; and (3) equally mixed brown weathered and gray un-weathered sandstones. Each of the three treatments was installed in a square plot that measures $\approx 64$ meters on each side. The total area of each plot is 4050 square meters. The three treatments were replicated once, creating a total of six plots or experimental units (Figure 1.8). The three treatments were randomly assigned to the six plots. Each of the six plots was physically separated and isolated from each other by a 2.5 -meter buffer zone where 
no loose spoil was dumped. The buffer zones will also serve as an access to drain pipes and instrumentation installed in the six plots.

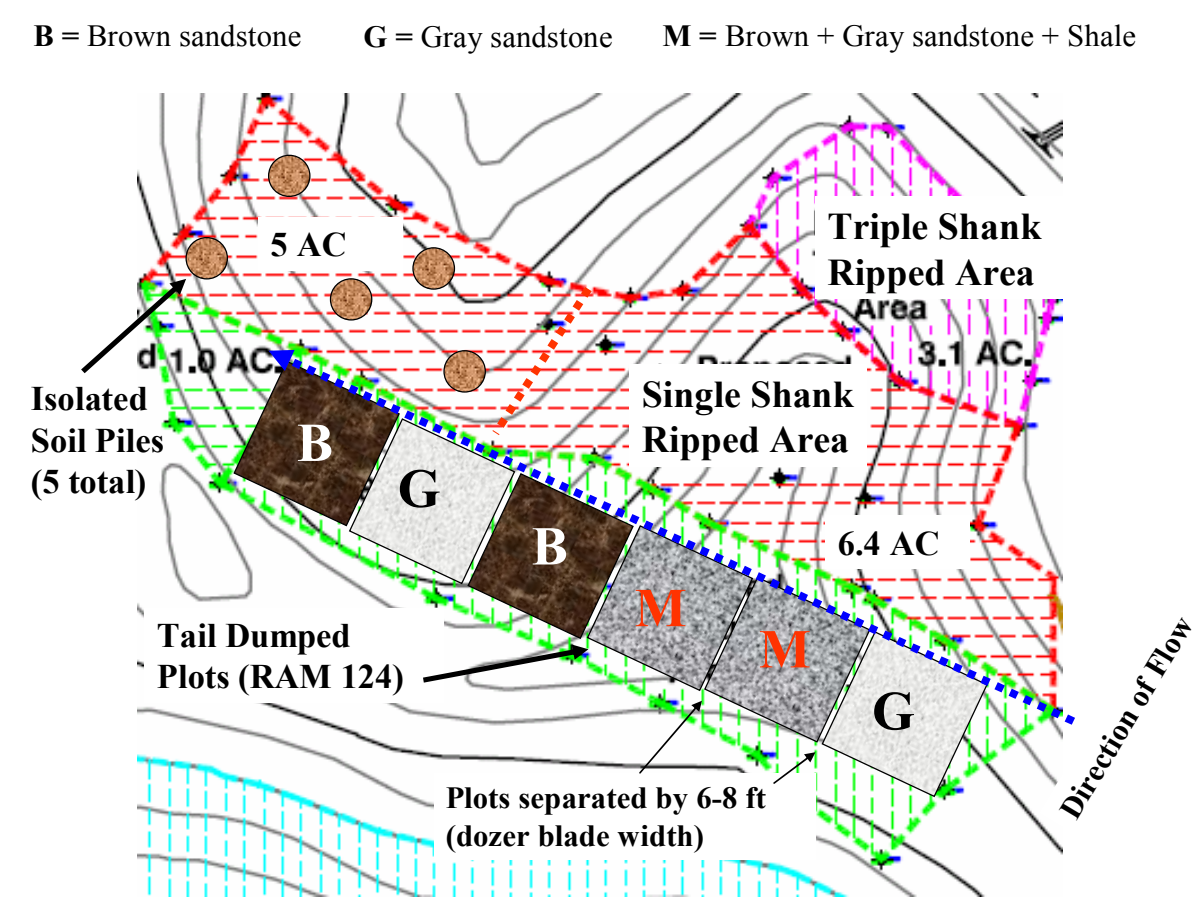

Figure 1.8. Conceptual view of the research area.

A rectangular foundation for the six plots was prepared with spoil material from the mountaintop removal operation. The foundation, which is about 3.5 hectares in size, was orientated along the long axis in a northwest-southeast direction on a $2 \%$ slope with the highest elevation occurring on the southeast edge. The foundation was then divided in half along the short axis and graded on a $2 \%$ slope so that the center line of each plot is at a lower elevation than the northeast and southwest edges (forming a "bathtub" configuration to facilitate the flow of water to the center and then to the exit point of each plot). The spoil in the foundation was then highly compacted by repeated passes of both rubber tired and tracked heavy equipment so that it is impervious to water.

At the exit point of each plot and in the area of the buffer zones, a pit was dug into the compacted foundation that measured 2 meters by 2 meters and 1 meter deep. The floor of the pit slopes to a 20-centimeter diameter hole drilled through about 5 meters of the compacted foundation and about 12 meters of rock overburden to an abandoned underground mine in the Peach Orchard coal seam below the plots. The underground mine is an abandoned conventional room and pillar operation on 6 meter by 18 meter University of Kentucky Research Foundation

Final Report - 10/01/03 thru 9/30/06

DE-FC26-02NT41624 
centers. The drainage system to the underground mine below the plots was installed to completely isolate each plot so that no drainage from one plot can mix with drainage from any other plot.

Prior to the placement of the three spoil types on the six plots, a system of drainage pipes and lysimeters were installed on top of the compacted foundation. Each of the six plots is drained by a perforated $10.2 \mathrm{~cm}$ PVC pipe (Figure 1.9). The PVC pipes span the entire length of each plot down the center of the "bathtub" to the exit point and into the pit where drainage enters into the underground mine below. Three pan lysimeters were also installed on top of the compacted foundation of each of the six plots (Figure 1.9). The lysimeters are 4.6 meters square and are drained to the exit points by PVC pipes that are 2.5 centimeters in diameter. The lysimeters and the PVC pipes were then carefully covered with approximately 1 meter of the spoil type specific to each plot to protect them from the impact of the spoil and rocks that would be dumped on them.

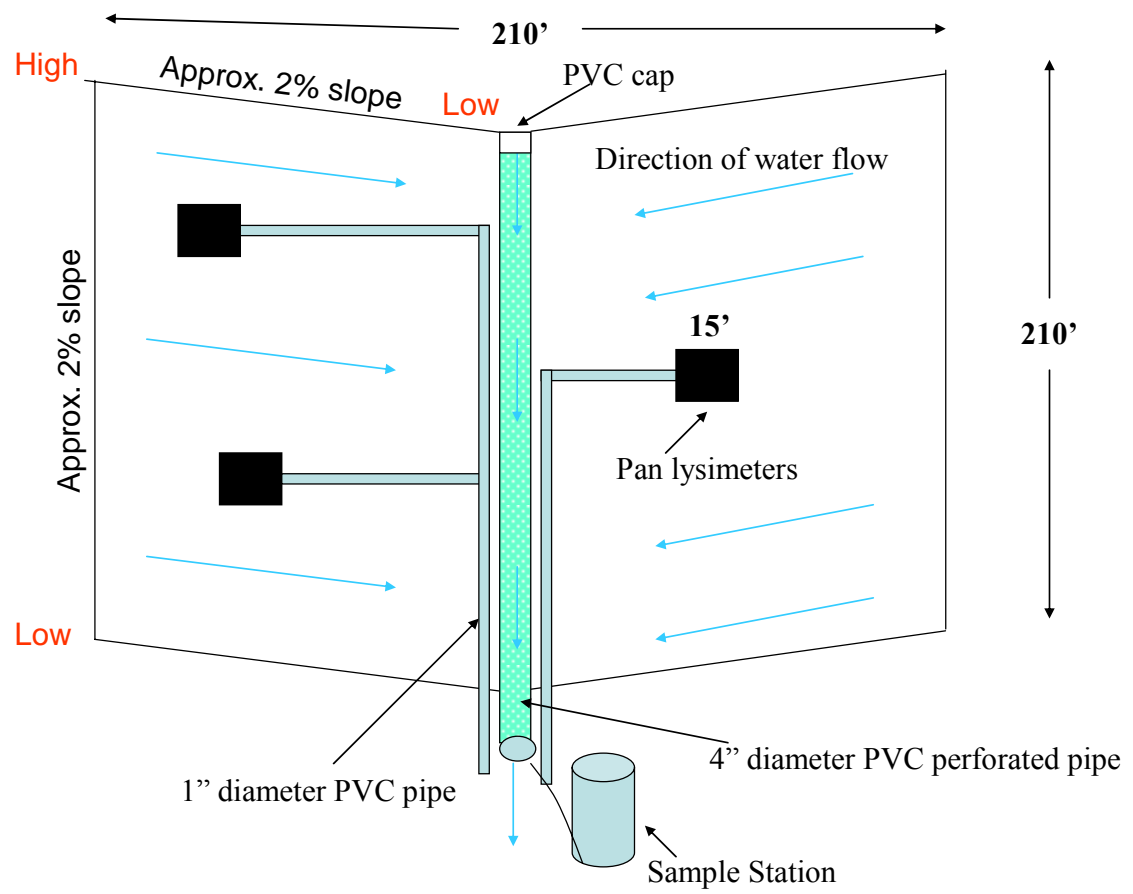

Figure 1.9. Lysimeter and drain tile position under loose spoil material.

Once the lysimeters and PVC drainage pipes were installed, spoil was dumped out of the end of large dump trucks onto the compacted foundation into tightly placed piles 
that are about 3.7 meters deep. The spoil piles were placed in parallel rows in such a way that they closely abut one another across each of the six plots. The spoil piles were then “struck-off" with one pass of a small bulldozer (D-5) down the length of each parallel ridge of spoil, pushing it into the parallel valleys on both sides. The spoil was dumped in the six plots and struck off as specified in Reclamation Advisory Memorandum Number 124 issued by the Kentucky Department of Natural Resources. Soil samples were collected from the sites and are currently being analyzed.

Four species of tree seedlings of 2:1 nursery stock were planted into the loosely graded spoil of the six plots on April 2, 2005. The four species were white oak (Quercus alba), red oak (Quercus rubra), yellow-poplar (Liriodendron tulipifera), and green ash (Fraxinus pennsylvanica). The tree seedlings will be the sampling units. The response variables will be tree height, tree diameter, and above and below ground biomass.

Instruments installed at each monitoring location included modified rain gauges at the ends of each of the six drains located in the pits (Figure 1.10), 36 sensors for time domain reflectometers ( 6 per plot) located at three different depths in the spoil, and a complete weather station.

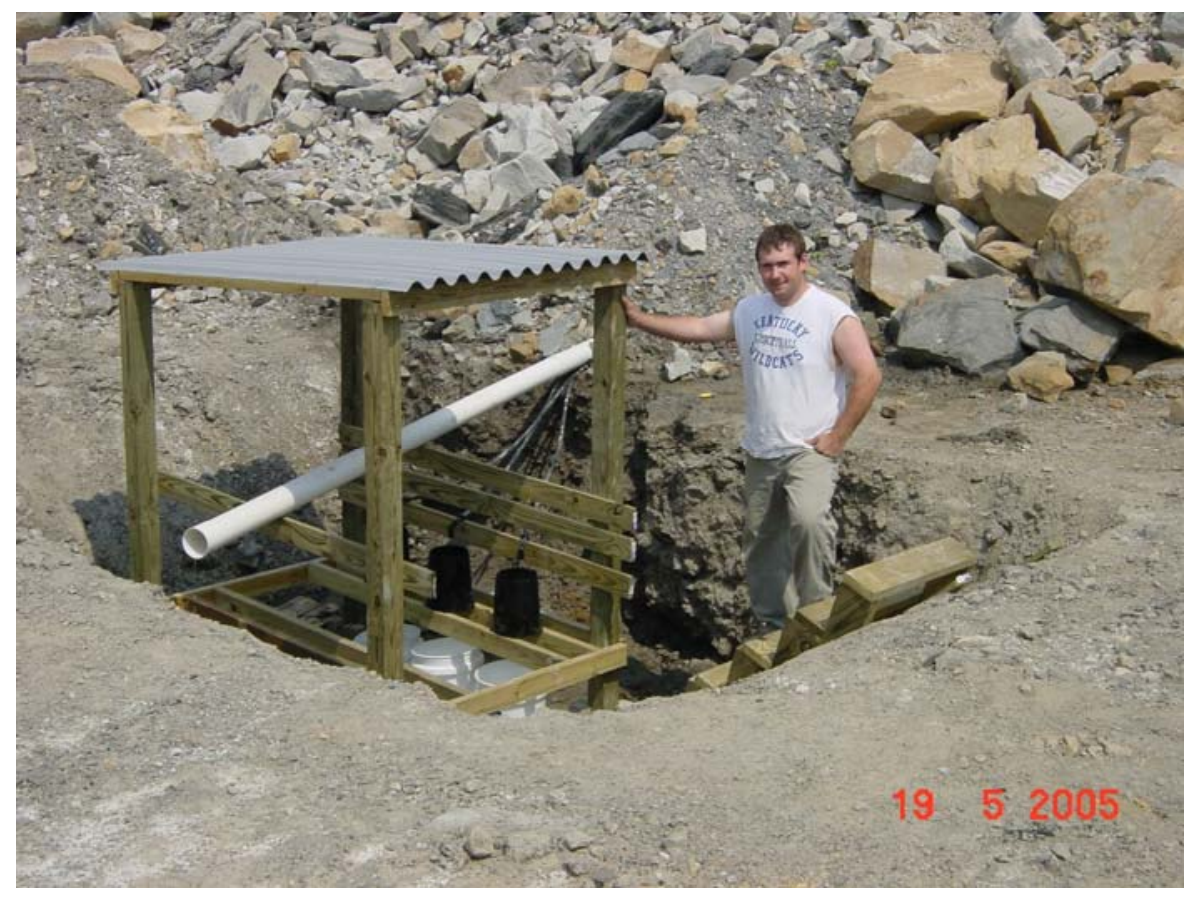

Figure 1.10. Monitoring station for water quality/hydrology measurements. 


\subsection{RESULTS AND DISCUSSION}

\subsubsection{Reforestation of Previously Reclaimed Pasture}

\subsubsection{Seedling Response}

At the 17 West site (Eastern Kentucky), average survival was greater than $70 \%$ for all species after three years growth except white pine (62\%) and black cherry (50\%) (Figure 1.11). Initial seedling height at 17 West was between 30 and $50 \mathrm{~cm}$ for all species planted except for black locust, which exhibited an average height of over $100 \mathrm{~cm}$ (Figure 1.12). By 2006, all species exhibited an increase in growth (averaged $25 \mathrm{~cm}$ ). Black locust demonstrated the most significant growth $(>100 \mathrm{~cm})$ over the three year period, while red oak exhibited the slowest growth $(<4 \mathrm{~cm}$ ) (Figure 1.12). Of the four dominant species at this site, white oak and red oak initially exhibited the highest average leaf area index $\left(>2000 \mathrm{~mm}^{2}\right)$, but 2004 data indicated a decline in leaf area for these species which is likely attributable to dieback (Figure 1.13). Black locust and ash exhibited similar average leaf area indices in 2003 at $1000 \mathrm{~mm}^{2}$, and showed similar increases of approximately $500 \mathrm{~mm}^{2}$ in 2004 (Figure 1.13). By 2006, dieback had been curtailed in all species except sugar maple (Figure 1.12). 
17- West

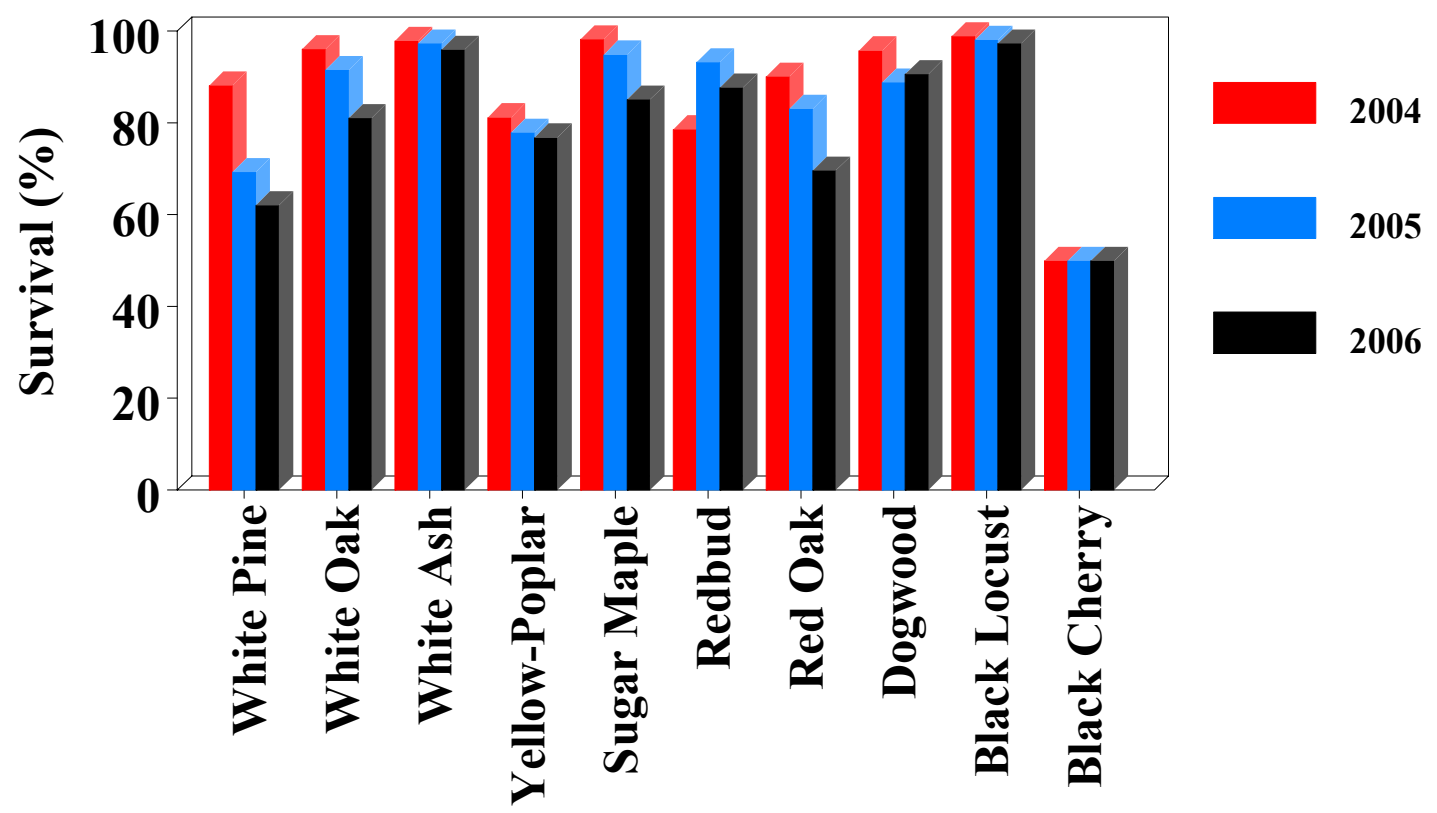

Figure 1.11. Average survival of planted seedlings at the 17 West mine in Martin Co. KY. 


\section{7- West}

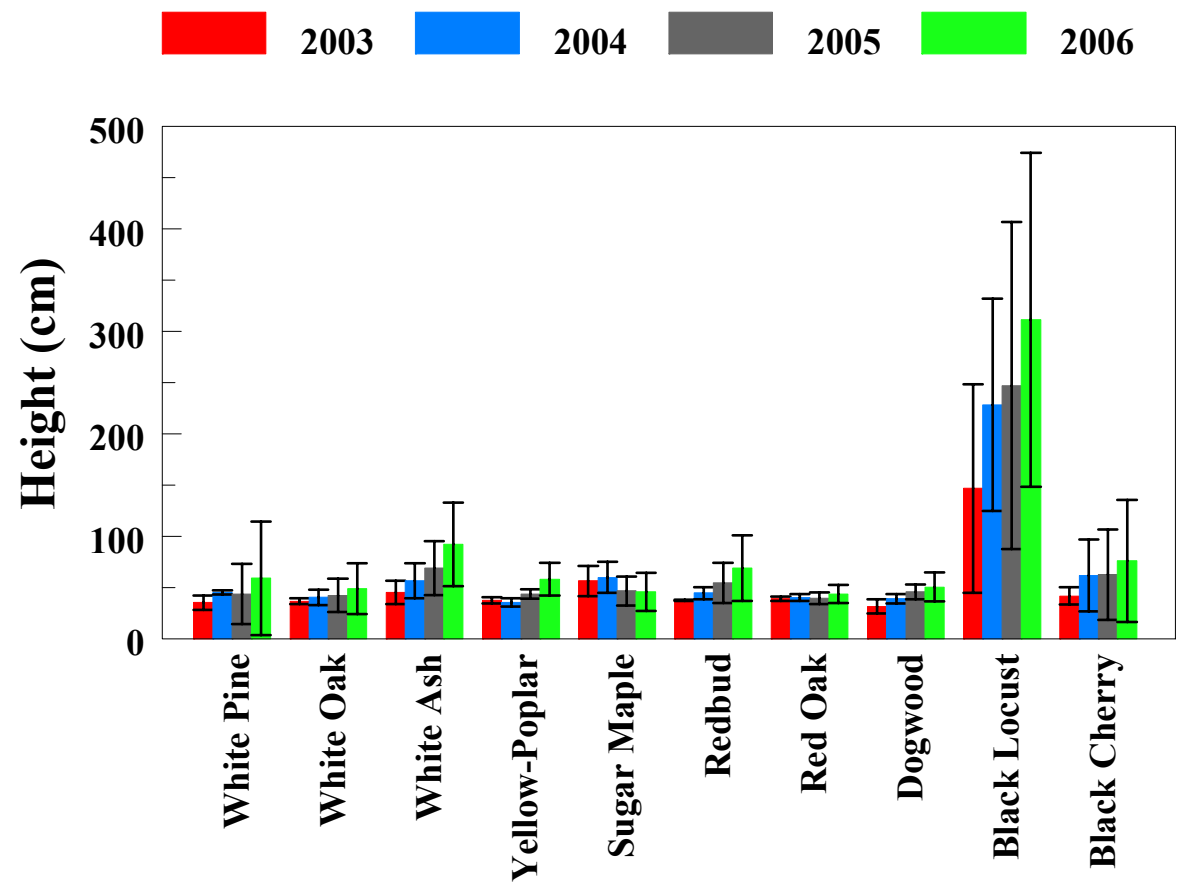

Figure 1.12. Average seedling height at the 17 West mine in Martin Co. KY.

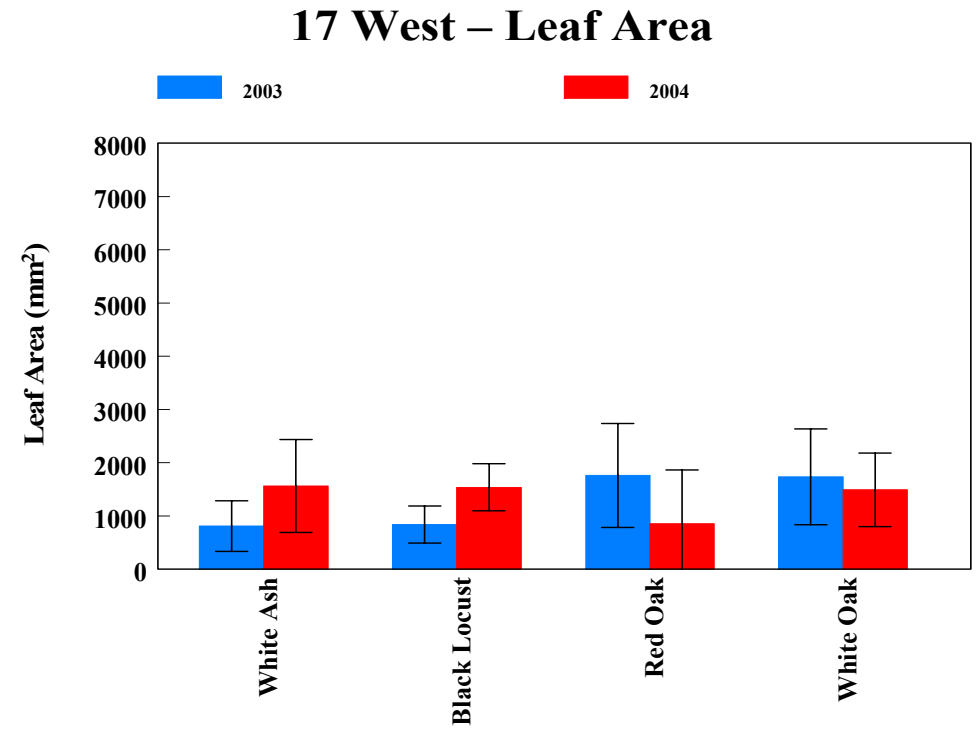

Figure 1.13. Average leaf area of dominant species at the 17 West mine in Martin Co. KY. 
Seedlings at the Gibraltar ripped site (Western Kentucky) exhibited average survival rates greater than $70 \%$ for all species after three years growth except white oak (49\%) and dogwood (48\%) (Figure 1.14). The seedlings showed an average initial height between 30 and $60 \mathrm{~cm}$ for all species planted (Figure 1.15). In 2004, ash, dogwood and loblolly pine exhibited slight increases in height, while the oaks, cypress and persimmon showed a decline in height. By 2006, all species exhibited increased height over that when they were planted with the exception of persimmon (Figure 1.15). As with the 17 West site, black locust showed good growth characteristics with an average height increase of $>100 \mathrm{~cm}$. Even though the oaks and cypress exhibited an initial decline in height, all three showed an increase in leaf area from 2003 to 2004, which suggests that growth was occurring and that these species were not stressed (Figure 1.16). In addition, the ash exhibited a doubling of leaf area between the two years while showing practically no increase in height. Hardwood seedlings (especially oaks) are known to expend a large amount of energy developing an extensive rooting system during the first few growing seasons; thus, the observed response was anticipated. Browsing by wildlife was also a commonly observed problem at this site. 


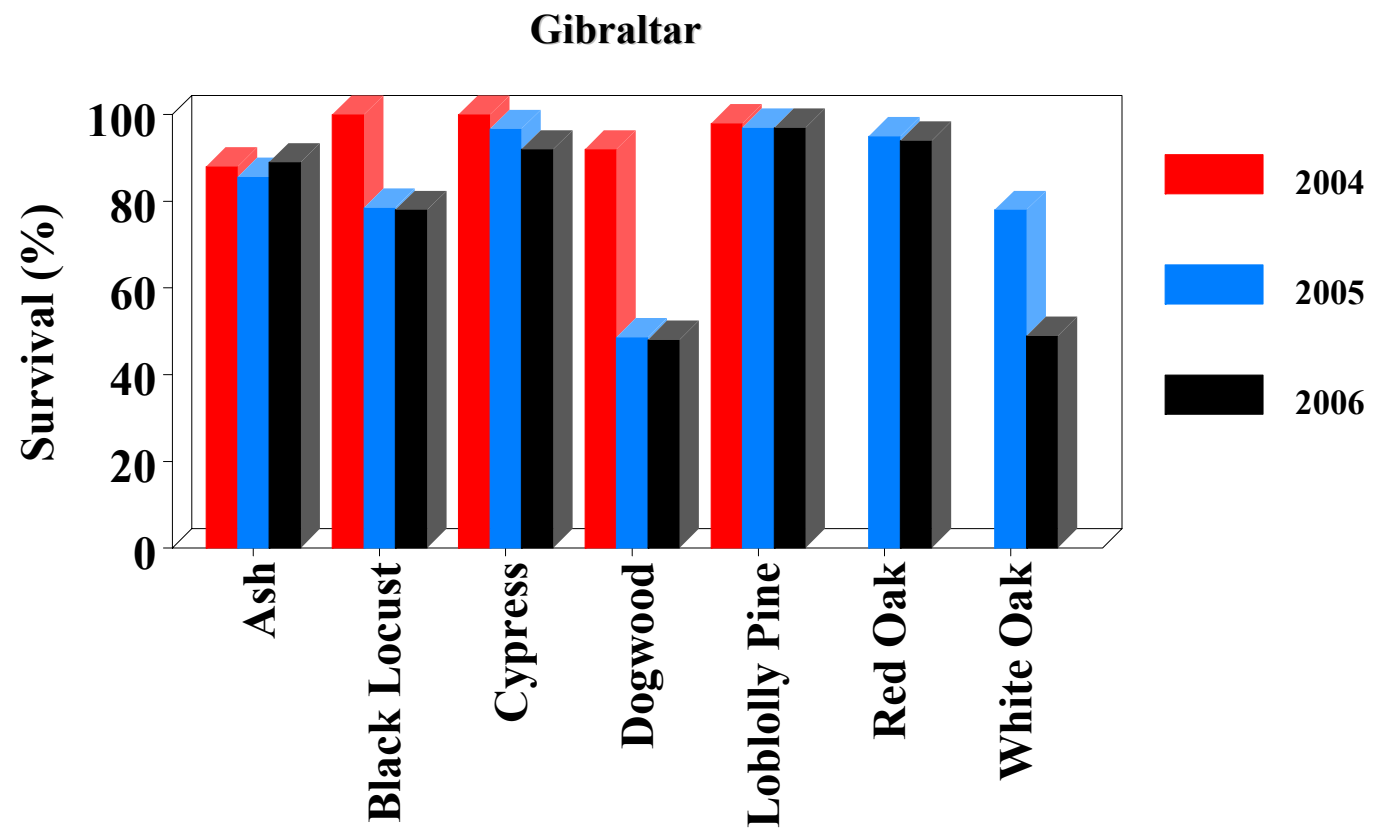

Figure 1.14. Average seedling survival at the Gibraltar mine in Muhlenberg Co. KY. 


\section{Gibraltar}

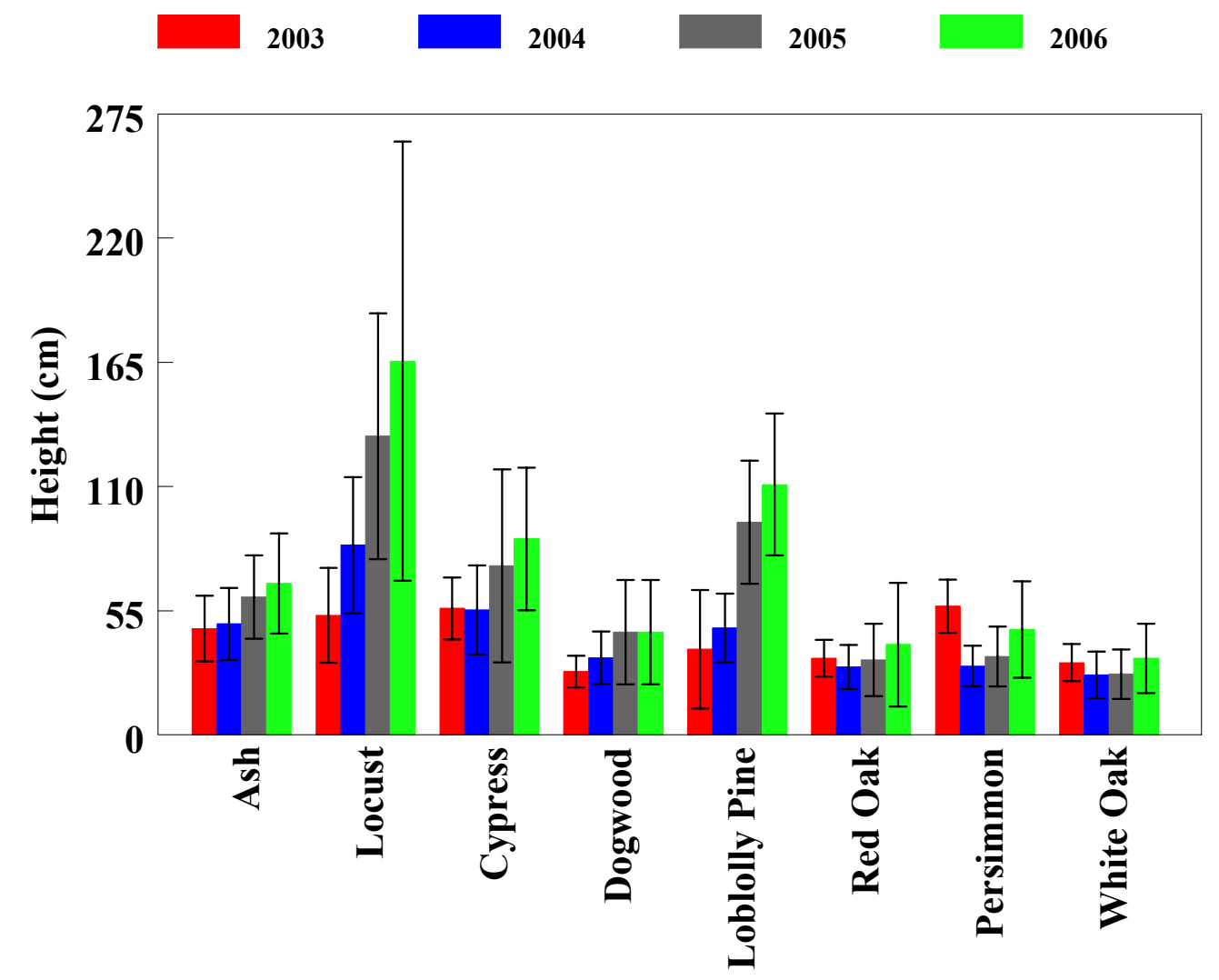

Figure 1.15. Average seedling height at the Gibraltar mine in Muhlenberg Co. KY. 


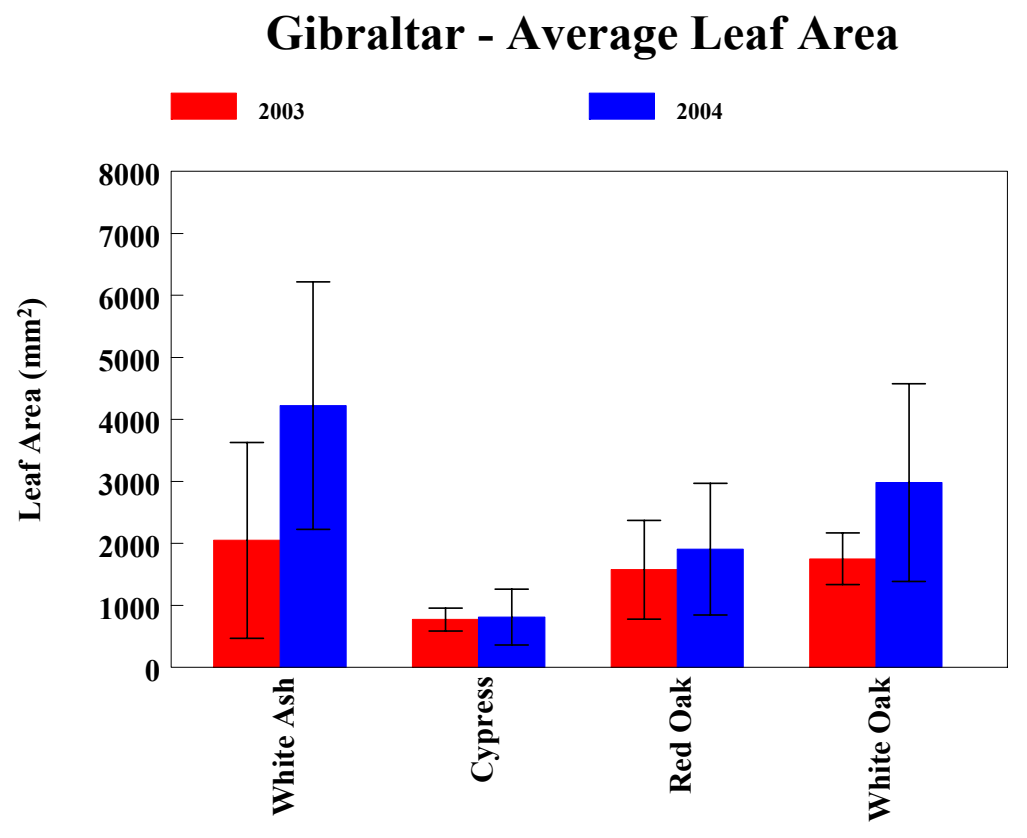

Figure 1.16. Average seedling height at the Gibraltar mine in Muhlenberg Co. KY.

\subsubsection{Spoil Characteristics}

A general increase in bulk density with depth was exhibited at both the 17 West and Gibraltar mine sites (Table 1.1). Although the averages are higher than what one may observe in a general agricultural soil (Brady and Weil, 2002), they fall within the range of those reported for ripped mine spoils in Kentucky (Conrad, 2002). In addition, the bulk density values at 5 and $15-\mathrm{cm}$ are similar to slightly lower than values observed at the Starfire mine in Perry Co. KY on uncompacted spoil (Angle et al., 2006).

Table 1.1. Bulk density at 5, 15 and $30.5 \mathrm{~cm}$ depths in ripped spoil at the 17 West and the Gibraltar mines in Martin and Muhlenberg counties KY, respectively.

\begin{tabular}{|l|cccc|}
\hline Treatment & Year & \multicolumn{3}{c|}{ Bulk Density $\left(\mathbf{g ~ c m}^{\mathbf{3 - 1}}\right)$} \\
\hline 17 West & $\mathbf{2 0 0 3}$ & $\frac{\mathbf{C m}}{1.41}$ & $\underline{\mathbf{1 5} \mathbf{~ m}}$ & $\underline{\mathbf{3 0 . 5}} \mathbf{~ m}$ \\
$\mathbf{1 7}$ West & $\mathbf{2 0 0 4}$ & 1.35 & 1.61 & 1.74 \\
$\mathbf{1 7}$ West & $\mathbf{2 0 0 5}$ & 1.28 & 1.54 & 1.69 \\
& & & & 1.68 \\
Gibraltar & $\mathbf{2 0 0 3}$ & 1.54 & 1.68 & 1.73 \\
Gibraltar & $\mathbf{2 0 0 4}$ & 1.49 & 1.66 & 1.67 \\
Gibraltar & $\mathbf{2 0 0 5}$ & 1.50 & 1.65 & 1.68 \\
\hline
\end{tabular}


Soil analyses revealed that total C and N levels fell from 2003 to 2005 at 17 West (Figure 1.17). Similarly, extractable (KCl extraction) nitrate $\left(\mathrm{NO}_{3}\right)$ and ammonium $\left(\mathrm{NH}_{4}\right)$ showed a reduce level in 2005 over that measured in 2003. There are several factors that may be responsible for these trends; however, the reduction is most likely a result of oxidation of previously accumulated SOM in the pasture spoils due to ripping (plowing), or weathering of a carbonate fraction in the spoil or soil amendment (lime). The tremendous reduction in both total $\mathrm{N}$ and soil extractable $\mathrm{N}$ suggests that the seedlings have been utilizing available nutrients for growth, while returning little to the forest floor. Litter fall collectors from this site yielded no measurable catch during the course of the study and the development of a litter layer was not observed.

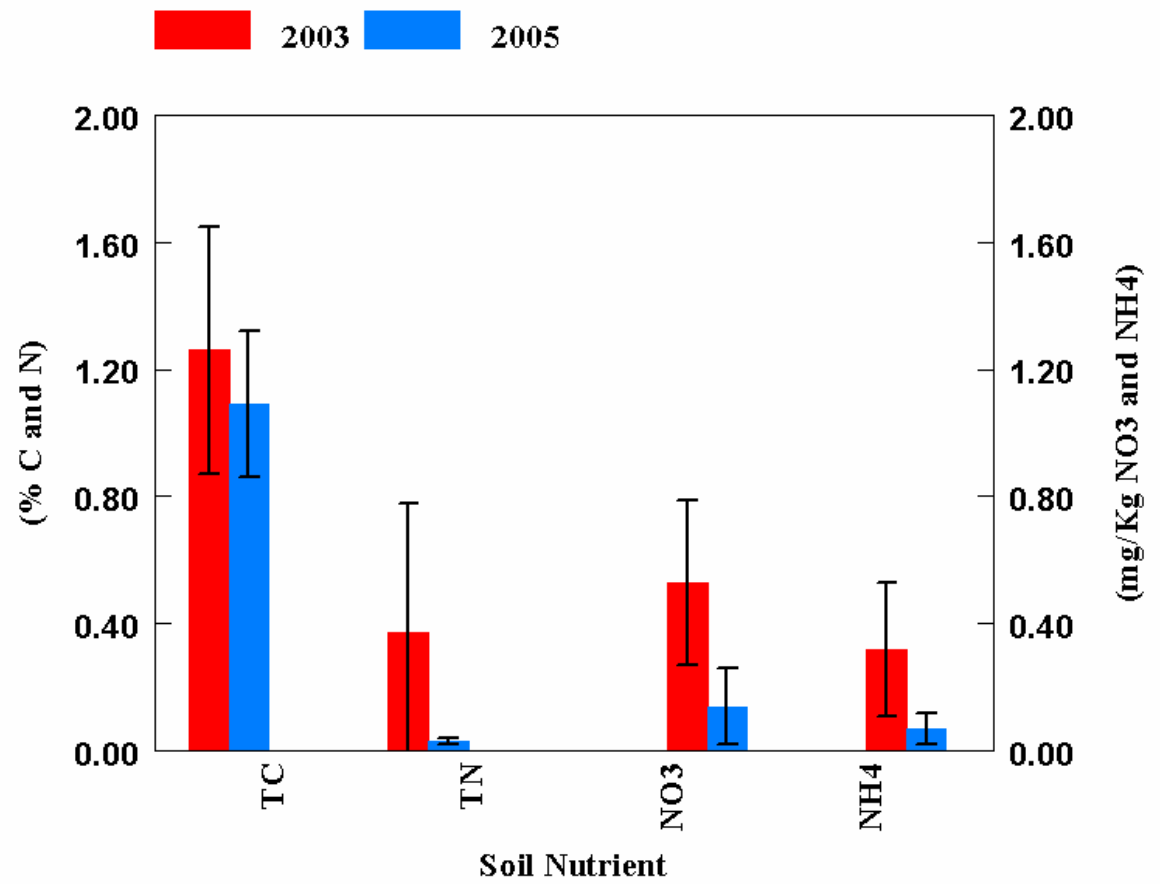

Figure 1.17. Soil carbon and nitrogen change at $0-5 \mathrm{~cm}$ depth for a three year period on the 17 West mine in Martin Co., KY.

Similar findings with respect to $\mathrm{C}$ and $\mathrm{N}$ dynamics were observed at the Gibraltar site (Figure 1.18). The primary differences between the sites was that the initial $\mathrm{C}$ content at Gibraltar was nearly double that found at 17 West. This difference may be explained by the nature of spoils between the sites. The surface spoil on the 17 West site was composed of a mixture of weathered and unweathered sandstones that exhibited very low University of Kentucky Research Foundation

Final Report - 10/01/03 thru 9/30/06

DE-FC26-02NT41624 
organic C levels when initially reclaimed. Whereas surface spoil on the Gibraltar site was created from stockpiled soils that were present on the pre-mined location. These soils contained some remnant amount of SOM that was transferred to the reclaimed pasture. As such, the Gibraltar site was more developed with respect to initial SOM content. Both sites existed as pasture prior to ripping and reforestation, so some SOM accumulation likely occurred due to grass establishment.

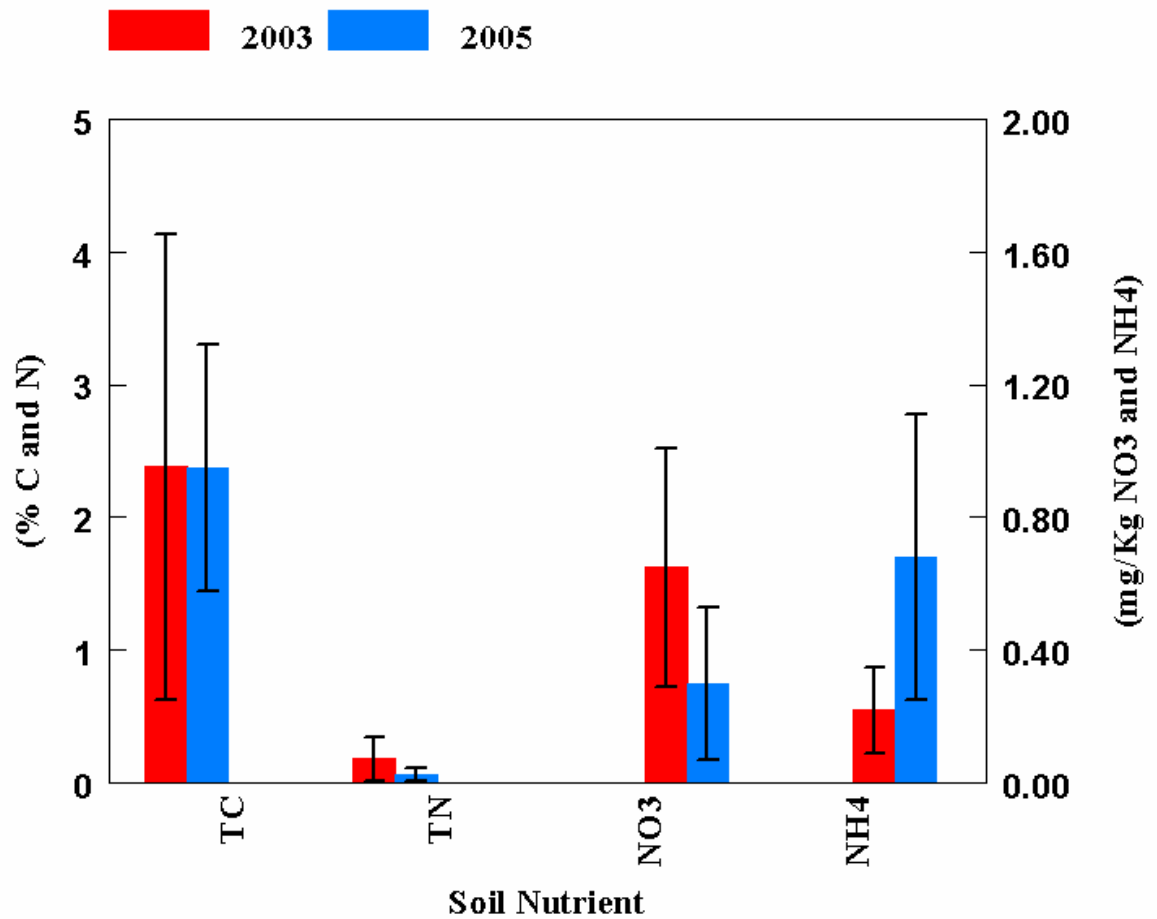

Figure 1.18. Soil carbon and nitrogen change at $0-5 \mathrm{~cm}$ depth for a three year period on the Gibraltar mine in Muhlenberg Co. KY.

From 2003 to 2005 , C accumulation in the soil fell from $8.8 \mathrm{Mg} \mathrm{ha}^{-1}$ to $6.97 \mathrm{Mg}$ $\mathrm{ha}^{-1}$ at the 17 West site and from $18.32 \mathrm{Mg} \mathrm{ha}^{-1}$ to $17.77 \mathrm{Mg} \mathrm{ha}^{-1}$ at Gibraltar. Given the limited growth rates for most planted species (black locust being the exception) total C sequestration during this time period is considered negligible. Given the young age of these trees and the technique examined, these results were not unexpected. We know that growth is initially slow for many of the species examined and we recognize that some $\mathrm{C}$ 
will be initially lost due to oxidation associated with ripping activities. Nevertheless, $\mathrm{C}$ in both biomass and soil will increase as these forests mature.

\subsubsection{Evaluating Low Compaction Reclamation Techniques on Reforestation Productivity- Bent Mountain}

Significant differences in both seedling survival and height were observed for the reclamation treatments examined, and the response was species specific. All species, with the exception of white ash, exhibited increased survival in the low compaction treatment plots over that observed in the compacted (control) plots. A general increase in height was also observed in the treatment plots over that observed in the control. A reduction in compaction by the various treatment techniques may be responsible for these results. In 2005, dry bulk density showed a decreasing trend by treatment in the order: triple shank ripper $<$ single shank ripper $<$ end dump $<$ excavated $<$ control (Table 1.2).

Table 1.2. Bulk density at 5, 15 and $30.5 \mathrm{~cm}$ depths in spoils from differing reclamation practices at the Bent Mt. mine in Pike Co. KY.

\begin{tabular}{|c|c|c|c|c|c|}
\hline \multicolumn{2}{|c|}{ Treatment Year } & \multicolumn{4}{|c|}{ Bulk Density $\left(\mathrm{g} \mathrm{cm}^{3-1}\right)$} \\
\hline & & $A V G \neq$ & $5 \mathrm{~cm}$ & $15 \mathrm{~cm}$ & $30.5 \mathrm{~cm}$ \\
\hline Control & 2004 & 1.77 & $\overline{1.53}$ & 1.72 & 1.87 \\
\hline Control & 2005 & 1.68 & 1.45 & 1.66 & 1.77 \\
\hline Excavated & 2004 & 1.66 & 1.42 & 1.61 & 1.77 \\
\hline Excavated & 2005 & 1.67 & 1.47 & 1.63 & 1.75 \\
\hline SS Ripper & 2004 & 1.68 & 1.48 & 1.64 & 1.77 \\
\hline SS Ripper & 2005 & 1.60 & 1.38 & 1.55 & 1.71 \\
\hline TS Ripper & 2004 & 1.67 & 1.41 & 1.65 & 1.78 \\
\hline TS Ripper & 2005 & 1.59 & 1.32 & 1.53 & 1.72 \\
\hline End Dump & 2004 & 1.72 & 1.48 & 1.69 & 1.82 \\
\hline End Dump & 2005 & 1.63 & 1.44 & 1.61 & 1.72 \\
\hline
\end{tabular}

†Depth weighted average.

\section{White Oak}

There was a general increase in the mean survival rate for white oak as the compaction level was decreased. Both ripping treatments and the end dump treatment exhibited significantly higher survival than the control and excavated treatments (Figure 1.19). The 
end dump also exhibited a significantly higher survival rate over that of the single shank ripper, while the triple shank ripper was not significantly different from either. Seedling height was significantly higher in the end dump treatment versus the excavated plots, but all other treatment were statistically similar (Figure 1.19).

\section{White Oak}

\section{$\square$ Height $(\mathrm{cm}) \multimap$ Survival (\%)}

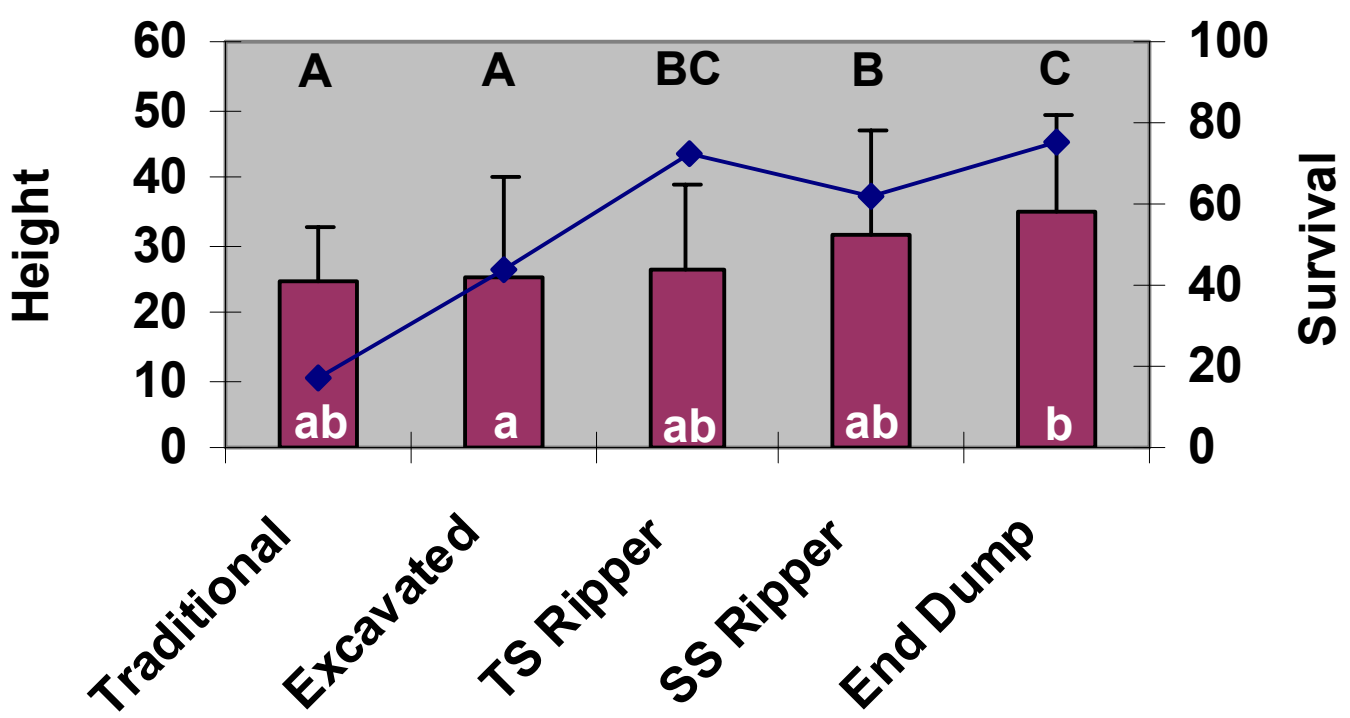

Figure 1.19. Mean cumulative height $(\mathrm{cm})$ and survival rate for white oak for the four low compaction and control (traditional) treatments. Means with the same letter are not significantly different at the $\mathrm{p}=0.05$ confidence level. Capital letters refer to statistical relationships for survival, while lower case letters refer to height.

\section{Northern Red Oak}

Northern red oak had a similar response to the low compaction treatments as seen for white oak, where both ripping treatments and the end dump treatment exhibited significantly higher survival than the control and excavated treatments (Figure 1.20). Although the response to treatments was similar, red oak survival ( 0 to $48 \%$ survival) by treatment was lower than that observed for white oak (16 to $75 \%$ survival). Because there was complete mortality of red oak in the control, statistical comparison of height by 
treatment could not be performed. Regardless, both ripping treatments exhibited similar height measures that were slightly above that of the end dump seedlings and the end dump seedlings were slightly taller than the excavated seedlings (Figure 1.20).

\section{Red Oak}

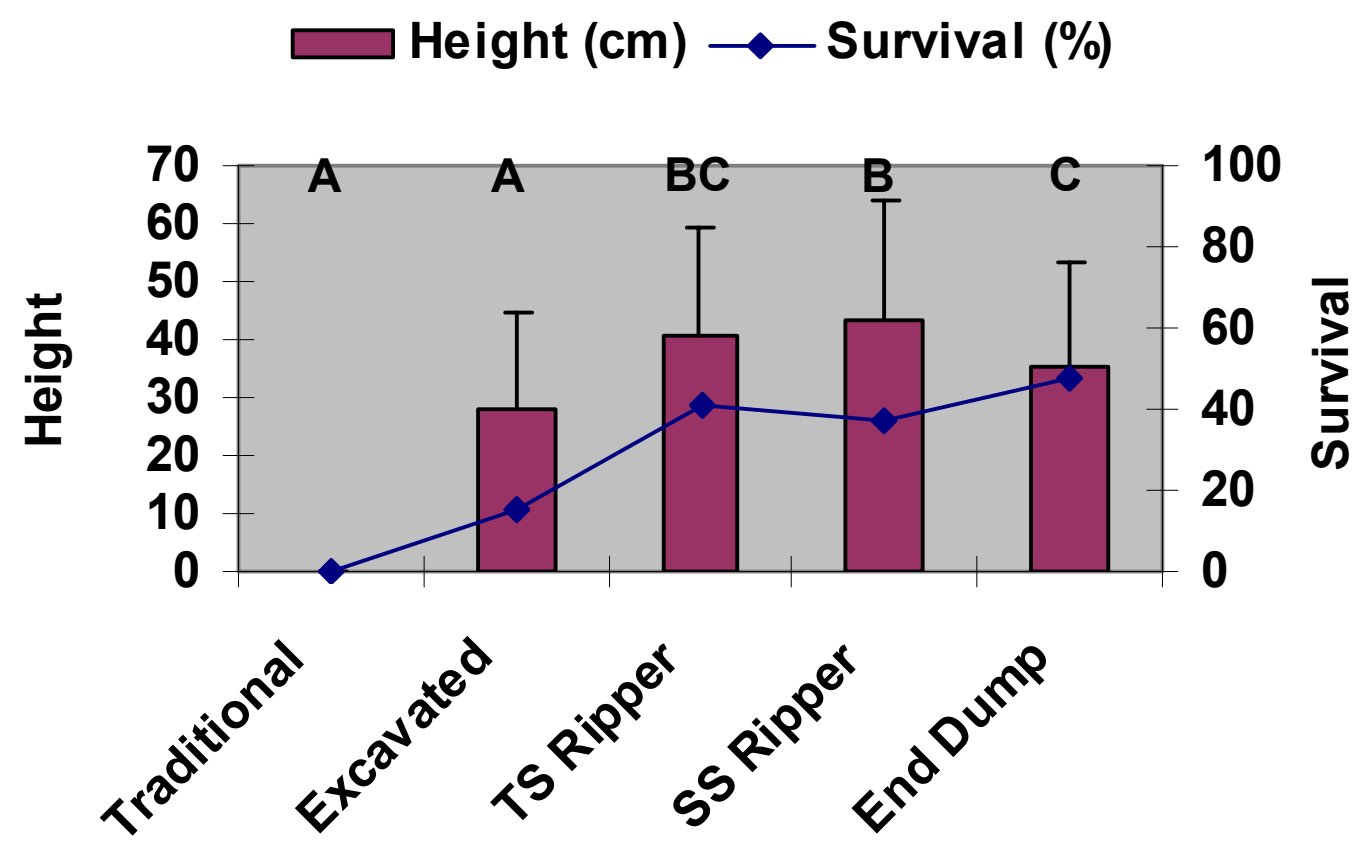

Figure 1.20. Mean cumulative height $(\mathrm{cm})$ and survival rate for northern red oak for the four low compaction and control (traditional) treatments. Means with the same letter are not significantly different at the $p=0.05$ confidence level. Capital letters refer to statistical relationships for survival, while lower case letters refer to height.

\section{Yellow Poplar}

Survival of yellow poplar was low for all treatments (Figure 1.21). The end dump treatment exhibited the highest survival at $43 \%$, while the other treatments exhibited survival rates lower than $25 \%$. Seedling height varied little between the ripped treatments and the end dump treatment, and all three were approximately $10 \mathrm{~cm}$ taller than that observed on the excavated plots. As with red oak, all seedlings died on the control plots. These findings are consistent with information our group has generated with respect to the suitability of yellow poplar on surface mine sites (Cotton, 2006). Yellow-poplar grows well in a wide range of soil and climactic conditions but achieves optimal growth in deep, rich, well drained soils of coves and valleys (Wharton and Barbour, 1973). Beck University of Kentucky Research Foundation

Final Report - 10/01/03 thru 9/30/06

DE-FC26-02NT41624 
(1990) found exceptional good growth of yellow-poplar on alluvial soils bordering streams, on loam soils of mountain coves, on talus slopes below cliffs and bluffs, and on well watered gravelly soils. Further, yellow-poplar cannot tolerate moisture extremes, preferring a moderately moist soil that is well drained and loose textured. The best growth has been observed on north and east aspects, lower slopes, sheltered coves, and on gentle concave slopes (Beck 1990). Unfortunately, the mine sites tend to be drier and less nutrient enriched than soils where yellow poplar naturally exists; thus, the long-term applicability of this species on open mined areas with unweathered spoils, such as that found at Bent Mountain, is questionable.

\section{Yellow Poplar}
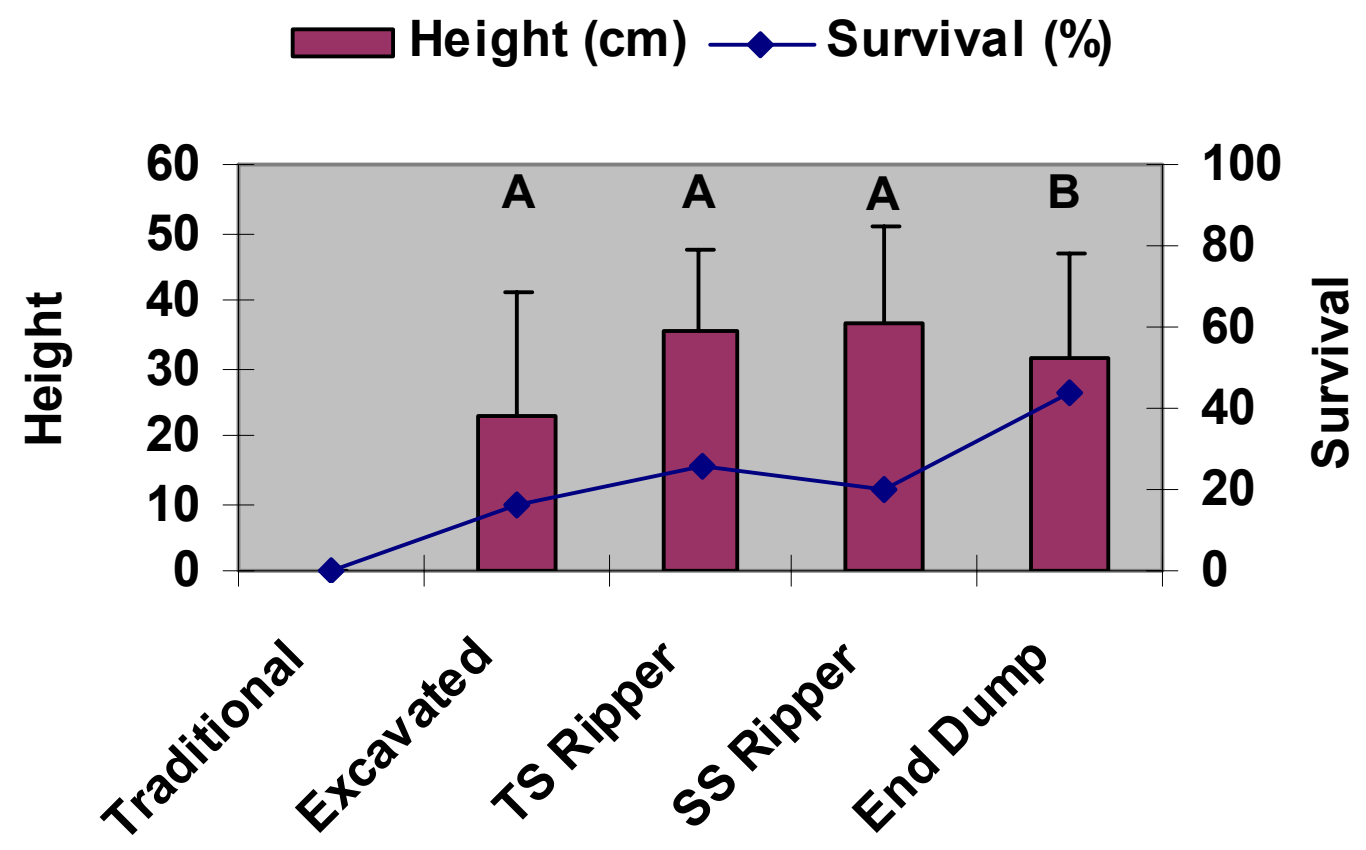

Figure 1.21. Mean cumulative height $(\mathrm{cm})$ and survival rate for yellow poplar for the four low compaction and control (traditional) treatments. Means with the same letter are not significantly different at the $p=0.05$ confidence level. Capital letters refer to statistical relationships for survival, while lower case letters refer to height.

\section{Black Locust}

Survival for black locust was high (73 to 94\%) for all treatments examined (Figure 1.22). The end dump and triple shank ripper treatments exhibited significantly higher survival than the control. The excavated and single shank ripper treatments did not differ 
from the other treatments with respect to survival. Both ripper treatments and the end dump treatment exhibited significantly higher growth than the excavated or control plots (Figure 1.22). Black locust also exhibited the highest growth rates of all species examined $(\approx 100 \mathrm{~cm}$ in three years). Similar results for black locust have been documented and earlier studies identified black locust as a favored site stabilizer because of its nitrogen fixing capability and adaptability to a wide range of soil physical and chemical conditions (Miles et al. 1973). Mixed-species plantings of nitrogen-fixing tree or shrub species with hardwood crop trees are commonly promoted for mine land revegetation (Ashby et al. 1985). In addition, interplanting with controlled densities of black locust seedlings may have potential for increased crop tree growth (Torbert and Burger, 2000). Although difficult to ascertain in these young stands, the success of black locust will likely have a positive impact on the other high value hardwood species planted in the study.

\section{Black Locust}

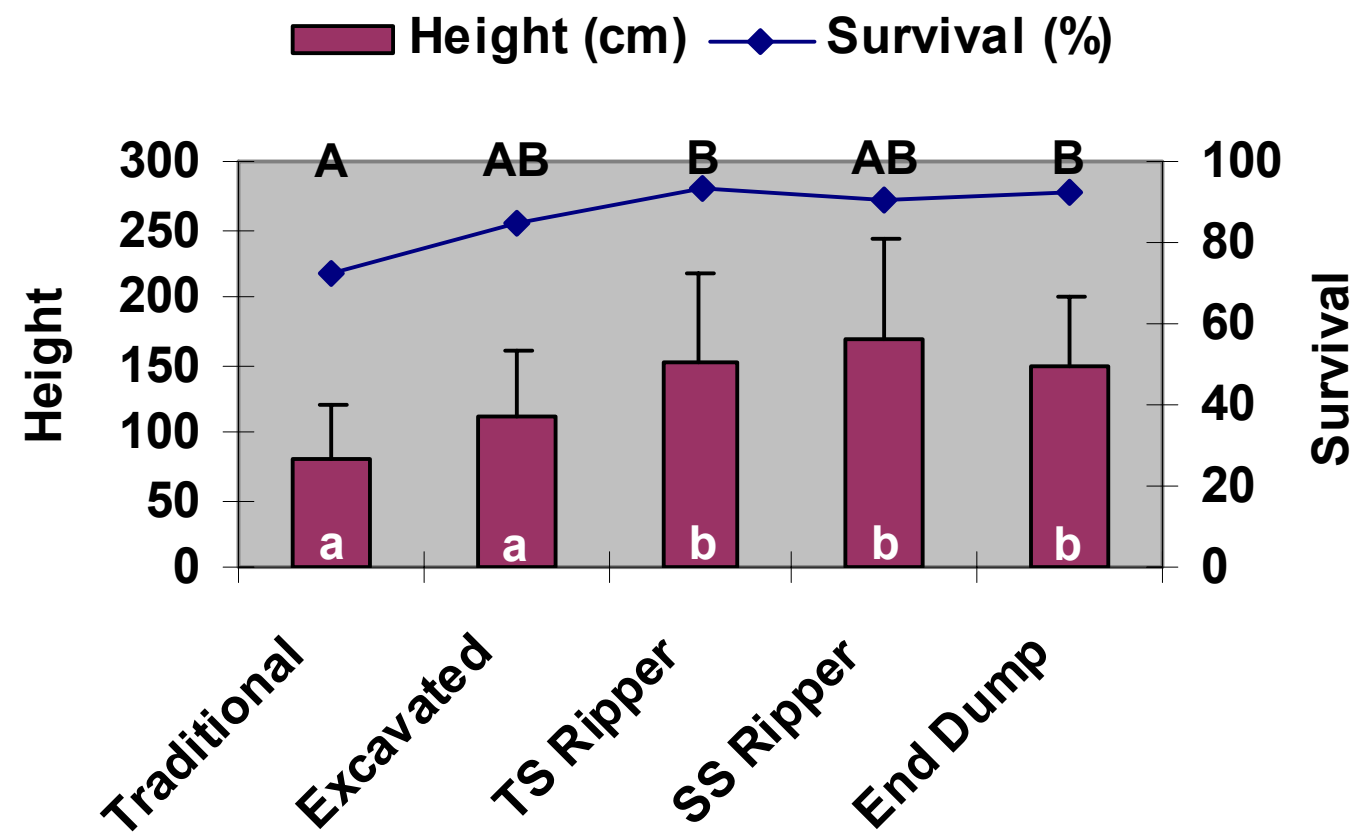

Figure 1.22. Mean cumulative height $(\mathrm{cm})$ and survival rate for black locust for the four low compaction and control (traditional) treatments. Means with the same letter are not significantly different at the $\mathrm{p}=0.05$ confidence level. Capital letters refer to statistical relationships for survival, while lower case letters refer to height. 


\section{White Ash}

Survival for white ash was high and similar to that observed for black locust (79 to 93\%) for all treatments examined (Figure 1.23). Growth was significantly greater in the single shank ripper treatment over all other treatments. Seedling height was significantly lower in the control than all other treatments. Angel et al. (2006) described similar results for white ash in compacted versus uncompacted spoils.

\section{White Ash}

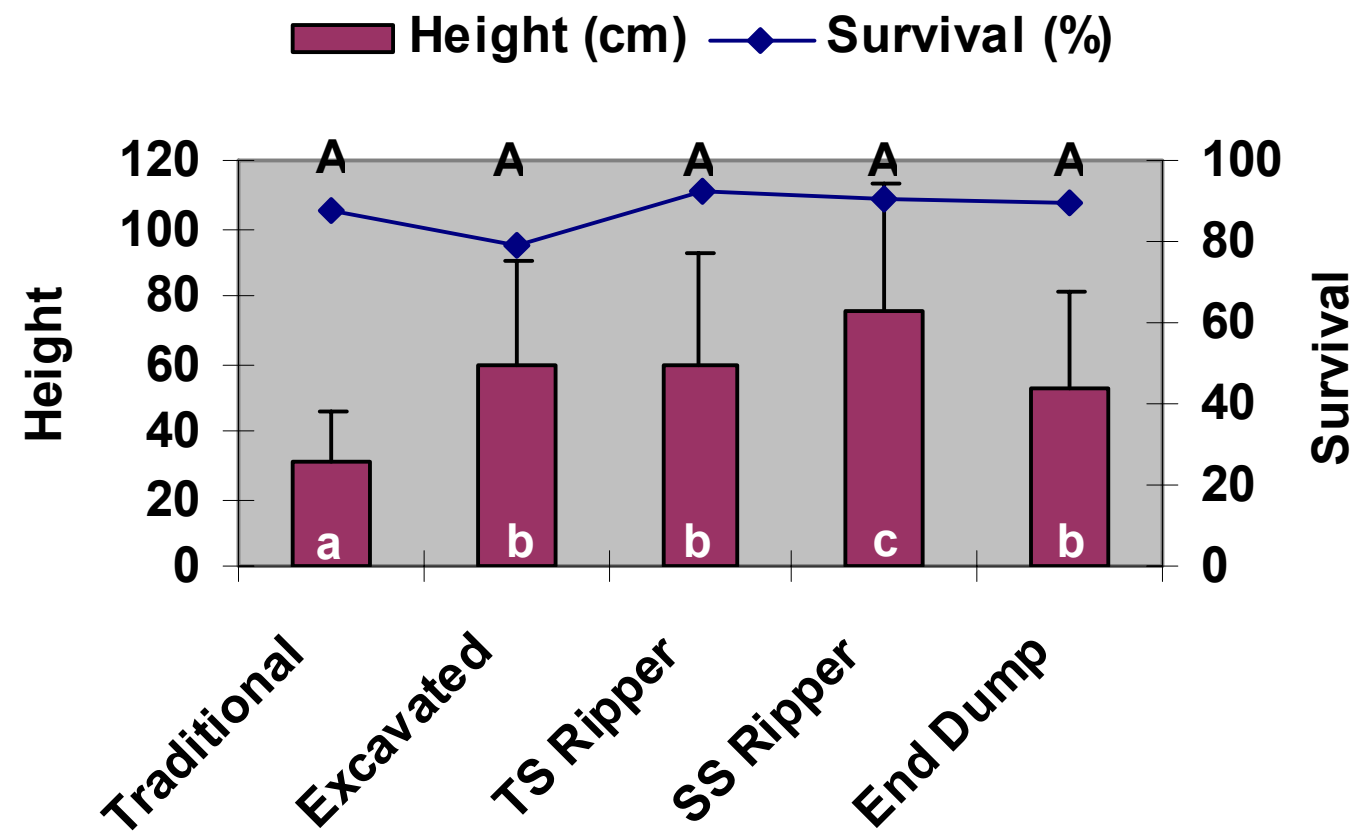

Figure 1.23. Mean cumulative height $(\mathrm{cm})$ and survival rate for white ash for the four low compaction and control (traditional) treatments. Means with the same letter are not significantly different at the $\mathrm{p}=0.05$ confidence level. Capital letters refer to statistical relationships for survival, while lower case letters refer to height.

Overall, the ripped and end dumped treatments out preformed the excavated and control treatments with respect to survival and growth. The excavated treatment generally produced better results than the control, but large-scale use of this method may be cost prohibitive given the marginal results obtained. Additional time is needed to fully evaluate treatment response. 


\subsubsection{Evaluating Spoil Amendment use on Reforestation Productivity - Laurel Fork and Nelson Creek}

Prior to planting, twenty-five seedlings of each species were collected for an assessment of growth characteristics and mycorrhizal inoculation index. Average height was 39.7 and $18.4 \mathrm{~cm}$ for the N. Red Oak and Loblolly Pine, respectively. The oak exhibited an average diameter of $5.1 \mathrm{~mm}$, while the pine had an average diameter of 3.4 $\mathrm{mm}$. The inoculation index for both species was low as exhibited in Table 1.3. As such, mycorrhizal plots received additional inoculation in the field to further enhance these numbers. Non-mycorrhizal plots received an annual application of the fungicide Bayleton ${ }^{\circledR}$ to suppress natural inoculation.

Table 1.3. Mycorrhizal inoculation index of seedlings prior to planting.

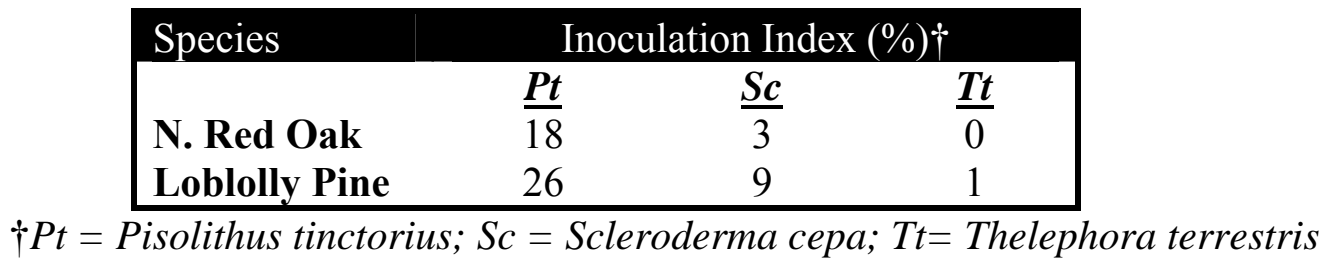

Both sites were ripped prior to planting to alleviate compaction created by initially reclaiming the sites as pasture and to incorporate compost where applied. The ripping provided good results at the Laurel Fork mine by reducing dry bulk density in the upper 5-cm of spoil to $1.23 \mathrm{~g} \mathrm{~cm}^{3-1}$ (Table 1.4). Application and incorporation of the compost resulted in a further decrease in bulk density both at the surface and through the entire $30.5-\mathrm{cm}$ depth examined. Incorporation of the compost will not only reduce compaction, but will also allow for better root penetration, gas exchange and water infiltration (Bledsoe et al., 1992).

Table 1.4. Bulk density at 5,15 and $30.5 \mathrm{~cm}$ depths in spoil (control) and compost amended spoil (compost) at the Laurel Fork mine in Knott Co. KY.

\begin{tabular}{|c|c|c|c|c|}
\hline Treatment & Year & \multicolumn{3}{|c|}{ Bulk Density $\left(\mathrm{g} \mathrm{cm}^{3-1}\right)$} \\
\hline & & $5 \mathrm{~cm}$ & $15 \mathrm{~cm}$ & $30.5 \mathrm{~cm}$ \\
\hline Control & 2004 & $\overline{1.23}$ & 1.48 & 1.65 \\
\hline Control & 2005 & 1.21 & 1.49 & 1.66 \\
\hline Compost & 2004 & 1.02 & 1.32 & 1.54 \\
\hline Compost & 2005 & 0.95 & 1.33 & 1.55 \\
\hline
\end{tabular}

University of Kentucky Research Foundation

Final Report - 10/01/03 thru 9/30/06

DE-FC26-02NT41624 
Ripping also provided good results at the Nelson Creek mine with a reduction in dry bulk density in the upper 5 -cm of spoil to $1.36 \mathrm{~g} \mathrm{~cm}^{3-1}$ (Table 1.5). As with the Laurel Fork site, application and incorporation of the compost resulted in a further decrease in bulk density both at the surface and through the entire $30.5-\mathrm{cm}$ depth examined. Although the effect was similar between the two sites, the Nelson Creek exhibited a somewhat higher final bulk density than that observed at Laurel Fork in the 5 and 15-cm depths.

Table 1.5. Bulk density at 5,15 and $30.5 \mathrm{~cm}$ depths in spoil (control) and compost amended spoil (compost) at the Nelson Creek mine in Muhlenberg Co. KY.

\begin{tabular}{|c|c|c|c|c|}
\hline \multicolumn{2}{|c|}{ Treatment Year } & \multicolumn{3}{|c|}{ Bulk Density $\left(\mathrm{g} \mathrm{cm}^{3-1}\right)$} \\
\hline & & $5 \mathrm{~cm}$ & $15 \mathrm{~cm}$ & $30.5 \mathrm{~cm}$ \\
\hline Control & 2004 & 1.36 & 1.51 & 1.65 \\
\hline Control & 2005 & 1.31 & 1.49 & 1.65 \\
\hline Compost & 2004 & 1.12 & 1.39 & 1.56 \\
\hline Compost & 2005 & 1.15 & 1.37 & 1.52 \\
\hline
\end{tabular}

Treatment effects on seedling vigor were noticeable very soon after transplanting occurred (Figures 1.24 and 1.25). After three years, growth and survival of planted seedlings differed with respect to species, site and treatments. Loblolly pine exhibited almost a doubling in growth at the Laurel Fork mine as compared to the Nelson Creek Mine (Table 1.6). Amendments had no effect on loblolly growth at Nelson Creek with rates averaging between 48 and $62-\mathrm{cm}$. Both compost and fertilizer had an effect on loblolly growth at Laurel Fork. The use of mycorrhizae in the absence of compost or fertilizer also had a significant effect over that of unamended and non-inoculated loblolly seedlings (control) (Table 1.6). Survival of loblolly pine was higher at Laurel Fork (58 to 93\%) than Nelson Creek (27 to 56\%) for all treatments examined (Table 1.7). The lowest survival for loblolly at Laurel Fork was 58\% (LCN), which was higher than all treatments at Nelson Creek except LCM. Unlike the growth results, there are no apparent trends for loblolly survival at either site that can be attributed to the amendments or inoculation. 


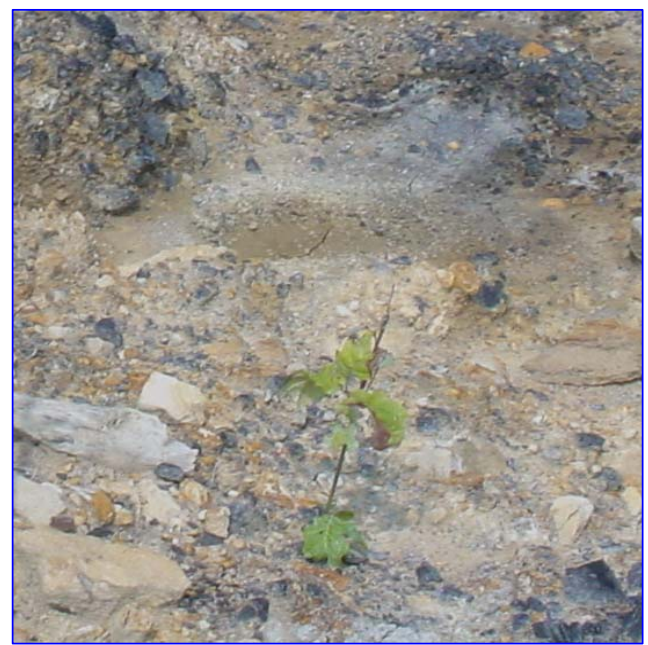

Figure 1.24. One-year old N. Red Oak on non- amended site, Muhlenberg Co. KY.

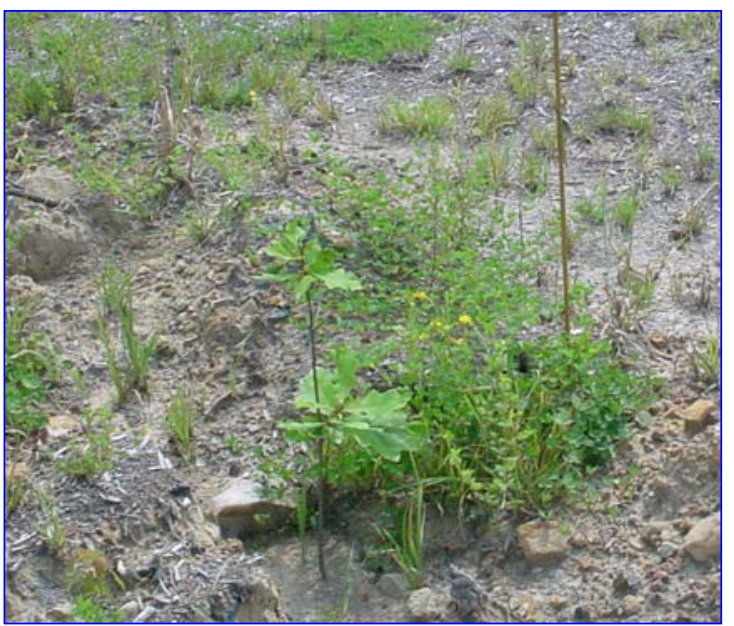

Figure 1.25. One-year old N. Red Oak on compost amended site, Muhlenberg Co. KY.

Table 1.6. Seedling height and growth for 3-yr loblolly pine and northern red oak growing under differing spoil amendment treatments at the Laurel Fork and Nelson Creek mines in Knott and Muhlenberg Counties, KY, respectively.

\begin{tabular}{|l|c|c|c|c|}
\hline \multicolumn{1}{|c|}{ Treatment } & \multicolumn{2}{c|}{ Laurel Fork (EKY) } & \multicolumn{2}{c|}{ Nelson Creek (WKY) } \\
\hline LCFM & Height (cm) & Growth (cm) & Height (cm) & Growth (cm) \\
LCFN & 120.1 & $103.8(\mathrm{AB})+$ & 71.9 & $55.4(\mathrm{~A})$ \\
LCM & 124.4 & $104.7(\mathrm{~A})$ & 72.4 & $53.6(\mathrm{~A})$ \\
LCN & 123.0 & $105.0(\mathrm{~A})$ & 77.4 & $58.9(\mathrm{~A})$ \\
LFM & 118.4 & $100.4(\mathrm{AB})$ & 81.3 & $62.4(\mathrm{~A})$ \\
LFN & 116.9 & $98.4(\mathrm{AB})$ & 80.1 & $58.3(\mathrm{~A})$ \\
LM & 111.7 & $93.2(\mathrm{AB})$ & 74.5 & $53.6(\mathrm{~A})$ \\
LN (control) & 105.4 & $87.6(\mathrm{~B})$ & 68.6 & $48.2(\mathrm{~A})$ \\
& 84.9 & $66.5(\mathrm{C})$ & 68.5 & $49.6(\mathrm{~A})$ \\
NROCFM & & & & \\
NROCFN & 50.3 & $11.0(\mathrm{AB})$ & 51.2 & $11.2(\mathrm{~A})$ \\
NROCM & 45.2 & $9.4(\mathrm{AB})$ & 50.6 & $-10.1(\mathrm{~A})$ \\
NROCN & 44.2 & $2.3(\mathrm{BC})$ & 29.1 & $-1.5(\mathrm{C})$ \\
NROFM & 44.5 & $6.4(\mathrm{AB})$ & 37.8 & $17.5(\mathrm{~A})$ \\
NROFN & 49.3 & $8.8(\mathrm{AB})$ & 50.9 & $11.0(\mathrm{~A})$ \\
NROM & 54.8 & $14.5(\mathrm{~A})$ & 50.5 & $7.3(\mathrm{~A})$ \\
NRON (control) & 46.9 & $3.7(\mathrm{BC})$ & 61.2 & \\
& 38.3 & $-0.4(\mathrm{C})$ & 42.3 & \\
\hline
\end{tabular}

$* \mathrm{~L}=$ loblolly pine; $\mathrm{NRO}=$ northern red oak; $\mathrm{C}=$ compost; $\mathrm{F}=$ fertilizer; $\mathrm{M}=$ mycorhizal; $\mathrm{N}=$ no mycorhizae.

\$Means for individual species and location followed by the same letter are not significantly different $(\alpha=0.05)$

University of Kentucky Research Foundation

Final Report - 10/01/03 thru 9/30/06

DE-FC26-02NT41624 
Table 1.7. Herbaceous biomass and seedling survival for 3-yr loblolly pine and northern red oak on plots with differing spoil amendment treatments at the Laurel Fork and Nelson Creek mines in Knott and Muhlenberg Counties, KY, respectively.

\begin{tabular}{|c|c|c|c|c|}
\hline \multirow[t]{2}{*}{ Treatment } & \multicolumn{2}{|c|}{ Laurel Fork (EKY) } & \multicolumn{2}{|c|}{ Nelson Creek (WKY) } \\
\hline & Survival (\%) & $\begin{array}{c}\text { Herb Biomass } \\
\left(g^{2-1} \mathrm{~m}^{2-}\right.\end{array}$ & Survival (\%) & $\begin{array}{c}\text { Herb Biomass } \\
\left(\mathrm{g} \mathrm{m}^{2-1}\right) \\
\end{array}$ \\
\hline LCFM & 68 & 391 & 52 & 85 \\
\hline LCFN & 76 & 324 & 46 & 128 \\
\hline LCM & 93 & 268 & 65 & 139 \\
\hline $\mathrm{LCN}$ & 58 & 224 & 56 & 96 \\
\hline LFM & 88 & 352 & 27 & 248 \\
\hline LFN & 87 & 215 & 44 & 162 \\
\hline LM & 83 & 222 & 36 & 73 \\
\hline LN (control) & 75 & 305 & 44 & 158 \\
\hline NROCFM & 64 & 505 & 52 & 110 \\
\hline NROCFN & 83 & 243 & 77 & 102 \\
\hline NROCM & 43 & 282 & 37 & 114 \\
\hline NROCN & 31 & 427 & 47 & 141 \\
\hline NROFM & 79 & 392 & 48 & 177 \\
\hline NROFN & 66 & 323 & 45 & 233 \\
\hline NROM & 76 & 467 & 33 & 185 \\
\hline NRON (control) & 64 & 210 & 45 & 168.5 \\
\hline
\end{tabular}

Northern red oak growth was low compared to loblolly and did not differ drastically between the two sites (Table 1.6). Treatment effects were observed on both sites and results varied. Fertilizer addition improved red oak seedling growth at Laurel Fork over treatments that did not receive any amendments. The addition of compost and no mycorrhizae also performed better than the no amendment (control) treatment at Laurel Fork. The use of compost without fertilizers had an inhibitory effect on seedling growth at Nelson Creek, while all other treatments were not significantly different from each other. As with loblolly pine, survival of red oak was higher at Laurel Fork over Nelson Creek for all treatments except NROCN (Table 1.7). Highest red oak survival was observed in the NROCFN treatment for both sites.

Survivability differences between the sites were initially suspected to be caused by competition from aggressive herbaceous species found within the plots. Herbaceous biomass content measured from clippings taken at each site, however, revealed that competition was not a problem. In general, biomass was much higher on the Laurel Fork University of Kentucky Research Foundation

Final Report - 10/01/03 thru 9/30/06

DE-FC26-02NT41624 
site as compared to Nelson Creek (Table 1.7). Within the sites there also appeared to be no significant correlation between survival by treatment and biomass. The decreased bulk density at Laurel Fork, compared to Nelson Creek, likely had some positive effect on seedling survival (Tables 1.4 and 1.5). Further assessments of other spoil physicochemical properties are planned to further elucidate the site differences.

\subsubsection{Evaluating Geophysical and Chemical Spoil Characteristics on Reforestation Productivity - Bent Mountain}

After end dumping of the differing spoil materials, bulk density measurements taken with a nuclear density gage. Table 1.8 shows that the sites differed little with respect to initial bulk density. These values are similar to those recorded in the prior year using the same reclamation techniques (Table 1.2).

Table 1.8. Bulk density at 5,15 and $30.5 \mathrm{~cm}$ depths in brown sandstone, gray sandstone, and mixed sandstones and shale at the Bent Mountain mine in Pike Co. KY.

\begin{tabular}{|cccc|}
\hline Treatment & \multicolumn{3}{c|}{ Bulk Density $\left(\mathbf{g ~ c m}^{\mathbf{3}}\right)$} \\
Brown & $\underline{\mathbf{5}} \mathbf{~}$ & $\underline{\mathbf{1 5}} \mathbf{~ m}$ & $\underline{\mathbf{3 0 . 5}} \mathbf{~}$ \\
Gray & 1.48 & 1.71 & 1.82 \\
Mixed & 1.51 & 1.72 & 1.82 \\
& 1.49 & 1.70 & 1.82 \\
\hline
\end{tabular}

By the second year (2006) after planting, the gray plots had an overall higher average survival (96\%) than the brown (83\%) and mixed plots $(84.5 \%)$ (Table 1.9). However, in regards to overall average growth, the brown plots showed significantly more growth in height and diameter than the gray and mixed plots by the second year (Table 1.10). The brown plots averaged 51.46 centimeters in height by the summer of 2006, whereas the gray plots averaged 37.74 and the mixed plots averaged 41.68. Furthermore, the brown plots averaged 0.415 inches in diameter at ground level by the summer of 2006, whereas the gray plots averaged 0.285 and the mixed plots averaged 0.31 (Table 1.11). 
Table 1.9. Second year (2006) percent survival by plot at the Bent Mountain Geohydrology site in Pike Co., KY.

\begin{tabular}{|lc|cccc|}
\hline & White Oak & Red Oak & Yellow Poplar & Green Ash & All species \\
\hline Plot 1 BR & 81 & 92 & 63 & 94 & 84 \\
Plot 2 GR & 95 & 100 & 85 & 96 & 95 \\
Plot 3 BR & 80 & 79 & 76 & 91 & 82 \\
Plot 4 MX & 87 & 80 & 69 & 100 & 83 \\
Plot 5 MX & 100 & 82 & 69 & 91 & 86 \\
Plot 6 GR & 100 & 100 & 86 & 96 & 97 \\
\hline
\end{tabular}

Table 1.10. Second year (2006) averages for tree height in centimeters by plot at the Bent Mountain Geohydrology site in Pike Co., KY.

\begin{tabular}{|lc|cccc|} 
& White Oak & Red Oak & Yellow Poplar & Green Ash & All species \\
\hline Plot 1 BR & 41.61 & 42.67 & 61.51 & 47.10 & 47.28 \\
Plot 2 GR & 25.08 & 31.96 & 56.00 & 39.88 & 36.48 \\
Plot 3 BR & 41.05 & 52.30 & 68.52 & 56.88 & 55.64 \\
Plot 4 MX & 27.88 & 39.78 & 60.05 & 43.10 & 42.39 \\
Plot 5 MX & 28.77 & 38.01 & 59.11 & 43.57 & 40.98 \\
Plot 6 GR & 26.45 & 34.57 & 57.45 & 38.46 & 39.00 \\
\hline
\end{tabular}

Table 1.11. Second year (2006) averages for tree diameter at ground level in inches by plot at the Bent Mountain Geohydrology site in Pike Co., KY.

\begin{tabular}{|lc|cccc|}
\hline & White Oak & Red Oak & Yellow Poplar & Green Ash & All species \\
\hline Plot 1 BR & 0.37 & 0.37 & 0.47 & 0.39 & 0.39 \\
Plot 2 GR & 0.23 & 0.26 & 0.35 & 0.31 & 0.28 \\
Plot 3 BR & 0.35 & 0.41 & 0.51 & 0.46 & 0.44 \\
Plot 4 MX & 0.24 & 0.32 & 0.39 & 0.34 & 0.32 \\
Plot 5 MX & 0.26 & 0.30 & 0.37 & 0.31 & 0.30 \\
Plot 6 GR & 0.22 & 0.28 & 0.37 & 0.29 & 0.29 \\
\hline
\end{tabular}

Water chemistry and hydrologic analyses are on-going and results are not available at this time.

\subsubsection{Influence of ReclamationTechnique on Mine Land Hydrology}

The primary objective of this portion of the applied research program was to contrast water quantity and quality aspects of traditional mine reclamation techniques, which encompass high levels of compaction typically located on flatter slopes, to utilization of loose spoil, which shows improved performance over traditional reclamation approaches (see above). Six of the 23 monitored sites were selected to illustrate comparisons. These six sites are 1) Starfire2 (Perry Co., KY) to represent more University of Kentucky Research Foundation 40

Final Report - 10/01/03 thru 9/30/06

DE-FC26-02NT41624 
traditional mined land reclamation technique (i.e. highly compacted spoil on a flat slope), 2) High Wall Bottom (Muhlenberg C., KY) to represent a lightly compacted spoil on a moderate-to-steep slope, 3) Martwick (Muhlenberg C., KY) to represent a loose-dumped spoil on a flat slope, 4) 17 West 1 and 17 West 2 (Martin Co., KY) to represent a loosedumped spoil, with light grading, on a steep slope, 5) 17 West 3 to represent a ripped site on a flat slope and 6) High Wall Top to represent a ripped site on a moderate-to-steep slope. Comparisons are made to illustrate the representative findings of this applied research. Note that the most important parameters, with respect to mined land reclamation, are peak flow and runoff volume (i.e. flooding) and sediment concentrations and loads (i.e. embeddedness; adverse impact on fish and aquatic invertebrates). Loss of $\mathrm{C}$ from sediment runoff is also of concern with respect to the overall project.

\section{Compacted Spoil versus Loose-dumped Spoil}

The Martwick site (loose-dumped) received nearly 50\% more rainfall than the Starfire 2 compacted site (1.4 versus 0.9 in.). Despite the much higher rainfall at the Martwick site, the peak flow was approximately one-half of that generated by the highly compacted Starfire 2 site $(0.15$ versus $0.8 \mathrm{cfs} / \mathrm{ac})$. Thus, the peak flow was greatly reduced using the loosed-dumped technique as compared to traditional mined land reclamation methods. As expected, the sediment load from the loose-dumped site was also much lower than the high-compaction site $(0.2$ versus $69 \mathrm{lb} / \mathrm{ac})$. Similarly, the volume of rainfall which became runoff was $27 \%$ for the highly compacted spoil versus $3.5 \%$ for the loose-dumped site. The average effluent sediment concentration from the loose-dumped site was almost non-existent compared to the compacted site (40 versus $5,000 \mathrm{mg} / \mathrm{L}$ ) even though the storm size was 50\% larger for the loose-dumped site. Hence, the loose-dumped site significantly lowered peak flow, runoff volume, sediment load and average sediment concentration as compared to the traditional mined land reclamation method of highly compacting the spoil.

\section{Compaction Influence}

It is expected that as spoil compaction increases, parameters such as peak flow, runoff volume, sediment concentration and load would increase. The Starfire 2 site 
(traditional method; flat slope) was contrasted with the High Wall Bottom site (lightly compacted; moderate-to-steep slope). The High Wall Bottom site received a 2.4 inch rainfall event whereas the Starfire site rainfall was 0.9 inches; a factor of about 2.5 times less. Despite the lower rainfall and the lesser slope, the detrimental influence of amount of compaction can be readily realized at the Starfire2 site as the peak flow was 2.5 times greater ( 0.15 versus $0.06 \mathrm{cfs} / \mathrm{ac}$ ), sediment load was five times greater (68.8 versus 13.4) and runoff volume was nine times greater.

\section{Slope Influence on Loose-dumped Spoil}

It is expected that as slope steepness increases for a loose-dumped spoil, parameters such as peak flow, runoff volume, sediment concentration and load would likewise increase. The Martwick site, with a flatter slope, was contrasted with the combination of 17 West 1 and 17 West 2, which were reclaimed with a single-equipment pass on a steep slope. The rainfall at Martwick was 1.4 inches whereas the rainfall at 17 West 1 and 17 West 2 was 0.5 inches. The rainfall at Martwick was approximately 3 times greater than that at 17 West 1 and 17 West 2, which was reflected in the peak flow ( 0.08 versus $0.03 \mathrm{cfs} / \mathrm{ac})$. Due to the flatness of the slope at Marwick, the loose-dumped spoil at this site compared to the much steeper 17 West sites generated approximately the same percent runoff. Additionally, sediment loads were small for the Martwick and 17 West sites, but the values were nine times higher $(1.8$ versus $0.2 \mathrm{lb} / \mathrm{ac})$ at the 17 West sites. Also note that the average sediment concentration was significantly lower at the Martwick site $(40 \mathrm{mg} / \mathrm{L}$ versus $1,050 \mathrm{mg} / \mathrm{L})$.

\section{Slope Influence on Ripped Spoil}

Although the ideal situation is to use the loose-dump spoil method, there are 1000 's of acres of traditionally reclaimed mined land. To enhance tree growth and reduce potential adverse environmental impacts, various ripping methods have been employed. Two ripped sites were being compared: 1) 17 West 3 to represent a ripped site on a flatter slope and 2) High Wall Top to represent a ripped site on a moderate-to-steep slope. Rainfall was 2.4 and 1.1 inches at 17 West 3 and High Wall Top, respectively. Thus, the steeper sloped site experienced the greater rainfall for these storm events. As 
such, the steeper sloped ripped spoil site (High Wall Top) would be expected to experience a higher peak flow, runoff volume, sediment load and average sediment concentration then the flatter ripped site (17 West 3). The results shown in Table 1.12 illustrate these concepts. Peak runoff rate and sediment load were nearly 10 times and 8 times greater for the steep sloped site as compared to the flatter slope of 17 West 3 . Similarly, runoff volume and average sediment concentration were approximately twice as high for the moderate-to-steep ripped spoil site.

\section{Ripped Spoil versus Lightly Compacted Spoil: Moderate-to-steep Slopes}

Both of High Wall sites: High Wall Top (ripped) and High Wall Bottom (lightly compacted) experienced the same 2.4 inch rainfall event, and each site is located on identical slopes. With respect to environmental impacts, it was not known if the preferred method would be slight compaction versus ripping the site. As seen in Table 1.12 , the ripped site produced a higher peak flow, percent runoff, and sediment load then the lightly compacted site. The peak runoff and percent runoff volume were approximately three times higher for the ripped site as compared to the slightly compacted site. Similarly, the sediment load was approximately twice as great for the ripped site compared to the slightly compacted site. Since 2.4 inches is a relatively large rainfall event it is speculated that some of the contour furrows created through ripping were over topped due to the amount of rain, thus resulting in the high peak flow rate, percent runoff and sediment load. Since the percent runoff was three times greater and the sediment load approximately two times higher for the ripped site versus the slightly compacted site there may be a dilution affect that resulted in the lower average sediment concentration for the ripped site. 
Table 1.12. Representative Hydrological Monitoring Results.

\begin{tabular}{|c|c|c|c|c|c|}
\hline & Site & $\begin{array}{c}\mathrm{SSC} \\
(\mathrm{mg} / \mathrm{L})^{1}\end{array}$ & $\begin{array}{l}\text { Runoff } \\
(\%)\end{array}$ & $\begin{array}{c}\mathbf{Q}_{\mathrm{g}} / \text { Arrea } \\
\left(\mathrm{ft}^{3} \mathrm{~s}^{-1} \mathrm{ac}^{-1)}\right.\end{array}$ & $\begin{array}{l}\text { Load } \\
\text { (lb/ac) }\end{array}$ \\
\hline \multirow[t]{2}{*}{ Compacted } & Starfire 2 & 5,006 & 27.0 & 0.15 & 68.8 \\
\hline & High Wall Bottom & 3,991 & 2.9 & 0.16 & 13.4 \\
\hline Loose- & Martwick & 37 & 3.5 & 0.08 & 0.2 \\
\hline \multirow[t]{2}{*}{ Dumped $^{2}$} & 17 West 1 & 1,227 & 1.6 & 0.02 & 2.3 \\
\hline & 17 West 2 & 855 & 5.2 & 0.04 & 1.4 \\
\hline \multirow[t]{2}{*}{ Ripped } & 17 West 3 & 579 & 4.7 & 0.02 & 3.1 \\
\hline & High Wall Top & 1,195 & 10.4 & 0.19 & 25.7 \\
\hline
\end{tabular}

${ }^{1}$ Average suspended sediment concentration

${ }^{2} 17$ West 1 and 17 West 2 sites were averaged due to proximity and similarities between sites.

\subsection{CONCLUSIONS}

Forest productivity varied across the state and between the different mine sites. Seedling success was found to be species specific and strongly influenced by reclamation practice. Although the stands are young (generally 3-yr old), some general inferences to success, productivity and potential for sequestering carbon may be ascertained. As stated earlier, carbon sequestration increases with increased stand productivity. Data from Bent Mountain revealed seedling survival and growth were influenced by spoil bulk density. As bulk density increased seedling survival and growth decreased. Although species specific, productivity by treatment was observed in the following order on that site: end dump $\approx$ single shank ripper $\approx$ triple shank ripper $>$ excavated $>$ traditional (control). Within a single treatment productivity may also be influenced by spoil makeup or amendments. At Bent Mountain we observed higher survival in end dumped plots composed of gray sandstone over that of brown sandstone and mixed sandstones and shale, while growth was elevated in the brown sandstone spoil. Soil amendments in the form of compost and fertilizer appeared to improve productivity in loblolly pine in plots located in eastern Kentucky, but not in plots located western Kentucky. For northern red oak; however, productivity appeared to be inhibited by the use of compost without fertilizer in western Kentucky, while this was not the case in eastern Kentucky. 
Carbon sequestration in terrestrial systems is generally evaluated as net $\mathrm{C}$ gain or loss over some period of time. Natural processes responsible for $\mathrm{C}$ loss such as microbial and plant respiration, plant exudate secretion and SOM oxidation are factors that must be considered on any site, but $\mathrm{C}$ loss via erosion and runoff may be the biggest contributor on disturbed mine lands. Results from our study showed that compaction alleviation not only improved seedling success and productivity, but also resulted in less suspended sediment concentration, runoff and erosion. For instance, a spoil with $2 \% \mathrm{C}$ would lose 1.37 pounds of $\mathrm{C}$ per acre versus 0.028 pounds from the Starfire 2 (compacted) and 17 West 2 (loose-dumped) sites, respectively as per the results in Table 1.12. As such, methods employed to enhance seedling performance also demonstrate ancillary benefits associated with internal drainage, offsite environmental impacts and $\mathrm{C}$ retention.

\section{DISTINGUISHING AND QUANTIFYING "NEW CARBON" FROM "OLD CARBON" ON RECLAIMED COAL MINE SITES}

\subsection{INTRODUCTION}

Projected climate change resulting from elevated atmospheric carbon dioxide has given rise to various strategies designed to sequester carbon in terrestrial ecosystems. Reclaimed coal mine soils represent one such potential carbon sink. However, quantifying "new" organic carbon (organic matter that has been added to soil through recent biological processes, such as plant root exudates and detrital matter) in reclaimed mine soils has proven to be difficult due to the presence of carbonate minerals and coal particles in the reclaimed coal mine spoils. Larger, visible coal particles can be removed, but smaller, indiscernible coal fragments and dust particles may be difficult to isolate as the have similar coloration to the parent materials.

Methods to determine organic carbon in mine spoils are problematic because they do not distinguish between "old" organic carbon (such as, fossilized plant matter, limestone, and coal fragments) and "new" organic carbon. Some researchers have tried simple techniques such as flotation to physically separate the coal particles, but this has proven to be unsuccessful (Akala and Lal, 2001). Other techniques such as diffuse reflectance infrared Fourier Transform (DRIFT) spectroscopy and ${ }^{13} \mathrm{C}$ CPMAS NMR 
spectroscopy (Rumpel et al., 2000) have been suggested but are expensive and instrument availability is limited. Methods employing rapid dichromate oxidation techniques (Nelson and Sommers, 1996) have also been found to be inappropriate as these methods cannot discriminate between carbon in carbonized materials and carbon in soil organic matter (SOM). This is due to the variation in organic carbon recovery with the type of carbonized material and time, temperature, and hazardous nature of heating the chromic acid mixture (Nelson and Sommers, 1996).

Wet and dry combustion techniques have been employed to remove inorganic carbon by acid dissolution and use evolved $\mathrm{CO}_{2}$ to quantify organic carbon, or use the difference between total carbon and quantified inorganic carbon to estimate organic carbon (Allison, 1960; Nommik, 1971). However, researchers have found acid dissolution to be ineffective in removing all carbonate carbon (Midwood and Boutton, 1998). A correction factor to account for unoxidized organic carbon sometimes has to be included and this may vary depending on the type of soil and soil horizon, indicating that there is no appropriate correction factor for all soils (Nelson and Sommers, 1996).

Thermal analysis techniques, which allow for measurement of a physical property of a substance (mass, temperature, enthalpy) while it is subjected to a controlledtemperature program (Wendlandt, 1986), may provide the avenue for monitoring SOM changes in soil containing coal and carbonate phases. For instance, differential scanning calorimetry (DSC) is commonly used to provide quantitative data for minerals in soil (Karathanasis and Harris, 1994). DSC has also been used to characterize soil organic carbon (SOC), monitor changes in organic matter associated with clays, and evaluate organic matter maturation during the composting process (Dell'Abate et al., 2000; Pietro and Paola, 2004; Lopez-Capel et al., 2005; Plante et al., 2005). Another thermal analysis technique, thermogravimetry (TG), was suggested for rapid, reliable and simultaneous screening of soil components such as organic carbon, nitrogen, clay, and carbonates (Siewert, 2004). The first derivative of the TG, derivative thermogravimetry (DTG), is obtained simultaneously. Subtle inflections on the TG are represented by discrete peaks on the DTG curve which allow for interpretation and resolution of thermal events. TG has been used to study coal and carbonate rocks (Warne, 1985; 1996; Varey et al., 1996; Avid et al., 2002; Dagounaki et al., 2004), oil shales (Levy and Kramer, 1988; Khraisha 
and Shabib, 2000), soil minerals (Karathanasis and Harris, 1994), and organic matter fractions (Leinweber et al., 1992; Dell'Abate et al., 2000; Pietro and Paola, 2004; Plante et al., 2005). Weight losses at temperatures less than $200{ }^{\circ} \mathrm{C}$ can be attributed to the loss of crystalline lattice water and hygroscopic water in salts and organic matter, those between 250 and $450{ }^{\circ} \mathrm{C}$ are attributed to organic matter whereas weight loss above 600 ${ }^{\circ} \mathrm{C}$ can be attributed to calcium carbonate minerals (Piotrowski, 1999; Dell'Abate et al., 2000, Dagounaki et al., 2004; Siewert, 2004; Lopez-Capel et al., 2005). Thus, TG/DTG could be used as a simple and direct method for quantifying "new" carbon in spoils of mixed materials at coal mine sites.

A standard procedure for measuring carbon sequestration in soil and geologic media is needed. Thus, a study was initiated to evaluate thermogravimetry (TG/DTG) as a potential cost-effective, rapid, and simple method for quantifying and differentiating "new" organic carbon from carbonates and coal. DSC was employed to confirm TG/DTG results and petrographic analysis was used as a standard method for validating the TG results.

\subsection{METHODS AND MATERIALS}

\subsubsection{Preparation of Standard Samples and Mixtures}

Samples of coal were collected from the Lewis Fork Mine in Perry Co., Kentucky in August 2004, washed with deionized water and air dried. They were subsequently ground using a SPEX Certiprep 8000 Mixer Ball Mill and sieved $(<1 \mathrm{~mm})$. Limestone (Southeastern States Pelleted) was utilized in order to standardize test runs with a known carbonate value. Grass litter, ground and sieved $(<1 \mathrm{~mm})$, was used as the "new" organic matter matrix. In addition to individual samples consisting of air dried grass litter, limestone, and coal, mixtures containing all three components were created for analysis.

Expected carbon concentrations in the mixtures were calculated on a dry weight mass to mass basis using baseline carbon concentrations from the individual samples. Different types of organic matter including cellulose (Sigma Aldrich), apple leaves (NIST), and extracted lignin (modified Klason lignin procedure, Van Soest, 1994) from wood shavings, were used as reference materials for correlation purposes. 


\subsubsection{Total Carbon and Nitrogen Content}

Total $\mathrm{C}$ (organic and inorganic) and $\mathrm{N}$ contents were determined by dry combustion using a LECO CHN 2000 analyzer. No more than $0.2000 \mathrm{~g}$ of sample was placed in a tin foil capsule and combusted in a resistance furnace at $950{ }^{\circ} \mathrm{C}$ using $\mathrm{O}_{2}$ as a carrier gas. The resulting gases were equilibrated in a ballast chamber followed by infrared detection of $\mathrm{CO}_{2}$ and $\mathrm{H}_{2} \mathrm{O} . \mathrm{N}_{2}$ was determined using a thermal conductivity detector after reduction of $\mathrm{N}$ oxides and removal of $\mathrm{CO}_{2}$ and $\mathrm{H}_{2} \mathrm{O}$. Calibration curves were validated on a daily basis by using a LECO standard (EDTA- $\mathrm{C}_{10} \mathrm{H}_{16} \mathrm{~N}_{2} \mathrm{O}_{8}$ - LECO Corp.) and quality control assured by running an EDTA standard for every ten samples.

\subsubsection{Organic Carbon Characterization}

\section{Differential Scanning Calorimetry (DSC)}

DSC is a technique where added energy, to an unknown sample and reference material, is measured as a function of temperature while the samples are subjected to a controlled temperature program (Karathanasis and Harris, 1994). Samples were scanned using the Dupont Instrument 910 DSC that utilizes a heat-flow principle of operation. Thermocouple junctions were connected directly to two thermally conducting bases with the sample (in an alumina pan) resting on one of the conducting bases and the reference (an empty, covered alumina pan) on the other base. Approximately $10 \mathrm{mg}$ of sample were used with a temperature ramp of $10{ }^{\circ} \mathrm{C} \mathrm{min}-1$ up to $600{ }^{\circ} \mathrm{C}$ and a nitrogen flow rate of 10 $\mathrm{mL} \mathrm{min}^{-1}$. Heat-flow DSC provides a signal that is essentially independent of the thermal properties of the sample (Karathanasis and Harris, 1994).

Thermogravimetric Analysis (TG/DTG)

TG/DTG was carried out with a Dupont 951 Thermogravimetric Analyzer using a platinum pan sample holder. Mass changes with incremental temperature increases were evaluated by means of the Thermal Analyst 2000 TA Instrument program. Weight loss was monitored by heating approximately $10 \mathrm{mg}$ of sample from an initial TGA temperature of $25{ }^{\circ} \mathrm{C}$ up to final temperature of $1000{ }^{\circ} \mathrm{C}$. Optimum results (representative weight loss per sample and the best thermal curve with minimum overlapping of peaks) were obtained using a temperature ramp of $20{ }^{\circ} \mathrm{C} \mathrm{min}^{-1}$ and a nitrogen flow rate of $20 \mathrm{~mL}$ $\min ^{-1}$. Each component for the standard mixture was individually added to the platinum pan, mixed to ensure homogeneity, and then analyzed on the TGA. This was to ensure University of Kentucky Research Foundation

Final Report - 10/01/03 thru 9/30/06

DE-FC26-02NT41624 
that the mixture contained known amounts of each component as opposed to a general mixture where the chances of density differences may have interfered with the calculated and actual TG recoveries of the components.

Quantitative determinations were based on weight loss and theoretical compositions of the standards. This method was then utilized to quantify the "new" or recent organic carbon on reclaimed coal mine sites.

\subsubsection{Petrographic Analysis}

Approximately 4-5 g of 20-mesh sample (1.5 g of each component for the 1:1:1 mixture of grass litter, coal, and limestone) were mixed with a small amount of epoxy resin, poured into 2.5 -cm-diameter phenolic ring molds and vacuum impregnated before being allowed to cure. Petrographic analysis was conducted on plugs of the standard and samples that had been polished according to standard procedures (Pontollilo and Stanton, 1994). A Zeiss Universal reflected-light microscope, using a 40x oil immersion lens, and a total magnification of 500X was used for all petrographic analyses. Duplicate pointcount petrographic analyses were performed under both reflected white-light and bluelight (450-490 nm). Analysis of 300 points on two separate pellets was sufficient to produce an acceptable precision of $\pm 2-3 \%$ (Taylor et al., 1998a). Petrographic composition of each sample was summarized as "new" organic matter (OM), coal, and minerals.

\subsubsection{Statistical Analysis}

Total $\mathrm{C}$ and $\mathrm{N}$ are given as mean values resulting from multiple analyses $(\mathrm{n}=20$ for standard samples and $\mathrm{n}=10$ for reference samples). Student's t-tests were used to determine differences between expected C (from LECO) and actual C from TG analyses at $\alpha=0.05$.

\subsection{RESULTS AND DISCUSSION}

\subsubsection{Initial $C$ and $N$ content (total)}

Results for C and N fractions of "old" (coal and limestone), "new" (grass litter), and reference samples are presented in Table 2.1 Expected $\mathrm{C}$ and $\mathrm{N}$ for the laboratory mixture was $50.17 \%$ and $1.43 \%$, Actual $\mathrm{C}$ and $\mathrm{N}$ results on replicate mixture samples $(n=20)$ yielded recoveries of 95\% (for C) and 104\% (for $N$ ).

University of Kentucky Research Foundation

Final Report - 10/01/03 thru 9/30/06

DE-FC26-02NT41624 
Table 2.1: Total C and $\mathrm{N}$ content from LECO analysis for standard and reference samples.

\begin{tabular}{|c|c|c|c|c|}
\hline Sample & \multicolumn{2}{|c|}{$\% \mathrm{C}$} & \multicolumn{2}{|c|}{$\% \mathbf{N}$} \\
\hline & Mean & S.D. & Mean & S.D. \\
\hline${ }^{\dagger}$ Grass Litter ${ }^{\mathrm{a}}$ & 43.42 & 0.14 & 1.94 & 0.02 \\
\hline${ }^{\dagger} \mathrm{Coal}^{\mathrm{a}}$ & 71.60 & 0.52 & 1.42 & 0.04 \\
\hline${ }^{\dagger}$ Limestone $^{\mathrm{a}}$ & 13.74 & 0.30 & 0.29 & 0.01 \\
\hline${ }^{\ddagger}$ Apple Leaves (NIST) ${ }^{b}$ & 47.99 & 0.10 & 2.34 & 0.01 \\
\hline${ }_{\text {Cellulose }}^{\mathrm{b}}$ & 43.11 & 0.08 & 0.05 & 0.01 \\
\hline Lignin ${ }^{\mathrm{b}}$ & 59.58 & 0.16 & 0.25 & 0.02 \\
\hline${ }^{\dagger}$ Mixture $(35: 45: 20)$ litter : coal : limestone & 50.17 & 0.34 & 1.43 & 0.03 \\
\hline
\end{tabular}

$\dagger: \mathrm{n}=20 ; \uparrow: \mathrm{n}=10 ;{ }^{\mathrm{a}}$ : standard samples; ${ }^{\mathrm{b}}$ : reference samples

EDTA recoveries ranged from $99.4 \%$ to $100.6 \%$ for $\mathrm{C}$ and $98.5 \%$ to $100.7 \%$

\subsubsection{Thermogravimetric Analysis}

The data analysis system plotted weight loss (\%) and first derivative as a function of temperature. Weight loss for each component is shown in Table 2.2. Representative TG/DTG patterns for the "old" and "new" C fractions; grass litter, coal, and limestone, are shown in Figure 2.1. TG/DTG curves showed pyrolysis peaks at distinctively different temperatures with the peaks for litter occurring at $270-395{ }^{\circ} \mathrm{C}$, for coal at 415 $520{ }^{\circ} \mathrm{C}$, and for limestone at $700-785{ }^{\circ} \mathrm{C}$. Several factors were employed to ensure peak identification. Use of nitrogen as the carrier gas instead of air and a temperature ramp of $20{ }^{\circ} \mathrm{C} \mathrm{min}{ }^{-1}$ instead of $10{ }^{\circ} \mathrm{C} \mathrm{min}^{-1}$ minimized baseline noise. In addition, it was also found that a nitrogen flow rate of $20 \mathrm{~mL} \mathrm{~min}^{-1}$ versus $10 \mathrm{~mL} \mathrm{~min}^{-1}$ greatly enhanced peak definition. 
Table 2.2: TG/DTG pyrolysis data for standards. $n=5$

\begin{tabular}{|lccc|}
\hline Sample & \multicolumn{3}{c|}{ Temperature Interval } \\
\hline & $270-400^{\circ} \mathrm{C}$ & $415-520^{\circ} \mathrm{C}$ & $>700^{\circ} \mathrm{C}$ \\
Grass Litter & \multicolumn{3}{c}{ Wt loss $\%$} \\
Coal & $58.6 \pm 1.1$ & nd & nd \\
Limestone & nd & $23.7 \pm 0.1$ & nd \\
& nd & nd & $39.8 \pm 0.7$ \\
Cellulose & & & \\
Lignin & $83.2 \pm 1.2$ & nd & nd \\
\hline
\end{tabular}

nd- not determined

Laboratory mixtures of the litter, coal, and limestone show distinct peaks for each component. The fact that there is no peak overlap greatly enhances the ability to "isolate" the different carbon fractions. Pyrolysis results are shown in Table 2.3. Different component ratios were used to check peak detectability and temperature intervals were selected based on the major DTG peaks for the individual components. Average recoveries of carbon for each component in the mixtures were $93.9 \pm 4.2 \%$ for coal, 94.2 $\pm 2.1 \%$ for litter and $108.9 \pm 2.9 \%$ for limestone $(n=10)$.

TG and DTG thermographs for the mixtures showed a weight loss in the 50-150 ${ }^{\circ} \mathrm{C}$ range indicative of dehydration reactions (Figure 2.2) (Pietro and Paola, 2004). The weight loss in the $270-375{ }^{\circ} \mathrm{C}$ region is characteristic of "new" organic matter as indicated in the thermographs of grass litter (Figure 2.1a), cellulose (Figure 2.3a), and apple leaves (NIST) (Figure 2.3b). This also correlates well with other studies that report combustion of carbohydrates, decarboxylation of acidic groups, and dehydration of hydroxylate aliphatic structures in the $200-350{ }^{\circ} \mathrm{C}$ range (Shulten and Leinweber, 1999; Pietro and Paola, 2004; Francioso et al., 2005). In addition, lignin decomposition occurs between $375-430{ }^{\circ} \mathrm{C}$ (Sheppard and Forgeron, 1987; Lopez-Capel et al., 2005,) and is 
characterized by a single broad peak (Figure 2.3c). The NIST apple leaves (Figure 2.3b) show overlapping peaks for both cellulose and lignin.

Weight loss for the coal fraction occurs between $415-520{ }^{\circ} \mathrm{C}$ and is attributed to the splitting of phenol hydroxyl groups, breaking of -C-C- bonds and partial transition of coal matter into a plastic state (Hodžic and Pašic, 1985; Markova et al., 1985; Morgan et al., 1987). The peak temperature for coal pyrolysis may shift depending on coal maturity or rank (Markova et al., 1985). As coal rank increases, so too does its aromaticity (Taylor et al., 1998b; Francioso et al., 2005) which may result in a higher pyrolysis temperature. 

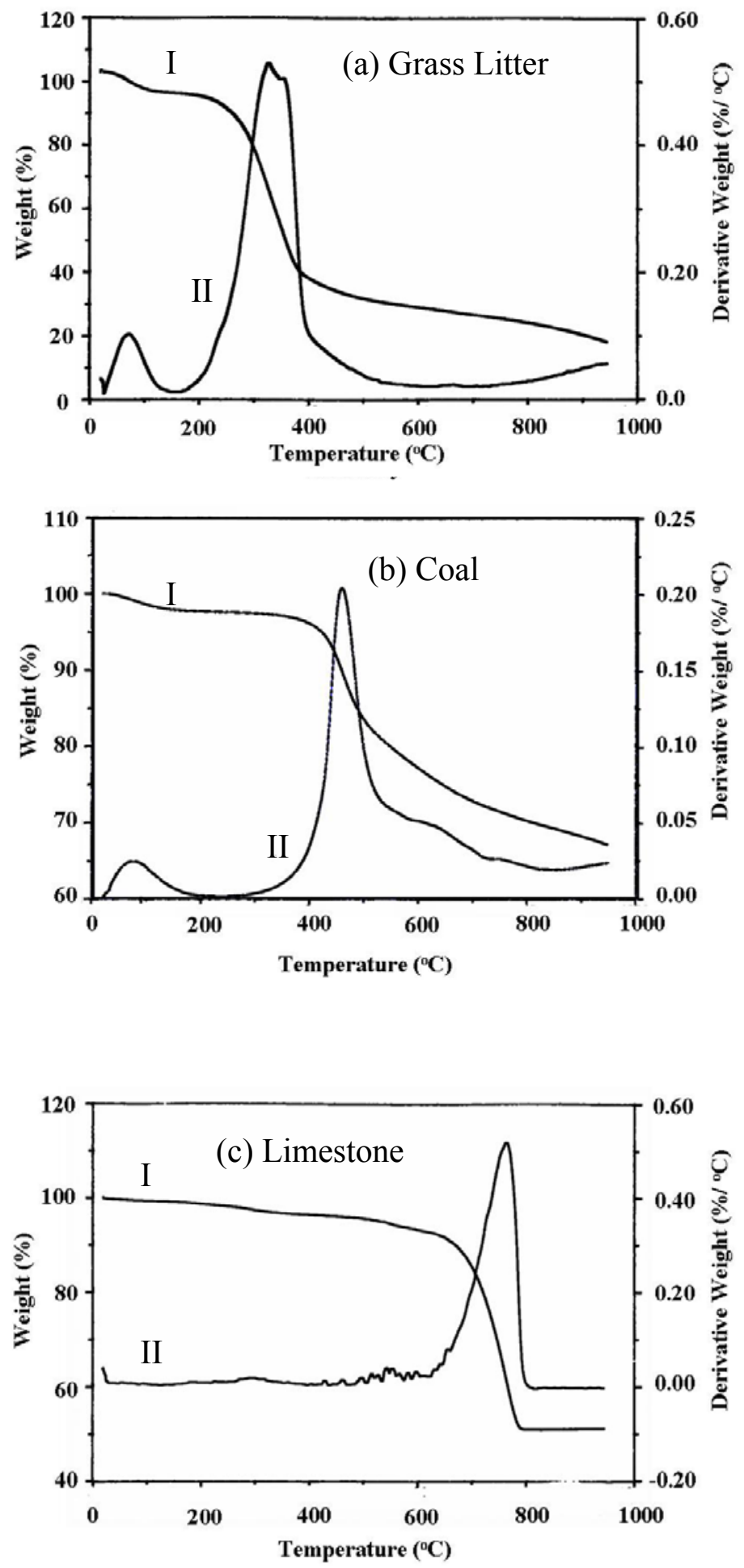

Figure 2.1. Representative TG (I) and DTG (II) patterns for (a) grass litter (b) coal and (c) limestone. 
Table 2.3: TG/DTG pyrolysis data for mixtures of litter, coal, and limestone

\begin{tabular}{|c|c|c|c|c|c|c|c|}
\hline \multirow[b]{2}{*}{ Sample } & \multirow[b]{2}{*}{$\begin{array}{c}\text { Mixture } \\
\text { Composition } \\
\text { by weight } \\
\text { (mg) }\end{array}$} & \multicolumn{4}{|c|}{\begin{tabular}{rr}
\multicolumn{2}{c}{ Temperature Interval } \\
$270-400^{\circ} \mathrm{C}$ & $415-520^{\circ} \mathrm{C}$
\end{tabular}} & \multicolumn{2}{|c|}{$>700^{\circ} \mathrm{C}$} \\
\hline & & $\begin{array}{c}\text { wt } \\
\text { loss } \\
\%\end{array}$ & $\begin{array}{l}\text { Recovery } \\
\text { (\%) }\end{array}$ & $\begin{array}{c}\text { wt } \\
\text { loss } \\
\%\end{array}$ & $\begin{array}{l}\text { Recovery } \\
\text { (\%) }\end{array}$ & $\begin{array}{c}w t \\
\text { loss } \\
\%\end{array}$ & $\begin{array}{c}\text { Recovery } \\
\text { (\%) }\end{array}$ \\
\hline 1 & $3.8: 2.9: 3.3$ & 19.3 & 86.8 & 6.7 & 96.2 & 14.7 & 111.5 \\
\hline 2 & 4.8:2.9:2.2 & 26.0 & 91.7 & 7.0 & 101.1 & 10.4 & 116.0 \\
\hline 3 & $5.0: 2.0: 3.0$ & 27.3 & 94.0 & 4.6 & 95.7 & 12.2 & 100.9 \\
\hline 4 & $2.9: 4.5: 2.6$ & 16.2 & 94.0 & 9.2 & 86.2 & 10.8 & 105.5 \\
\hline 5 & $4.3: 2.3: 3.4$ & 23.5 & 94.3 & 5.4 & 98.2 & 14.9 & 108.8 \\
\hline 6 & 2.8:4.4:2.8 & 16.0 & 98.1 & 8.8 & 84.0 & 12.4 & 110.9 \\
\hline 7 & $3.0: 4.7: 2.3$ & 16.2 & 91.8 & 11.4 & 101.9 & 10.0 & 109.4 \\
\hline 8 & $1.4: 6.2: 2.4$ & 8.1 & 99.1 & 12.4 & 84.8 & 10.0 & 103.3 \\
\hline 9 & $3.8: 3.9: 2.0$ & 21.1 & 98.4 & 9.5 & 92.9 & 9.5 & 114.0 \\
\hline 10 & 3.9:3.7:2.8 & 21.6 & 94.0 & 8.7 & 98.4 & 10.3 & 108.5 \\
\hline $\bar{x}$ & & & 94.2 & & 93.9 & & 108.9 \\
\hline
\end{tabular}

Mixture composition is given by weight $(\mathrm{mg})$ in the order litter : coal : limestone. 


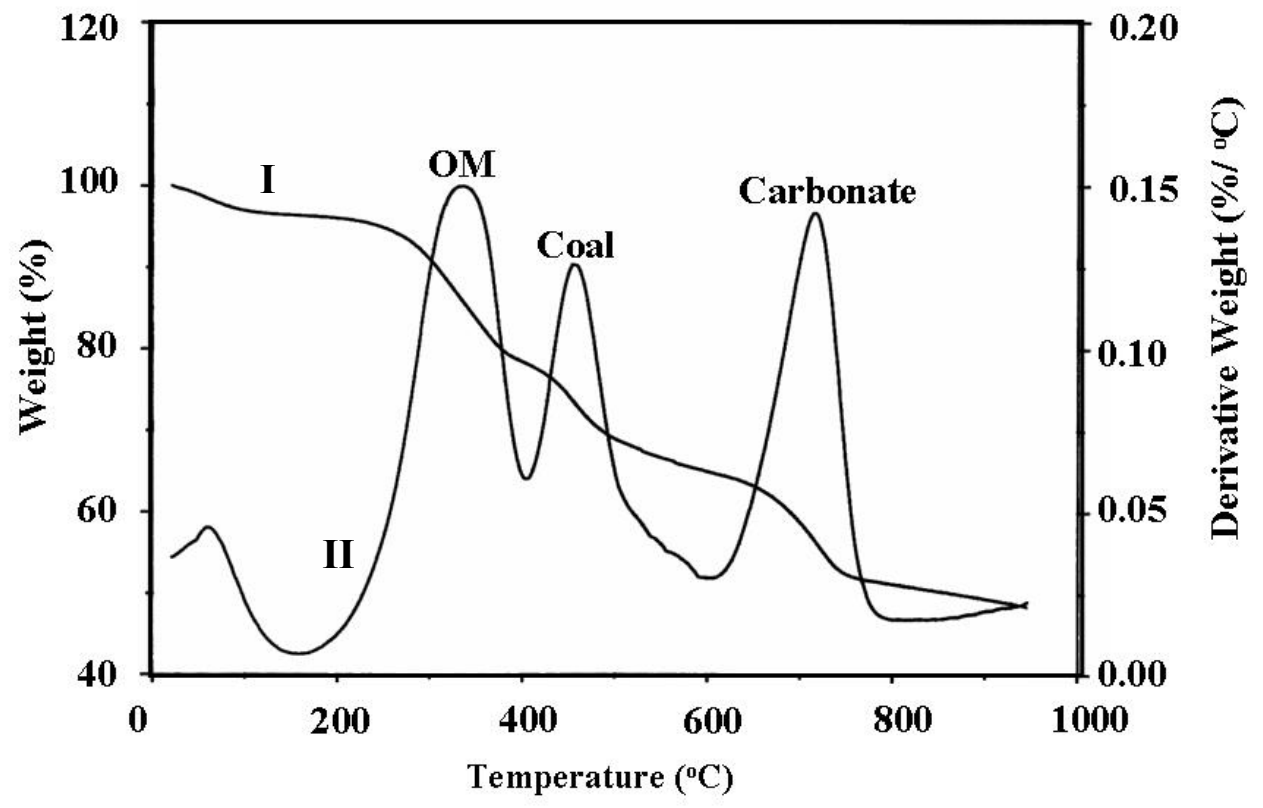

Figure 2.2. Representative TG (I) and DTG (II) for a laboratory mixture of grass litter, coal, and limestone. 

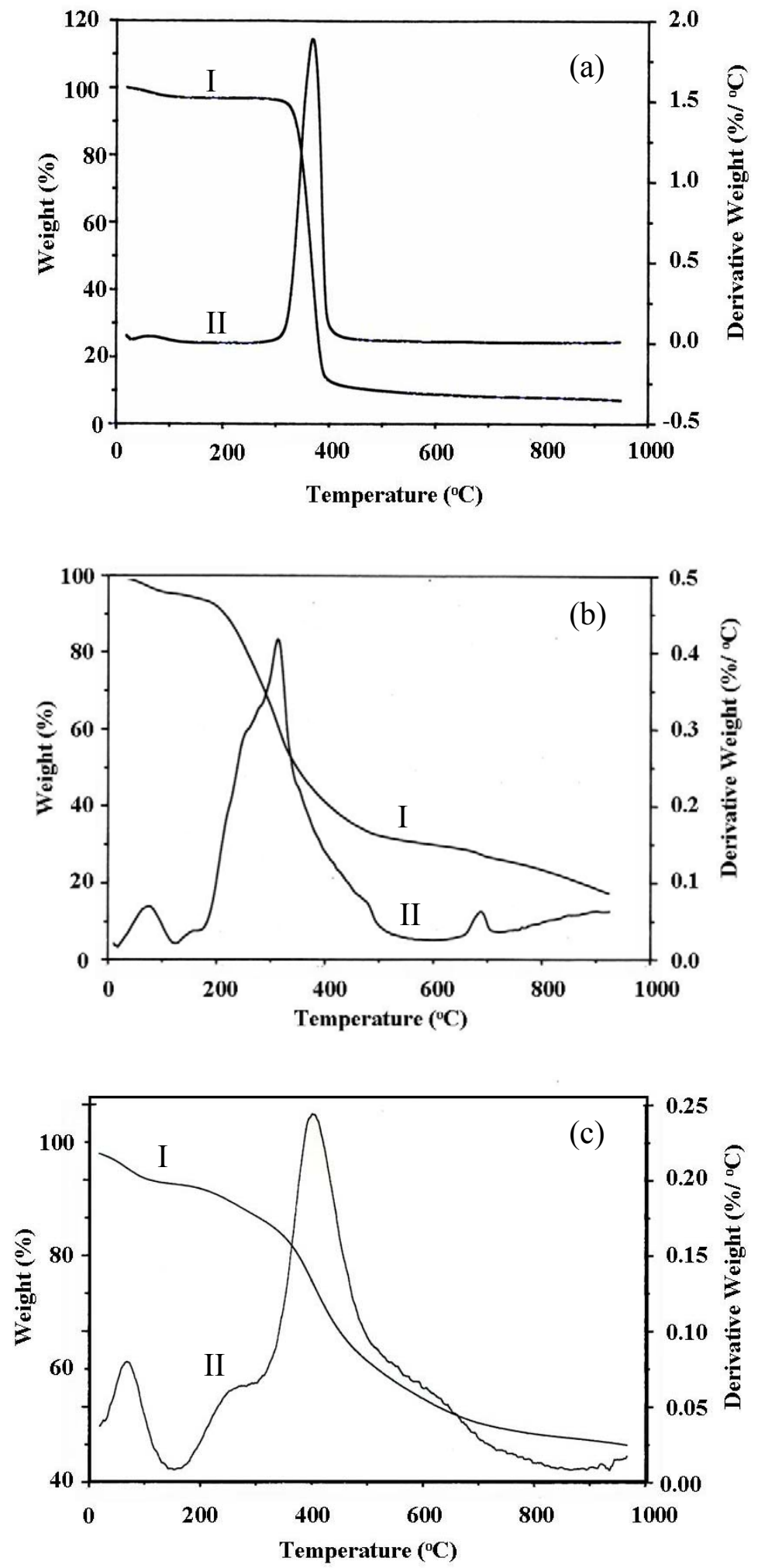

Figure 2.3. Representative TG (I)/DTG (II) patterns for (a) cellulose, (b) NIST apple leaves, and (c) lignin. 
For instance, peak temperatures of $420{ }^{\circ} \mathrm{C}$ and $513{ }^{\circ} \mathrm{C}$ were found for high volatile and low volatile coals respectively (Biagini et al., 2002) whereas peak temperatures $>400$ ${ }^{\circ} \mathrm{C}$ were found for highly decomposed peat or lignite (Sheppard and Forgeron, 1987). This confirms that the "new" organic matter peak will not be masked by that of the coal. Weight loss in the $650-750{ }^{\circ} \mathrm{C}$ range (Figure 2.2) is attributed to carbonate thermal degradation (Schnitzer and Hoffman, 1966; Pietro and Paola, 2004; Siewert, 2004; Bhargava et al., 2005).

Comparing TG and LECO results, linear relationships are observed for each component in the mixtures $(\mathrm{n}=10)$ containing grass litter, coal, and limestone (Figures 2.4 $a, b$, and c). No significant differences were observed between the experimental data and the 1:1 model (Figure 2.4) at $\alpha=0.05$. This is supported by high linear regression values $(>0.9)$ for each component. However, TG analysis tends to provide consistently higher estimates of carbon in the limestone fraction than are obtained using the LECO analyzer. This observation may be due to incomplete combustion of carbonates in the LECO. Temperature ranges suggested by literature include $<580{ }^{\circ} \mathrm{C}$ for siderite $\left(\mathrm{FeCO}_{3}\right) ; 580$ $690{ }^{\circ} \mathrm{C}$ for magnesite $\left(\mathrm{MgCO}_{3}\right) ; 690-800{ }^{\circ} \mathrm{C}$ for $\mathrm{MgCO}_{3}$ from dolomite $\left(\mathrm{CaMg}\left(\mathrm{CO}_{3}\right)_{2}\right)$; and $>950{ }^{\circ} \mathrm{C}$ for calcite $\left(\mathrm{CaCO}_{3}\right)$ (Karathanasis and Harris, 1994). Calcite may have decomposed to a greater extent using the TG since the temperature maximum used was $1000{ }^{\circ} \mathrm{C}$ as opposed to a maximum temperature of $950{ }^{\circ} \mathrm{C}$ with the LECO. Another possibility may be due to density differences when using a whole mixture (for the LECO samples) as opposed to weighing out the individual components to make up a mixture for each sample before TG analysis.

\subsubsection{Differential Scanning Calorimetry Analysis}

DSC patterns show inflections between $270{ }^{\circ} \mathrm{C}$ and $382{ }^{\circ} \mathrm{C}$ for the grass litter. A sharp endothermic peak occurs between $291{ }^{\circ} \mathrm{C}$ to $355^{\circ} \mathrm{C}$ for cellulose (Figures $2.5 \mathrm{a}$ and b), a broader exothermic peak between $287{ }^{\circ} \mathrm{C}$ and $390{ }^{\circ} \mathrm{C}$ for lignin, followed by an exothermic peak between $420{ }^{\circ} \mathrm{C}$ to $525{ }^{\circ} \mathrm{C}$ for coal (Figures $2.5 \mathrm{c}$ and $\mathrm{d}$ ). The endothermic peak at approximately $573{ }^{\circ} \mathrm{C}$ on the coal DSC (Figure 2.6b) represents evidence of quartz. These observations confirm the pyrolysis peaks obtained with the TG/DTG for the organic matter and coal fractions. However, identification of the

Final Report - 10/01/03 thru 9/30/06

DE-FC26-02NT41624 
carbonate peaks is not possible due to the lower temperature maximum of the DSC (600 ${ }^{\circ} \mathrm{C}$ versus $1000{ }^{\circ} \mathrm{C}$ for the TGA). DSC may enable separation of the cellulose and lignin peaks, as well as used to differentiate mineral types.

\subsubsection{Petrographic Analysis}

Optical microscopy revealed that "new" organic matter, grass litter, and sycamore leaves exhibit strong fluorescence (yellow, green, red and brown) under blue-light illumination and also distinctive cell morphology (Figures 2.6a, and b). "Old" organic matter, coal, and limestone, are very different in their morphological structure and appearance in reflected white-light and blue-light. Limestone appears massive and highly reflective under white-light (Figure 2.6c). Most of the coal appears as angular macerals including vitrinite (coalified woody material) and inertinite (for example, preserved fragments of fossil charcoal) that show no fluorescence under blue-light and are characterized by gray to light-gray or white color in white-light (Figure 2.6d). These variations in petrographic composition make it possible to differentiate between the different carbon fractions in the mixture. Duplicate point-count analyses of a 1:1:1 mixture of grass litter, coal, and limestone yielded $39.2 \pm 1.2 \%$ "new" organic matter, $35.0 \pm 2.4 \%$ coal, and $25.9 \pm 1.2 \%$ minerals (in this case, limestone). These results may suggest that particle density differences led to some separation during vacuum impregnation. The least dense fraction, litter, was pulled to the top, yielding a higher recovery than expected followed by the coal fraction. Recovery of limestone, the most dense of the three fractions, was below the expected value (33.3\%). This separation could probably be avoided by using less epoxy in the initial impregnation, thus providing a thicker mixture that would minimize any density differences. 
(a) Grass litter fraction

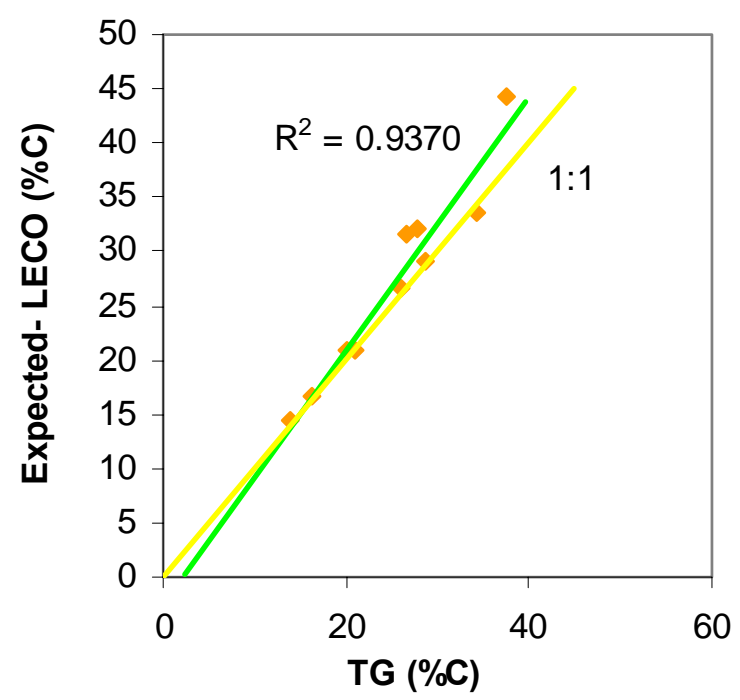

(b) Coal fraction

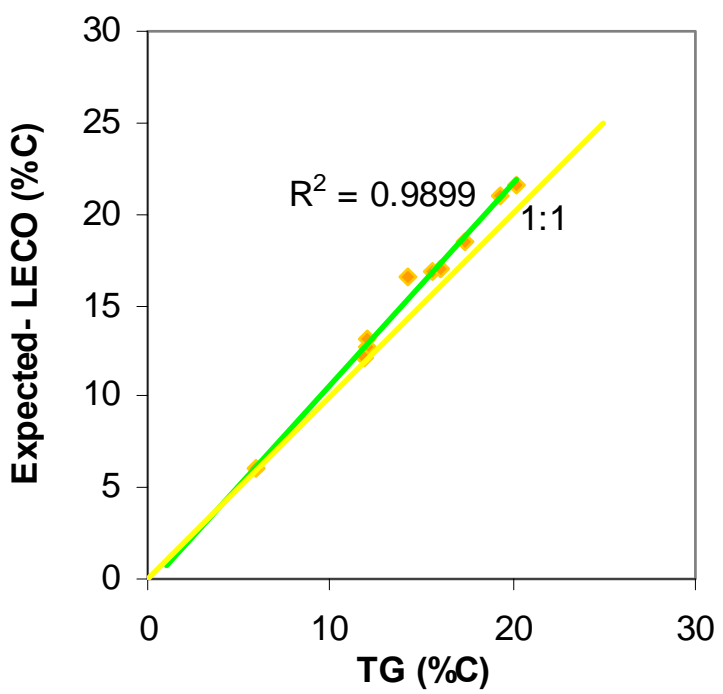

(c) Limestone fraction

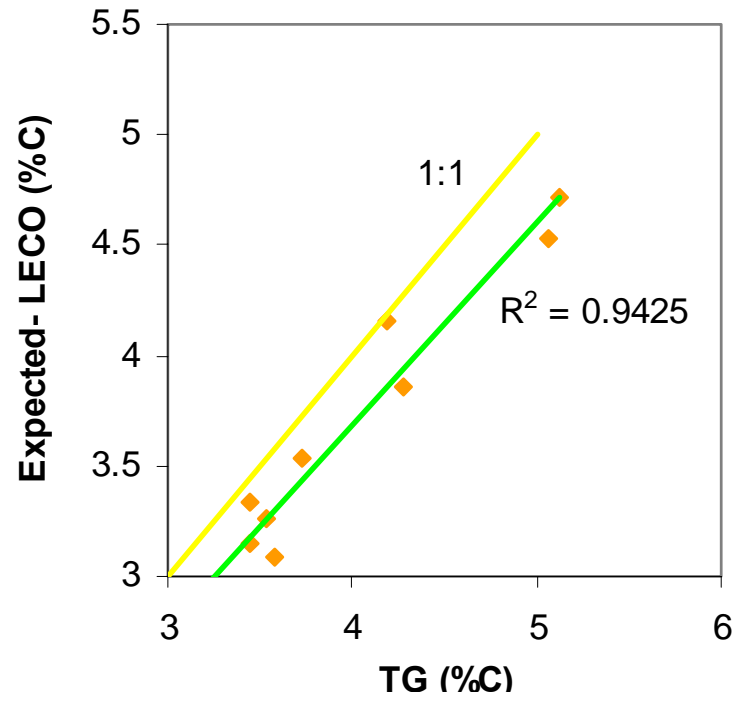

Figure 2.4. Expected C (\%) versus TG (\%) for (a) grass litter, (b) coal, (c) limestone fractions from mixtures, $n=10$. Figures (a), (b), and (c) also show relationship between actual recoveries and a theoretical perfect linear regression line $(1: 1)$. 

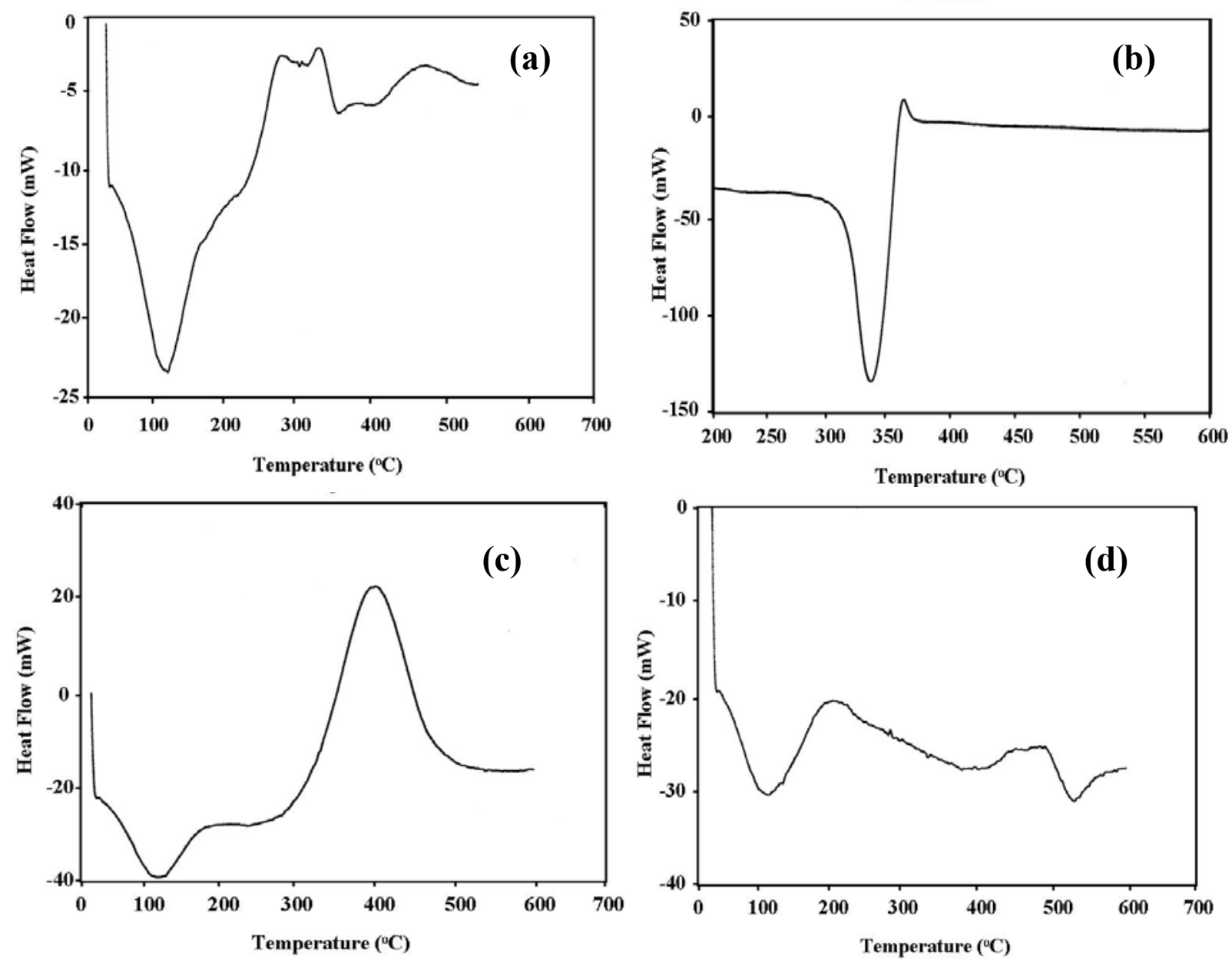

Figure 2.5. Representative DSC patterns for (a) grass litter, (b) cellulose, (c) lignin, and (d) coal. 

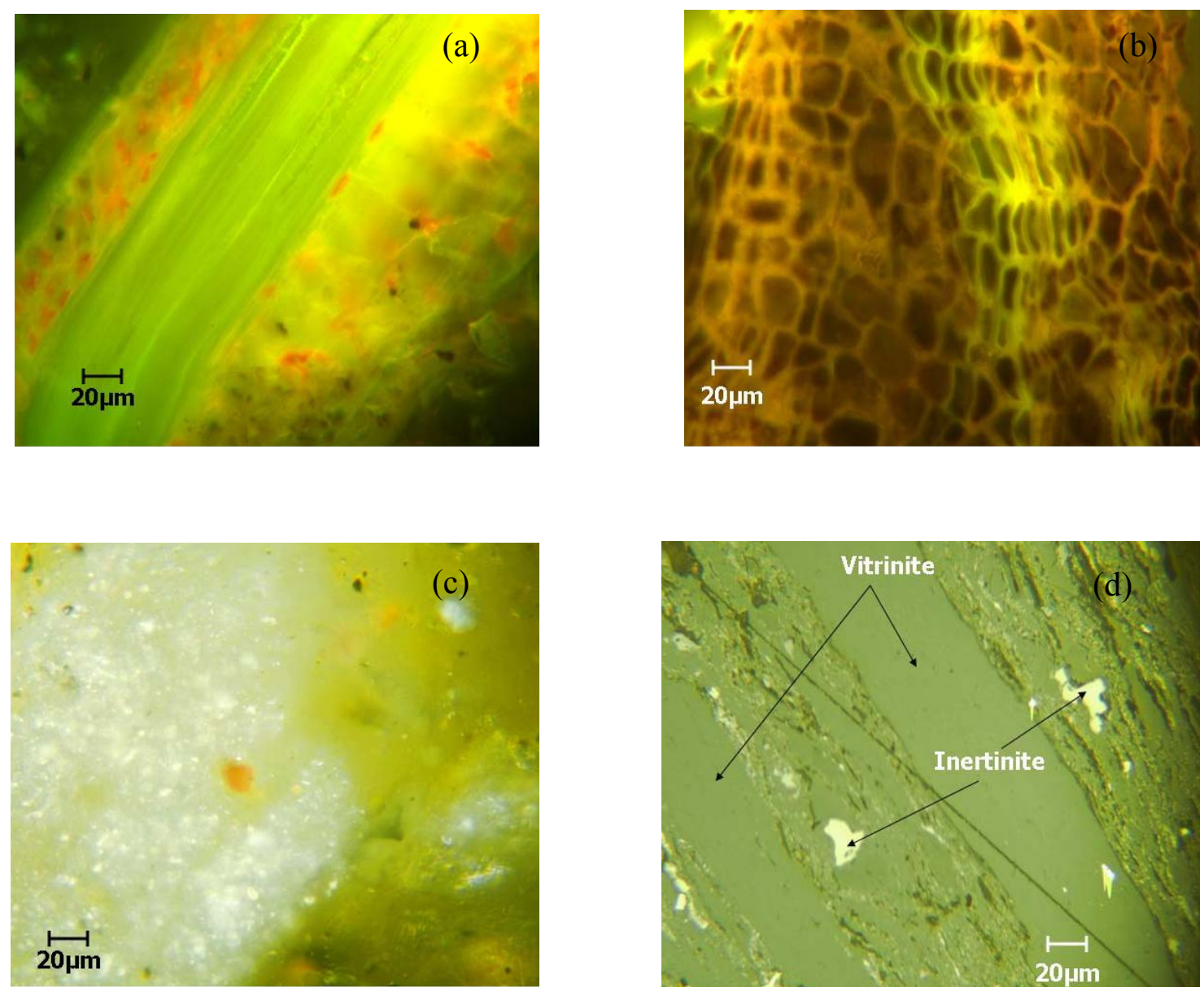

Figure 2.6. Representative photomicrographs of (a) grass litter, (b) sycamore leaves, (c) limestone, and (d) coal. All photomicrographs were taken under oil immersion, a, b, and c using blue-light and d using reflected white-light illumination.

\subsection{CONCLUSIONS}

TG/DTG has the potential to differentiate and quantify "new" organic carbon in soils containing coal and carbonate minerals and has the distinct advantage of analyzing whole samples without pre-treatment. The TG/DTG technique is rapid (1-2 hours for complete analysis) and easy to use giving repeatable results. However, potential pitfalls of 
using TG/DTG may include interference from impurities such as high mineral content (pyrite- $400-550{ }^{\circ} \mathrm{C}$; goethite- $300-400{ }^{\circ} \mathrm{C}$ ) and clay (kaolinite- $400-600{ }^{\circ} \mathrm{C}$ ) in soil samples. Similarly, mineral matter dispersed throughout the coal (clays, carbonates, and pyrite) may produce additional overlapping peaks during pyrolysis. As indicated previously, carbonates such as siderite may decompose at temperatures $<580{ }^{\circ} \mathrm{C}$ and could potentially overlap with the peak for coal. Presence of some of these minerals may be problematic for identification and quantification of "new" organic matter (between $250-450{ }^{\circ} \mathrm{C}$ ). Elemental analyses and X-ray diffraction (XRD) data may help to account for such interferences. Larger sample weights $(>15 \mathrm{mg})$ and larger particle size $(>1 \mathrm{~mm})$ may also limit reproducibility of thermal curves. However, potential overlapping weight-loss temperature regions may be minimized and resolution enhanced by manipulating procedural conditions (carrier gases, flow rates, and temperature ramps).

Petrographic analysis takes several days for sample preparation and analysis. Particle density differences may limit the use of petrography as, in this study, they overestimated the organic matter fraction and underestimated the carbonate fraction $(118 \%$ and $78 \%$, respectively) compared to thermogravimetry which provided a more accurate measure for these fractions, (94.2\% for litter and 108.9\% for carbonate). Organic petrography, however, may be useful in helping to decipher the TG/DTG curves as rank (and possible maceral content) may influence the location of peaks (Morgan et al., 1987).

These results suggest that petrographic analysis can be used as a proxy for detection of "new" organic matter. However, thermogravimetry appears to be the superior of the two as it provides a cost-effective, rapid, direct, and simple method to differentiate and quantify "new" organic matter in soil media containing coal and carbonate minerals. Further work is required to validate this method on actual field samples from reclaimed coal mine sites.

\section{EVALUATING FACTORS THAT INFLUENCE CARBON SEQUESTRATION ON A CHRONOSEQUENCE OF REFORESTED MINE LANDS}

\subsection{INTRODUCTION}

Coal mining in the United States has disturbed approximately 2.4 million hectares since 1930 (Shoch et al., 2003) with the majority of these lands residing in the Appalachian 
region (Zeleznik and Skousen, 1996). Surface mining operations lead to a loss of soil quality, a net decrease in soil capability and function, and severely deplete soil organic carbon (SOC) due to enhanced mineralization, erosion, and leaching (Akala and Lal, 2001). The $\mathrm{C}$ content of spoil material (mine soils) is typically very low compared to undisturbed surface soils (Bussler et al., 1984), and the potential to increase the C capital of reclaimed mine soils can be significant (IPCC, 2000). Researchers have proposed that mine soils can act as large sinks for SOC and may provide an excellent setting for sequestering carbon given that they have lost a large fraction of their antecedent SOC pool (Lal, 2004). Global $\mathrm{C}$ accumulation on degraded lands has been estimated at $0.3 \mathrm{Mg} \mathrm{C}^{-1} \mathrm{yr}^{-1}$ (IPCC, 2000; Nabuurs et al., 1999), making carbon sequestration on reclaimed coal mine sites complementary to traditional reclamation objectives.

Globally, soils hold nearly three times the amount of carbon contained within standing vegetation and twice that residing in the atmosphere (Schlesinger, 1991). In U.S. forests, mineral soils contain about $60 \%$ of the ecosystem C stock with an additional $10 \%$ stored within the forest floor (Birdsey et al., 1993). Trees and large roots account for the final $30 \%$ of the forest C capital. Akala and Lal (2001) found that the SOC sequestration of reclaimed mine soils in Ohio ranged between 50 and $60 \mathrm{Mg} \mathrm{ha}^{-1}$ for 0 to $15-\mathrm{cm}$ depth over a 25 -year period. Stahl et al., (2003) found that SOC in the 0 to $15-\mathrm{cm}$ depth in a reclaimed coal mine in Wyoming increased from $10.9 \mathrm{~g} \mathrm{C} \mathrm{kg}^{-1}$ to $18.6 \mathrm{~g} \mathrm{C} \mathrm{kg}^{-1}$ over a 5 year period (1983-1998) with a further increase to $20.5 \mathrm{~g} \mathrm{C} \mathrm{kg}^{-1}$ by 2002. Shoch et al., (2003) estimated that 1 ton $\mathrm{C} \mathrm{ha}^{-1} \mathrm{yr}^{-1}$ of carbon could be sequestered over the first 20 years of reclamation in the top $30 \mathrm{~cm}$ of soil on Grant Town Power Plant sites in West Virginia. Although the potential for sequestering $\mathrm{C}$ on these sites is promising, gross errors may have been introduced in these estimates because they are based on time-elapsed (repeated) soil sampling that may have included mixed geological material.

It may be possible to use stable isotopic data, $\mathrm{C} / \mathrm{N}$ ratios and elemental data to provide a means for differentiating "new" carbon (carbon that has been added to soil through recent biological processes, such as plant root exudates and detrital matter) from "old" carbon (such as, fossilized plant matter, limestone, and coal fragments). The $\delta^{13} \mathrm{C}$ values of plants depend on the photosynthetic pathway used for carbon fixation (Deines, 1980). Most woody plants in temperate zones and forest communities use the Calvin cycle 
$\left(\mathrm{C}_{3}\right)$ (Wolf et al., 1994) and have values ranging from -32 to $-20 \%$ (mean $=-27 \%$ ). Tropical grasses, marine, desert, and salt marsh plants utilize the Hatch-Slack cycle $\left(\mathrm{C}_{4}\right)$ and have $\delta^{13} \mathrm{C}$ values ranging from -8 to $-18 \%$ (mean $=-13 \%$ ) (Wolf et al., 1994; Whiticar, 1996). Soils exhibit $C$ isotope signatures that reflect $C_{3}$ or $C_{4}$ biomass inputs and used to estimate organic matter turnover Boutton et al., 1998; Kelly, 1998; Krull and Skjemstad, 2003). Others have used $\mathrm{C} / \mathrm{N}$ ratios as an indicator of decomposition (Krull and Skjemstad, 2003; Dell'Abate et al., 2000; Francioso et al., 2005) and to provide information on the capacity of soil to store and recycle nutrients (Sikora and Stott, 1996). In addition, large isotopic differences between organic and inorganic soil $\mathrm{C}\left(\delta^{13} \mathrm{C}\right.$ of lithogenic carbonates are near $0 \%$ ) can also be used to elucidate influences of inorganic $\mathrm{C}$ on $\delta^{13} \mathrm{C}$ values of soil organic C (Midwood and Boutton, 1998).

Results from the previous section (Section 2) indicated that thermogravimetric (TG) and derivative thermogravimetry (DTG) analysis can be used as a cost-effective, rapid and simple method to quantify and differentiate "new" organic carbon from coal and carbonate minerals (Maharaj, 2006). TG/DTG analysis showed "new" organic matter is pyrolyzed between $270-395{ }^{\circ} \mathrm{C}$, coal at $415-520{ }^{\circ} \mathrm{C}$, and carbonates at $700-785{ }^{\circ} \mathrm{C}$. Use of this method, or stable isotope data, will allow us to assess $\mathrm{C}$ change over time but does little to tell us what is responsible for the change.

In order to determine how much $\mathrm{C}$ an area can sequester within the below ground biomass, we must understand processes that control this sequestered carbon. From a carbon budgeting approach, it seems logical to study processes responsible for the accumulation of soil organic matter (SOM) such as litter decomposition, soil respiration and microbial activity in order to gain some perspective on how a system is cycling C. SOM is a heterogeneous mixture containing compounds that range from highly metabolized components to compounds that are only decomposable by a few select microorganisms. SOM is difficult to study because it is in a state of continuous turnover through many interconnected pools with different retention times (Scholes et al., 2001), ranging from less than a year, to years and decades, to centuries and millennia (Parton, 1997). Even though a particular atom of $C$ that was taken up by a plant may be released back to the atmosphere days, years, or centuries later, the net $\mathrm{C}$ balance may not change 
due to another $\mathrm{C}$ atom taking its place. Everything is relative to specific spatial and temporal scales.

The source of SOM begins with the fixation of $\mathrm{CO}_{2}$ into carbohydrates by plants. $\mathrm{CO}_{2}$ enters the plant through stomata. Once inside the leaf, $\mathrm{CO}_{2}$ interacts with the rubisco enzyme complex to form carbohydrates that become plant tissues and storage pools with various residence times. Leaf residence time is different for deciduous trees (1 year) and conifers (2-8 years), branches have residence times of years to decades, boles have residence times of decades to centuries, and fine roots have residence times of a few days to several years (Beedlow et al., 2004). Some of the $\mathrm{C}$ assimilated is respired back to the atmosphere by autotrophs (Schlesinger, 1997; Attiwill et al., 1993). Additional C is transferred to soils by root exudates, litter fall, and root death (Schlesinger, 1997, Attiwill et al., 1993). Heterotrophic organisms, especially bacteria and fungi, metabolize these substrates for their own growth and maintenance, respiring some $\mathrm{CO}_{2}$ back to the atmosphere (Schlesinger, 1997; Attiwill et al., 1993). Although some C is lost via these processes, some of these substrates are 'left over', either because they are protected from microbes by the environment, protected by their inherently undecomposable make-up, or are metabolized into more stable, resistant organic compounds by a process known as humification (Schlesinger, 1997; Attiwill et al., 1993). This leftover carbon is the SOM.

Processes by which soil fauna transform organic substrates into more stable compounds are influenced by the quality of litter and physical environment of soil. The physical environment includes soil texture ( $\%$ sand, silt and clay), mineralogy, $\mathrm{O}_{2}$ availability, moisture, temperature and the formation and disruption of soil aggregates (Hobbie et al, 2000; Schlesinger, 1997, Torn et al, 1997; Jobaggy et al, 2000). As stated above, these abiotic products of biotic processes are difficult to study because the complex mixtures have varying turnover times, from days to millennia. The residence times and content of the organic matter are determined by the activities of the microbial communities, and are thus subject to all of the controls mentioned above for the microbes.

The amount of $\mathrm{C}$ fixed into a system is determined by the amount of available nutrients, and the fate of the $\mathrm{C}$ once it has been deposited into the soil is determined by the amount of nutrients. For example, the quality, meaning the amount of nutrients relative to carbon, of litter inputs will determine the decay rates that are driven by microbial nutrient 
demands. This, in turn, determines the amount of "left over" carbon that will be contained within the soil organic carbon pool (Hessen, 2004).

With this in mind, the objectives of this study were (1) to evaluate the use of thermogravimetry (TG/DTG) in a field setting, (2) to utilize stable isotopic data, $\mathrm{C} / \mathrm{N}$ ratios, and elemental data as potential multi-proxy evidence for differentiating "new" carbon from "old" carbon, (3) examine some of the ecosystem processes that govern the amount of carbon sequestered into soil organic matter (decomposition and soil respiration), (4) determine C sequestration rates of "new" (SOM) on reclaimed coal mine sites, and (5) compare these processes and accumulation rates to adjacent natural forests regenerating from logging.

\subsection{MATERIALS AND METHODS}

\subsubsection{Mine Locations and Reclamation Approach}

Four reforested coal mine sites in Kentucky (KY) representing a chronosequence of time since reclaimed were chosen for the study: 0 and 2 years located at Bent Mountain $(\mathrm{n}=4)$, and 3 and (7) 8 years (vegetation and soil initially sampled at age 7, then resampled for soil and C-cycling at age 8) located at the Starfire Mine (n=3). The Bent Mountain mine site is located at Brushy Fork near the community of Meta in Pike County, KY and the Starfire mine is located in eastern Perry County and western Knott County, KY.

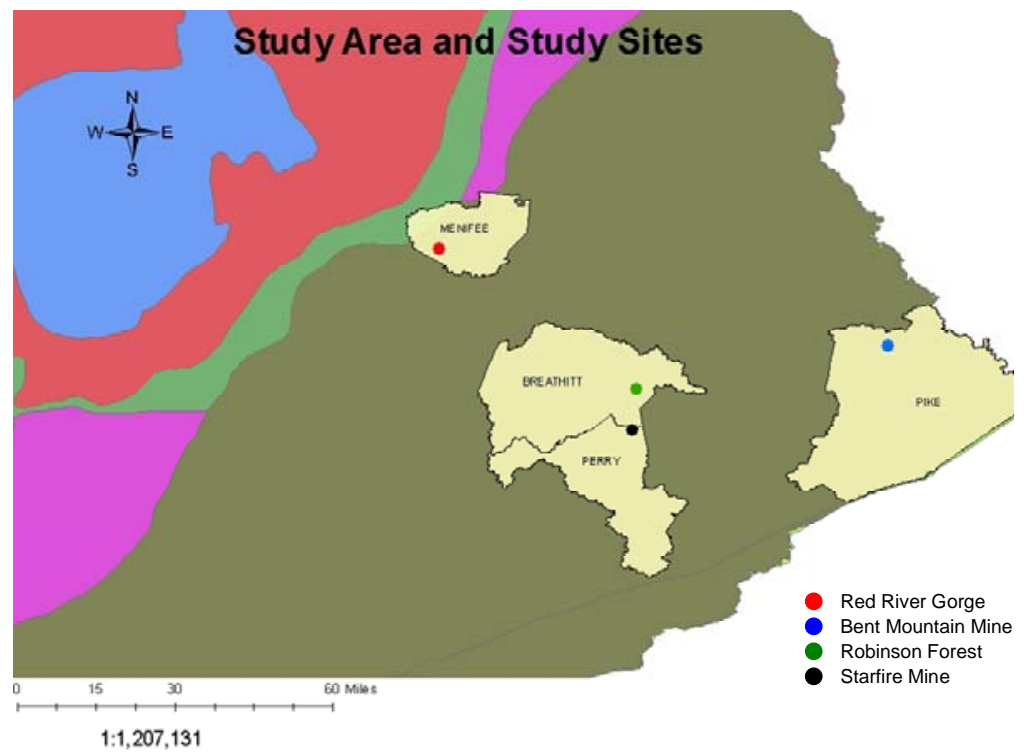

Figure 3.1. Locations of reclaimed coal mines and reference sites in KY used in this study.

University of Kentucky Research Foundation

Final Report - 10/01/03 thru 9/30/06

DE-FC26-02NT41624 
Both sites were mined using mountaintop-removal techniques whereby overburden (rock above the coal seam) is removed and then replaced following the extraction of the coal. Topsoil covering the sites before mining was relatively thin; thus, a mixture of nontoxic, non-acidic shale and sandstones were used as a soil substitute material during reclamation. The soil substitute material was transported to its placement location using rock trucks, where it was dumped and graded using dozers. The sites were then finished using a loose-dumped reclamation technique. To create loose-dumped areas, large earthmoving trucks dumped spoil material on a stabilized site in consecutive piles that tightly abutted each other. The loose-dumped, uncompacted spoil exhibited high surface variation that was extremely rough and characterized by unleveled spoil piles with high tops and low depressions, interspersed with large boulders. The loose-dump technique was chosen because it provided the best conditions for evaluating $\mathrm{C}$ change. The sites are essentially "rock piles" when planted and contain little to no herbaceous vegetation or SOM. As such, $\mathrm{C}$ change can be directly related to tree growth and survival. After finishing, the sites were planted with various hardwood species at a density of approximately 400 trees per hectare. Planted seedlings on these sites exhibited higher growth and survival rates compared to those planted on reclaimed sites using traditional (graded) techniques (Graves et al., 2000; Angel et al., 2006).

\subsubsection{Reference Study Sites}

Most of the reference study sites are located within the University of Kentucky's Robinson Forest (Fig 3.1). Robinson Forest is a 5,983 ha research forest centrally located in the Cumberland Plateau Region. No large scale harvests have occurred on the forest since the early 1900's. However, several small patch cuts $(<5$ ha) and subcatchment harvests ( $<50$ ha) have been performed for research purposes over the last 60 years. Study sites within Robinson Forest include two four yr old upper slope SW facing regenerating clear-cuts; two $12 \mathrm{yr}$ old upper slope SW facing regenerating clear-cuts; and one $20 \mathrm{yr}$ old upper slope SW facing regenerating clear cut. The other $20 \mathrm{yr}$ old upper slope SW facing regenerating clear cut is located in the Red River Gorge. Three $80 \mathrm{yr}$ old upper slope NE 
facing and three $80 \mathrm{yr}$ old upper slope SW facing forests were also evaluated in Robinson Forest to represent a "mature" condition.

\subsubsection{Biomass Harvest}

A whole-tree harvesting method was employed to evaluate carbon accumulation in biomass as a function of time on the mined sites. Trees were extracted from the sites and separated into the following components: foliage, stem, branches, and roots. Biomass estimates of the various components were obtained in the field using a portable analytical scale and a heavy-duty hanging scale. Four tree species (Platanus occidentalis: Sycamore, Fraxinus Americana: White Ash, Quercus alba: White Oak, and Liriodendron tulipifera: Yellow Poplar) representing 3 age classes (2, 3 and 7 years of age) on loose spoil material were examined. The trees were manually and randomly sampled by using a chain saw and shovels (Figure 15). The root collar diameter (RCD), crown height and width, and seedling height were measured prior to harvest. The trees were then subdivided into the 4 tree components and weighed using a portable analytical scale and a heavy-duty hanging scale. Subsamples of each tree component were taken to the laboratory where leaf area, dry weight, and physical and chemical analyses were performed. Samples from each fraction were taken to the laboratory, dried at $50{ }^{\circ} \mathrm{C}$ and re-weighed to obtain moisture content. All samples were subsequently rinsed with deionized water, oven-dried, ground in a mill, and analyzed for total C and total N on the LECO 2000 CHN analyzer. Biomass estimates on a

$\mathrm{kg} \mathrm{ha}^{-1}$ basis were determined using an average biomass value multiplied by survival within a plot of known size and planting density at each location. Dry bulk density was measured at each site using a duel-probe nuclear density probe (Conrad et al., 2002).

\subsubsection{Accumulation Soil Sampling}

Composite soil samples were taken from the upper $10 \mathrm{~cm}$ and sample sites were chosen randomly within forested plots on both the Bent Mountain and Starfire Mine sites in May 2005. It is important to note that samples from the Starfire Mine were taken in proximity to the rhizosphere area of $\mathrm{N}$-fixing black locust (Robinia pseudo-acacia L.) trees which invaded the planted mixed-hardwood species plots. Visible leaves, stems, and roots were removed from the soil samples before air drying. The dried samples were then crushed using a ball mill (SPEX Certiprep 8000 Mixer), sieved $(<1 \mathrm{~mm})$, and mixed to ensure homogeneity. 


\subsubsection{Total Carbon and Nitrogen Content}

Total C (organic and inorganic) and $\mathrm{N}$ contents were determined by dry combustion using a LECO CHN 2000 analyzer. No more than $0.2000 \mathrm{~g}$ of sample was placed in a tin foil capsule and combusted in a resistance furnace at $950{ }^{\circ} \mathrm{C}$ using $\mathrm{O}_{2}$ as a carrier gas. The resulting gases were equilibrated in a ballast chamber followed by infra-red detection for $\mathrm{CO}_{2}$ and $\mathrm{H}_{2} \mathrm{O} . \mathrm{N}_{2}$ was determined by a thermal conductivity detector after reduction of $\mathrm{N}$ oxides and removal of $\mathrm{CO}_{2}$ and $\mathrm{H}_{2} \mathrm{O}$. Calibration curves were validated on a daily basis by using a LECO standard (EDTA- $\mathrm{C}_{10} \mathrm{H}_{16} \mathrm{~N}_{2} \mathrm{O}_{8}$ - LECO Corp.) and quality control assured by running an EDTA standard for every ten samples.

\subsubsection{Organic Carbon Characterization}

Thermogravimetric analysis (TG/DTG) was carried out with a Dupont 951 Thermogravimetric Analyzer using a platinum pan sample holder. Mass changes with incremental temperature increases were evaluated by means of the Thermal Analyst 2000 TA Instrument program. Weight loss was monitored by heating approximately a $10 \mathrm{mg}$ sample from an initial TGA temperature of $25{ }^{\circ} \mathrm{C}$ up to a final temperature of $1000{ }^{\circ} \mathrm{C}$. Optimum results (representative weight loss per sample and the best thermal curve with minimum overlapping of peaks) were obtained using a temperature ramp of $20{ }^{\circ} \mathrm{C} \mathrm{min}{ }^{-1}$

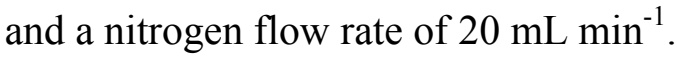

\subsubsection{C/N and Isotopic Ratios}

All samples were ground to a fine powder $(<125 \mu \mathrm{m})$ using a ball mill until they acquired a powder-like consistency. Samples were weighed into 5x9-mm silver capsules (Costech Analytical code 041067) using a Sartorius microbalance. To remove carbonate, each sample was treated repeatedly with $50 \mu \mathrm{L}$ sulfurous acid until all effervescence ceased. This was necessary to remove any carbonates. Analysis of elemental $\mathrm{C}, \mathrm{N}$ and stable $\mathrm{C}$ and $\mathrm{N}$ isotope ratios were determined using a Costech 4010 Elemental Analyzer coupled via a Conflo III device to a Thermo-Finnigan Delta XP Isotope Ratio Mass Spectrometer. Standard deviations for both $\delta^{13} \mathrm{C}$ and $\delta^{15} \mathrm{~N}$ were $0.06 \%$. Standard deviations for $\mathrm{N}$ and $\mathrm{C}$ were $0.04 \%$ and $0.63 \%$, respectively. The stable $\mathrm{C}$ and $\mathrm{N}$ isotope ratios were expressed as $\delta^{13} \mathrm{C}$ and $\delta^{15} \mathrm{~N}$ per mil (\%o) units relative to U.S.G.S. 24 (NIST RM 8541) and IAEA-N1 (NIST RM 8547), respectively. 


\subsubsection{Elemental Analyses}

Elemental analyses were done on an ICP-OES (Varian-Vista-Pro-CCD Simultaneous) after extraction using the $\mathrm{HNO}_{3}-\mathrm{HCl}$ microwave-based digestion method [U.S. Environmental Protection Agency (USEPA), 1996, method 200.2]. Quality assurance-quality control protocols were followed for all analytical procedures as outlined in USEPA (1994) method 6020.

\subsubsection{Cycling Experimental Design}

$\mathrm{CO}_{2}$ respiration, leaf litter decomposition, soil organic matter content, microbial biomass and activity, litterfall and root biomass was measured on a young chronosequence of forests regenerating from logging: 1) four yr old SW facing regenerating clear-cut, 2) 12 yr old SW facing regenerating clear-cut and 3) $20 \mathrm{yr}$ old SW facing regenerating clear cut. All of these sites were replicated twice, making a total of six natural forest sites. The same ecosystem processes and parameters were also measured on a young chronosequence of forests regenerating after mining: 1) $1 \mathrm{yr}$ old reforested surface mine, 2) $3 \mathrm{yr}$ old reforested surface mine and 3) $8 \mathrm{yr}$ old reforested surface mine. All of these sites were replicated twice, making a total of six reforested surface mine sites. $20 \mathrm{~m}^{2}$ plots were installed at each site and contained the following monitoring equipment: 1) leaf litter bags, 2) litter baskets, 3) soil $\mathrm{CO}_{2}$ collars, 4) homogeneous soil plugs, and 5) soil moisture probes (Fig 3.2). Additional sites were added for soil organic matter analysis and microbial biomass and activity. These sites included three $80 \mathrm{yr}$ old NE facing natural forests, three $80 \mathrm{yr}$ old SW facing natural forests, two $2 \mathrm{yr}$ old reclaimed grassland surface mines, and two $8 \mathrm{yr}$ old reclaimed grassland surface mines.

The chronosequence approach "trades space for time" as a way to observe longerterm successional patterns than is possible in most studies. It is important to note that these studies have inherent limitations. For example, site conditions and history are never identical in different locations, and these differences can easily be misinterpreted as change due to age or time (Yanai et al. 2000). One solution is to remeasure sites within a chronosequence over many years (Yanai et al. 2000), and to look for correspondence 
between changes over time within sites and among sites of different ages at any point in time.

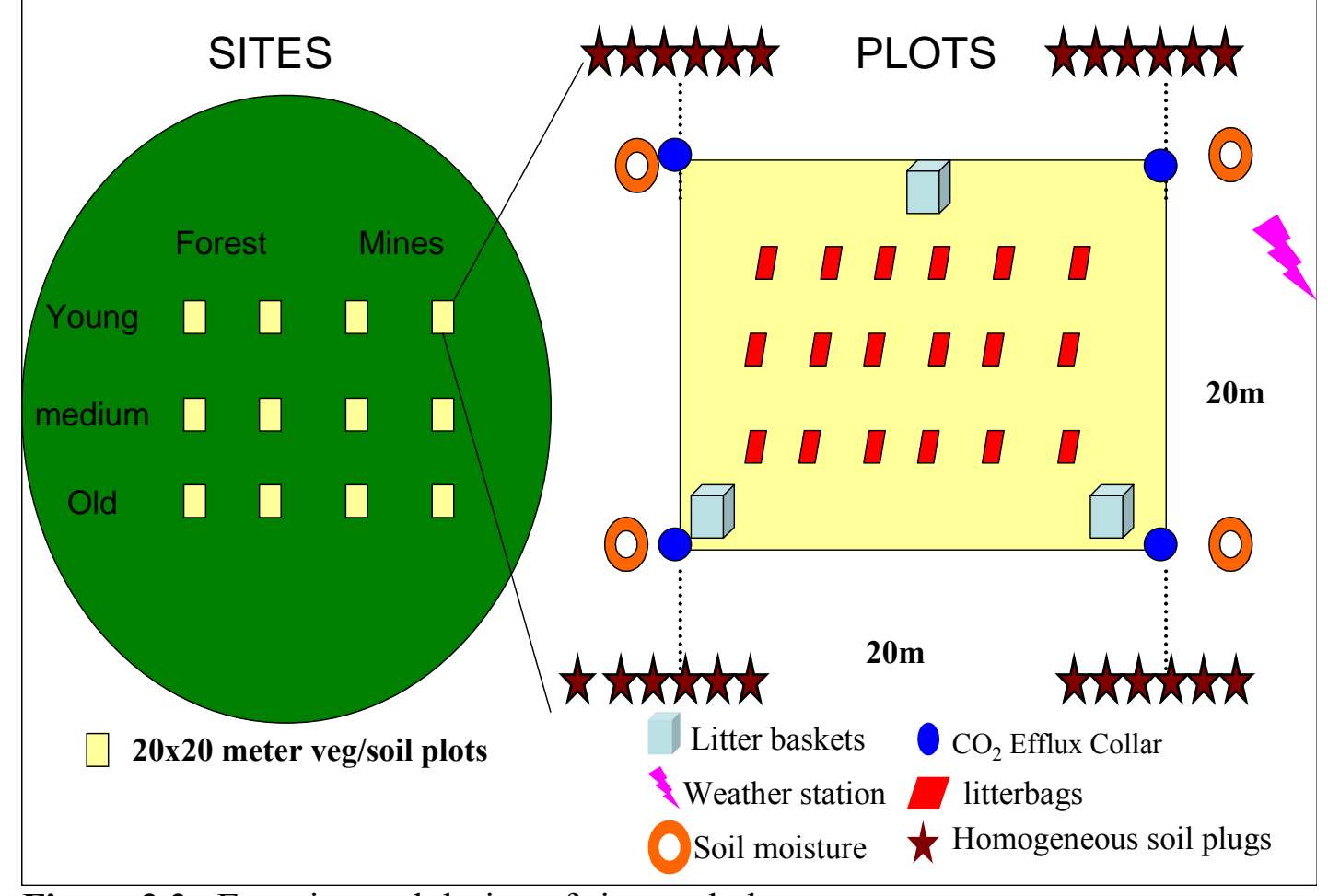

Figure 3.2. Experimental design of sites and plots.

\subsubsection{Decomposition}

Plant litter decomposition was studied using the litter bag approach (Sala et al., 2000). This is a useful technique to analyze differences in decomposition rates. Freshly senesced leaf litter was collected from Robinson Forest and Starfire mine in October 2004. Approximately $10 \mathrm{~g}$ of dried mixed litter, consisting of Platanus occidentalis, Quercus rubra and Acer saccharrum, was placed into $20 \mathrm{~cm}^{2}$ mesh 2-mm bags, sealed with polyester thread and transferred to the field in February 2005. Three bags were collected from each study site every few months for 13 months, totaling 5 collection dates. At each collection date, litter bags were collected, placed in coolers and transferred to the laboratory for analysis. Soil and vegetation was removed from the decomposing litter and bags, and samples were placed in a drying oven at $100^{\circ} \mathrm{C}$ for 24 hours. Once dried, the 
samples were weighed and then ground with a ball mill (SPEX Certriprep 8000 Mixer), followed by mixing to ensure homogeneity. Percent carbon and nitrogen were determined using a LECO $2000 \mathrm{CHN}$ analyzer. Decay constants were calculated using the formula:

$$
\ln \left(\mathrm{X}_{\mathrm{t}} / \mathrm{X}_{0}\right)=-\mathrm{kt}
$$

where $X_{0}$ is the initial mass, $X_{t}$ is the residual litter mass at time $t$ expressed as a proportion of initial dry mass, and $\mathrm{K}$ is the decay constant expressed in days ${ }^{-1}$ (Sala et al., 2000). One-way ANOVA with repeated measures for time were run on samples using SAS.

\subsubsection{Soil Respiration}

Soil respiration was measured every three weeks over the 13-month sampling period using a LICOR 8100 infrared gas analyzer. Soil temperature and moisture was recorded with each $\mathrm{CO}_{2}$ measurement. Soil collars were placed in the four corners of the $20 \mathrm{~m}^{2}$ plots so that approximately 1 inch of the collar remained above the soil. Soil moisture was measured using a $10 \mathrm{~cm} \mathrm{ECH}_{2} \mathrm{O}$ probe, which measures the dielectric constant of the soil in order to find its volumetric water content. Soil temperature was measured by a temperature probe attached to the LICOR 8100 infrared gas analyzer. Once the data was collected, it was analyzed using SAS to perform a one-way ANOVA with repeated measures for time.

\subsubsection{Microbial Activity}

Microbial activity was estimated using the dehydrogenase assay described by Tabatabai et al. (1994). In September 2005, ten composite soil samples were taken from the upper $10 \mathrm{~cm}$ of the soil profile on all 12 natural and mined sites, in addition to the six $80 \mathrm{yr}$ old natural forests (NE and SW facing slopes) and 4 reclaimed grassland surface

mine sites. The samples were chosen randomly on all sites. Samples were immediately placed in a cooler and returned to the lab within two days of collection. Samples were analyzed within 1 week of collection.

$20 \mathrm{~g}$ of air-dried, sieved $(<2 \mathrm{~mm})$ soil from each composite sample was mixed with $0.2 \mathrm{~g} \mathrm{pf} \mathrm{CaCO}_{3}$. A $6 \mathrm{~g}$ sub-sample from this mixture was placed in each of three test tubes where $1 \mathrm{ml}$ of $3 \%$ aqueous solution of 2,3,5-Triphenyltetrazolium chloride (TTC) and 2.5 University of Kentucky Research Foundation 
$\mathrm{ml}$ of distilled water was added. The contents of each tube was mixed with a glass rod, sealed with a stopper, and incubated at $37^{\circ} \mathrm{C}$ for $24 \mathrm{hr}$. After $24 \mathrm{hrs}$, the stopper was removed and $10 \mathrm{ml}$ of methanol was added. The tubes were then shaken for 1 minute and the procedure was repeated two more times. The contents of the test tubes were then filtered through a glass funnel plugged with absorbent cotton. Once the suspension was quantitatively transferred to a flask, concentrations of TPF were determined colorimetrically using a spectrophotometer at a wavelength of $485 \mathrm{~nm}$ with methanol as the blank. The amount of TPF is equivalent to dehydrogenase activity, which is an indicator of microbial activity (Tabatabai et al, 1994). Differences among measurements were analyzed using SAS one-way ANOVA.

\subsubsection{Litterfall}

Three litter baskets were placed on all research sites (Fig 7). Litter was collected in October/November of 2005 , placed in paper bags and oven-dried at $100^{\circ} \mathrm{C}$ for $2-3$ days. Litter was then weighed and ground with a ball mill (SPEX Certriprep 8000 Mixer), followed by mixing to ensure homogeneity. Total carbon and nitrogen were determined using a LECO $2000 \mathrm{CHN}$ analyzer. This resistant furnace works by combusting the sample at $950^{\circ} \mathrm{C}$ using $\mathrm{O}_{2}$ as the carrier. The sample was prepared by weighting no more than $0.2000 \mathrm{~g}$ inside tin foil and followed by combustion. The gases released from combustion are then equilibrated in a ballast chamber before infrared detection of $\mathrm{CO}_{2}$ and $\mathrm{H}_{2} \mathrm{O}$. A thermal conductivity detector is used to determine the amount of $\mathrm{N}_{2}$ after the reduction of oxides and removal of $\mathrm{CO}_{2}$ and $\mathrm{H}_{2} 0$. To ensure accuracy, calibration curves were validated on a daily basis using LECO standard (EDTA-C10H16N2O8 LECO Corp.) and standards were run every 10 samples. Each sample was replicated 3 times and averaged to account for variability. Area of the litter basket was calculated and extrapolated to represent $\mathrm{g} / \mathrm{m}^{2} / \mathrm{yr}$. Differences were evaluated using SAS one-way ANOVA.

\subsubsection{Microbial biomass $C$ and $N$}

Microbial biomass was measured using the chloroform fumigation extraction method (Horwath and Paul, 1994) on composite samples collected in September 2005. For each composite sample, three sub samples were created; one sub sample for determining gravimetric moisture $\left(48\right.$ hours at $\left.100^{\circ} \mathrm{C}\right)$, one non-fumigated sample $(20 \mathrm{~g}$ University of Kentucky Research Foundation

Final Report - 10/01/03 thru 9/30/06

DE-FC26-02NT41624 
oven-dry equivalent) for immediate extraction with $0.5 \mathrm{M} \mathrm{K} \mathrm{K}_{2} \mathrm{SO}_{4}$, and one fumigated sample ( $20 \mathrm{~g}$ oven-dry equivalent). Soil samples that were fumigated were placed in 100 $\mathrm{ml}$ glass beakers and then into vacuum desiccators containing an open beaker with $40 \mathrm{ml}$ of ethanol free chloroform and boiling chips. The desiccators were evacuated until the chloroform boiled followed by venting. This evacuation -venting process was repeated 5 times, yet the last time the chamber was not vented to ensure the chloroform was saturated inside. Both the fumigated sub samples and the non-fumigated sub samples were covered with garbage bags and stored in the dark for 5 days. On the fifth day, the desiccators with the fumigated sub samples were vented. The fumigated and non-fumigated sub samples were then placed in specimen cups, $100 \mathrm{ml}$ of $0.5 \mathrm{M} \mathrm{K}_{2} \mathrm{SO}_{4}$ was added, and the samples were shaken for $1 \mathrm{hr}$. After shaking, the solutions were filtered through Whatman No. 1 filter paper, and the extracts were frozen until further analysis.

Microbial biomass carbon was determined using a Shimatzu TOC/TIC analyzer. The difference between the $\mathrm{C}$ in the fumigated and non-fumigated samples is the chloroform-labile $\mathrm{C}$ pool (EC) and is proportional to microbial biomass $\mathrm{C}(\mathrm{C})$ :

$$
\mathrm{C}=\mathrm{EC} / \mathrm{kEC}
$$

Where $\mathrm{kEC}$ is soil specific, but was estimated as 0.45 (Beck et al, 1997). Microbial biomass $\mathrm{N}$ was measured by digesting $20 \mathrm{ml}$ of extract using Kjeldahl digestion. The digests were then run on an auto analyzer for total $\mathrm{N}$. The difference between $\mathrm{N}$ in the fumigated and non-fumigated samples is the chloroform-labile $\mathrm{N}$ pool, and is proportional to microbial biomass $\mathrm{N}(\mathrm{N})$ :

$\mathrm{N}=\mathrm{EN} / \mathrm{kEN}$

Where kEN is soil specific, but was estimated as 0.54 (Brookes et al, 1985).

\subsection{RESULTS AND DISCUSSION}

\subsubsection{Biomass Harvest}

A chronosequence approach was initiated to evaluate carbon accumulation (biomass and soil) as a function of time on the mined sites. Since the trees planted during this study are only 2 and 3 years of age, older stands within the same planting area that used the same 
reclamation practice were examined to provide information for older sites. This data is used to project a trajectory that the planted areas may follow with respect to $\mathrm{C}$ and biomass accumulation in relation to growth.

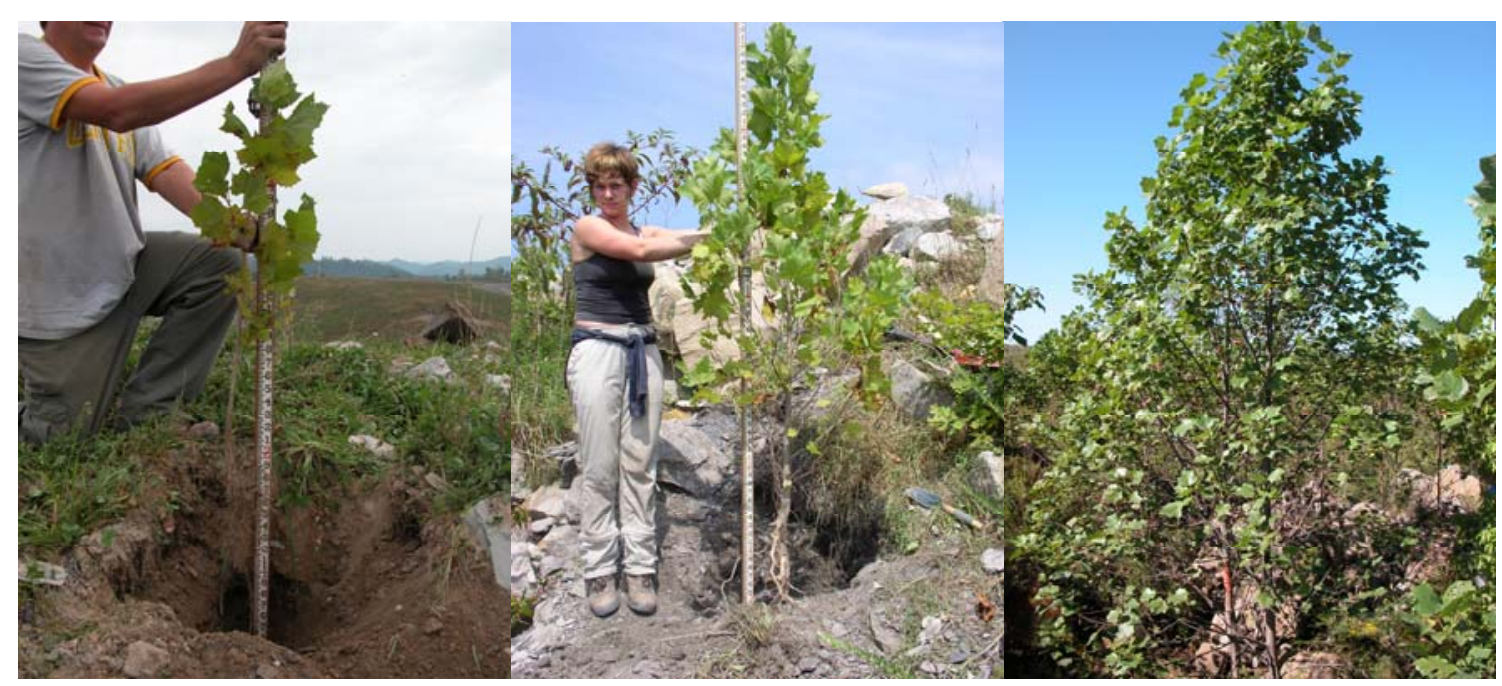
a. Two-year-old Sycamore
b. Three-year-old Sycamore
c. Seven-year-old Sycamore

Figure 3.3. Two (a), three (b), and seven-year-old (c) Sycamore were manually and randomly harvested by using a chain saw and shovels.

Carbon captured in tree biomass, including biomass in the above ground and below ground components was measured by randomly choosing three replicates of each tree species at three age classes (Figure 3.3). The equations developed by Jenkins et al. (2003) were used to compute the root biomass estimates of 7 year trees because its complexity of harvesting. The carbon contents in trees vary with tree age and tree species. The average tree carbon of each tree was $8,571 \mathrm{~kg} \mathrm{ha}^{-1}, 5,590 \mathrm{~kg} \mathrm{ha}^{-1}, 12,300 \mathrm{~kg} \mathrm{ha}^{-1}$, and 25,005 $\mathrm{kg} \mathrm{ha}^{-}$ ${ }^{1}$ for 7 years old White Ash, White Oak, Yellow Poplar, and Sycamore, respectively. The tree carbon content varied between 25 to $90 \mathrm{~kg} \mathrm{ha}^{-1}$ for 2 years old trees, between 514 to $841 \mathrm{~kg} \mathrm{ha}^{-1}$ for 3 years old trees, and between 5,590 to $25,005 \mathrm{~kg} \mathrm{ha}^{-1}$ for 7 years old trees (Figure 3.4). 


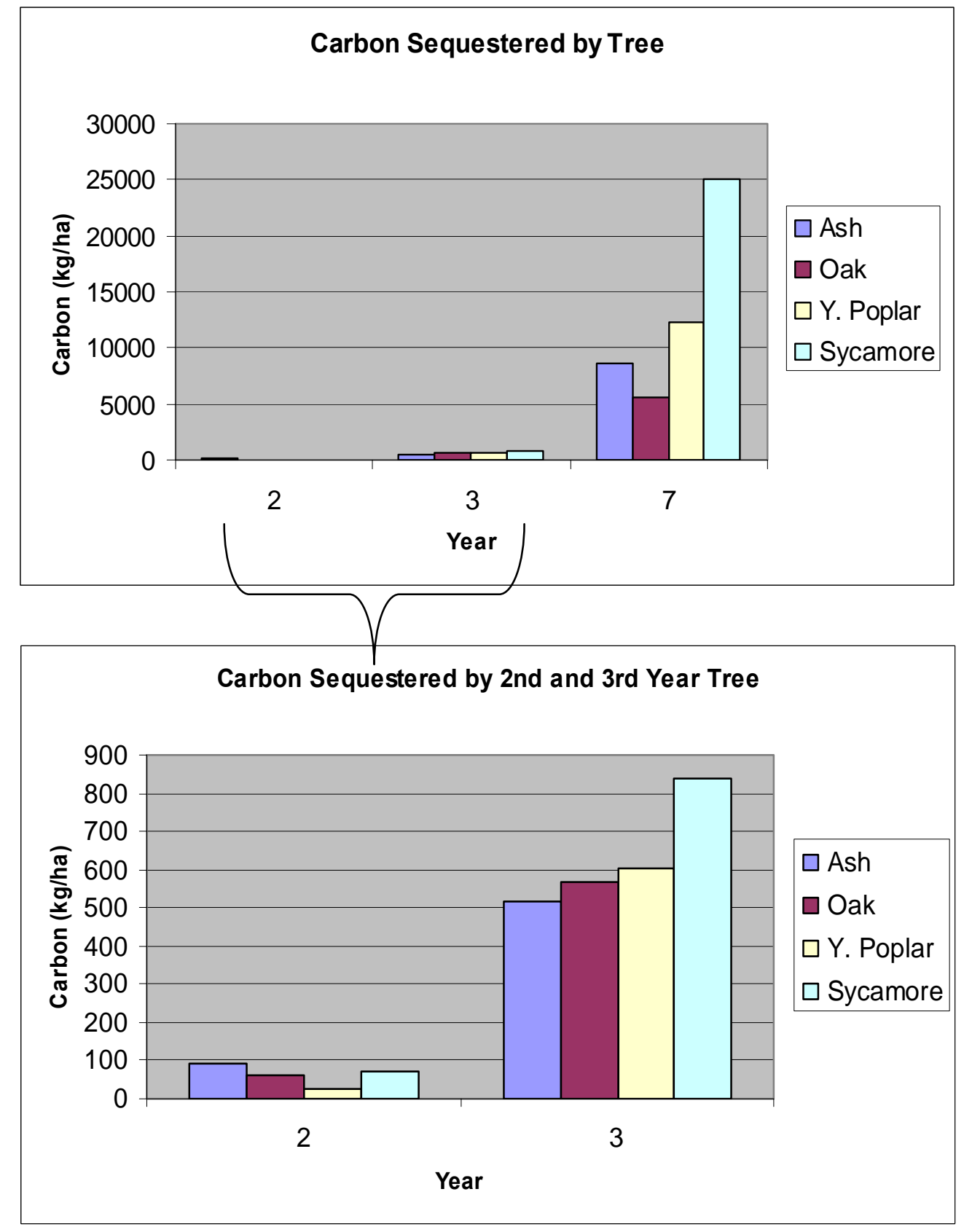

Figure 3.4. Carbon sequestered by four tree species, representing 3 age classes (2, 3, and 7 years) on a loose dump mined site in the Southern Appalachian Coalfield region.

The amount of carbon in the rhizosphere soils ranged from 4,958 to $15,127 \mathrm{~kg} \mathrm{ha}^{-1}$ (2 years old), ranged from 16,203 to $21,744 \mathrm{~kg} \mathrm{ha}^{-1}$ (3 years old), and ranged from 28,259 to $41,921 \mathrm{~kg} \mathrm{ha}^{-1}$ (7 years old) (Figure 3.5). Johnson and Todd (1998) reported that forests regenerating following whole-tree harvesting in eastern Tennessee added $26,000 \mathrm{Mg} \mathrm{C} \mathrm{ha}^{-1}$ to above ground biomass and $27,000 \mathrm{Mg} \mathrm{C}^{-1}$ to mineral soil reserves during 15 years. A University of Kentucky Research Foundation Final Report - 10/01/03 thru 9/30/06 DE-FC26-02NT41624 
century-old reference forest at the same site added 60 and $12 \mathrm{Mg} \mathrm{C}^{-1}$ to forest biomass and soil during the same period. Our mined site average soil carbon for 7 years old trees was comparable to that of Johnson and Todd (1998) sites and indicated that our reforestation of the mined sites has tremendous potential to sequester carbon. Carbon accumulation rate increased by 750 to $5,028 \mathrm{~kg} \mathrm{ha}^{-1} \mathrm{yr}^{-1}, 4,842$ to $9,685 \mathrm{~kg} \mathrm{ha}^{-1} \mathrm{yr}^{-1}, 4,825$ to $17,363 \mathrm{~kg} \mathrm{ha}^{-1} \mathrm{yr}^{-1}$, and 2,744 to $9,888 \mathrm{~kg} \mathrm{ha}^{-1} \mathrm{yr}^{-1}$ for White Ash, White Oak, Yellow Poplar, and Sycamore, respectively (Figure 3.6).

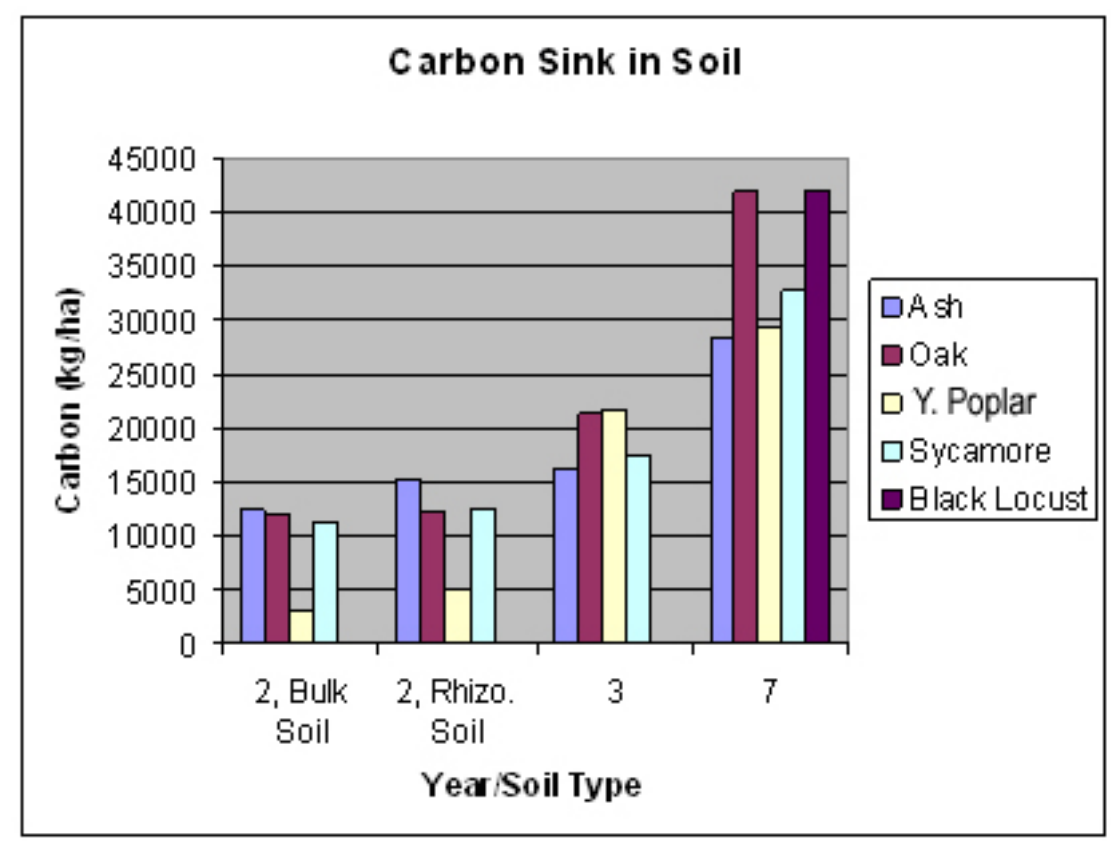

Figure 3.5. Soil carbon sequestered on mined study sites. Rhizosphere soils were presented for 3 and 7 years old trees. 


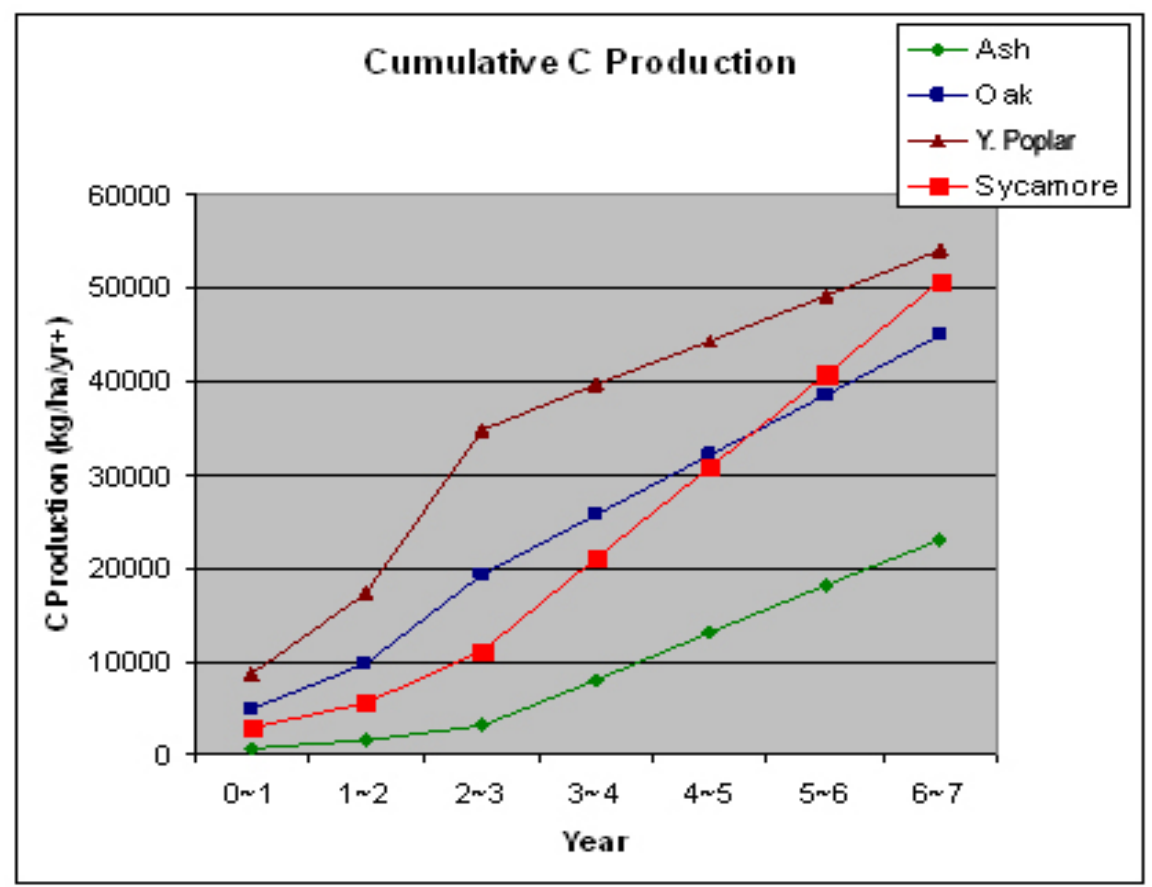

Figure 3.6. Cumulative carbon sequestered by tree and soil on study mined sites.

\subsubsection{Litterfall}

Transfer of carbon from plants to soil occurs via litter/detritus, root turnover, or root exudates (Bertin, 2003; Bowden, 1993). Within the young reforested surface mines (age 13), litter inputs are minimal (7.1(7) and 18.7(7) g/m $/ 2 / y r$, respectively). As these forests age and the canopy begins to close, litter inputs increase twelve fold (189.3(17) $\mathrm{g} / \mathrm{m}^{2} / \mathrm{yr}$ ). However, litterfall amounts are still much less than natural forests regenerating from timber harvest. On the natural forest sites, litterfall also increases with stand age (age 4, 12 and 20 ), with litterfall amounts ranging from 309(21), 347.2(18), and 468.4(72) $\mathrm{g} / \mathrm{m}^{2} / \mathrm{yr}$, respectively.

\subsubsection{Carbon Efflux: Soil Respiration, Microbes, and Decomposition}

Cumulative yearly soil carbon respiration rates differed greatly among the young reforested mine sites and the natural forests (Figure 3.7). In the older reforested mine site; however, there was no significant difference of cumulative yearly carbon efflux from the natural forests (Figure 3.7). There was also no significant difference among different aged natural forests in regards to cumulative yearly carbon efflux (Figure 3.7). The similarities 
of soil respiration between younger natural forests (age 4-20) and the older reforested mine sites (age 8) may suggest that soil biotic conditions are similar.

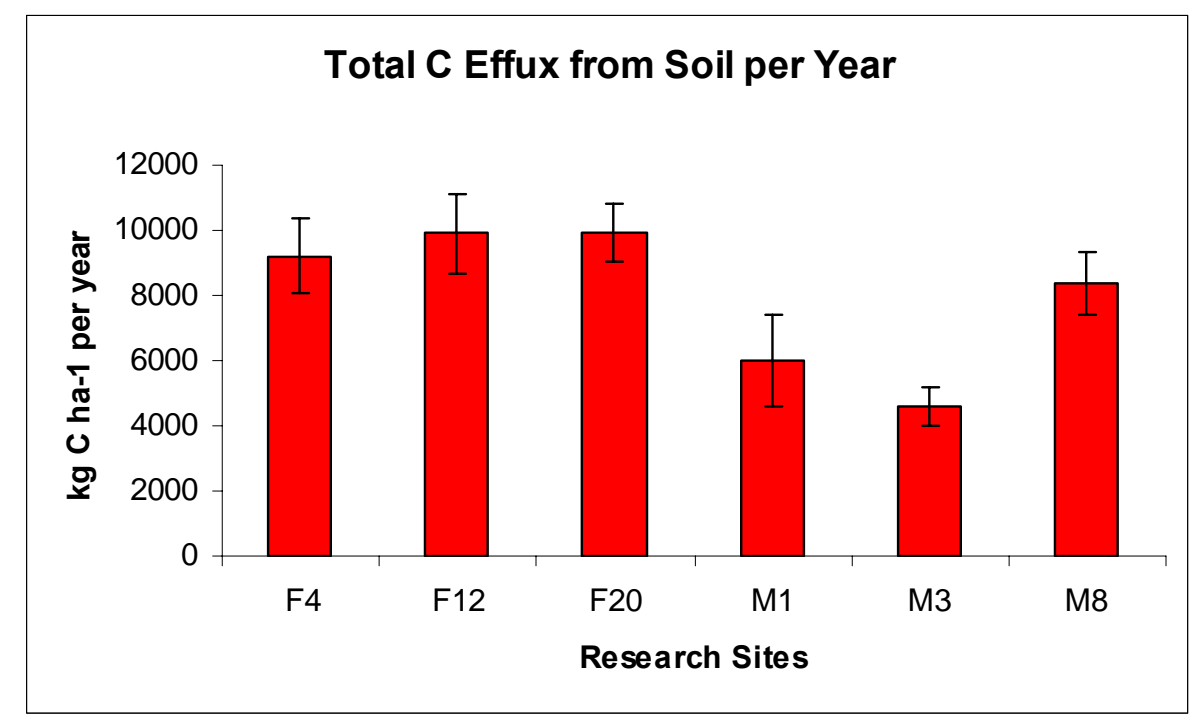

Figure 3.7. Average $\mathrm{C}$ efflux from soil for the year $2005 \mathrm{in} \mathrm{kg} \mathrm{C} / \mathrm{ha} / \mathrm{yr}$. F indicates forests regenerating after logging and $\mathrm{M}$ indicates forests regenerating after mining. The numbers following $\mathrm{F}$ and $\mathrm{M}$ indicate the age of the stand. Error bars indicate standard error.

Originally, we thought that on the mined sites, there was a greater proportion of root respiration than microbial respiration because microbial populations were thought to be depleted on these drastically disturbed sites. This is true for the younger reforested mine sites (age 1 and 3), which show very little dehydrogenase activity, an indicator of microbial activity (Figure 3.8). However, dehydrogenase activity appears to be similar among the older reforested mine sites and all of the natural forest sites except for F4. Microbial biomass nitrogen is also similar among the older reforested mine site and some of the natural forest sites (F12 and F20) (Figure 3.9). While microbial activity and biomass nitrogen appear to be similar, microbial biomass carbon still has not recovered to the natural forest amount (Figure 3.9). 


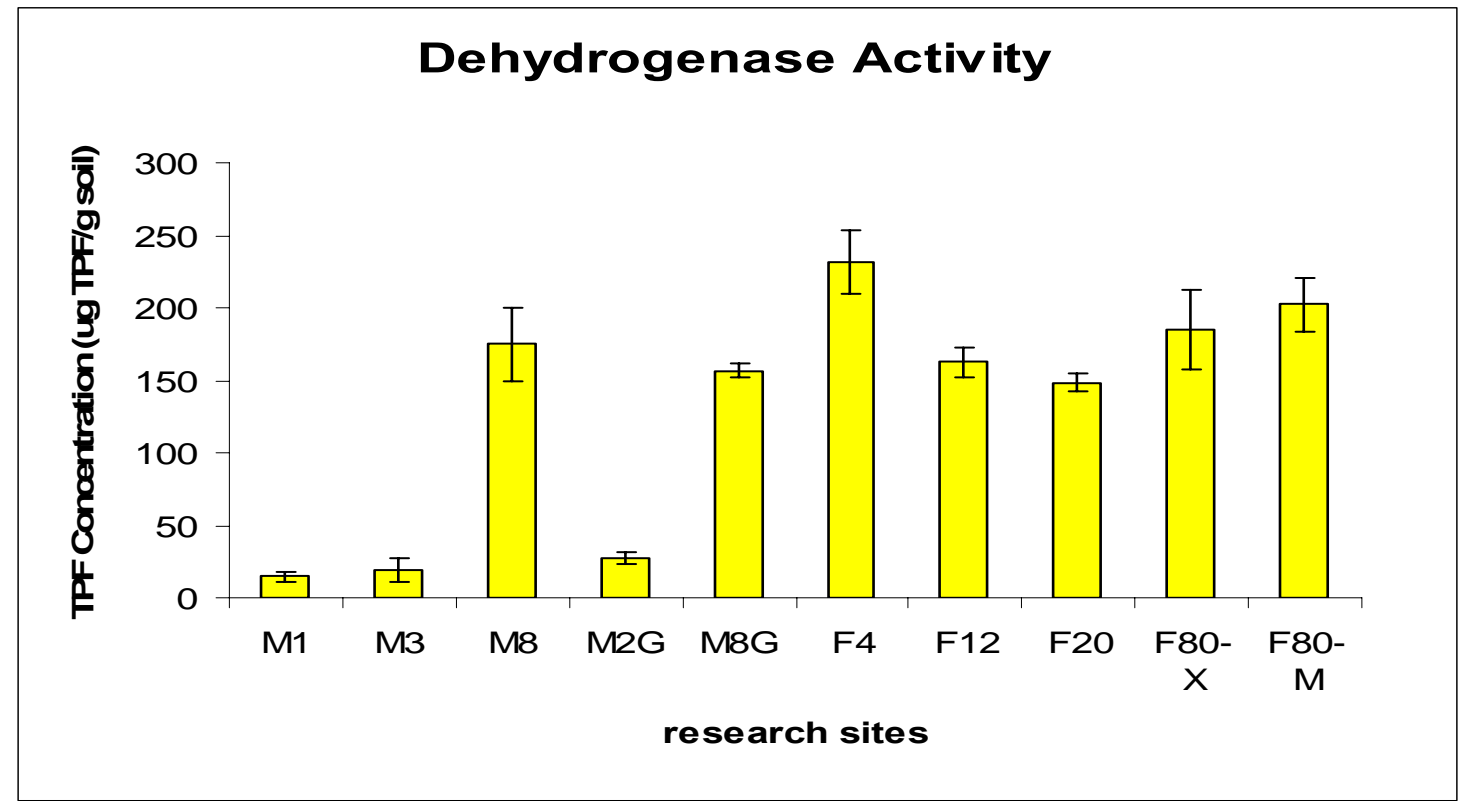

Figure 3.8. Dehydrogenase Activity in top $10 \mathrm{~cm}$ of soil collected in fall 2005. Results are reported in ug TPF/g soil. F indicates forests regenerating after logging and $\mathrm{M}$ indicates forests regenerating after mining. The numbers following $\mathrm{F}$ and $\mathrm{M}$ indicate the age of the stand. $\mathrm{M} 2 \mathrm{G}$ and $\mathrm{M} 8 \mathrm{G}$ are reclaimed grassland mine sites and F80-X and F80-M are 80 year old forests that are either xeric (SW facing) or mesic (NE facing). Error bars indicate standard error. 


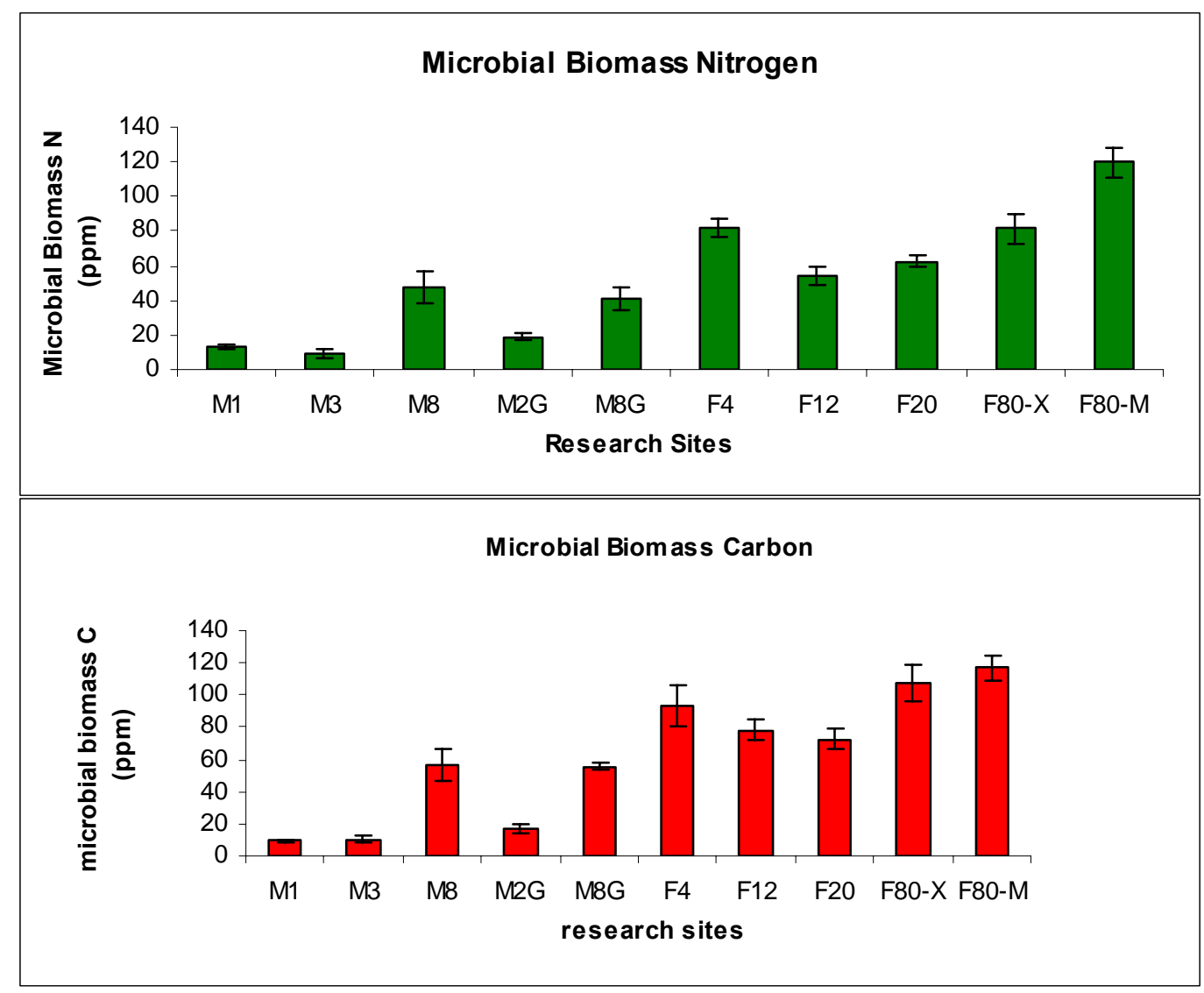

Figure 3.9. Microbial Biomass $\mathrm{C}$ and $\mathrm{N}$ data from the top $10 \mathrm{~cm}$ of soils collected in the fall 2005. Results reported in ppm. F indicates forests regenerating after logging and $\mathrm{M}$ indicates forests regenerating after mining. The numbers following $\mathrm{F}$ and $\mathrm{M}$ indicate the age of the stand. M2G and M8G are reclaimed grassland mine sites and F80-X and F80-M are 80 year old forests that are either xeric (SW facing) or mesic (NE facing). Error bars indicate standard error.

While respiration rates for the younger reforested mine sites are significantly lower than all other sites, the rates are still higher than expected for having such minimal microbial activity. Since these sites were hydroseeded with grasses, in addition to native hardwood trees, there is most likely an increased abundance of fine root production. Fine roots have been shown to respire more than course roots. Jackson et al. (1997) estimated that $33 \%$ of NEP is used for the production of fine roots due to increased surface area. However, some studies have shown that fine root production in some forest and prairie ecosystems could account for $75 \%$ of total NPP (Nadelhoffer and Raich, 1992). It has also been shown that fine root production was higher in pastures than forests in the Appalachian 
region, and $\mathrm{CO}_{2}$ respiration rates were only slightly lower in pastures than in forests (10.9 $\mathrm{Mg} \mathrm{C} /$ ha and 12.6 Mg C/ha respectively) (Bolstad 2005).

Other explanations of higher than expected rates are a longer growing season for these younger sites due to increased solar radiation. For the younger mine sites, $\mathrm{CO}_{2}$ efflux peaks later in the season (September) whereas the natural forest sites and the older reforested mine sites show a $\mathrm{CO}_{2}$ efflux peak in July (Figure 3.10). Soil temperature is much higher on these sites, and the soil stays warmer later in the season (Figure 3.10). Another possible reason for higher than expected respiration rates is the nature of the soil environment. Large boulders are interdispersed with fragmented rock and dirt in these reclaimed areas. Trees and grasses can only grow in small areas between the large boulders. Measurements could be skewed because of a higher concentration of $\mathrm{CO}_{2}$ effluxing out of areas not blocked by large rocks. 

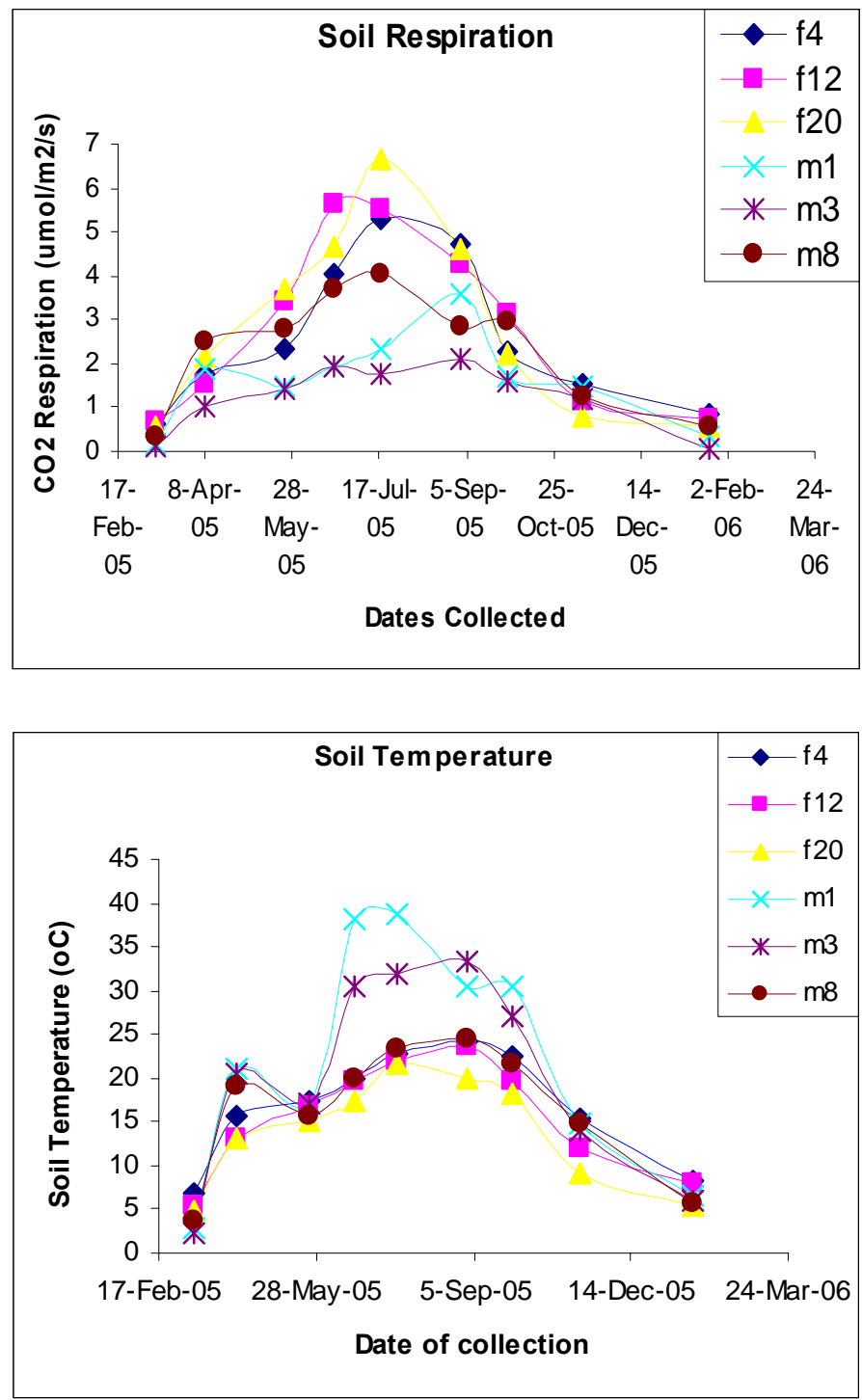

Figure 3.10. Soil Respiration and Soil Temperature taken every 3 weeks over the course of $2005 / 2006$. Soil Respiration results are reported in umole/m2/s and soil T is reported in ${ }^{0} \mathrm{C}$. $\mathrm{F}$ indicates forests regenerating after logging and $\mathrm{M}$ indicates forests regenerating after mining. The numbers following $\mathrm{F}$ and $\mathrm{M}$ indicate the age of the stand.

Decomposition rates of mixed leaf litter were significantly lower between younger reforested mine sites and all other sites (Figure 3.11). The older reforested mine sites had decomposition rates that were similar to the 12 year old natural forest, and the four and 20 year old natural forests had the highest decomposition rates (Figure 3.11). While the younger reforested mine sites had lower rates than all other sites, decomposition still University of Kentucky Research Foundation

Final Report - 10/01/03 thru 9/30/06

DE-FC26-02NT41624 
occurred at a rate higher than what we expected. Microbial activity was minimal on these sites, as shown by the dehydrogenase activity results (Figure 3.8). As a result, decomposition on these sites must be occurring mainly through abiotic processes. These sites do receive a significantly higher amount of solar radiation and are subject to harsher rain conditions (Figure 3.10). This would increase fragmentation and leaching of chemicals from leaves in the summer months when these abiotic conditions are at their extremes. Decomposition rates for these younger reforested mine sites were at their maximum in the summer months (Figure 3.12). Vossbrinck et al. (1979) found that litter with inhibited microbial activity (saturated with copper sulfate and mercuric chloride) decomposed faster than litter with microbial activity for the first few months. After two months, litter with microbial activity began to decompose at a faster rate. The mass loss of litter decomposing solely through abiotic conditions was attributed to increased leaching losses.

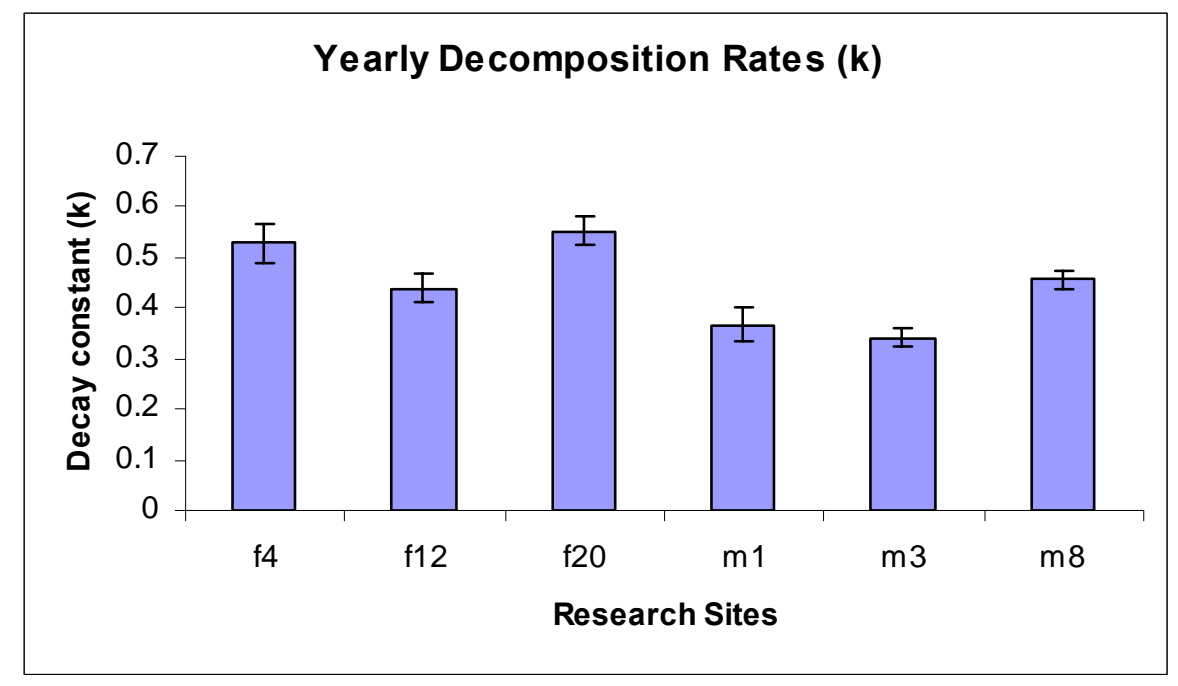

Figure 3.11. Decomposition rates for mixed oak-maple-sycamore leaf litter in 2005.

Decay constants were calculated using the equation - (ln (\%Mass Remaining)/ (100))/ ( $\mathrm{t})$ in years). Error bars indicate standard error. 


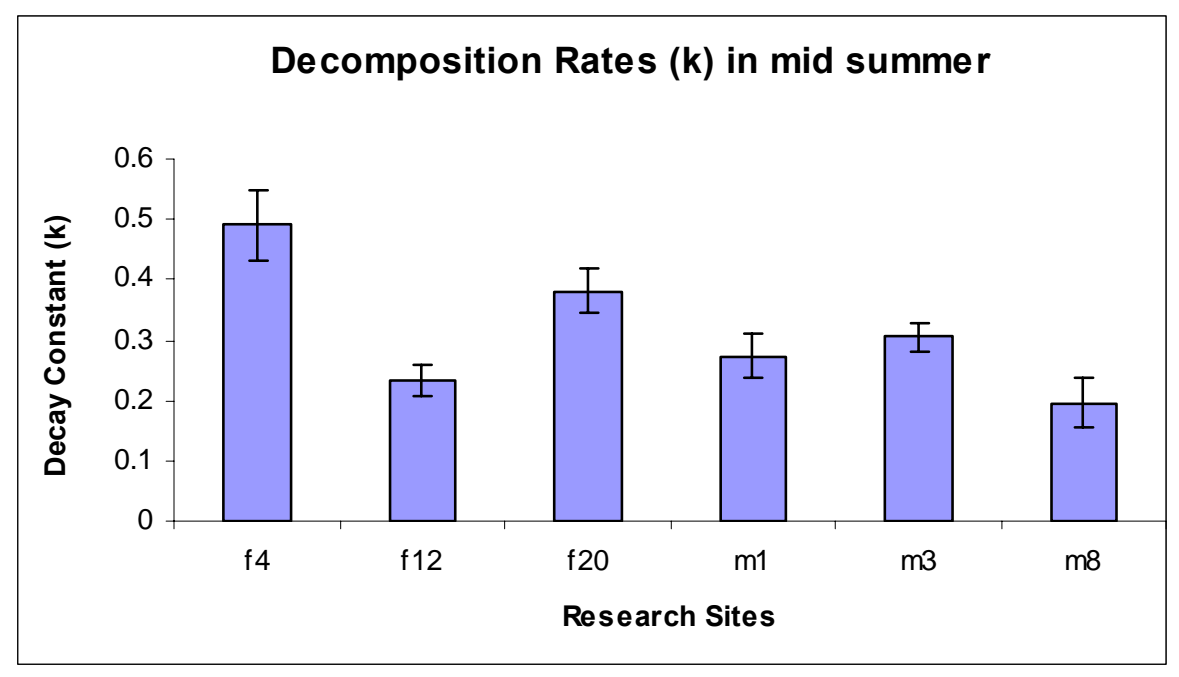

Figure 3.12. Decomposition rates for mixed oak-maple-sycamore leaf litter for summer 2005. Decay constants were calculated using the equation - (ln (\%Mass Remaining)/ $(100)) /(t)$ in years). Error bars indicate standard error.

Nitrogen content of decomposing mixed leaf litter increased over the duration of 2005 on all sites (Figure 3.13). Nitrogen enrichment of litter followed the same trend as decomposition rates, with the older aged natural forest having the most nitrogen enrichment and the younger reforested mine sites having the least amount of nitrogen enrichment (Figure 3.13). Most of the increased nitrogen can be attributed to microbial immobilization. However, since the younger mine sites show an increase in nitrogen, and have minimal microbial biomass $\mathrm{N}$, other inputs of nitrogen must be involved. $\mathrm{C} / \mathrm{N}$ ratios of decomposing litter also follow the same trend as decomposition rates and nitrogen enrichment (Figure 3.14). 


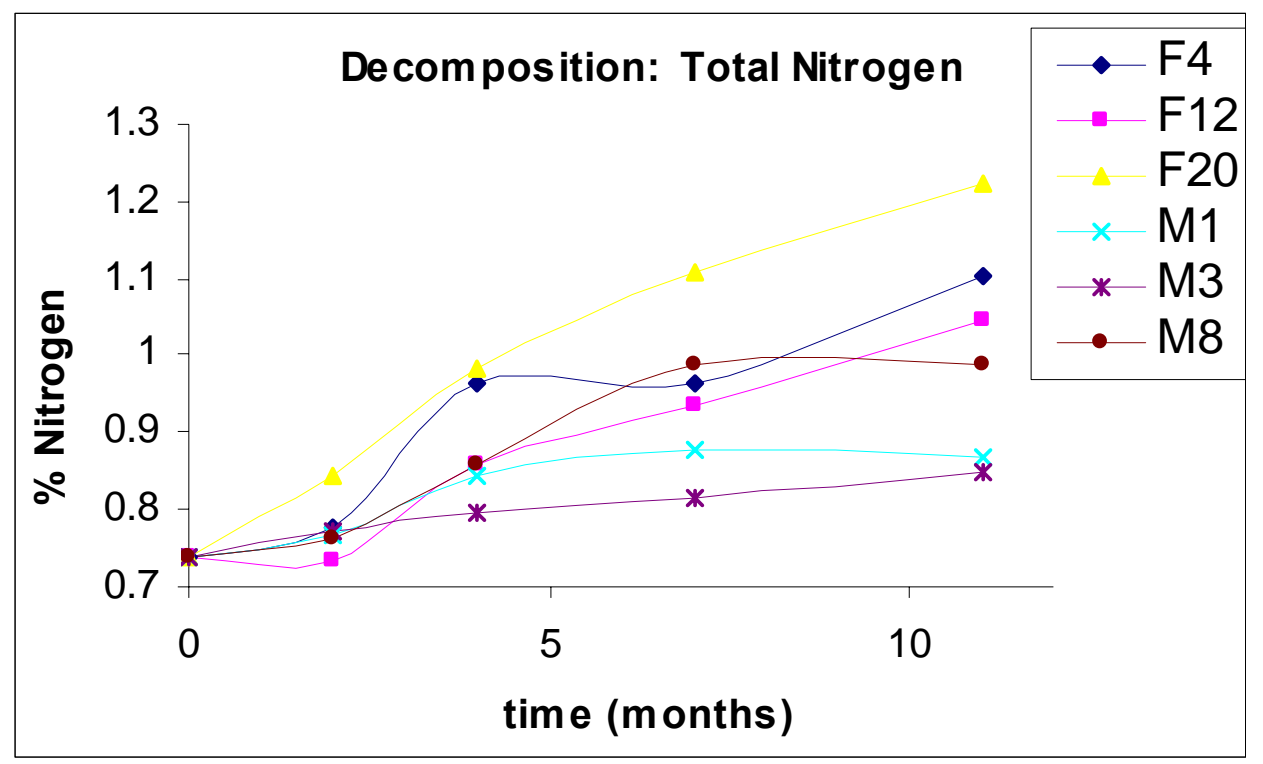

Figure 3.13. Percent nitrogen of decomposing litter over 2005. F indicates forests regenerating after logging and $\mathrm{M}$ indicates forests regenerating after mining. The numbers following $\mathrm{F}$ and $\mathrm{M}$ indicate the age of the stand.

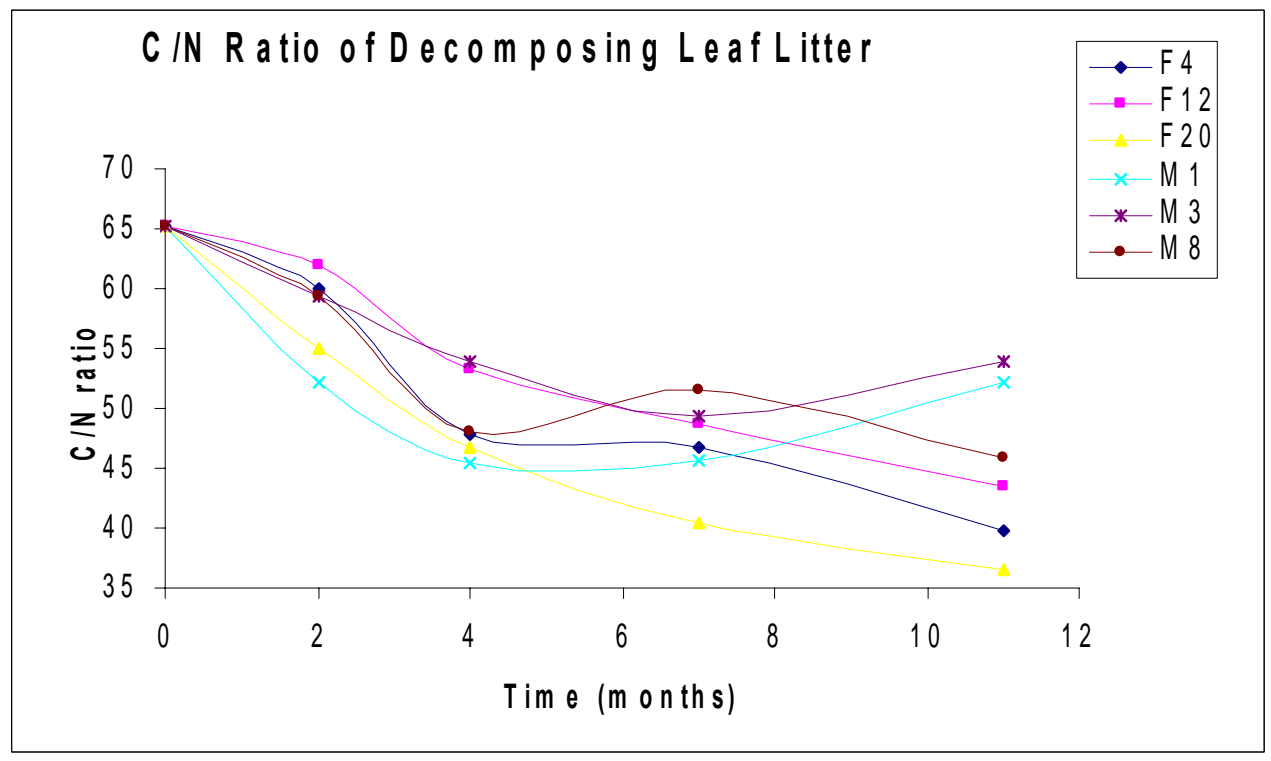

Figure 3.14. $\mathrm{C} / \mathrm{N}$ ratio of decomposing litter over 2005. $\mathrm{F}$ indicates forests regenerating after logging and $\mathrm{M}$ indicates forests regenerating after mining. The numbers following $\mathrm{F}$ and $\mathrm{M}$ indicate the age of the stand. 


\subsubsection{Isotopic Ratios and Elemental Analyses}

Carbon isotopic results from laboratory standards indicated that $\delta^{13} \mathrm{C}$ was more enriched in the limestone sample than in the litter (-3.23 vs. $-27.73 \%$, respectively) as well as being more enriched than cellulose and lignin (Table 3.1). Results also indicated that the $\delta^{13} \mathrm{C}$ for lignin was more depleted than cellulose and litter. Similar trends were reported by Kelly et al. (1998) and Francioso et al. (2005).

Table 3.1. $\mathrm{C} / \mathrm{N}$ and $\mathrm{C}$ isotope values for standard samples. All samples were treated with sulfurous acid to remove carbonates before analysis.

\begin{tabular}{|l|c|ccc|}
\hline Sample & $\mathbf{\%} \mathbf{N}_{\text {corr }}$ & $\mathbf{~} \mathbf{o}_{\text {corr }}$ & $\mathbf{C} / \mathbf{N}_{\text {atomic }}$ & $\mathbf{\delta}^{\mathbf{1 3}} \mathbf{C}_{\text {corr }}(\mathbf{\% o})$ \\
\hline Coal & 1.54 & 75.32 & 56.87 & -24.79 \\
Litter & 1.92 & 42.33 & 25.73 & -27.73 \\
Cellulose & 0.13 & 9.36 & 81.37 & -3.23 \\
Lignin & 0.09 & 43.24 & 550.94 & -25.14 \\
& 0.04 & 6.00 & 163.24 & -28.32 \\
\hline
\end{tabular}

Isotopic results for field samples showed a gradual depletion in $\delta^{13} \mathrm{C}$ values over time, with values becoming more negative between the 0 -year to the 80 -year sites (Figure 3.15). This may indicate an increased contribution from $\mathrm{C}_{3}$ plants as forest communities developed (mean $\delta^{13} \mathrm{C}=-27 \%$ ). In addition, the enriched $\delta^{13} \mathrm{C}$ value at the 0 -year site may indicate a greater concentration of parent carbonate material. 


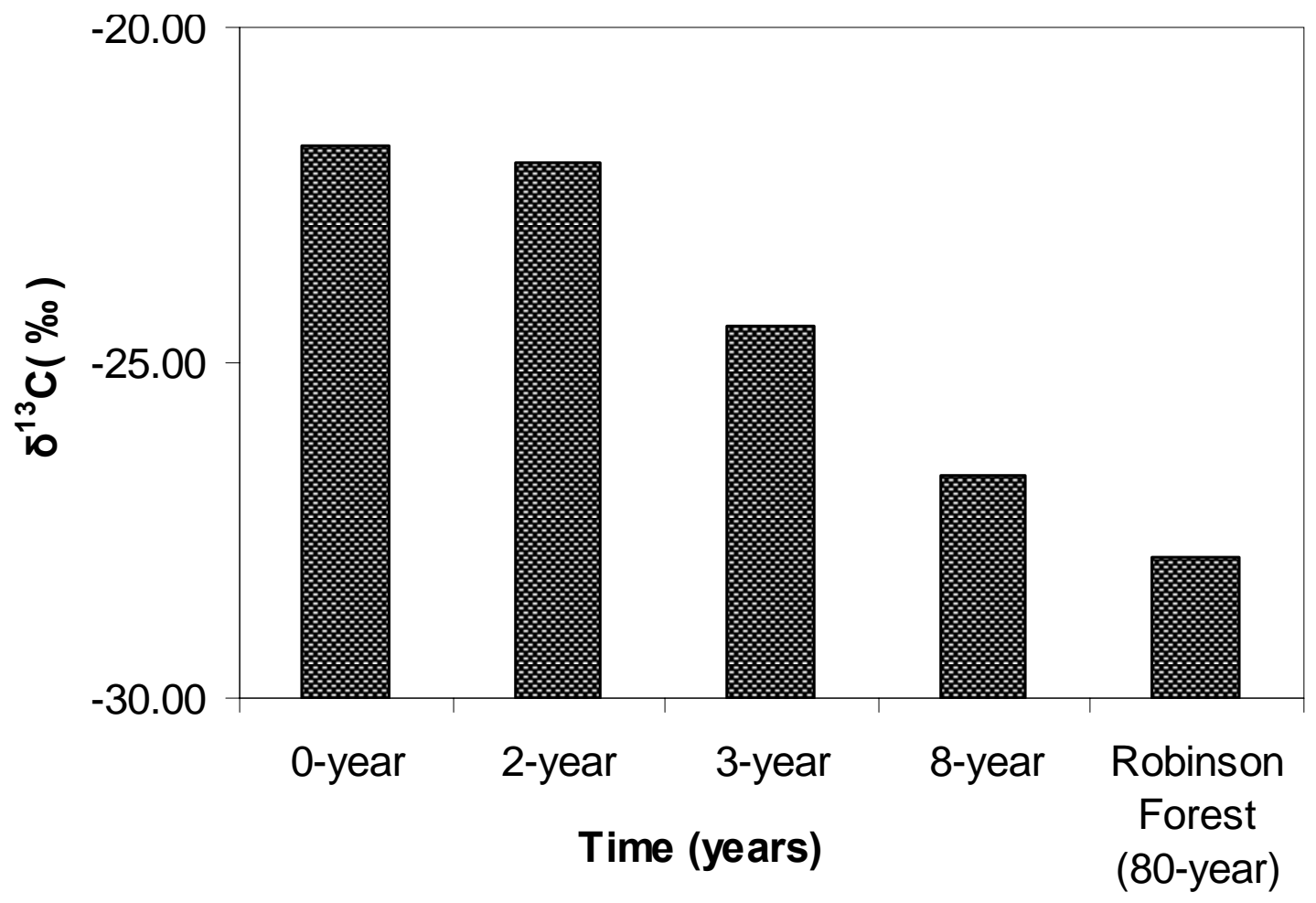

Figure 3.15. Variation of $\delta^{13} \mathrm{C}$ with age of reclaimed coal mine sites.

Evidence of higher carbonate parent material at the 0 -year site and subsequent decreasing carbonate fraction over time is indicated by a decrease in $\mathrm{Ca}$ and $\mathrm{Mg}$ concentrations (Figure 3.16). As the trees grow on these plots, increased root production allows for increased water infiltration and physical weathering of parent material. In addition, the combined respiratory activities of roots and microorganisms result in $\mathrm{CO}_{2}$ production in the rhizosphere which dissolves in the soil water to form carbonic acid. This process could increase the solubility of primary minerals, such as $\mathrm{Mg}$ and $\mathrm{Ca}$, and enhance nutrient availability to plants as well as leaching (Waring and Schlesinger, 1985). 


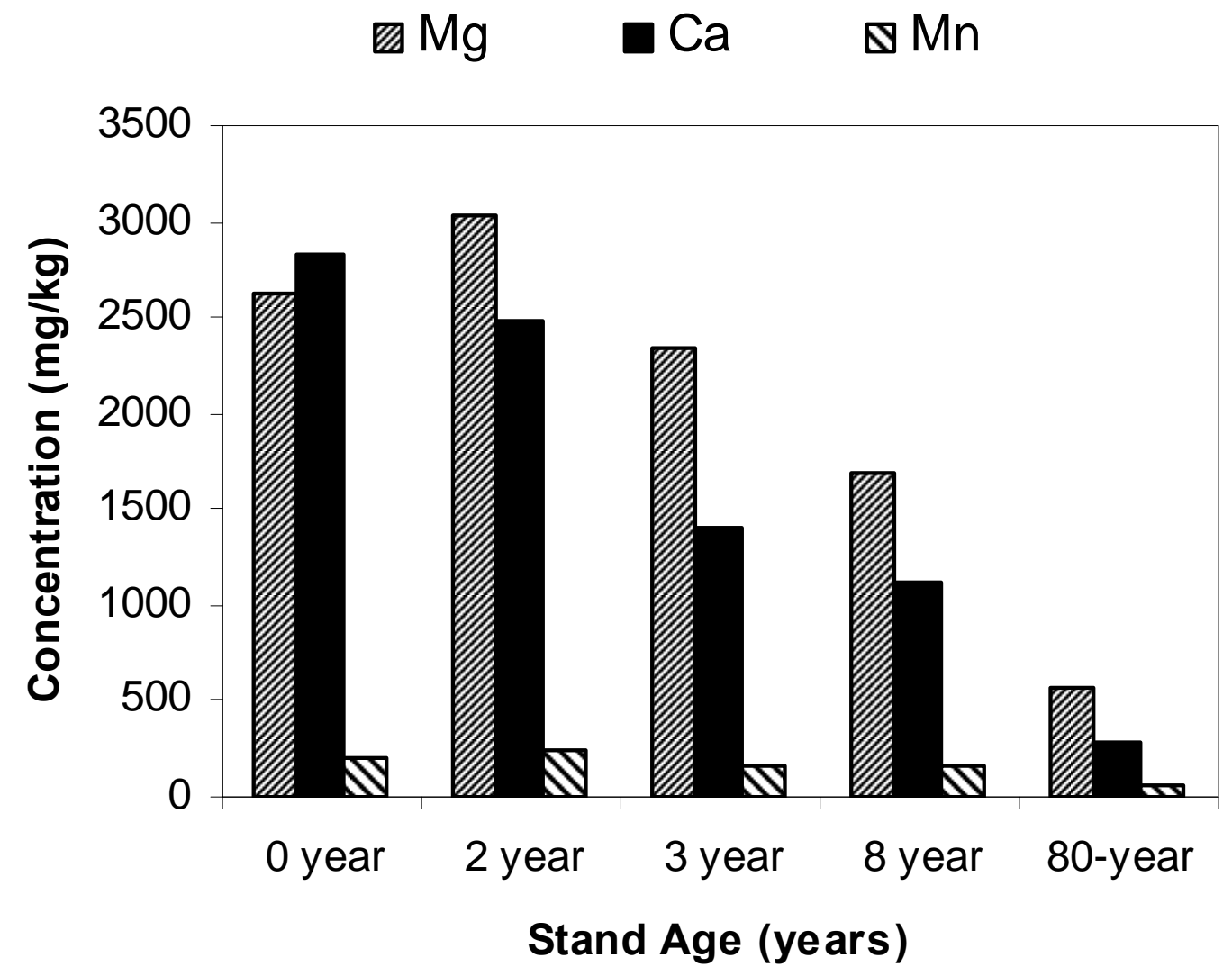

Figure 3.16. Variation of $\mathrm{Ca}, \mathrm{Mg}$, and $\mathrm{Mn}$ concentrations over time for samples from reclaimed coal mine sites, Bent Mountain (0 and 2-year) and Starfire Mine (3 and 8-year). 80-year Robinson Forest is the reference site.

The newly placed spoil material on the 0 -year site is characterized by extremely low $\mathrm{N}$ values $(0.02 \%)$. Similar results on minesoils were reported by Jencks et al. (1982). There is a general increase in total nitrogen $(\mathrm{N})$ between the 0 -year to the 80 -year sites $(0.02$ to $0.34 \%$ ). During $\mathrm{N}$ turnover reactions in soil, ${ }^{14} \mathrm{~N}$ is preferentially lost into the atmosphere compared to ${ }^{15} \mathrm{~N}$, creating a natural ${ }^{15} \mathrm{~N}$ enrichment of soil $\mathrm{N}$ relative to atmospheric $\mathrm{N}_{2}$ (Weaver and Danso, 1994).

Results showed an enrichment of $\delta^{15} \mathrm{~N}(-0.02$ to $1.97 \%$ ) between the 0 -year to the 3 -year site (Table 3.2) however, there is a dramatic decrease in $\delta^{15} \mathrm{~N}$ (from 1.97 to $0.17 \%$ ) values between the 3-year to 8-year sites. The initial enrichment in $\delta^{15} \mathrm{~N}$ between the 0 -year and 3-year sites could be due to nominal microbial nitrogen biomass (Figure 3.9), little decomposition, and minimal root development. However, microbial biomass concentrations increased from the 3-year to the 8 -year site $\left(9.3 \pm 2.6 \mathrm{~N} \mathrm{mg} \mathrm{kg}^{-1}\right.$ to $47.8 \pm$ University of Kentucky Research Foundation 89 Final Report - 10/01/03 thru 9/30/06 DE-FC26-02NT41624 
4.2 $\mathrm{N} \mathrm{mg} \mathrm{kg}^{-1}$ ) (Figure 3.9). Decomposition rates would have also increased leaving humic material rich in $\mathrm{N}$-groups (such as amino acids). But, because the 3 and 8 -year samples were collected from rhizosphere areas in close proximity to black locusts (leguminous, $\mathrm{N}_{2-}$ fixing trees), this could have resulted in an increase in microbial $\mathrm{N}$-fixation over the same time period resulting in an overall depletion in $\delta^{15} \mathrm{~N}$. Previous researchers have found that nitrogen-fixing terrestrial plants have more negative isotopic compositions than non- $\mathrm{N}_{2}$ fixers resulting from microbial nitrogen fixation (Fogel and Cifuentes, 1993; Krull and Skjemstad, 2003; Muzuka and Shunula, 2006).

The $\mathrm{C} / \mathrm{N}$ ratio increased between the 0 -year and 3-year sites (21.0 to 34.7). This increase could be due to fine root turnover, windblown material, as well as contribution from parent carbonate materials since, at this stage, the soil development is minimal as it is still dominated by the spoil material. There was also a 3-fold increase in $\% \mathrm{~N}$ between the 3 -year to the 8-year site (Table 3.2). This may have resulted from humic material rich in $\mathrm{N}$ groups as decomposition increased over time. Further support for this decrease in $\mathrm{C} / \mathrm{N}$ ratios was indicated by previous work which found that areas dominated by black locust had high $\mathrm{N}$ inputs from symbiotic $\mathrm{N}_{2}$ fixation and high $\mathrm{N}$ content. Nitrification rates were also found to be high in black-locust soil (Jencks et al., 1982; Vimmerstedt et al., 1989; Montagnini et al., 1991).

Table 3.2. $\mathrm{C} / \mathrm{N}$ and $\mathrm{C}$ and $\mathrm{N}$ isotopes values for field samples. All samples were treated with sulfurous acid to remove carbonates before analysis.

\begin{tabular}{|c|c|c|c|c|c|}
\hline Sample & $\% \mathrm{~N}_{\text {corr }}$ & $\% \mathrm{C}_{\text {corr }}$ & $\mathrm{C} / \mathbf{N}_{\text {atomic }}$ & $\delta^{15} \mathrm{~N}_{\text {corr }}(\%)$ & $\delta^{13} C_{\text {corr }}(\%)$ \\
\hline${ }^{\mathrm{a}} 0$ year & 0.02 & 0.43 & 21.03 & -0.02 & -21.76 \\
\hline${ }^{\mathrm{a}} 2$ year & 0.05 & 0.98 & 22.39 & 1.12 & -22.00 \\
\hline $\mathrm{b}_{3}$ year & 0.06 & 1.71 & 34.72 & 1.97 & -24.46 \\
\hline${ }^{b} 8$ year & 0.20 & 3.40 & 18.51 & 0.17 & -26.67 \\
\hline${ }^{\dagger} 80$-year & 0.34 & 8.53 & 29.04 & 1.73 & -27.89 \\
\hline $\begin{array}{l}\text { Robinson } \\
\text { Bent Mou } \\
\text { Starfire M }\end{array}$ & $\begin{array}{l}\text { rest refe } \\
\text { in Site } \\
\text { e Site }\end{array}$ & site. & & & \\
\hline
\end{tabular}


The shift from the linear line (Figure 3.17) to more depleted $\delta^{13} \mathrm{C}$ could also indicate greater $\mathrm{OM}$ accumulation from developing $\mathrm{C}_{3}$ tree stands. The decrease in the $\mathrm{C} / \mathrm{N}$ ratio between the 3-year and 8-year sites may indicate increased $\mathrm{N}$ concentrations due to black locust trees as shown earlier. However, Robinson Forest, the 80-year reference site, is primarily oak (Quercus spp.) dominated, a non- $\mathrm{N}_{2}$ fixer, and shows a negative $\delta^{13} \mathrm{C}$ shift of $4.91 \%$ with a corresponding higher $\mathrm{C} / \mathrm{N}$ ratio from the 0 -year. This also supported the data showing accumulating OM with stand development on reforested coal mine sites.

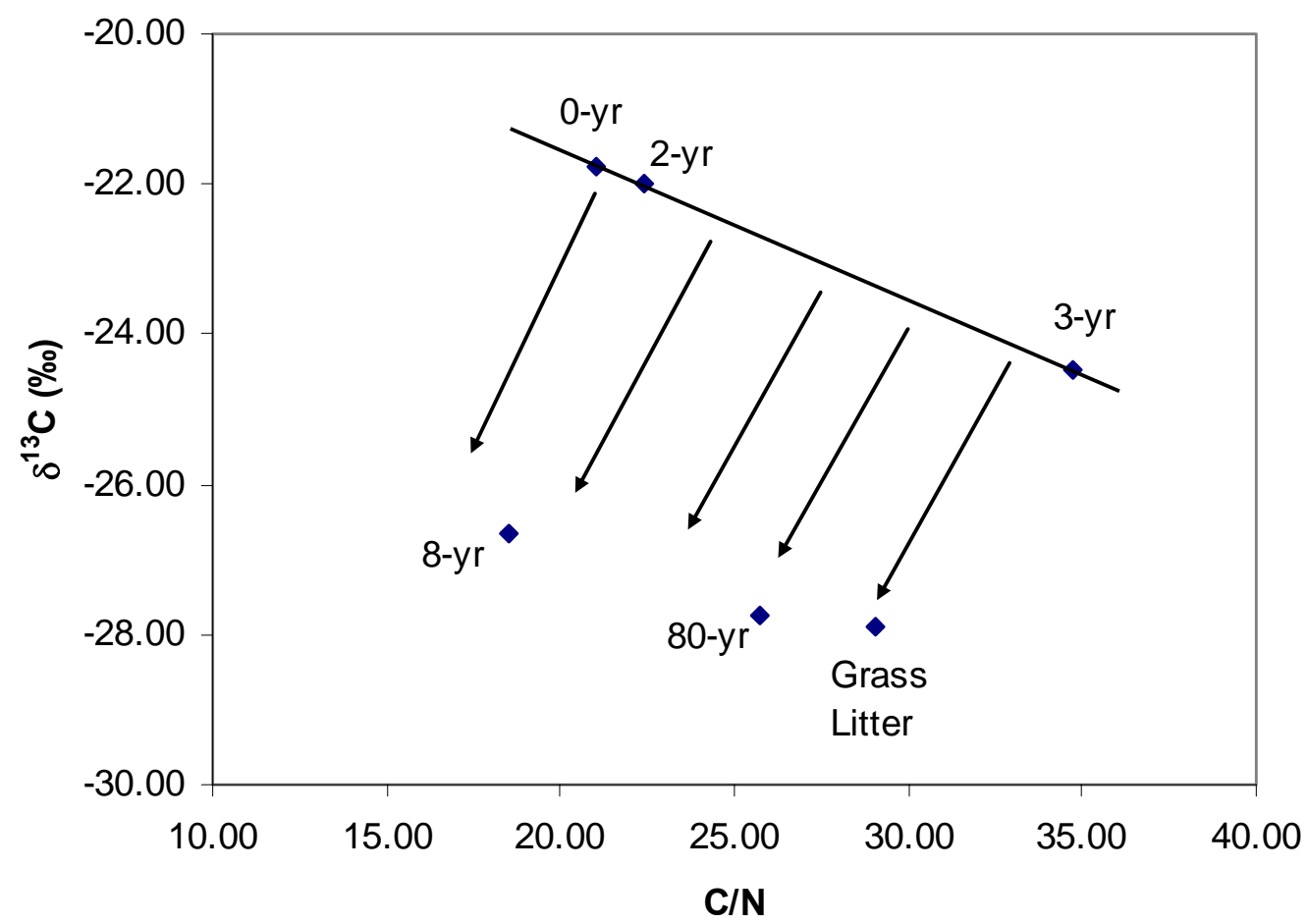

Figure 3.17. Variation of $\delta^{13} \mathrm{C}$ with $\mathrm{C} / \mathrm{N}$ ratios over time for (a) Bent Mountain Site (0 and 2-year); (b) Starfire Mine Site (3 and 8-year); (c) 80 -year forested reference site; and (d) grass litter. 


\subsubsection{Thermogravimetry}

Results from the method development section (2) of this report showed TG/DTG curves with pyrolysis peaks at distinctively different temperatures for litter $\left(270-395{ }^{\circ} \mathrm{C}\right)$, coal $\left(415-520{ }^{\circ} \mathrm{C}\right)$, and limestone $\left(700-785{ }^{\circ} \mathrm{C}\right)$. Application of this technique to field samples indicated an increase in peak intensity in the $270-395{ }^{\circ} \mathrm{C}$ region signifying an increase in the "new" organic matter fraction over time. For the Bent Mountain site, the organic matter fraction increased from $0.03 \%$ to $0.095 \%$ between years 0 and 2 (Figure 3.18), while the Starfire site showed an increase from $0.095 \%$ to $1.47 \%$ between years 3 and 8 (Figure 3.19). However, the peak that represents coal pyrolysis $\left(415-520{ }^{\circ} \mathrm{C}\right.$ ), indicates variation in coal-bound carbon from $0.54 \%$ to $0.91 \%$ ( 0 to 2-year sites) and $0.97 \%$ to $2.25 \%$ ( 3 to 8 -year sites), whereas the $\mathrm{C}$ values for the carbonate $\left(700-785{ }^{\circ} \mathrm{C}\right.$ ) region varied between $0.88 \%$ and $0.75 \%$ ( 0 to 2 -year sites) and $0.36 \%$ to $<0.01 \%$ ( 3 to 8 year sites). The variations in the coal and carbonates fractions reflect the heterogeneity of spoils on mine sites and may be problematic when using time-elapsed soil sampling.

The combined coal and carbonate fractions were used to represent "old" carbon (COC) for this application of TG/DTG, as opposed to the "new" OM fraction. Generally, there was very little change in the COC between the 0-year, 2-year, and 3-year sites (Figures 3.18a, b, and figure 3.19a) (care must be taken when interpreting the thermographs due to different y-axis scales). The 8-year site, however, exhibited an increase in "new" $\mathrm{C}(15 \%$ over the 3 -year site) and a decrease in the carbonate-bound carbon (approximately 36\%) (Figure 3.19b). Research has shown that the initial rate of SOC sequestration is low for up to 5 years after converting degraded soils to natural forests (Lal, 2001). The TG/DTG pattern for the reference site, 80-year Robinson Forest, showed a peak within the $270-395{ }^{\circ} \mathrm{C}$ region similar to that found for the "new" $\mathrm{C}$ fraction (approximately $4.70 \% \mathrm{C}$ ). There was a slight shift to about $425{ }^{\circ} \mathrm{C}$ which could be indicative of more humic material from decomposition (Figure 3.20). This corresponded to observations of other authors who found lignin decomposition occurring between $375-430{ }^{\circ} \mathrm{C}$ (Sheppard and Forgeron; 1987; Lopez-Capel et al., 2005). 

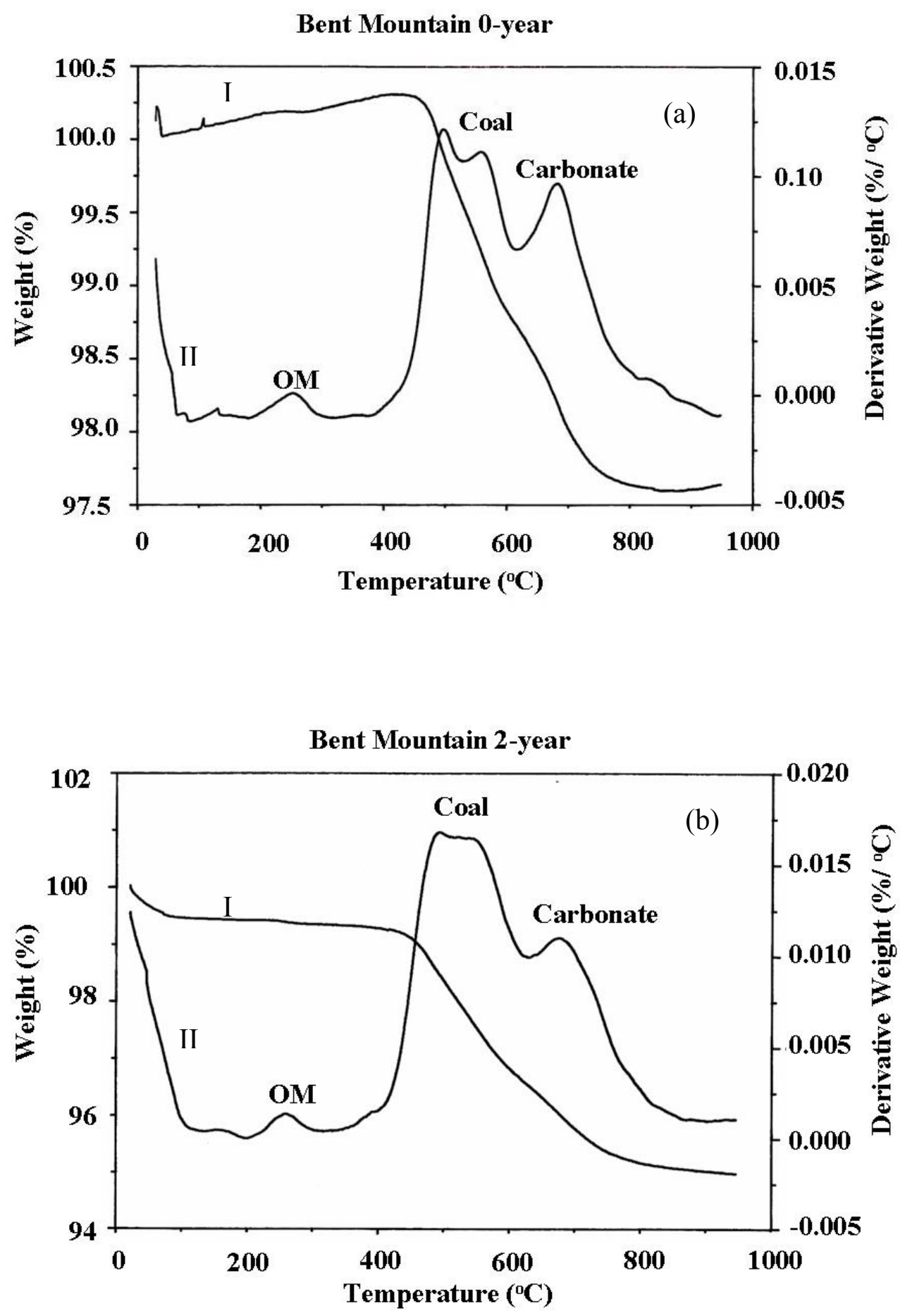

Figure 3.18. Representative TG/DTG patterns for Bent Mountain- (a) 0-year and (b) 2-year. 

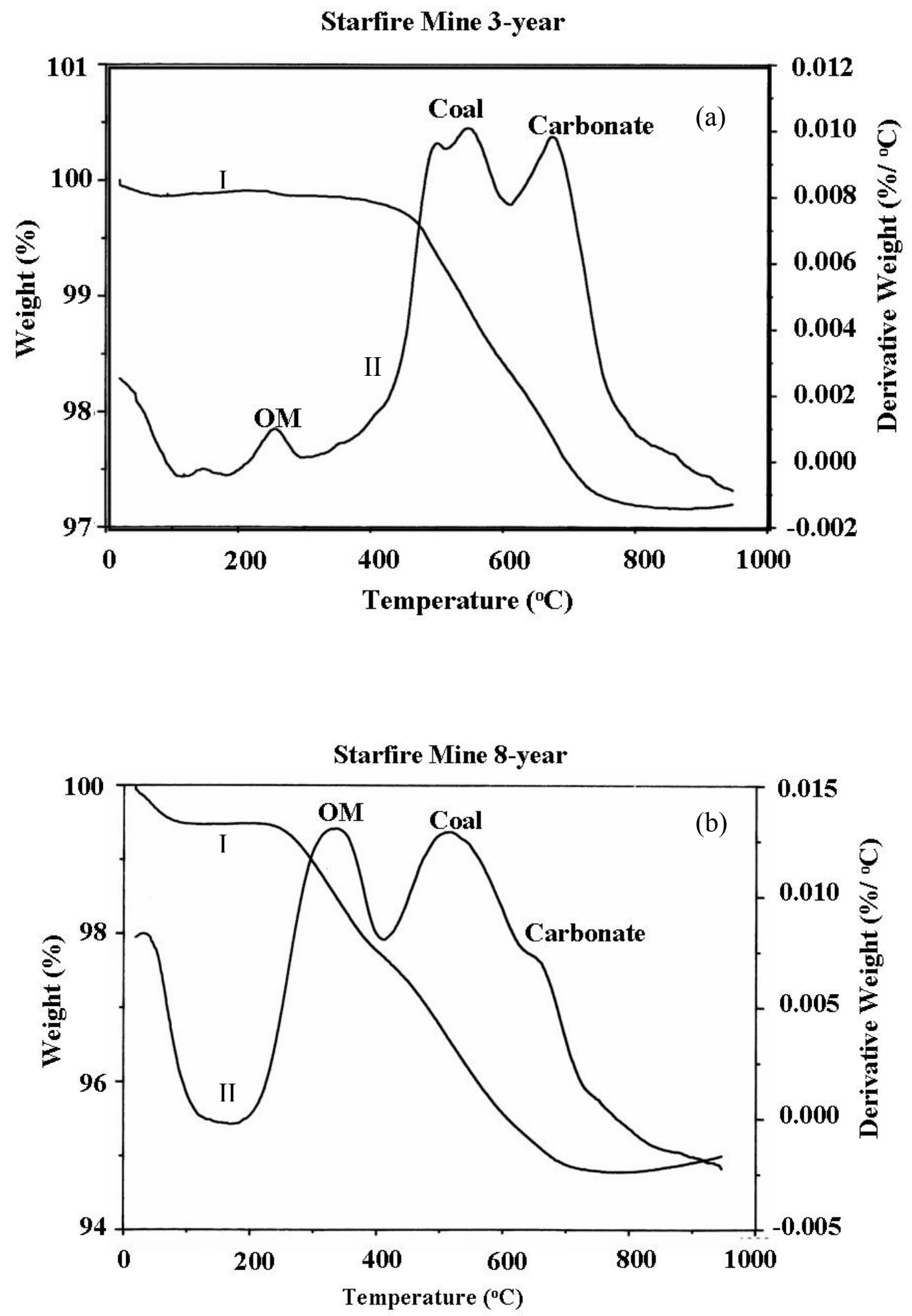

Figure 3.19. Representative TG (I)/DTG (II) patterns for Starfire Mine- (a) 3-year and (b) 8-year. 


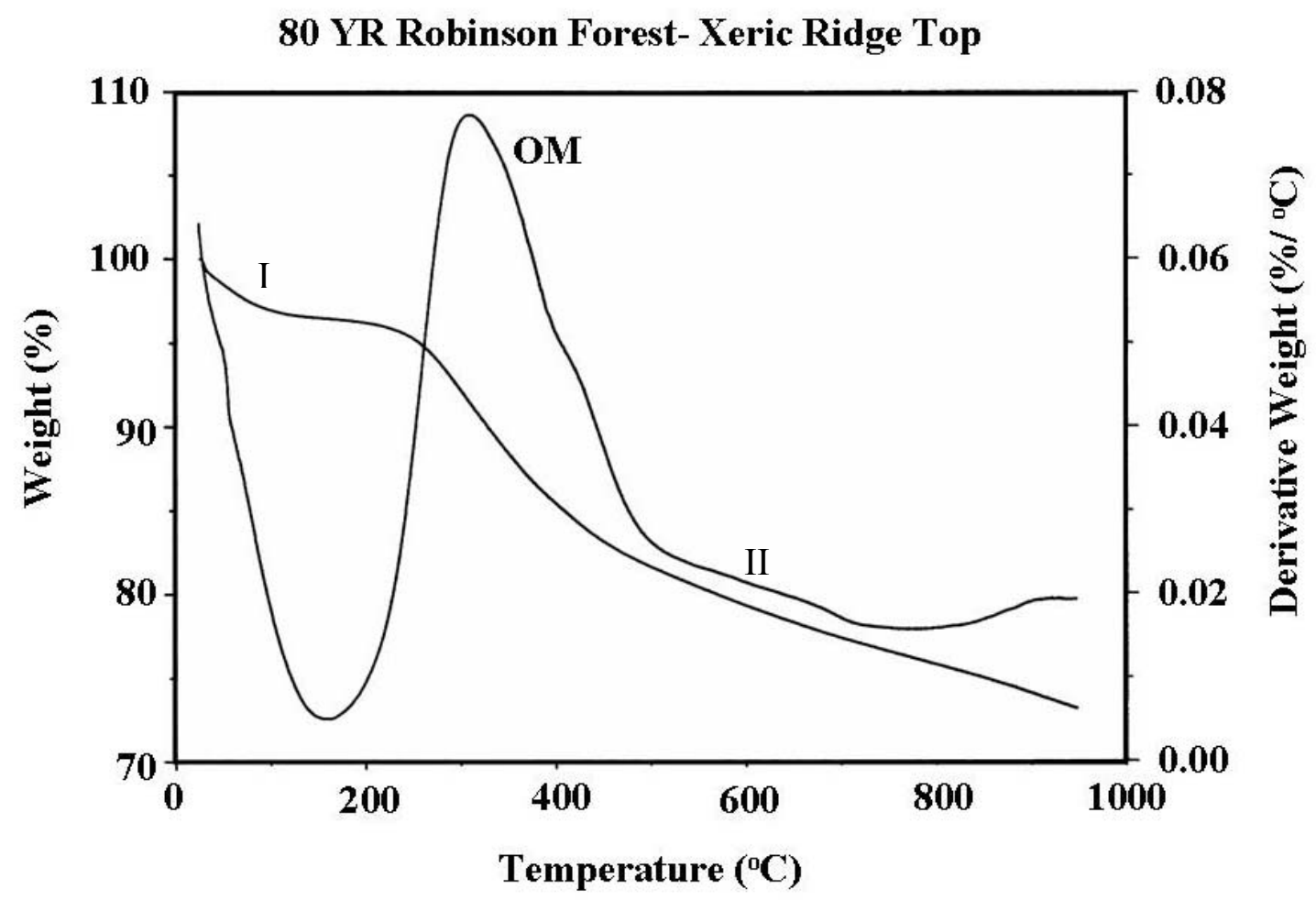

Figure 3.20. Representative TG (I)/DTG (II) pattern for Robinson Forest reference site- 80 -year. 


\subsection{CONCLUSIONS}

\subsubsection{Carbon Processes}

Our results suggest that many of the ecosystem processes and parameters that control carbon accumulations and transformations in reforested surface mines are initially different than regenerating reference stands, but become similar as the systems age. The young (1 and 3-yr) reforested mine lands likely differ from young regenerating forest because initial $\mathrm{C}$ and $\mathrm{N}$ pools differ greatly between the two ecosystem types. Loosedumped spoil is limited with respect to initial N concentrations and SOM is absent, while a clear-cut forest will retain some SOM that was present before the cut and will also contain woody debris and litter generated during the harvest. As such, time zero conditions, from the chronosequence standpoint, differ and the mine spoils need time to catch-up to the regenerated condition. By year eight; however, soil respiration, microbial biomass and activity, and decomposition rates are similar between the two systems indicating that processes responsible for $\mathrm{C}$ accumulation in the reforested mine setting have been restored to a level similar to that of a non-mined area.

\subsubsection{Carbon Accumulation}

Changes in "new" C accumulation over time were observed and shown in Figure 3.21 , with an increase from approximately $1000 \mathrm{~kg} / \mathrm{ha}$ to $>13,000 \mathrm{~kg} / \mathrm{ha}$ (year 3 to year 8). This was coupled with a simultaneous expansion of plant biomass (of $>12,000 \mathrm{~kg} / \mathrm{ha}$, average of five species measured) due to stand development for the corresponding years. It is important to note that the "old" C at Starfire was slightly elevated over that at Bent Mountain due to the heterogeneous nature of spoil replacement at the two sites. In contrast, there was a small decrease $(<1,000 \mathrm{~kg} / \mathrm{ha})$ in "old" soil from the 3 to 8 -year sites which is likely due to decreases in parent carbonate rocks (decreased $\mathrm{Ca}$ and $\mathrm{Mg}$ concentrations) as described earlier. These observations lend even further support for TG/DTG findings.

Whereas it has been shown that $\delta^{13} \mathrm{C}, \mathrm{C} / \mathrm{N}$ ratios, and changes in $\mathrm{Ca}$ and $\mathrm{Mg}$ can be used as proxy tools for qualifying SOC changes over time on the reclaimed coal mine sites, the exact SOC accumulation rate cannot be determined. However, it has been 
shown that the TG/DTG method can physically indicate changes in SOC accumulation in the presence of very different organic and inorganic phases. Therefore, potentially it can be used as a metric for quantifying SOC accumulation on reclaimed mine sites of different ages without the need for time-elapsed sampling. Based on TG/DTG data from this study, "new" organic carbon, on eastern KY reclaimed coal mine sites is being accumulated at an average rate of $2.92 \mathrm{Mg} \mathrm{ha}^{-1} \mathrm{yr}^{-1}$ for the upper $10 \mathrm{~cm}$ following 8 years of reclamation. This rate falls within or exceeds the range for SOM accumulation reported in the literature (Jastrow, 1996; Akala and Lal, 2001; Jones, 2002; Shoch et al., 2003; Stahl et al., 2003; Janzen, 2006). Higher than previously reported C accumulation rates was anticipated considering the reclamation technique used in this study (loose dump). This reclamation approach provides an initial condition that is essentially devoid of SOC, so the $\mathrm{C}$ accumulating capacity is greater than other spoil or soil types that contain SOC at the onset of planting. Application of the TG/DTG method also allowed us to better track changes in the SOM fraction over other methodologies. In addition the method provided a more cost-effective, rapid and simple accounting procedure for the new organic $\mathrm{C}$ fraction than repeated sampling (as referred to earlier). More importantly, it supported the hypothesis that TG/DTG can be used to assess "new" SOM accumulation in mixed geological material, especially in areas dominated by coal and carbonate materials. 


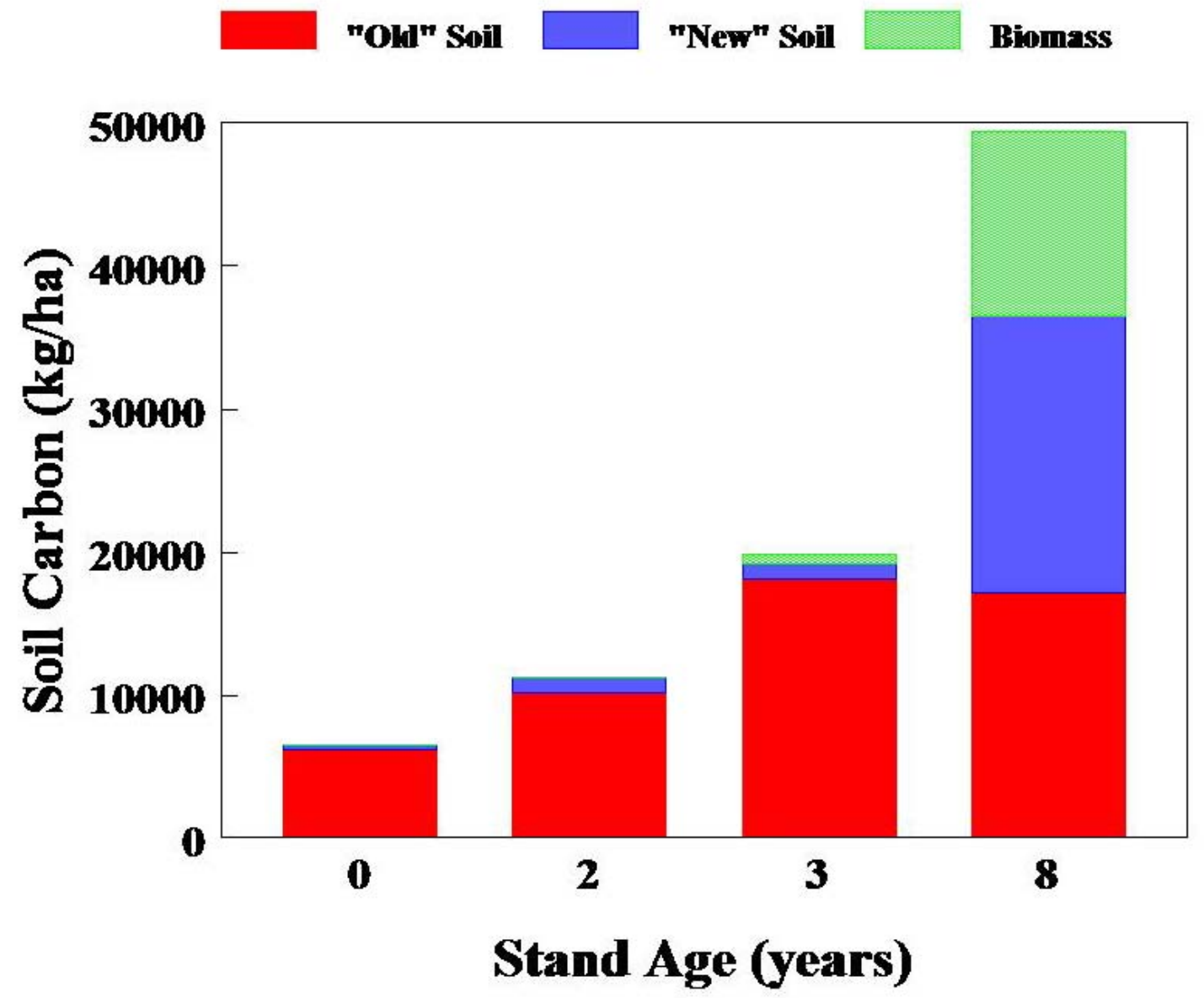

Figure 3.21. Variations in "old" and "new" soil in relation to biomass changes over forest stand development. 


\section{ESTIMATING PRODUCTIVITY AND VALUE OF WHITE OAK (QUERCUS ALBA) ON LOOSE GRADED MINE LANDS}

\subsection{INTRODUCTION}

To properly manage forestland it is essential to classify, map, evaluate, and interpret the resource (Pritchett and Fischer 1987). Site quality, according to Pritchett and Fischer (1987), is the sum of all factors that influence the capacity of the forest to produce trees or other vegetation. The quality of a site is directly influenced by the productive capacity of the land, and as a result, various methods have been developed over time to quantify the accuracy of this relationship for predictive purposes. The historic objective of forestland classification has been to determine the wood volume of a site; however, since the quality of a site largely determines species composition and regeneration success or failure (Sims 1994), it would be prudent to thoroughly examine site quality for other purposes as well, such as restoration success.

The matter of forest site classification has been discussed in the United States since the early 1900's and over time the various methods to quantify site quality have gone from basic observations of tree growth to multifactor analysis (Pritchett and Fischer 1987). To illustrate the variable conditions found in these systems, Carmean (1975) stated that a forest has a set of primary site factors independent of the forest community (climate, topography, parent material, surface and ground water) as well as a set of secondary site factors that are dependent of the forest community (forest microclimate, forest soil, litter layer, moisture regime, water table). All of these variables control the supply of growth factors (light, water, energy, nutrients) to the plants. There are a multitude of different systems to evaluate the quality of a site, but the scale of the project and the variability of the site factors should determine the method used for classification (Carmean 1975).

Traditionally, site quality has been determined through measurements of tree height and age that are correlated and graphed according to their relationships (Sterrett 1921; Frothingham 1921, 1918; Roth 1918, 1916; Watson 1917; Graves 1906). The site index (SI), or the average height of dominant and codominant trees growing in well-stocked, even-aged stands at a given age (50 in the eastern US), was developed by Frothingham in 1918 and is still widely used today. Site indexing has had widespread use throughout the Appalachians to determine volume and site 
quality (Lamson 1987; Stout and Schumway 1982). The benefits of using site index to evaluate a forest include good correlation with site productivity, easy measurement, and dependence from stand density (McQuilkin 1989). For site indexing to be accurate and meaningful, the site needs to have suitable trees available for the required height range and age, and there need to be accurate site index curves available by which to measure the site (Sims 1994). Suitable trees are those that have been free to grow into a dominant or codominant crown position, have a straight single stem, have been free from suppression, and have not been significantly damaged (McQuilkin 1989).

The aforementioned method of site quality evaluation is traditional and based on minimally disturbed land; however, we seek to compare degraded mined lands with a reference, or natural, stand of trees to determine existing site quality. Kentula et al. (1993) questioned whether created or restored wetlands performed the same ecological functions as natural wetlands. They also were interested in what constituted a successful ecological restoration. Because local and regional ecological conditions vary, Kentula et al. (1993) saw the need for a monitoring and assessment method that would serve as the basis for ecologically defensible management strategies for the restoration and creation of disturbed systems. The comparison of conditions found in restored systems to those found in regional reference systems is key to discerning restoration success.

The concept of a reference system approach is a relatively new one. Moore et al. (1999) gave three definitions of the concept: 1.) the variability of natural conditions in an ecosystem (Kaufmann et al. 1998; Kaufmann et al. 1994; Swanson et al. 1994), 2.) a standard one may use to measure change in an ecosystem (Kaufmann et al. 1998; Morgan et al. 1994), and 3.) a standard one may be used to measure the success of ecological restoration or management objectives (Christensen 1996). This system of site quality evaluation has been used to measure restoration success of watersheds (Hessburg et al. 1999), tallgrass prairie (Brye et al. 2002), giant sequoia (Sequoiadendron giganteum [Lindl.] Buchholz) (Stephenson 1999), and ponderosa pine (Moore et al. 1999). Even though ecologists use the term "reference system" to mean a pristine system not tampered with by humans, it may also represent the ultimate goal, regardless of disturbance, of any restored ecosystem. 
The performance curve, a key tool in the reference system approach, shows the development of specific ecological conditions over time as succession progresses in relation to those found in regional reference systems (Figure 4.1). If a key property of the restored system is not recovered, such as soil chemistry, we may find that some functions of the ecosystem, such as tree height, may never reach reference conditions (metric 1 in Figure 4.1) (Kolka et al. 2002). On the other hand, other metrics, such as tree diameter, may exceed those found in the reference system (metric 3 in Figure 4.1). Overall, it is expected that in time all functions will recover to those found in reference systems.

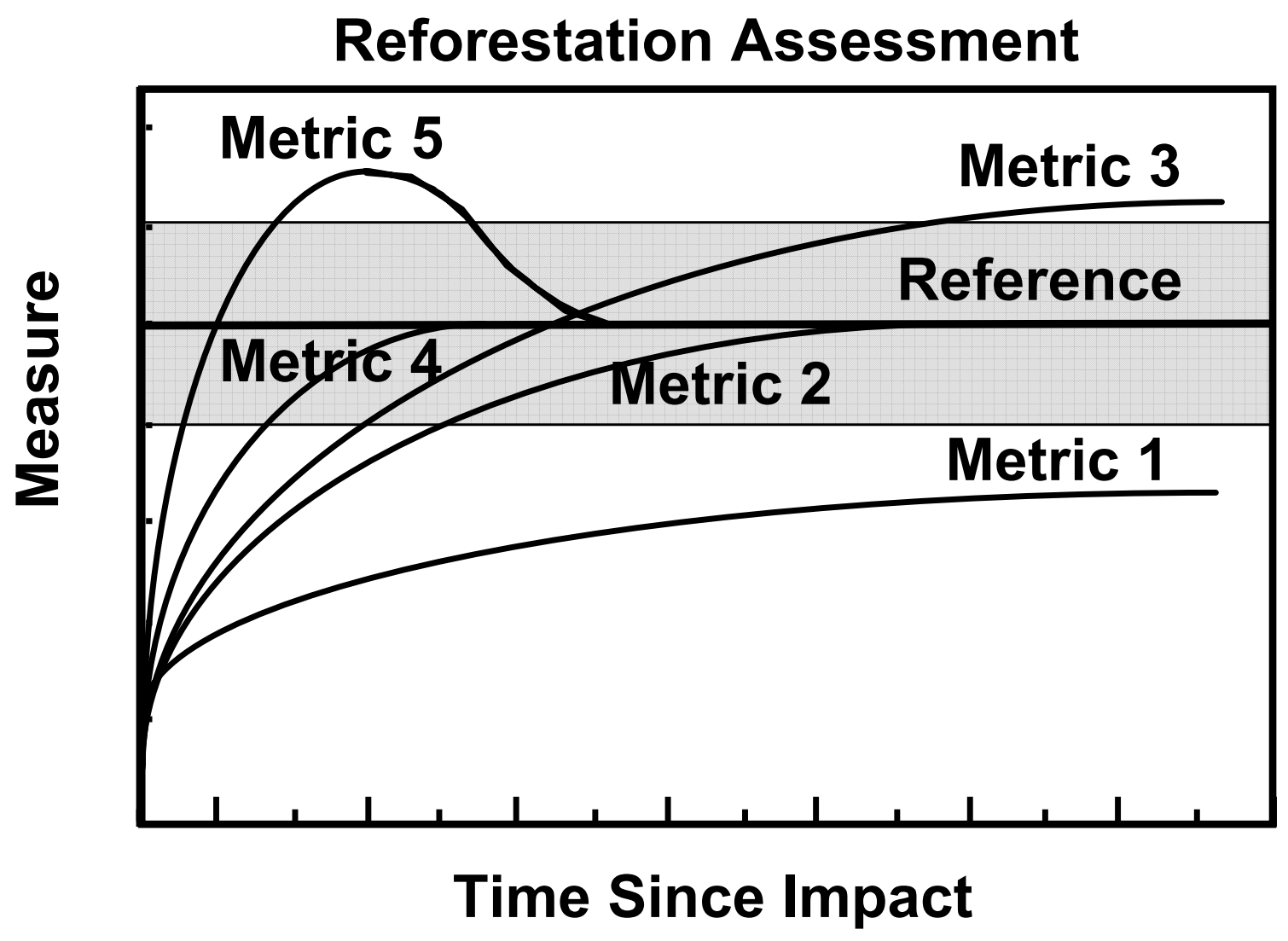

Figure 4.1. The Wetlands Research Program's reforestation assessment showing growth trajectories or performance curves in relation to a reference range (Kentla et al. 1993).

Carmean (1975) reported that we need to develop integrated methods of site quality evaluation and landscape classification that include information about mensuration, soils, and University of Kentucky Research Foundation 
ecology; he further stressed the need for information about the quality as well as the quantity of the yield. As such, a method specific to the eastern Kentucky coal fields needs to be developed that characterizes the vast diversity and abundance of these forestlands. Although this method will not restore forests to their former ecological status, it will help provide a greater understanding on whether the methods we use are working effectively. This method is needed to assist in restoring the forests that are a keystone to this region's economy and ecology. In addition, the method will allow us to form predictive models on whether a young restored system is moving on a trajectory similar to that of the reference state. These models will also allow us to estimate the future value of a restored area.

\subsubsection{Species Selection}

White oak (WO) was chosen as the representative hardwood species for the study because it is native to the region, is highly valued for a variety of reasons, is a key component of the native ecosystem, is abundant in the region which provided ample opportunity for finding suitable study areas, and performs well on loose graded mine spoils (see Chapter 1 this report).

White oak is a very important timber tree in Kentucky as well as throughout the eastern United States. Rogers (1990) reported that white oak wood is tough, resistant to decay and very heavy, making it the most important lumber tree of the white oak group. Traditionally, its wood has been used for barrel staves, hardwood flooring, and boat building (Rogers 1990). The historic demand for white oak wood has been high, and it is now reserved mostly for the use of flooring, furniture, veneer and barrels (Hardin et al. 2001), while lower grades of white oak are used for railroad ties, pilings, bridge planking, and mine timbers. Braun (1950) included white oak as one of the ten most prominent species in the mixed mesophytic association described in her landmark text, Deciduous Forests of Eastern North America. The remnants of the mixed mesophytic association are some of the most complex, diverse, and productive temperate forests found in the nation (Rogers 1990), if not the world (Burger 2002).

White oak grows in a wide variety of climactic and soil conditions (Rogers 1990), but the best development has been observed on north and east facing lower slopes and coves where the soil is deep and moist with good internal drainage (Hardin et al. 2001; Rogers 1990). While this may be true, white oak may also be found in higher abundance but of a smaller stature on west 
and south facing slopes (Rogers 1990). The range of white oak is the entire eastern half of the US, with the exception of Maine, southern Florida and southern Louisiana. It is found as far west as eastern Texas and Oklahoma, and ranges in elevation from sea level to 5,500 feet in the southern Appalachians (Hardin et al. 2001). The 2004 Forest Inventory and Analysis for Kentucky revealed that oak-hickory was the predominant forest type, which covered $72 \%$ of the state's timberland, and that oak-pine was a distant second and covered 9\% (USDA FIA 2004). Multiple studies conducted in the southern Appalachian hardwood region found that white oak was seventh-ranked (out of 32 trees) in importance in relative value, was fast growing, intermediate in shade tolerance, very long lived, and of high value to wildlife (USDA Forest Service 1965; Halls 1977; Harlow et al. 1979; Trimble et al. 1974; Trimble 1975).

White oak has the ability to grow to a maximum range of 24-30 meters (80-100 feet) tall and develop a dbh up to a maximum range of 91-122 cm (36-48 inches)(Rogers 1990). Hardin et al. (2001) reported a known maximum of 150 feet height by 108 inches dbh, and a maximum age of 450 years, although 600 year old trees have been reported (Rogers 1990). In the open, white oak will exhibit a short stocky bole with a wide spreading rugged crown, and in a closed canopy it will grow into a tall straight trunk with a compact crown (Rogers 1990). Numerous sources cite white oak as a very slow growing species, attaining only a $3 \mathrm{~cm}$ diameter in seedlings and saplings after 10 years of growth (Hodges and Gardiner 1993; Rogers 1990; Wharton and Barbour 1973). It grows slower than scarlet, Northern red oak, and black oak, but faster than chestnut oak, hickory and beech. Rogers (1990) stated that white oak stands at age 80 normally contain 28-168 $\mathrm{m}^{3} \mathrm{ha}^{-1}$ of wood (2,000-12,000 $\left.\mathrm{ft}^{3} \mathrm{ac}^{-1}\right)$. The same source found that in fully stocked even-aged stands of mixed oak, total volumes were $89.3 \mathrm{~m}^{3} \mathrm{ha}^{-1}\left(6,380 \mathrm{ft}^{3} \mathrm{ac}^{-1}\right)$ at age 100 on WO SI(80). Total rotation length can be over 120 years, but with early and regular thinning, especially on good sites, it can be reduced to 60 years (Rogers 1990).

\subsubsection{Study Objectives}

The forests of eastern Kentucky are diminishing at a high rate due to surface mining. For many reasons, these forests are essential to the identity, productivity, and stability of the state's ecology and economy. Given that efforts to re-establish these stands have not been completely effective, a study was designed with the following objectives: 
1.) To develop an integrated method of site quality evaluation specific to the vegetation and soils of the eastern Kentucky coal fields to measure the progress of planted stands growing on degraded land

2.) To develop growth curves based on observations of tree height, diameter, and age that accurately characterize even-aged, naturally-regenerated white oak forests found in eastern Kentucky, and to use these curves to assess planted tree growth and value on degraded lands in eastern Kentucky

\subsection{MATERIALS AND METHODS}

\subsubsection{Study Area Description}

The majority of the study area was located in the Eastern Coal Fields physiographic region of Kentucky, with a small number of sites falling into the Eastern Pennyroyal region (Figure 4.2). Smalley thoroughly described this section of the Cumberland Plateau in two parts, the Northern Cumberland Plateau (1986) and the Cumberland Mountains (1984), which border the southern edge of this section of the plateau. A historical description of the region was provided by Braun (1950) as well.

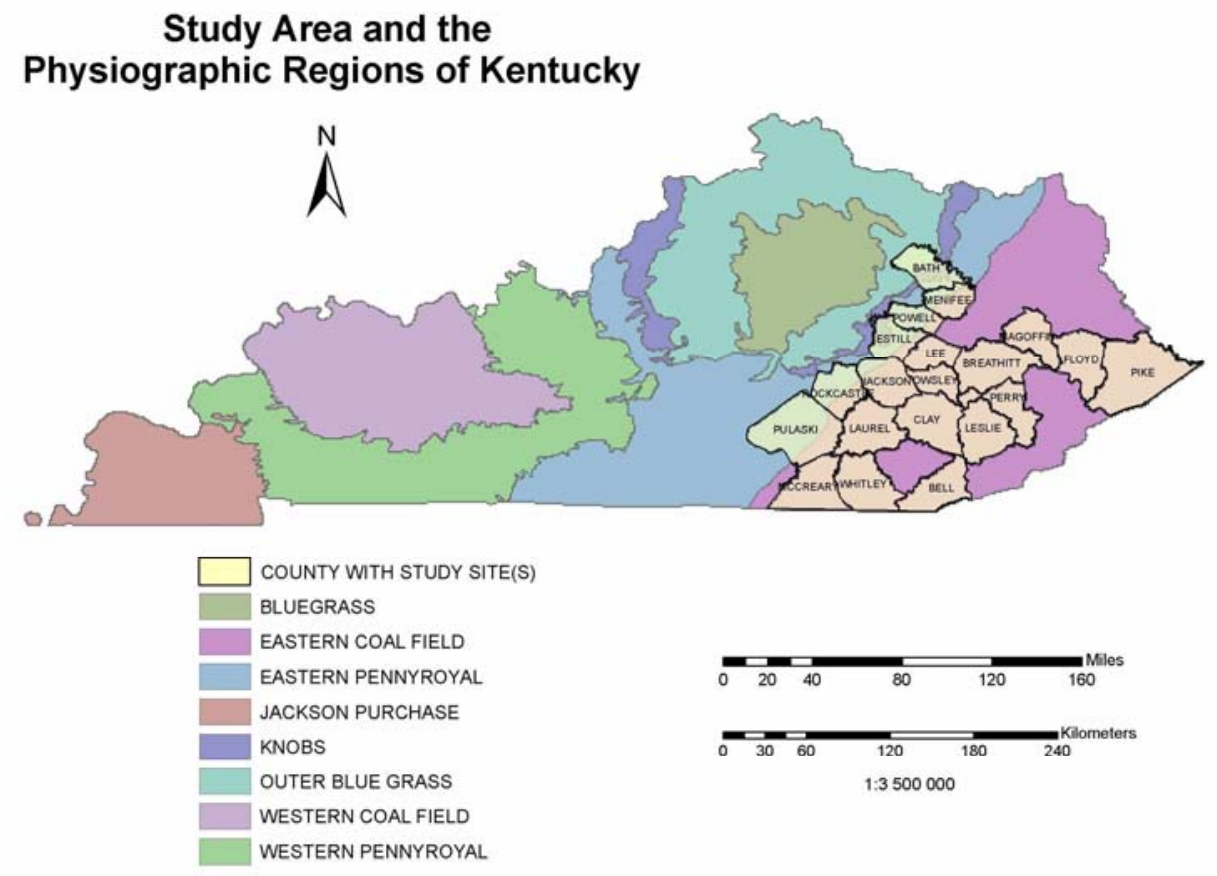

Figure 4.2. Study area and the physiographic regions of Kentucky.

University of Kentucky Research Foundation

Final Report - 10/01/03 thru 9/30/06

DE-FC26-02NT41624 


\subsubsection{Reference Study Sites}

Within twenty counties in the study area, forty study sites were identified, established, and measured (Figure 4.3). The 40 study sites were further subdivided into five age classes $(5,10$, 20, 40, and 80 years old); each age class was composed of eight study sites. This was done to show a chronosequence of development that could be used to describe the reference range for various silvicultural variables.

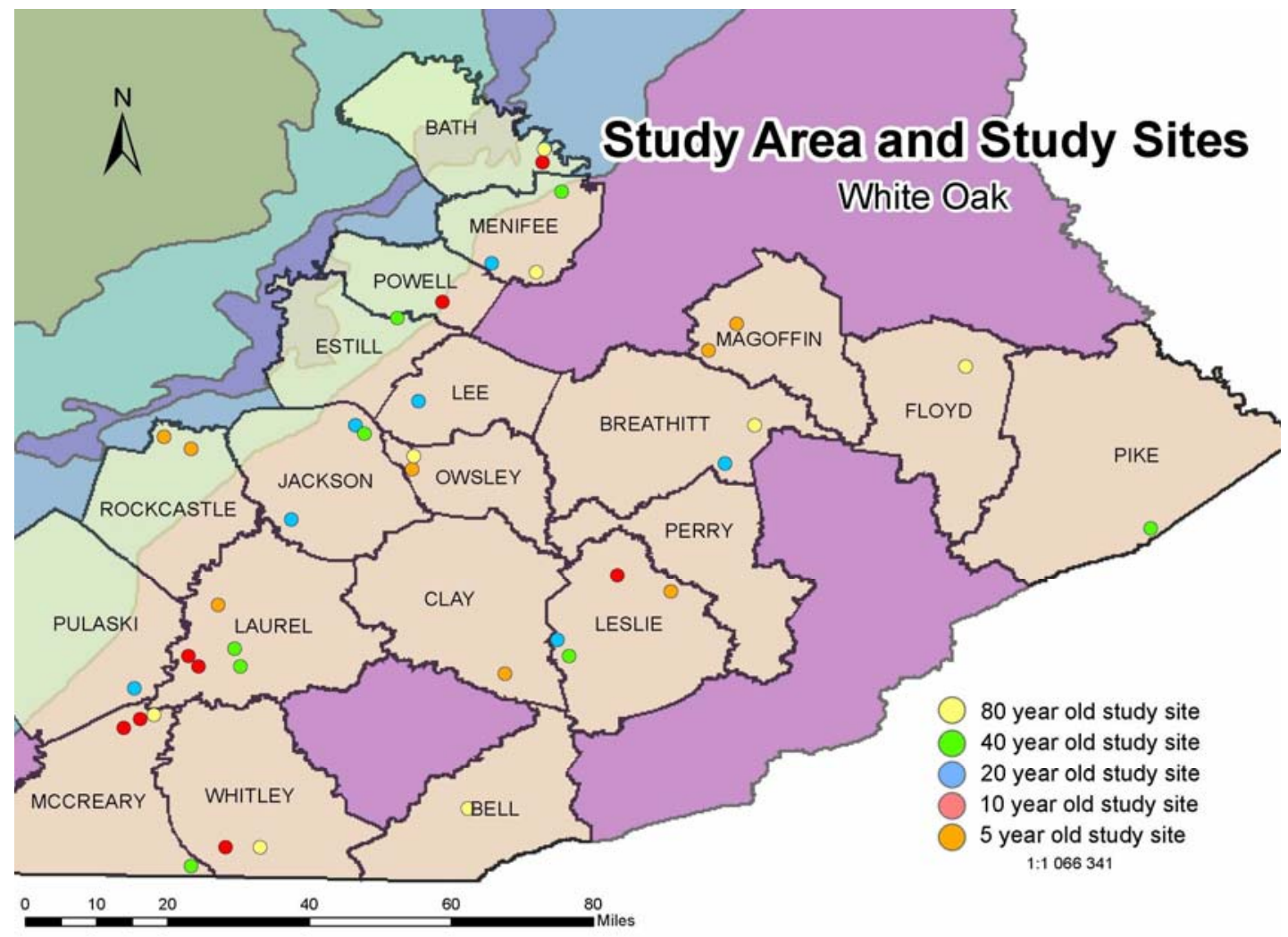

Figure 4.3. White oak study sites grouped according to age class

Most of the study sites were located on public land, namely the USFS

Daniel Boone National Forest (DBNF). The main block of the DBNF runs in a southwesterly direction from just above Morehead, Kentucky, down to the Kentucky/Tennessee border in McCreary County, Kentucky. Another isolated patch of the DBNF, the Redbird District found further east, was utilized for this study as well. Contact was made with the forest's GIS 
coordinator, who in turn produced a series of maps depicting the location of clearcuts they had implemented in the target age ranges. Maps developed for yellow-poplar and white oak stands were constructed from data from three USFS forest types. Forest type 54 was considered a white oak forest type, with $70 \%$ hardwood content with at least $50 \%$ of it being white oak.

Other entities that allowed study sites on their lands included the Kentucky Nature Preserves Commission, Kentucky State Parks, and the University of Kentucky's Robinson Forest. Finding the 5-year old sites presented a challenge, since the DBNF had not clearcut its lands since 1997. As a result, the majority of the 5-year old sites were found on private land. Help in identifying these landowners came from the Kentucky Division of Forestry, particularly the Betsy Lane and Pineville District Offices.

\subsubsection{Suitable Reference Areas}

There were a number of requirements that were upheld when areas were chosen for study sites. A usable site was one that was even-aged, had ample sampling points $(\mathrm{n}=30)$, had a favorable slope position and aspect for the species, was relatively free of pest and disease damage, fell within the correct age range, and had similar land use history as the majority of the other sites.

\subsubsection{Reference Study Site Layout}

Systematic random sampling was utilized to design the layout of the study sites. Once a suitable area was identified, a 10m buffer was paced off from any road or other edge and the start point would be randomly established and flagged as 0 . Using an engineering tape, a $20 \mathrm{~m}$ transect was laid out parallel to the contour of the slope, and flags were placed at the $10 \mathrm{~m}$ and $20 \mathrm{~m}$ points. From the 0,10 , and $20 \mathrm{~m}$ flagged points, perpendicular transects were established to a length of $20 \mathrm{~m}$, making a $20 \mathrm{~m}^{2}$ site. On these perpendicular transects, the $10 \mathrm{~m}$ and $20 \mathrm{~m}$ distances were flagged (Figure 4.4), and designated as 6 replicated plot centers within the site. 


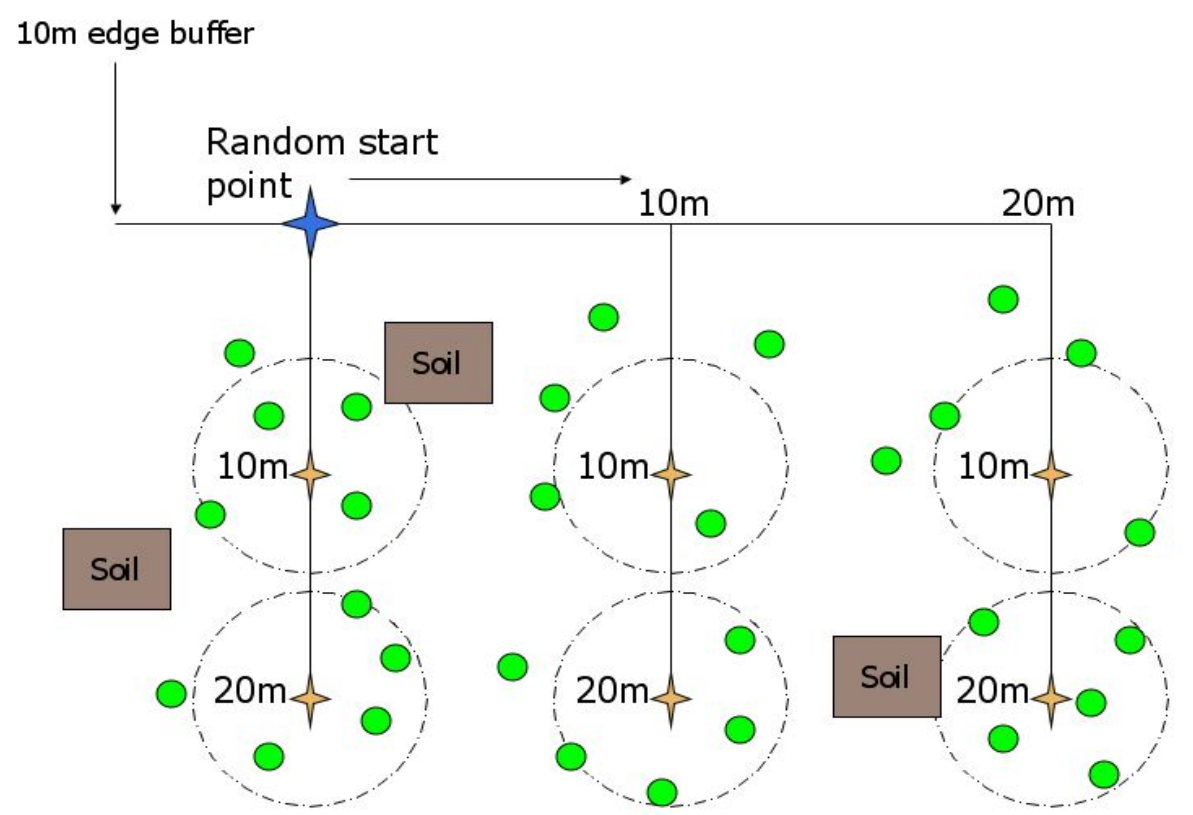

Figure 4.4. Study site layout showing six replicated plots and three soil plots

The five closest dominant or codominant trees to each plot center were measured as sample points. Each site had 30 sampling points for a total of 1,200 sampling points measured. Oftentimes, the older the stand being sampled, the bigger the overall site became due to the spacing of the trees, which led to a shrinking and swelling of the site dimensions. It was hard to find 30 80-year old trees in a $20 \mathrm{~m}^{2}$ area, and in retrospect, so plots were adjusted to accommodate. Sampled trees had to be healthy dominant or codominant canopy trees, single stemmed, unsupressed, relatively undamaged, and not significantly bigger or smaller than the age class being sampled (McQuilkin 1989).

As trees age within a stand, the age range and physical spacing becomes wider largely due to competition, stand dynamics, and succession. After a stand is cut, many individuals have the ability to colonize a site, but due to limited resources, high mortality during early stand development is common. Consequently, younger stands are very dense and even-aged where older stands are more open and less even-aged. Once the stand attains canopy closure, density decreases over time and resources are more evenly distributed. To minimize the effects of this phenomenon, age ranges were organized as depicted in Table 4.1.

University of Kentucky Research Foundation

Final Report - 10/01/03 thru 9/30/06

DE-FC26-02NT41624 
Table 4.1. Age class determination for even-aged cuts

\begin{tabular}{ccc}
$\underline{\text { Age Class }}$ & Age Range & $\underline{\text { Years Cut }}$ \\
\cline { 2 - 3 } 5 & $4-6$ & $1999-2001$ \\
10 & $8-12$ & $1993-1997$ \\
20 & $17-23$ & $1982-1988$ \\
40 & $36-44$ & $1961-1989$ \\
80 & $75-85$ & $1920-1930$
\end{tabular}

\subsubsection{Reference Tree and Site Measurements}

Each study site was visited twice. The first visit was to establish the site and measure tree and site conditions, and occurred between January and October of 2005. After laying out the site, thirty trees were located in the manner described above and measured for total height using a Haglof Vertex Laser Hypsometer. Diameter at breast height was determined with a standard dbh tape. Due to the lack of height, all 5-year old seedlings were measured one inch above mineral soil for a ground line diameter. Two trees per study site were cored, sanded and read in the field and in the lab to verify stand age. Again, due to the lack of girth, trees in the five and ten year old study sites were lopped and a section was cut, sanded, and read to determine stand age.

Other information recorded for each study site included slope position, aspect, elevation, GPS position, directions, and plot layout. An attempt to characterize the plant diversity and vegetation of the reference sites was made, and to do this, all identifiable understory, midstory, and overstory vegetation observations were recorded and charted according to canopy position, age class, and species. For each species, total vegetation observations per age class were summed and plotted to show diversity trends in yellow-poplar and white oak plots between 0-80 years of growth. The goal was to characterize and describe the study site as thoroughly as possible.

\subsubsection{Mine Measurements and Analysis}

University of Kentucky Research Foundation 
Starfire Mine is located in Perry and Knott Counties, Kentucky, which lie in the heart of the Cumberland Plateau. It is a mountain top removal mine that has been in operation since the early 1980's. Land mined by this company in the late 1980's was reclaimed to hay and pastureland, and it was here that in 1996 and 1997 the University of Kentucky established nine 1-ha ${ }^{2}$ reforestation test cells (Thomas et al. 1999). These areas were constructed to represent three subsurface treatments: conventional ( 3 cells), strike off ( 3 cells), and loose dump reclamation (3 cells). Conventional reclamation, which results in a smooth and highly compact surface, is the accepted practice of surface mining. Strike off reclamation is a method in which the spoil is loosely dumped in piles, and then the tops of the piles are "struck off" with the use of a bulldozer, which results in a moderately compact surface. Loose dumped reclamation occurs when the spoil is loosely dumped in piles and left alone, and creates the least compact planting material. Micro-topography of the three subsurface treatments varied greatly, ranging from completely smooth ground (conventional) to extremely rough (loose dumped) (Angel et al. 2006). Surface amendments (straw and bark) were also applied to selected cells at a rate of 125 tons $\mathrm{ha}^{-1}$, and other areas were left alone to serve as the control.

Each cell was divided into twenty-one $0.04 \mathrm{ha}^{2}$ growth plots into which a particular species was planted. Six bare-root (1-0) tree species, including white oak, were planted in 1996 and 1997 (Thomas et al. 1999).

Since the inception of the Starfire Mine reforestation plots, annual measurements of height, survivability, and diameter have been recorded and compiled into a database. These measurements were obtained, organized, analyzed, and used as a test for the method developed by this study. Nine years of data from Starfire were obtained but since growth was negligible in the first four years, only the past five years of data were used for tree height and diameter comparison. Starfire Mine was chosen because it is one of the older post-SMCRA reforestation sites in the region with available data.

\subsection{RESULTS AND DISCUSSION}

\subsubsection{Characterization of Reference Study Sites}

White oak sites were situated on southwest aspects for the most part (40\%), but sites were also found on southeast (25\%), south (15\%), west (10\%), and northwest (5\%) aspects as well. 
White oak sites were mainly found on upper slope positions (47.5\%), with fewer sites on the lower $(27.5 \%)$ and $\mathrm{mid}(25 \%)$ slope positions. An average elevation of $380 \mathrm{~m}(1247 \mathrm{ft})$ was observed for the sites with the highest at $645 \mathrm{~m}(2115 \mathrm{ft})$ and the lowest was at $286 \mathrm{~m}(939 \mathrm{ft})$.

\subsubsection{Height Development}

The summary of mean heights per age class for both species follows.

Table 4.2. Mean heights and standard deviations per age class for white oak stands in the eastern Kentucky coal fields

\begin{tabular}{ccc} 
& \multicolumn{2}{c}{ White Oak } \\
Age class & $\underline{\text { mean height }(\mathrm{m})}$ & $\underline{\text { SD }}$ \\
5 & 1.74 & 0.71 \\
10 & 5.52 & 1.35 \\
20 & 12.10 & 2.59 \\
40 & 20.10 & 3.50 \\
80 & 28.58 & 4.22
\end{tabular}

This data was used to construct the reference ranges, or updated site index curves, for height found in Figures 4.5 below. 


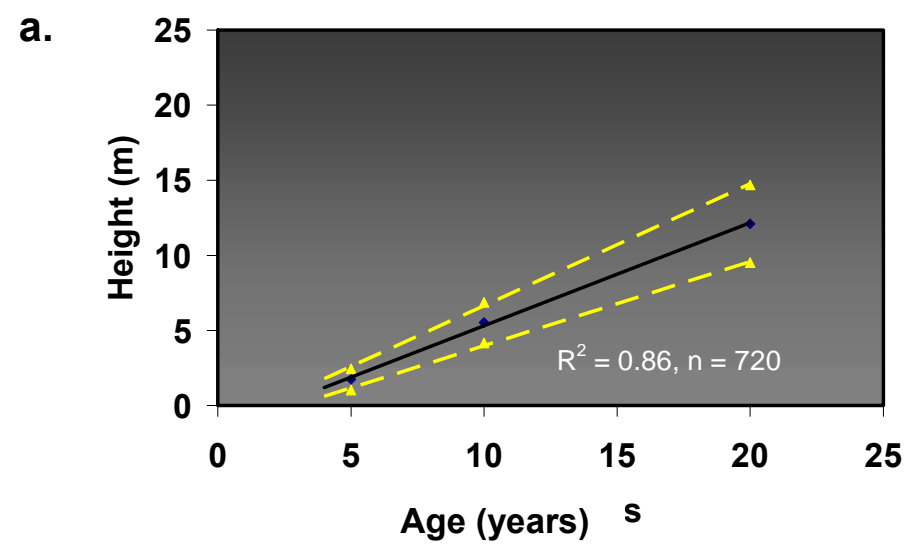

b.

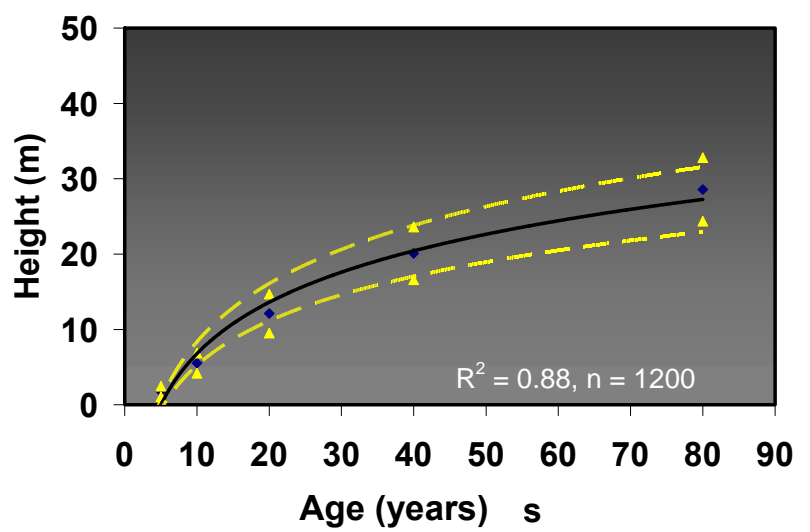

Figure 4.5. (a.) Reference height range for white oak, 0-20 years; (b.) Reference height range for white oak, 0-80 years

Nyland (2002) summarized the four phases of even-age stand development: 1.) stand initiation, which can last up to two decades and in which there is a rapid accumulation of living vegetation, 2.) stem exclusion, characterized by high mortality caused by competition pressure and self-thinning, 3.) transition, during which the permanent understory forms in gaps created over time, and 4.) steady-state, in which the biomass of the stand fluctuates only slightly and remains fairly stable (after Spies 1997; Oliver 1981; Bormann and Likens 1979).

Reference height ranges were depicted in two ways to reflect the above concept. During the first twenty years the height development curve shown in Figure 4.5a is linear to reflect the intense competition characterized by the period of stem exclusion. Figure $4.5 \mathrm{~b}$ illustrates the mean height using a logarithmic curve, which better exemplified height growth after the stand University of Kentucky Research Foundation 
had matured. The height growth of hardwoods begins to taper off after age 50, and they typically lose their ability to gain height after age 80 .

Honeycutt (1981) examined white oak growth in Robinson Forest and found, at a mean age of 57 on Shelocta soils on mid slope position at WO SI(20), a mean height of $21 \mathrm{~m}$. The mean height of 40 -year old stands in this study was $20.10 \mathrm{~m}$, indicating that the site quality for this age class, when compared to the sample from Honeycutt's study, was likely higher. Each age class contained 240 sampling points and the overall $\mathrm{R}^{2}$ for white oak height measurements was 0.88 . The mean site index at age 50 for all white oak stands in this study was $22.62 \mathrm{~m}$ or $74.25 \mathrm{ft}$. When the 80-year old mean height was used to calculate site index based on the upland oak site index (Carmean et al. 1989), an index of 75 was obtained, which indicates a high quality site for white oak.

\subsubsection{Diameter Development}

The summary of mean diameter measurements for both species grouped according to age class follows in Table 4.3.

Table 4.3. Mean diameters and standard deviations per age class for white oak stands in the eastern Kentucky coal fields

\begin{tabular}{ccc}
\hline & White Oak \\
$\underline{\text { Age class }}$ & $\underline{\text { mean diameter }(\mathrm{cm})}$ & $\underline{\mathrm{SD}}$ \\
5 & 2.10 & 0.74 \\
10 & 3.59 & 1.18 \\
20 & 11.53 & 2.72 \\
40 & 18.72 & 3.85 \\
80 & 35.93 & 6.83 \\
\hline
\end{tabular}

This data was used to construct the reference ranges for diameter growth represented in Figure 4.6.

University of Kentucky Research Foundation

Final Report - 10/01/03 thru 9/30/06

DE-FC26-02NT41624 

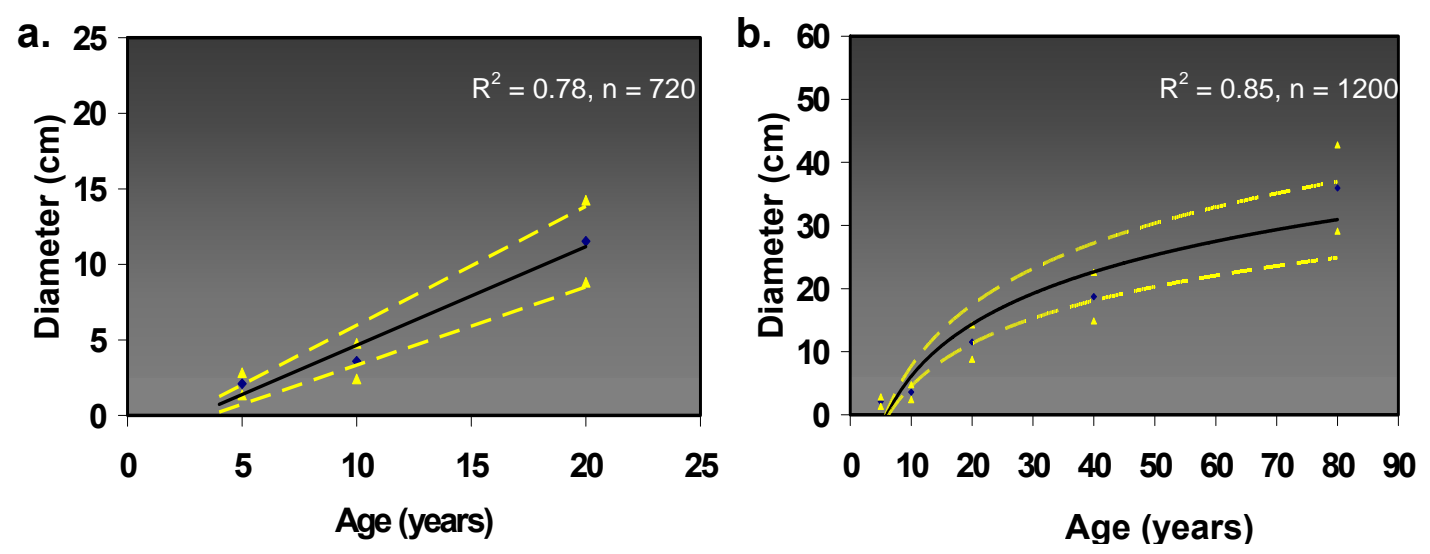

Figure 4.6. (a.) Reference diameter range for white oak, 0-20 years; (b.) Reference diameter range for white oak, 0-80 years

For reasons explained in section 4.1.2, diameter curves were plotted linearly for 0-20 years, and logarithmically for all age classes sampled. Height was easily comparable among stands due to its relative dependence from the effects of density; however, diameter was not as comparable since it was directly affected by stand density (Schifley 2004).

White oak had a mean diameter at age 20 of $11.53 \mathrm{~cm}$, at age 40 of $18.72 \mathrm{~cm}$, and at age 80 of $35.93 \mathrm{~cm}$. A total of 240 trees were sampled per age class and the overall $\mathrm{R}^{2}$ of white oak diameters was 0.83 . Honeycutt (1981) studied white oak in relation to topography and soil in Robinson Forest, and found in a sample of 4 white oaks a mean diameter of $23 \mathrm{~cm}$ at age 40 , which was slightly higher than the study average $(18.72 \mathrm{~cm})$. Crown position has been cited as the single most important factor in tree diameter growth (Trimble 1969), and that an oak that has a superior canopy position will gain diameter faster than an overtopped oak. While collecting data, an attempt was made to sample trees that were as similar as possible, and crown position was always considered; even so, the standard deviations for diameters for both species in age classes 20, 40, and 80 were consistently higher than standard deviations for height, which confirms what is known: that variation in diameter was influenced by changes in stand density during the stem exclusion phase (Schifley 2004). 


\subsubsection{Comparing Reference to Reclamation}

The end result of this study was to discern the quality of degraded lands

in eastern Kentucky, and there are no lands in this state that have been disturbed more than those affected by surface mining. Starfire Mine presented a good opportunity to test the method against trees growing on reforestation plots planted on land reclaimed with three different methods: conventional, strike off, and loose dumped reclamation.

Tree survival has consistently been over $50 \%$ in the loose dumped and strike off cells since 1997 (Table 4.4). These numbers may be satisfactory with

Table 4.4. White oak percent survival for Starfire Mine reforestation cells, 1997-2004

\begin{tabular}{|c|c|c|c|c|c|c|c|c|c|}
\hline Method & $\underline{\text { Species }}$ & $\underline{1997}$ & $\underline{1998}$ & $\underline{1999}$ & $\underline{2000}$ & $\underline{2001}$ & $\underline{2002}$ & $\underline{2003}$ & $\underline{2004}$ \\
\hline Loose Dump & WO & 88 & 69 & 87 & 70 & 83 & 80 & 84 & 81 \\
\hline Strike Off & WO & 94 & 55 & 78 & 66 & 68 & 71 & 70 & 69 \\
\hline Conventional & WO & 49 & 25 & 49 & 25 & 27 & 27 & 24 & 21 \\
\hline
\end{tabular}

respect to obtaining bond release for the mining company, but they tell us nothing about the quality of these sites, nor do they provide us with any information about the suitability of the site for long term forest development. With this in mind, height growth was analyzed (Figures 4.7) as well as diameter growth (Figures 4.8) to provide answers to this dilemma. 
a.

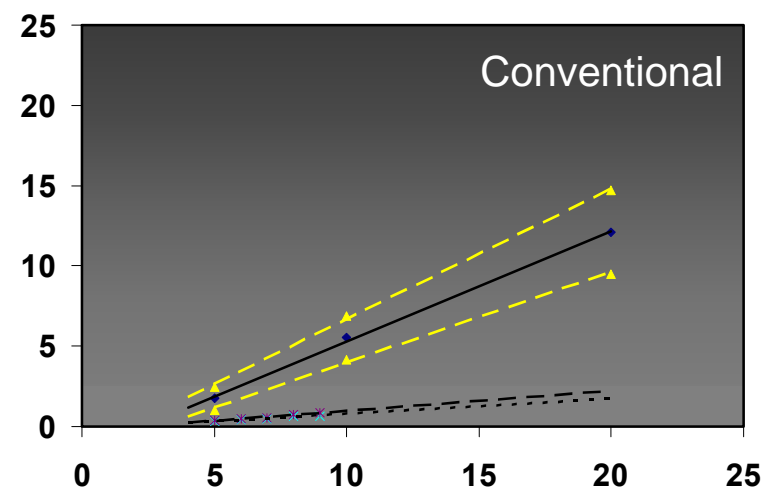

b.

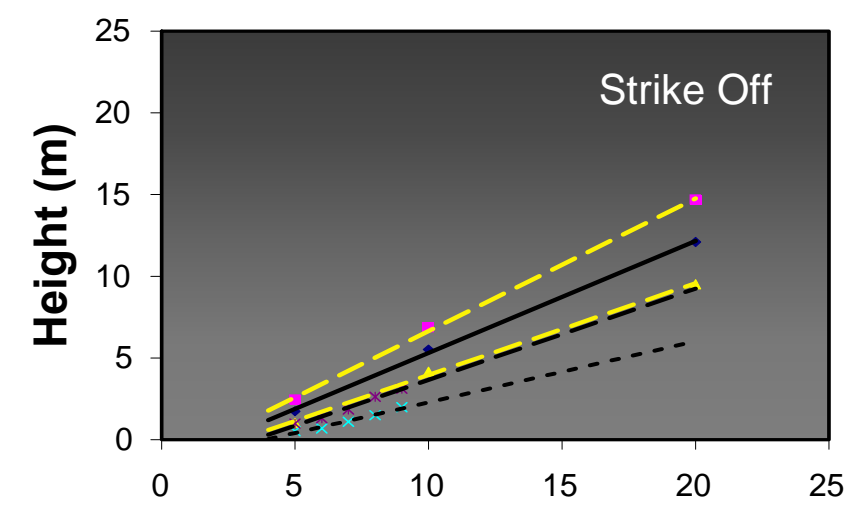

C.

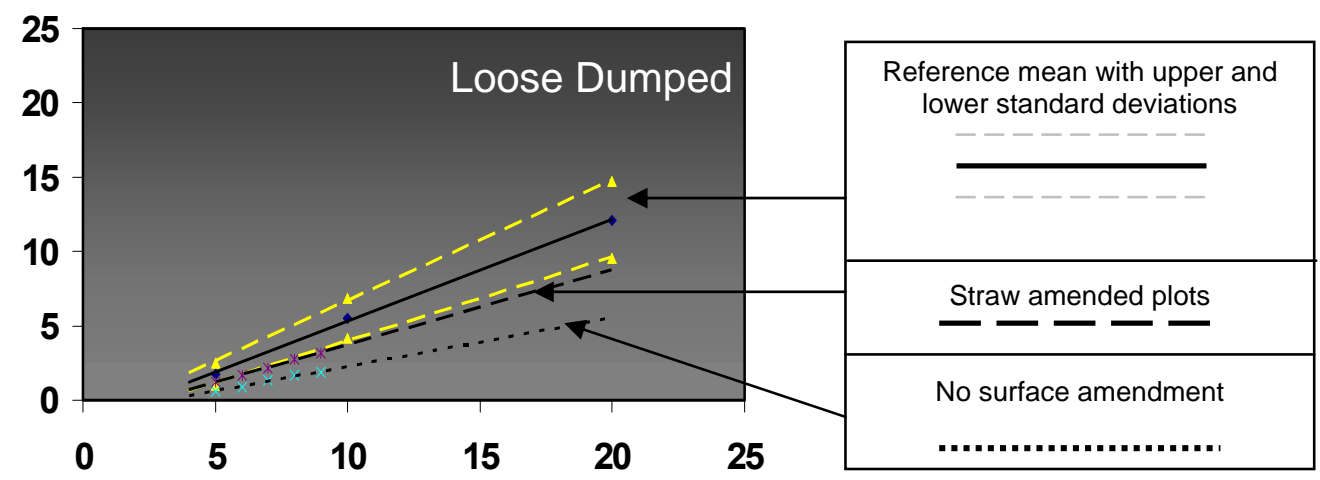

\section{Age (years)}

Figure 4.7. Chronosequence of height development for white oak comparing mean tree heights from reference stands to mean tree heights from reforestation plots on Starfire Mine that have and have not been amended with straw mulch, and have been reclaimed with (a.) conventional reclamation, (b.) strike off reclamation, and (c.) loose dumped reclamation 
The reference ranges depicted on the above graphs are the same as those found in Figure 4.5. What was analyzed was how close the height growth trajectories of the straw amended and control reforestation plots were coming to the height reference range.

Figure 4.7a. shows the results of trees planted on conventionally reclaimed mine land and accurately reflected the conditions that trees typically faced on conventionally reclaimed mine land - both growth trajectories for the straw-amended and control plots were almost flat and well below that of the reference. The high degree of compaction hindered root development, hydraulic conductivity, and nutrient uptake, and thereby caused the trees to grow at a stunted pace (Conrad 2002). Surface water on these plots either ponded or ran off at a rapid pace due to the compaction, and anoxic conditions were an additional problem facing tree development in these areas.

Tree heights in the strike off and loose dumped plots came closer to reference range (Figure 4.7b., 4.7c.), and reflected the looser spoil material that allowed better rooting capacity, water retention, and nutrient flow. Strike off reclamation produced slightly more compact spoil that resulted in higher amounts of runoff and drier conditions. Loose dumped reclamation (Figures 4.7c.) appeared to produce tree heights in both species that most closely approached the tree heights found in the reference stands. Early research on pre-SMCRA mined sites in southern Illinois (Ashby 1998) showed that uncompacted sites resulted in some of the most productive areas in the state for growth of white oak. Another study found that the majority of hardwood species (5 out of 6), which included white oak, showed increased survivability as compaction was minimized on Starfire Mine (Angel et al. 2006). It is known that white oak seedling establishment is best on loose soil because the radicle cannot penetrate excessively compact surfaces (Rogers 1990).

At this time, statistical analyses indicated that the average heights on the reclamation plots for the most recent year collected (growing year 9 or 2005) were significantly different than the reference mean for the same age, and all surface and subsurface treatments were producing trees with heights that were falling short of reference heights (Table 4.5). This was not surprising, even on loose dumped spoil, due to the open growing conditions the planted trees experienced on the mine. 
Table 4.5. Summary of linear regressions (p-values) comparing mean reference tree height (cm) to mean mine tree height for white oak (reference $n=240$ ) for all surface and subsurface treatments

\section{WO-Control WO-Mulch}

Conventional

Strike Off

Loose Dump
$<0.0001$

$<0.0001$

$<0.0001$
$<0.0001$

$<0.0001$

$<0.0001$

Even though this was the case, it must be emphasized that to get any kind of performance, a surface amendment must be used in conjunction with tree planting. The straw amended plots outperformed the control plots on all three reclamation methods (Figure 4.7). The use of mulch is a common practice in reclamation due to its ability to control erosion, supply nutrients, protect seedlings, alleviate compaction, reduce evaporation, and stabilize soil temperatures (Angel et al. 2006; Evangelou 1981; Plass 1978). Francis (1979) reported that on frangipan soils, yellow-poplar that were grown on bedded plots had taller heights over those planted without bedding. Another study revealed that bedding reduced bulk density values for loblolly pine stands, and increased total porosity and macroporosity by 19 and $24 \%$, respectively (Lister et al. 2004). While all of these benefits are important, the addition of nutrients through mulch cannot be understated, as mine spoils are often deficient in nutrients. Early investigations (Schramm 1966) of spoil material found that these soils were deficient in nitrogen; however, later studies reported that nutrient availability in spoil was as variable as the spoil itself (Lindsay and Nawrot 1981). Rodrigue (2001) concluded that the nutrition of a spoil was dependent on the surface overburden material, its $\mathrm{pH}$, and its degree of weathering, and that the variability of the nutrient content was reflective of variable site conditions after mining. 
a.

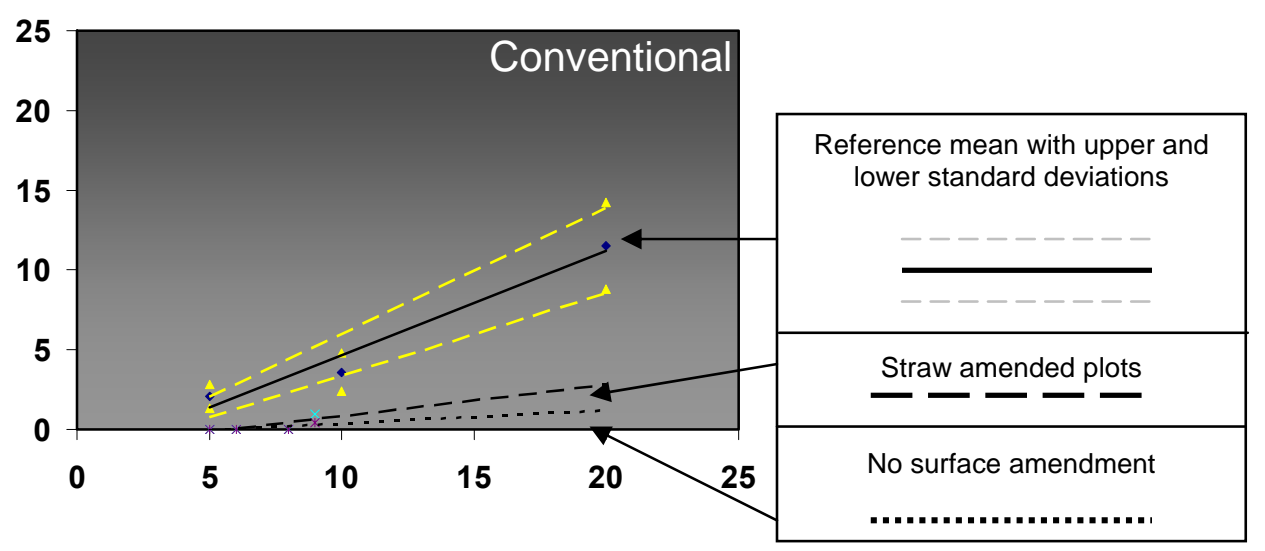

b.

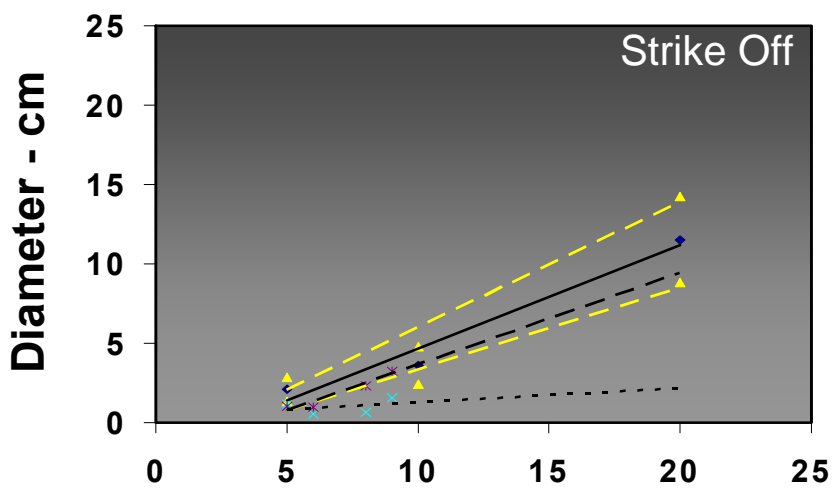

C.

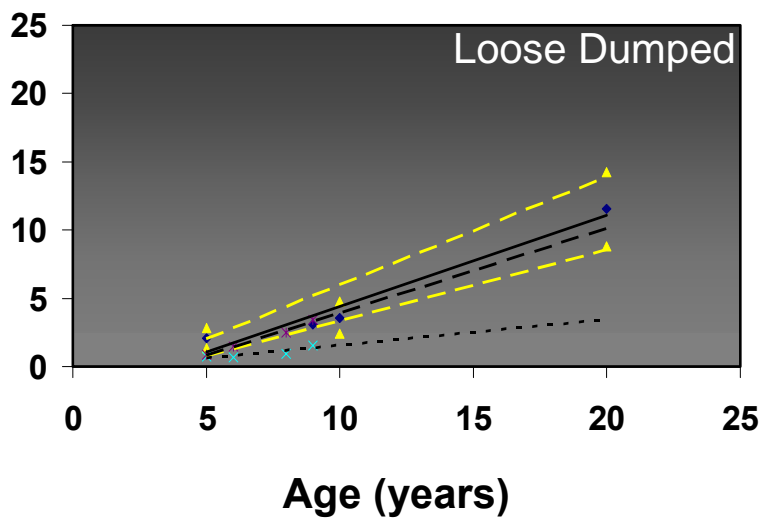

Figure 4.8. Chronosequence of diameter development for white oak comparing mean tree diameters from reference stands to mean tree diameters from reforestation plots on Starfire Mine that have and have not been amended with straw mulch, and have been reclaimed with (a.) conventional reclamation, (b.) strike off reclamation, and (c.) loose dumped reclamation 
Diameter growth was also examined in the same manner as height, using the reference range graphs (Figures 4.6) as a base against which we compared diameter development of planted trees on Starfire Mine (Figures 4.8). It was the degree of closeness of the mine plot growth trajectories to the reference range in which we were interested.

Compared to height growth, diameter growth of trees on the reforestation plots came closer, and in some cases, exceeded that found in the reference stands. Often, tree plantings on mines are measured for height and survival only since these attributes are key to bond release, and there exists sparse information about comparable diameter measurements.

As with height, white oak (Figure 4.8a.) diameters showed little response to growing on conventionally-reclaimed mine land. The hardpacked spoil in these cells inhibited diameter growth primarily by restricting water and nutrient flow to the tree. When tested, mean diameters for both species produced from conventionally reclaimed mine land, with or without mulch, were significantly different and lower than those found in the reference stands

Strike off reclamation dramatically improved diameter growth for white oak when amended with straw mulch (Figures 4.8b.). When year nine mean diameters were compared between reference stands and mine plots, there was no significant difference between the two, and in fact, the mine diameters exceeded the reference mean for white oak, which indicated that with respect to diameter, this surface and subsurface combination (strike off and straw mulch) reflected conditions found in the reference stands needed for white oak growth.

A similar trend occurred in the loose dumped plots. Even though white oak diameters from the mine plots at age 9 were significantly different than those in the reference, the diameters fell within the natural deviation of the reference diameters (Figure 4.8c., Table 4.6), which suggested that the open-grown conditions and surface and subsurface treatments were allowing the white oaks to allocate more carbon to diameter, versus height growth.

From the analysis of height and diameter growth found on the mine plots, we are growing shorter and thicker trees compared to those found in reference stands in the eastern Kentucky coal fields. We feel this is occurring mainly due to the open grown conditions found on the mine plots and lack of competition from other species because the trees are planted in plots. Table 4.6 discloses the results of the independent t-tests that were run to compare dbh growth of trees grown on the mine to those found in white oak reference stands. 
Table 4.6. Summary of linear regressions (p-values) comparing mean reference tree $\mathrm{dbh}(\mathrm{m})$ to mean mine tree $\mathrm{dbh}$ for white oak (reference $\mathrm{n}=240$ ) for all surface and subsurface treatments

\section{WO-Control WO-Mulch}

$\begin{array}{lll}\text { Conventional } & <0.0001 & <0.0001 \\ \text { Strike Off } & <0.0001 & >0.05^{*} \\ \text { Loose Dump } & <0.0001 & =0.0026^{*}\end{array}$

*Mine value higher than 9-year reference value

\subsubsection{Mine Site Indices and Sawtimber Value}

The poor survival and growth exhibited by the conventional reclamation method suggest that it has essentially no value from a timber perspective. Both height and diameter values for this treatment were well below that exhibited by a poor site $(\mathrm{SI}=40)$ as described by Schnur (1937).

Given that we observed differences in height and diameter growth on the mine plots as compared to the reference stands, value was assessed independently. In addition, the mulch treatment appeared to most closely resemble the reference stand so assessments will be for those. Both the strike-off and loose dump treatments were projected to have an average height of $\approx 30$ ft. by year 20 (Table 4.7). This is similar to that which would be expected on an average upland oak site $(\mathrm{SI}=60)$ at age 20. If growing conditions remain the same, we would expect the sites to yield 6,300 board feet per acre by year 50. Using current stumpage values for sawtimber oak in the region, the value at 50 years would be approximately $\$ 1,000$ per acre. As noted earlier, the site index for the reference stand based upon height was found to be 75 which relates to a nearly doubling of expected board feet and dollar value per acre at year 50 over that of the strike-off and loose dump stands (Table 4.7). 
Table 4.7. Site index and stumpage value as a function of stand height for white oak on mulched mine land and regenerating forests in eastern Kentucky.

\begin{tabular}{|c|c|c|c|c|c|}
\hline Treatment & $\begin{array}{c}\text { AVG Ht. } \\
20 \text { yr (ft.) })^{\Delta}\end{array}$ & $\begin{array}{c}\text { Site } \\
\text { Index }\end{array}$ & $\begin{array}{c}20 \text { yr Yield } \\
\left.\text { (Bd. Ft. Ac } \text { ( }^{-1}\right)\end{array}$ & $\begin{array}{c}50 \text { yr Yield } \\
\text { (Bd. Ft. Ac } \text { Ac }^{-1}\end{array}$ & $\begin{array}{l}50 \text { yr Value } \\
\text { (\$ per Acre) }\end{array}$ \\
\hline Conventional & 6.88 & $<40$ & $N A$ & $N A$ & $N A$ \\
\hline Strike-Off & 31.2 & 60 & $N A$ & 6,300 & 1,020 \\
\hline Loose Dump & 28.5 & 60 & $N A$ & 6,300 & 1,020 \\
\hline Reference & 39.7 & 75 & 250 & 11,750 & 1,904 \\
\hline
\end{tabular}

${ }^{\Delta}$ Mine heights projected from regression trend lines (Figure 4.8).

$\dagger$ From USDA Tech. Bull. 560 for upland oak (adapted from Schnur, 1937).

International rule

*Used average value for TN oak sawtimber for the $3^{\text {rd }}$ quarter of 2006 (Timber Mart-South, 2006). Not adjusted for inflation.

Using diameter for calculating site index showed that the strike-off, loose dump and reference stands exhibited excellent site characteristics $(\mathrm{SI}=80)$ (Table 4.8). A SI of 80 would yield 13,750 board feet of timber per acre at 50 years with an estimated value of $\$ 2,228$ per acre.

Table 4.8. Site index and stumpage value as a function of stand dbh for white oak on mulched mine land and regenerating forests in eastern Kentucky.

\begin{tabular}{|c|c|c|c|c|c|}
\hline Treatment & $\begin{array}{l}\text { AVG DBH } \\
20 \mathrm{yr}(\text { in. })^{\Delta}\end{array}$ & $\begin{array}{c}\text { Site } \\
\text { Index } \uparrow\end{array}$ & $\begin{array}{c}20 \text { yr Yield } \\
\left(\text { Bd. Ft. Ac }{ }^{-1}\right) \stackrel{?}{?}\end{array}$ & $\begin{array}{c}50 \text { yr Yield } \\
\left(\text { Bd. Ft. } \text { Ac }^{-1}\right)\end{array}$ & $\begin{array}{c}50 \text { yr Value } \\
\text { (\$ per Acre) }\end{array}$ \\
\hline Convential & 0.98 & $<40$ & $N A$ & $N A$ & $N A$ \\
\hline Strike-Off & 3.93 & 80 & 350 & 13,750 & 2,228 \\
\hline Loose Dump & 4.13 & 80 & 350 & 13,750 & 2,228 \\
\hline Reference & 4.54 & 80 & 350 & 13,750 & 2,228 \\
\hline
\end{tabular}

${ }^{\Delta}$ Mine dbh's projected from regression trend lines (Figure 4.8).

$\dagger$ From USDA Tech. Bull. 560 for upland oak (adapted from Schnur, 1937).

International rule

*Used average value for TN oak sawtimber for the $3^{\text {rd }}$ quarter of 2006 (Timber Mart-South, 2006). Not adjusted for inflation. 
Current projections indicate that both the strike-off and loose dump treatments with mulch addition are similar for white oak growth and value as seen in the regenerating reference stands. Because of the open grown nature of the mine land and the limited data set (9 years), growth response may change as canopy closure is achieved. Self-thinning or managed thinning in the mined areas may also influence these values between years 10 and 20.

\subsection{CONCLUSIONS}

There is a need to qualitatively evaluate reforestation projects on mined land in eastern Kentucky to ensure future economic and ecologic benefits, goods, and services that healthy forests provide. Conventionally reclaimed land holds no promise in the way of future forest development due mainly to the high degree of compaction. Tree heights, and tree diameters from the conventional stands were consistently lower than those found in the reference stands. On the other hand, strike off reclamation produced the tallest white oak heights, and loose dump and strike off reclamation equally produced the widest white oak diameters. The use of mulch proved to be essential to producing height and diameter growth similar to that found in reference stands for both species on all subsurface treatments. It would take a substantially longer period of time for trees growing on reclaimed mine land without mulch to reach reference conditions according to the results of this study. The two areas that mulch affects are the most problematic for growing trees on surface mines: compaction and nutrient availability. The mulch likely served to jump-start the establishment of a microbial population that was necessary to cycle essential nutrients on a newly formed unweathered soil. The mulch may also have alleviated compaction through reducing bulk density and increasing total porosity. Finally, the mulch added to the initial nutrient availability of the spoil where there was limited amounts before and allowed seedlings an early source of nutrients. Whether the mulch is more important as a nutrient source or for its influence on soil moisture and compaction alleviation cannot be ascertained from this study; however, studies are underway to examine this important issue (See Section 1.2.2.3. of this report). 


\section{REFERENCES}

Akala, V.A., and R. Lal. 2001. Soil organic carbon pools and sequestration rates in reclaimed minesoils in Ohio. Journal of Environmental Quality. 30: 2098-2104.

Allison, L.E. 1960. Wet-combustion apparatus and procedure for organic and inorganic carbon in soil. Soil Science Society of America Journal. 24: 36-40.

Angel, PN, DH Graves, C Barton, RC Warner, PW Conrad, RJ Sweigard, C Agouridis. 2006. Surface mine reforestation research: evaluation of tree response to low compaction reclamation techniques. P. 45-58 in Proceedings of the $7^{\text {th }}$ ICARD and ASMR Conference. 26-30 March 2006. St. Louis, MO.

Ashby, WC. 1999. Growth of white and red oak seedlings and seed on mined ungraded cast overburden. P. 84-89 in JW Stringer and DW Loftis (eds.) Proceedings of the 12th Central Hardwoods Forest Conference. 29 Feb. 1-2 Mar. 1999. Lexington, KY. USDA Forest Service Southern Forest Research Station, GTR SRS-24.

Ashby, WC. 1998. Reclamation with trees pre- and post-SMCRA in southern Illinois. International Journal of Surface Mining, Reclamation, and the Environment 12:117-121.

Ashby, WC and KA Kolar. 1998. Thirteen-year hardwood tree performance on a Midwest surface mine. P. 124-133 in D Throgmorton, J Nawrot, J Mead, J Galetovic, and W Joseph (eds.) Mining-Gateway to the Future. Proceedings of the $25^{\text {th }}$ Anniversary and $15^{\text {th }}$ Annual Meeting of the American Society for Surface Mining and Reclamation. 17-22 May 1988. St. Louis, MO.

Ashby, WC. 1991. Surface mine tree planting in the Midwest pre- and post-PL 95-87. P. 617-623 in W Oaks and J Bowden (eds.) Technologies for Success. Proc. American Society for Surface Mining and Reclamation, Vol. 2. 14-17 May 1991. Durango, CO.

Attiwill, P.M., M.A. Adams. 1993. Tansely Review No. 50. Nutrient Cycling in Forests. New Phytologyst 124: 561-582.

Avid, B., B. Purevsuren, M. Born, J. Dugarjav, Y. Davaajav, and A. Tuvshinjargal. 2002. Pyrolysis and TG analysis of Shivee Ovoo coal from Mongolia. Journal of Thermal Analysis and Calorimetry. 68: 877-885. 
Beck, T., R. G. Joergensen, E. Kandeler, F. Makeschin, E. Nuss, H.R. Oberholzer, and S. Scheu. 1997. An interlaboratory comparison of ten different ways of measuring soil microbial biomass C. Soil Biology and Biochemistry. 29 (7): 1023-1032.

Beck, DE . 1990. Yellow-poplar. P. 406-416 in RM Burns and BH Honkala (eds.) Silvics of North America, Vol. 2, Hardwoods. USDA Forest Service, Agriculture Handbook 654.

Beedlow, P.A., Tingey, D.T., D.L. Phillips, W.E. Hogsett, and D.M. Olszyk. $2004 . \quad$ Rising atmospheric $\mathrm{CO} 2$ and carbon sequestration in forests. Frontiers in Ecology and the Environment. 2(6): 315-322.

Bertin, C., X. Yang, L. Weston, 2003. The role of root exudates and allelochemicals in the rhizosphere. Plant and Soil Science 256: 67-83

Birdsey, R.A., A.J. Plantinga, and L.S. Heath. 1993. Past and prospective carbon storage in United States forests. Forest Ecology Management. 58: 33-40.

Bhargava, S., F. Awaja, and N.D. Subasinghe. 2005. Characterization of some Australian oil shale using thermal, X-ray and IR techniques. Fuel. 84: 707-715.

Biagini, E., F. Lippi, L. Petarca, and L. Tognotti. 2002. Devolatilization rate of biomasses and coal-biomass blends: an experimental investigation. Fuel. 81: 1041-1050.

Birdsey, R.A., A.J. Plantinga, and L.S. Heath. 1993. Past and prospective carbon storage in United States forests. Forest Ecology Management. 58: 33-40.

Bledsoe, L., Varsa, E.C., Chong, S.K., Olsen, F.J., Klubek, B.P., and Stucky, D.J. (1992). The effects of deep tillage on reclaimed mine spoils. In R.E. Dunker et al (eds.) Prime Farmland Reclamation (pp 51-58). University of Illinois at Urbana-Champaign: Department of Agronomy.

Bolstad, P.V., J.M. Vose. 2005. Forest and pasture carbon pools and soil respiration in the southern Appalachian Mountains. Forest Science 51(4) 372-383.

Bormann, FH and GE Likens. 1979. Pattern and Process in a Forested Ecosystem. SpringerVerlag: New York, NY.

Boutton, T.W., S.R. Archer, A.J. Midwood, S.F. Zitzer, and R. Bol. 1998. $\delta^{13}$ C values of soil organic carbon and their use in documenting vegetation change in subtropical savanna ecosystem. Geoderma. 82: 5-41. 
Bowden, R.D., K.J., Nadelhoffer, R.D. Boone, J.M. Melillo, and J.B. Garrison. 1993. Contributions of aboveground litter, belowground litter, and root respiration in total soil respiration in a temperate hardwood forest. Canadian Journal of Forest Research. 23:1402-1407.

Brady, NC and RR Weil. 2002. The Nature and Properties of Soils, $13^{\text {th }} \mathrm{ed}$. Prentice Hall: Upper Saddle River, NJ.

Braun, EL. 1950. Deciduous Forests of Eastern North America. The Blakiston Co.: Philadelphia, PA.

Brooks, P. C., A. Landman, G. Pruden, and D.S. Jenkinson. 1985. Chloroform fumigation ad the release of soil nitrogen: a rapid extraction method to measure microbial biomass nitrogen in soil. Soil Biology and Biochemistry. 17:837-842.

Brye, KR, JM Norman, and ST Gower. 2002. Assessing the progress of a tallgrass prairie restoration in southern Wisconsin. Am. Midl. Nat. 148:218-235.

Burger, JA, JE Johnson, JA Andrews, and JL Torbert. 1994. Measuring minesoil productivity for forests. P. 48-56 in International Land Reclamation and Mine Drainage Conference. USDOI Bureau of Mines Special Publication SP 06C-94.

Burger, JA and JL Torbert. 1992. Restoring forests on surface-mined land. Virginia Cooperative Extension Publication No. 460-123. Blacksburg, VA. $16 \mathrm{p}$.

Burger, JA. 1999. Academic research perspective on experiences, trends, constraints and needs related to reforestation of mined land. P. 63-74 in $\mathrm{KC}$ Vories and D Throgmorton (eds.) Proceedings of the Enhancement of Reforestation at Surface Coal Mines: Technical Interactive Forum. 23-24 Mar. 1999. Fort Mitchell, KY.

Burger, JA. 2002. Achieving forestry goals on mined land: mined site condition, species composition, and stand development of economically viable hardwood forests. P. 107-115 in KC Vories and D Throgmorton (eds.) Proceedings of Market-Based Approaches to Mined Land Reclamation and Reforestation: Technical Interactive Forum. 15-16 Mar. 2002. Fort Mitchell, KY.

Bussler, B.H., W.R. Byrnes, P.E. Pope, and W.R. Chaney. 1984. Properties of minesoil reclaimed for forest land use. Soil Science Society of America Journal. 48: 178-184. 
Carmean, WH, JT Hahn, and RD Jacobs. 1989. Site index curves for forest tree species in the eastern United States. USDA Forest Service North Central Forest Experiment Station, GTR NC-128. 142 p.

Carmean, WH. 1975. Forest site quality evaluation in the United States. Advances in Agronomy 27:209-269.

Christensen, NL. 1996. The scientific basis for ecosystem management. Ecological Applications 6:665-691.

Conrad, PW. 2002. An evaluation of the impact of spoil handling methods on the physical properties of a replaced growing medium and on tree survival. PhD Dissertation. University of Kentucky, Lexington.

Cotton, CC. 2006. Developing a method of site quality evaluation for Quercus alba and Liriodendron tulipifera in the eastern Kentucky coal field. MS Thesis. University of Kentucky, Lexington.

Dagounaki, C., K. Chrissafis, A. Kassoli-Fournaraki, A. Tsirambides, C. Sikalidis, and K.M. Paraskevopoulos. 2004. Thermal characterization of carbonate rocks. Kozani area, Northwestern Macedonia, Greece. Journal of Thermal Analysis and Calorimetry. 78: 295-306.

Dell'Abate, M.T., A. Benedetti, and P. Sequi. 2000. Thermal methods of organic matter maturation monitoring during a composting process. Journal of Thermal Analysis and Calorimetry. 61: 389-396.

Deines, P. 1980. The isotopic composition of reduced organic carbon. In: P. Fritz and J.C. Fontes (eds.). Handbook of Environmental Isotope Geochemistry: The Terrestrial Environment, vol. 1. Elsevier, Amsterdam. pp. 329-406.

Evangelou, RA. 1981. Preparation of surface mined coal spoils and establishment of vegetative cover. University of Kentucky Coop. Ext. Serv., AGR-89.

Fisher, M. J., I. M. Rao, M. A. Ayarza, C. E. Lascano, J. I. Sanz, R. J. Thomas, and R. R. Vera. 1994. Carbon storage by introduced deep rooted grasses in the South American savannas. Nature 371: 236-238.

Fogel, M.L., and L.A. Cifuentes. 1993. Isotope fractionation during primary production. In: M.H. Engel and S.A Macko (eds.). Organic geochemistry principles and applications. Plenum Press, New York. pp. 73-94.

Francioso, O., D. Montecchio, P. Gioacchini, and C. Ciavatta. 2005. Thermal analysis (TGDTA) and isotopic characterization $\left({ }^{13} \mathrm{C}-{ }^{15} \mathrm{~N}\right)$ of humic acids from different origins. Applied Geochemistry. 20: 37-544. 
Francis, JK. 1979. Yellow-poplar rooting habits. USDA Forest Service Southern Forest Research Station, Research Note SO-246. 3 p.

Frothingham, EH. 1918. J. Forestry 16:754-760.

Frothingham, EH. 1921. J. Forestry 19:1-14.

Graves, HS. 1906. Forest Mensuration. John Wiley and Sons: New York, NY.

Graves, DH, JM Ringe, MH Pelkki, RJ Sweigard, and R Warner. 2000. High value tree reclamation research. P. 413-421 in Singhal and Mehrotra (eds.) Environmental Issues and Management of Waste in Energy and Mineral Production. Balkema, Rotterdam, The Netherlands.

Halls, LK. (ed.). 1977. Southern fruit-producing woody plants used by wildlife. USDA Forest Service Southern Forest Research Station, GTR SO-16.

Hardin, JW, DJ Leopold, and FM White. 1996. Harlow and Harrar's Textbook of Dendrology, $9^{\text {th }}$ ed. McGraw Hill: Boston, MA.

Harlow, WM, ES Harrar, and FM White. 1979. Textbook of Dendrology, $6^{\text {th }}$ ed. McGraw Hill Book Co.: New York, NY.

Hessburg, PF, BG Smith, and RB Salter. 1999. Detecting change in forest spatial patterns from reference conditions. Ecological Applications 9(4):1232-1253.

Hesson, D.O., G.I. Agren, T.R. Anderson, J.J. Elser, and P.C. De Rutter. 2004. Carbon sequestration in ecosystems: the role of stoichiometry. Ecology 85 (5) 1179-1192.

Hobbie, S.E., J.P. Schimel, S.E. Trumbore, and J.R. Randerson. 2000. Control over carbon storage and turnover in high altitude soils. Global Change Biology: 196-210.

Hodges, J and E Gardiner. 1992. Ecology and physiology of oak regeneration. P. 54-65 in DL Loftis and CE McGee (eds.) Oak Regeneration: Serious Problems, Practical Recommendations. Proceedings. 8-10 Sept. 1992. Knoxville, TN. USDA Forest Service Southeasten Forest Experiment Station, GTR SE-84.

Hodžic, E., and Z. Pašic. 1985. Differential thermal analysis of ashes of some Yugoslav brown coals. Thermochimica Acta. 93: 365-368.

Honeycutt, CW. 1981. Growth of white oak in relation to soil and site properties in eastern Kentucky. MS Thesis. University of Kentucky, Lexington.

Horwath and Paul, 1994. Methods of Soil Analysis, Microbiological and biochemical Properties, 1994.

University of Kentucky Research Foundation

Final Report - 10/01/03 thru 9/30/06

DE-FC26-02NT41624 
Intergovernmental Panel on Climate Control. 1991. Climate Change - IPPC Response Strategies. Island Press, Washington, DC, 272 pp.

Intergovernmental Panel on Climate Control. 2000. Land Use, Land Use Change, and Forestry. Cambridge University Press, Cambridge, UK.

Jackson, R.B., Mooney, H.A., Schulze E.D. 1997. A global budget for fine root biomass, surface area, and nutrient contents. Proceedings of the National Academy of Sciences, USA 94: 7362-7366.

Janzen, H.H. 2006. The soil carbon dilemma: Shall we hoard it or use it? Soil Biology and Biochemistry. 38: 419-424.

Jastrow, J.D. 1996. Soil aggregate formation and the accrual of particulate and mineral associated organic matter. Soil Biology and Biochemistry. 28: 665-676.

Jencks, E.M., E.H. Tyron, and M. Contri. 1992. Accumulation of nitrogen in minesoils seeded to black locust. Soil Science Society of America Journal. 46: 1290-1293.

Jenkins, J. C., D. C. Chojnacky, L. S. Heath, and R. A. Birdsey. 2003. National-Scale Biomass Estimators for United States Tree Species. Forest Science. 49(1): 12-35.

Jobaggy, E.G. and Jackson, R.B. 2000. The vertical distribution of soil organic carbon and its relation to climate and vegetation. Ecological Applications 10 (2) 423-436.

Johnson, D.W., and D.E. Todd, Jr. 1998. Harvesting effects on long-term changes in nutrient pools in a mixed oak forest. Soil Sci. Soc. Am. J. 62:1725-1735.

Jones, J. 2002. Influence of soil acidity levels on vegetative reclamation and wildlife habitat on rights-of-way transecting drastically-disturbed land. In: J.W. Goodrich-Mahoney. D.F. Mutrie, and C.A. Guild (eds.). Environmental Concerns in Rights-of-Way Management. Seventh International Symposium. Elsevier Science.

Karathanasis, A.D., and W.G. Harris. 1994. Quantitative thermal analysis of soil materials. In: J.E. Amonette and J.W. Stucki (eds.). Quantitative Methods in Soil Mineralogy. SSSA Miscellaneous Publication, Madison, WI. pp. 360-411.

Kaufmann, MR, LS Huckaby, CM Regan, and J Popp. 1998. forest reference conditions for ecosystem management in the Sacramento Mountains, New Mexico. USDA Forest Service Rocky Mountain Forest Research Station, GTR RMRS-19.

Kelly, E.F., S.W. Blecker, C.M.Yonker, C.G. Olson, and L.C. Todd. 1998. Stable isotope composition of soil organic matter and phytoliths as paleoenvironmental indicators. Geoderma. 82: 59-81.

University of Kentucky Research Foundation 128

Final Report - 10/01/03 thru 9/30/06

DE-FC26-02NT41624 
Kentula, ME, RP Brooks, SE Gwin, CC Holland, AD Sherman, and JC Sifneos. 1993. An Approach to Improving Decision Making in Wetland Restoration and Creation. CK Smoley, Inc.: Boca Raton, FL.

Kern, J. S., and M. G. Johnson. 1993. Conservation tillage impacts on national soil and atmospheric carbon levels. Soil Science Society of America Journal 57: 200-210.

Khraisha, Y.H., and I.M. Shabib. 2002. Thermal analysis of shale oil using hermogravimetry and differential scanning calorimetry. Energy Conversion and Management. 43: 229-239.

Kolka, RK, CC Trettin, EA Nelson, CD Barton, and DE Fletcher. 2002. Application of the EPA wetland research program approach to a floodplain wetland restoration assessment. $J$. of Env. Monitoring and Restoration 1(1):37-51.

Krull, E.S., and J.O. Skjemstad. 2003. $\delta^{13} \mathrm{C}$ and $\delta^{15} \mathrm{~N}$ profiles in ${ }^{14} \mathrm{C}$-dated Oxisol and Vertisols as a function of soil chemistry and mineralogy. Geoderma. 112: 1-29.

Leinweber, P., H.R. Schulten, and C. Horte. 1992. Differential thermal analysis, thermogravimetry and pyrolysis-field ionization mass spectrometry of soil organic matter in particle-size fractions and bulk soil samples. Thermochimica Acta. 194: 175-187.

Lal, R. 2004. Soil carbon sequestration to mitigate climate change. Geoderma. 123: 1-22.

Lal, R., J. M. Kimble, and R. F. Follett. 1998. Land use and soil C pools in terrestrial ecosystems. Pages 1-10 in R. Lal, J. M. Kimble, R. F. Follett, and B. A. Stewart, eds. Management of Carbon Sequestration in Soil. CRC Lewis Publisher, Boca Raton.

Lamson, NI. 1987. Estimating northern red oak site-index class from total height and diameter of dominant and codominant trees in central Appalachian hardwood stands. USDA Forest Service Northeastern Forest Experiment Station, Research Paper NE-RP-605.

Levy, M., and R. Kramer. 1988. Comparative TGA and DSC studies of oil shales. Thermochimica Acta. 134: 327-331.

Lindsay, RE and JR Nawrot. 1981. Evaluation of natural revegetation of problem spoil banks. P. 367-375 in Symposium on Surface Mining Hydrology, Sedimentology, and Reclamation. 7-11 Dec. 1981. University of Kentucky, Lexington, KY.

Lister, TW, JA Burger, and SC Patterson. 2004. Role of vegetation in mitigating soil quality impacted by forest harvesting. SSSAJ 68:263-271.

Lopez-Capel, E., S.P. Sohi, J.L. Gaunt, and D.A.C. Manning. 2005. Use of thermogravimetrydifferential scanning calorimetry to characterize modelable soil organic matter fractions. Soil Science Society of America Journal. 69: 136-140.

University of Kentucky Research Foundation

Final Report - 10/01/03 thru 9/30/06

DE-FC26-02NT41624 
Markova, H.I., S.P. Valceva, and R.P. Petrova. 1985. DTA and TGA of coals and bituminous rocks. Thermochimica Acta. 93: 385-388.

McQuilkin, RA. 1989. Measuring site index in the central hardwood region. USDA Forest Service North Central Forest Experiment Station.

Midwood, A.J., and T.W. Boutton. 1998. Soil carbonate decomposition by acid has little effect on $\delta^{13} \mathrm{C}$ of organic matter. Soil Biology and Biochemistry. 30: 1301-1307.

Miles, VC, RW Ruble, and RL Bond. 1973. Performance of plants in relation to spoil classification in Pennsylvania. P. 13-31 in RJ Hutnik and G Davis (eds.) Ecology and Reclamation of Devestated Land, Vol. 2. Gordon and Breach, New York.

Montagnini, F., B. Haines, and W.T. Swank. 1991. Soil-solution chemistry in black locust, pine/mixed hardwoods and oak/hickory forest stands in the southern Appalachians, U.S.A. Forest Ecology and Management. 40: 199-208.

Moore, MM, WW Covington, and PZ Fule. 1999. Reference conditions and ecological restoration: a southwestern ponderosa pine perspective. Ecological Applications 9(4):1266-1277.

Morgan, P.A., S.D. Robertson, and J.F. Unsworth. 1987. Combustion studies by thermogravimetric analysis. Fuel. 66: 210-215.

Morgan, P, GH Aplet, JB Haufler, HC Humphries, MM Moore, and WD Wilson. 1994. Historical range of variability: a useful tool for evaluating ecological change. J. of Sustainable Forestry 2:87-111.

Muzuka, A.N.N., and J.P. Shunula. 2006. Stable isotope composition of organic carbon and nitrogen of two mangrove stands along the Tanzanian coastal zone. Estuarine Coastal Shelf Science. 66: 447-458.

Nabuurs, G. J., A. J. Dolman, E. Verkaik, P. J. Kuikman, C. A. van Diepen, A. P. Whitmore, W. P. Daaman, O. Oenema, P. Kabat, and G. M. J. Mohren. 1999. Article 3.3 and 3.4 of the Kyoto Protocol: consequences for industrialised countries' commitment, the monitoring needs and possible side effects. Environmental Science and Policy 3: 123-134.

Nadelhoffer, K.J., J.W. Raich. 1992. Fine root production estimates and belowground carbon allocation in forest ecosystems. Ecology Vol 73, No. 4: 1139-1147. 
Nelson, D.W., and L.E. Sommers. 1996. Total carbon, organic carbon, and organic matter; In: D.L. Sparks (ed.). Methods of Soil Analysis, Part 3. Chemical Methods, SSSA Book Series 5. SSSA, Madison, WI. pp. 961-1010.

Nommik, H. 1971. A modified procedure for determination of organic carbon in soils by wet combustion. Soil Science. 11: 300-336.

Nyland, RD. 2002. Silviculture: Concepts and Applications. McGraw Hill Book Company: New York, NY.

Oliver, CD. 1981. Forest development in North America following disturbances. For. Ecol. and Mgt. 3:153-168.

Parton, W.J., D.S. Schimel, D.V.Cole, and D.S. Ojima. 1987. Analysis of factors controlling soil organic matter levels in Great Plains Grasslands. Soil Science Society of America Journal 51: 1173-1179.

Pietro, M., and C. Paola. 2004. Thermal analysis for the evaluation of the organic matter evolution during municipal solid waste aerobic composting process. Thermochimica Acta. 413: 209-214.

Piotrowski, S. 1999. Examination of contemporary lake sediments by means of thermal analysis. Journal of Thermal Analysis and Calorimetry. 57: 527-540.

Plante, A.F., M. Pernes, and C. Chenu. 2005. Changes in clay-associated organic matter quality in a $\mathrm{C}$ depletion sequence as measured by differential thermal analyses. Geoderma. 129: 186-199.

Plass, WT. 1978. Use of mulches and soil stabilizers for land reclamation in the eastern United States. P. 329-337 in Reclamation of Drastically Disturbed Lands. Madison, WI.

Pontolillo, J., and R.W. Stanton. 1994. Coal petrographic laboratory procedures and safety manual, II. United States Geology Survey Open-File Report. pp. 94-631.

Pope, PE. 1989. Reforestation of mine lands in the Illinois coal basin. Purdue University, Agri. Exp. Sta. Bull. 565. Lafayette, IN.

Pritchett, WL and RF Fisher. 1987. Properties and Management of Forest Soils, $2^{\text {nd }}$ ed. John Wiley and Sons: New York, NY.

Rogers, R. 1990. White oak. P. 605-613 in RM Burns and BH Honkala (eds.) Silvics of North America, Vol. 2, Hardwoods. USDA Forest Service, Agriculture Handbook 654. 
Rodrigue, JA. 2001. Woody species diversity, forest and site productivity, stumpage value, and carbon sequestration of forests on mined lands reclaimed prior to the passage of the Surface Mining Control and Reclamation Act of 1977. MS Thesis. Virginia Polytechnic Institute and State University, Blacksburg.

Roth, F. 1916. Forest. Quart. 15:3-13.

Roth, F. 1918. J. Forestry 16:749-753.

Rumpel, C., I. Kogel-Knabner and H. Knicke. 2000. Composition and distribution of organic matter in physical fractions of a rehabilitated mine soil rich in lignite-derived carbon. Geoderma. 98: 177-192.

Sala, Osvaldo E., Robert B. Jackson, Harold A. Mooney, Robert W. Howarth. 2000.

Methods in Ecosystem Science. Springer-Verlag, New York.

Schlesinger, W.H. Biogeochemistry: An analysis of global change. Academic Press, 1997.

Schlesinger, W.H. 1991. Biogeochemistry: An analysis of global change. Academic Press, San Diego, CA.

Schifley, SR. 2004. Oak growth and response to thinning. P. 198-204 in Upland Oak Ecology Symosium: history, current conditions, and sustainability. USDA Forest Service Southern Research Station, GTR SRS-73.

Schnitzer, M., and I.A. Hoffman. 1966. A thermogravimetric approach to the classification of organic soils. Soil Science Society of America Proceedings. 30: 63-66.

Schnur, G.L. 1937. Yield, stand and volume tables for even-aged upland oak forests. USDA Tech. Bulletin 560. Washington, DC.

Schramm, JR. 1966. Plant colonization studies on black wastes from anthracite mining in Pennsylvania. Reclamation and Revegetation Research 6:109-120.

Schulten, H.R., and P. Leinweber. 1999. Thermal stability and composition of mineral- bound organic matter in density fraction of soil. European Journal of Soil Science. 50: 237-248.

Sheppard, J.D., and D.W. Forgeron. 1987. Differential thermogravimetry of peat fractions. Fuel. 66: 232-236.

Shoch, D., S. Brown, and M. Delaney. 2003. An assessment of carbon sequestering potential following mine reclamation on the Grant Town Power Project, Grant Town West Virginia. http://.www.edison.com/files/Edison_report_Winrock_final_20Aug03.pdf. (accessed Oct 2004).

University of Kentucky Research Foundation

Final Report - 10/01/03 thru 9/30/06

DE-FC26-02NT41624 
Siewert, C. 2004. Rapid screening of soil properties using thermogravimetry. Soil Science Society of America Journal. 68: 1656-1661.

Sikora, L.J., and D.E. Stott. 1996. Soil organic carbon and nitrogen. In: J.W. Doran, and A.J. Jones (eds.). Methods for assessing soil quality. SSSA Spec. Publ. 49. SSSA, Madison, WI. pp. 157-167.

Sims, D. 1994. Hardwood site and stand inventory. P. 3-12 in DJ Moorhead and KD Coder (eds.) Southern Hardwood Management. USDA Forest Service Southern Region, Management Bulletin R8-MB 67.

Smalley, GW. 1984. Classification and evaluation of forest sites in the Cumberland Mountains. USDA Forest Service Southern Forest Experiment Station, GTR SO-50. 84 p.

Smalley, GW. 1986. Classification and evaluation of forest sites on the northern Cumberland Plateau. USDA Forest Service Southern Forest Experiment Station, GTR SO-60. 76 p.

Spies, TA. 1997. Forest stand structure, composition, and function. P. 11-30 in KA Kohm and JF Franklin (eds.) Creating a forest for the $21^{\text {st }}$ Century. Island Press: Washington, DC.

Stahl, P.D., J.D. Anderson, L.J.Ingram, G.E. Schumanand D.L. Mummey. 2003. Accumulation of organic carbon in reclaimed coal mine soils of Wyoming. In: R.I. Barnhisel (ed.). Proceedings of the 2003 National Meeting of the American Society of Mining and Reclamation and the ninth Billings Land Reclamation Symposium. American Society of Mining and Reclamation, Lexington, KY.

Stephenson, NL. 1999. Reference conditions for giant sequoia forest restoration: structure, process, and precision. Ecological Applications 9(4): 1253-1265.

Sterrett, WD. 1921. J. Forestry 19:382-389.

Stone, EA. 1984. Site quality and site treatment. P. 41-52 in EA Stone (ed.) Forest Soils and Treatment Impacts. Proceedings of the $6^{\text {th }}$ North American Forest Soils Conference. Knoxville, TN.

Stout, BB and DL Schumway. 1982. Site quality estimation using height and diameter. Forest Science 28:639-645.

Swanson, FJ, JA Jones, DA Wallin, and JH Cissel. 1994. Natural variability - implications for ecosystem management. P. 85-99 in USDA Forest Service Pacific Northwest Research Station, GTR PNW-318.

Tabatabai et al, 1994. Methods of Soil Analysis, Microbiological and biochemical Properties, 1994.

University of Kentucky Research Foundation

Final Report - 10/01/03 thru 9/30/06

DE-FC26-02NT41624 
Taylor, G.H., M. Teichmüller, A. Davis, C.F.K Diessel, R. Littke, and P. Robert. 1998a. Methods and Procedures. In: Organic Petrology. Berlin, Stuttgart Borntraeger. pp. 335450 .

Taylor, G.H., M. Teichmüller, A. Davis, C.F.K Diessel, R. Littke, and P. Robert. 1998a. Methods and Procedures. In: Organic Petrology. Berlin, Stuttgart Borntraeger. pp. 86174.

Thomas, WB, MH Pelkki, and JM Ringe. 1999. Native high value tree reclamation on surface mined spoils in eastern Kentucky. P. 79-83 in JW Stringer and DW Loftis (eds.) Proceedings of the $12^{\text {th }}$ Central Hardwoods Forest Conference. 29 Feb. - 1-2 Mar. 1999. Lexington, KY. USDA Forest Service Southern Forest Research Station, GTR SRS-24.

Timber Mart-South. 2006. Timber Mart-South Tennessee Stumpage Prices for the $3^{\text {rd }}$ Quarter of 2006. Daniel Warnell School of Forestry and Natural Resources. University of Georgia: Athens, GA.

Torbert, JL, SS Schoenholz, JA Burger, and RE Kreh. 2000. Growth of three pine species after eleven years on reclaimed minesoils in Virginia. N. J. of Appl. For. 17(3):1-5.

Torbert, JL and JA Burger. 2000. Forest Land Reclamation. P. 371-398 in RI Barnhisel, RG Darmody, and WL Daniels (eds.) Reclamation of Drastically Disturbed Lands. SSSA: Madison, WI. Agronomy Monograph No. 41.

Torbert, JL, AR Tuladhar, JA Burger, and JC Bell. 1998. Minesoil property effects on the height of ten-year old white pine. JEQ 17:189-192.

Torbert, JL, JA Burger, JE Johnson, and JA Andrews. 1994. Indices for indirect estimates of productivity of tree crops. Office of Surface Mining Cooperative Agreement OR 966511, Final Report. Virginia Polytechnic Institute and State University, Blacksburg.

Trimble, GR. 1969. Diameter growth of individual hardwood trees. USDA Forest Service Northeastern Forest Experiment Station, Research Paper NE-145.

Trimble, GR, Jr. and EH Tryon. 1974. Grapevines a serious obstacle to timber production on good hardwood sites in Appalachia. North. Logger Timber Process. 23(5):22-24.

Trimble, GR, Jr. 1975. Summaries of some silvical characteristics of several Appalachian hardwood trees. USDA Forest Service Northeastern Experiment Station, GTR NE-16. 5 p. 
United States Congress. 1977. Surface Mining Control and Reclamation Act. PL95-87 Federal Register. P. 445-532.

USDA Forest Service. 2004. Forest inventory and analysis factsheet, Kentucky. 4 p.

USDA Forest Service. 1965. Silvics of forest trees of the United States. USDA Agr. Handbook 271.

USEPA. 1994. Inductively coupled plasma mass spectrometry, method 6020, Rev. 0. In: SW-846: Test methods for evaluating solid waste, physical/chemical methods. United States Environmental Protection Agency Office of Solid Waste, Washington, DC. pp. 6020-1-6020-18.

USEPA. 1996. Microwave assisted acid digestion of siliceous and organically based matrices, method 3052, Rev. 0. In: SW-846: Test methods for evaluating solid waste, physical/chemical methods. United States Environmental Protection Agency Office of Solid Waste, Washington, DC. pp. 3052-1-3052-20.

Van Soest, P.J. 1994. Lignin. In: Nutritional Ecology of the Ruminant. Cornell University Press, Ithaca, New York. pp. 177-195.

Varey, J. E., C.J. Hindmarsh, and K.M. Thomas. 1996. The detection of reactive intermediates in the combustion and pyrolysis of coals, chars and macerals. Fuel. 75: 164-176.

Vossbrinck, C.R., D.C. Coleman, T.A. Woolley. 1979. Abiotic and biotic factors in litter decomposition in a semiarid grassland. Ecology, Vol. 60. No. 2. 265-271.

Waring, R.H., and W.H. Schlesinger. 1985. Decomposition and forest soil development. In: Forest Ecosystems: concepts and management, Academic Press, Orlando, Florida. pp. 181-208.

Warne, S. St. J. 1985. The assessment of the coal-organic matter contents of geological materials by differential thermal analysis. Thermochimica Acta. 86: 337-342.

Warne, S. St. J. 1996. Thermal analysis and coal assessment: an overview with new developments. Thermochimica Acta. 272: 1-9.

Watson, R. 1917. J. Forestry 15:553-563.

Weaver, R.W., and S.K.A. Danso. 1994. Dinitrogen Fixation. In: R.Weaver, J.S. Angle, and P.S. Bottomley (eds.). Methods of soil analysis, microbiological and biochemical properties. Book Series 5, Part 2. SSSA, Madison, WI. pp. 1019-1045. SSSA

Wendlandt, W.W. 1986. In: P.J. Elving and J.D. Winefordner (eds.) Thermal Analysis, 3rd ed. Wiley-Interscience, New York. pp. 1-8.

University of Kentucky Research Foundation

Final Report - 10/01/03 thru 9/30/06

DE-FC26-02NT41624 
Wharton, ME and RW Barbour. 1973. Trees and Shrubs of Kentucky. University Press: Lexington, KY.

Whiticar, M.J. 1996, Stable isotope geochemistry of coals, humic kerogens and related natural gases. International Journal of Coal Geology. 32: 191-215.

Winjum, J. K., and P. E. Schroeder. 1997. Forest plantations of the world: their extent, ecological attributes and carbon storage. Agricultural and Forest Meterology 84: 153-167.

Wolf, D.C., J.O. Legg, and T.W. Boutton. 1994. Isotopic Methods for the Study of Soil Organic Matter Dynamics. . In: R.Weaver, J.S. Angle, and P.S. Bottomley (eds.). Methods of soil analysis, microbiological and biochemical properties. Book Series 5, Part 2. SSSA, Madison, WI. pp. 865-906.

Yanai, R.D., M.A. Arthur, T.G Siccama, and C.A. Federer. 2000. Challenges of measuring forest floor organic matter dynamics: repeated measures from a chronosequence. For. Ecol. Manage. 138:273-283.

Zeleznik, J. D., and J. G. Skousen. 1996. Survival of three tree species on old reclaimed surface mines in Ohio. Journal of Environmental Quality 25: 1429-1435.

Zilberman, D., and D. Sunding. 2001. Climate change policy and the agricultural sector. Pages 629-643 in R. Lal, J. M. Kimble, R. F. Follett, and B. A. Stewart, eds. Assessment methods for soil carbon. Lewis Publishing, Boca Raton, FL. 